\title{
Transitions to Adulthood: A National Survey of Adolescents in Egypt (1st edition)
}

Sahar El Tawila

Omaima El-Gibaly

Barbara L. Ibrahim

Population Council

Fikrat El Sahn

Sunny Sallam

See next page for additional authors

Follow this and additional works at: https://knowledgecommons.popcouncil.org/departments_sbsr-pgy How does access to this work benefit you? Let us know!

\section{Recommended Citation}

El Tawila, Sahar, Omaima El-Gibaly, Barbara L. Ibrahim, Fikrat El Sahn, Sunny Sallam, Susan M. Lee, Barbara Mensch, Hind Wassef, Sarah Bukhari, and Osman Galal. 1999. "Transitions to Adulthood: A National Survey of Adolescents in Egypt (1st edition)." Cairo: Population Council. 


\section{Authors}

Sahar El Tawila, Omaima El-Gibaly, Barbara L. Ibrahim, Fikrat El Sahn, Sunny Sallam, Susan M. Lee, Barbara Mensch, Hind Wassef, Sarah Bukhari, and Osman Galal 


\section{Published by The Population Council One Dag Hammarskjold Plaza \\ New York, NY 10017}

The Population Council seeks to improve the wellbeing and reproductive health of current and future generations around the world and to help achieve a humane, equitable, and sustainable balance between people and resources. The Council, a nonprofit, non-governmental research organization established in 1952, has a multinational board of trustees; its New York headquarters supports a global network of regional and country offices.

(C) 1999 Population Council

For further information and copies

Please write to:

The Population Council

Regional Office for West Asia and North Africa

P.O. Box 115 - Dokki - Giza - Egypt

Tel: $20-25701733$

Fax: 20-2 5701804

Email: pcouncil@pccairo.org

Printed by

The Palm Press

34 El Mansour Mohamed Street, Zamalek 11211

Cairo, Egypt

Fax: (20 2) 340 9868, Tel: 3415458,3409867 


\section{Transitions to Adulthood A National Survey of Egyptian Adolescents}

Barbara Ibrahim, Ph.D.

The Population Council

Regional Office for

West Asia and

North Africa

\author{
Sunny Sallam, \\ MB. Ch.B, DrPH \\ High Institute of Public \\ Health \\ Alexandria University
}

Sahar EI Tawila, Ph.D. Social Research Center American University in Cairo
Omaima EI Gibaly, MD, Ph.D.

Department of Public Health and Community Medicine Faculty of Medicine Assiut University
Fikrat El Sahn, MB. Ch.B, DrPH High Institute of Public Health Alexandria University

With:

Susan M. Lee Barbara Mensch

Hind Wassef Sarah Bukhari Osman Galal 


\section{Table of Contents}

PREFACE

ACKNOWLEDGMENTS

ACRONYMS

LIST OF TABLES

LIST OF FIGURES

CHAPTER 1 ADVANCING OUR UNDERSTANDING OF ADOLESCENCE IN EGYPT

I. INTRODUCTION

II. STUDY OBJECTIVES AND DEFINITIONS

III. INSTITUTIONAL COLLABORATION/THE RESEARCH TEAM

IV. THIS SUMMARY REPORT

CHAPTER 2 METHODOLOGY AND SCOPE OF THE STUDY

I. SAMPLING DESIGN

II. STUDY INSTRUMENTS AND METHODOLOGY

III. IMPLEMENTATION OF THE STUDY DESIGN AND DATA COLLECTION

IV. LESSONS FROM FIELDWORK

V. THE UNIQUE FEATURES OF THE STUDY

VI. SOME TECHNICAL NOTES

CHAPTER 3 CHARACTERISTICS OF THE SAMPLE

I. REPRESENATIVENESS OF THE SURVEY OF ADOLESCENTS IN EGYPT 19

II. CHARACTERISTICS OF THE SAMPLE OF RESPONSIBLE ADULTS 21

III. CONSTRUCTION OF THE SOCIOECONOMIC STATUS INDEX OF ELIGIBLE 22

HOUSEHOLDS

CHAPER 4 HEALTH PROFILE OF EGYPTIAN ADOLESCENTS

I. NUTRITIONAL STATUS

II. SEXUAL MATURATION

III. HEALTH BEHAVIOR

IV. GENERAL HEALTH

V. HEALTH SEEKING BEHAVIOR

VI. DISCUSSION AND POLICY IMPLICATIONS

\section{CHAPTER 5 EDUCATION PROFILE OF EGYPTIAN ADOLESCENTS}

I. ACCESS TO EDUCATION

II. ADOLESCENTS' SCHOLASTIC PERFORMANCE

III. THE SCHOOL EXPERIENCE: ADOLESCENTS' PERSPECTIVE

CHAPTER 6 ECONOMIC ROLES OF ADOLESCENTS

I. ADOLESCENTS' PARTICIPAITION IN ECONOMIC ACTIVITIES: CURRENT EXPERIENCE

II. PROFILE OF WORKING ADOLESCENTS

III. ADOLESCENTS' WORKING CONDITIONS

105

IV. REMUNERATION

108

V. PROFILE OF HOUSEHHOLDS OF WORKING ADOLESCENTS 110

VI. OUT-OF-SCHOOL AND OUT-OF-WORK ADOLESCENTS

112

VII. HEALTH STATUS OF WORKING ADOLESCENTS

113

VIII. CONCLUSION 
CHAPTER 7 AGENTS OF SOCIALIZATION

1. THE FAMILY: INTERACTION WITH PARENTS AND SIBLINGS 17

II. PEER RELATIONSHIPS 123

III. PSYCHOLOGICAL PROFILE OF ADOLESCENTS AND FAMILY/PEER SUPPORT 127

IV. HEALTH STATUS, MENTAL HEALTH, AND COMMUNICATION WITH FAMILY 133

AND PEERS

V. ADOLESCENTS' DAILY ACTIVITY PROFILE

VI. ROLE MODELS

VII. CONCLUSION 142

CHAPTER 8 TRANSITIONS TO MARRIAGE AND REPRODUCTIVE ROLES

I. REPRODUCTIVE HEALTH KNOWLEDGE 143

I1. REPRODUCTIVE HEALTH PRACTICES

III. GENDER ROLE ATTITUDES AND EXPECTATIONS 162

IV. CHARACTERISTICS OF THE IDEAL SPOUSE

V. KNOWLEDGE OF MARRIAGE CONTRACT 171

VI. DIVORCE 173

VII. CONCLUSION 175

CHAPTER 9 EVER-MARRIED ADOLESCENT WOMEN

I. PREVALENCE AND CLUSTERING OF ADOLESCENT MARRIAGE

II. DESCRIPTION OF THE MARRIED SAMPLE 179

III. CHARACTERISTICS OF ADOLESCENT MARRIAGE 181

IV. GENDER ROLES IN THE HOUSEHOLD 185

V. REPRODUCTIVE HEALTH 187

VI. CONCLUSION 193

CHAPTER 10 SOME IMPLICATIONS FOR ADVOCACY AND ACTION
1. HEALTH PRIORITIES

II. EDUCATION 198

III. EMPLOYMENT 199

IV. REPRODUCTIVE HEALTH 199

V. MARRIED ADOLESCENTS 1200

IV. CONCLUSION 201

APPENDIX 1

APPENDIX 2
207

APPENDIX 3 209

APPENDIX 4 211

BIBLIOGRAPHY 215

ABOUT THE AUTHORS
217 


\section{Preface}

Egypt holds a unique place among developing countries due to its longstanding commitment to gather information on the numbers and well-being of its population. The first national census was conducted at the close of the nineteenth century, and more recent surveys have recorded the status of its households, work force, and women of childbearing age on a regular basis. But until now, there has never been a systematic effort to gather data on the group of young Egyptians poised between childhood and adulthood - its adolescents. This information gap led to speculation and distortion in the past, as policy planners relied on localized studies or journalistic inferences to determine the needs and problems of this age group.

Today Egypt has the largest cohort of adolescents in its history, more than 13 million boys and girls between the ages of 10 and 19 according to the 1996 census. Their experiences during the transition to adulthood will profoundly affect how the nation makes its transition into the next century. Every young person who leaves school too early, fails to receive viable work skills, or accumulates burdens of ill health will be poorly prepared for a full, productive adulthood. Conversely, investments today that enhance the education, health status, and channels for participation of young people in their communities will have far-reaching positive effects in the future.

We are pleased to contribute to the growing interest in adolescent needs in Egypt through the presentation of this research report. It contains the early findings of a nationally representative survey of over 9,000 adolescents aged 10 to 19 and their parents, conducted in 1997. In deciding to undertake this major research effort, the authors aimed to provide as comprehensive a picture as possible of the contemporary situation of Egyptian young people. Inevitably, some topics had to be omitted; the survey does not provide information on the religious, military, or political activities of adolescents, nor their participation in nongovernmental organizations. What it does attempt to achieve is a fuller understanding of the major developmental 'tasks' each adolescent undertakes as he or she moves toward the roles and responsibilities of adulthood, as well as household perspectives on the services and institutions available in Egypt to support those transitions.

We sincerely hope that the information in this report will prove useful to a wide spectrum of audiences. Researchers will find many areas within our findings that invite further study. Development activists should find information to assist in better targeting their programs and services for youth. For journalists and others in the media, this report may help to stimulate more informed coverage of adolescent issues. And especially for policymakers and those responsible for allocating resources in Egypt, we offer this report in the hope that its findings will encourage broader investments to address adolescent needs.

Barbara Ibrahim

Cairo, March 1999 


\section{Acknowledgements}

A project of this magnitude cannot achieve its objectives without the active support of many individuals and institutions. From its inception, the Adolescence and Social Change in Egypt project benefited from its association with leaders from four institutions committed to research and to improving adolescent lives. We are especially grateful for the support provided by the late Dr. Mohamed Al-Amin, Dean of the High Institute of Public Health, Alexandria University during the early phases of the study. Exceptional encouragement throughout the life of the project came from Dr. Ali Zarzour, Faculty of Medicine, Department of Public Health, Assiut University. Dr. Hoda Rashad, Director of the Social Research Center of the American University in Cairo (AUC) was instrumental in finding solutions to myriad problems that arose over the course of the study. We are also indebted to the members of the Institutional Review Board of AUC for helpful suggestions on study design and execution. Many other individuals in Egypt offered advice and encouragement to this project through the Senior Advisory Committee (see listing of names on page 207).

This study was strengthened by close collaboration with a number of official agencies in Egypt. Our principal partner for all aspects of the research was the Ministry of Health and Population (MOHP). The First Undersecretary for Population, Dr. Moushira Shafei, encouraged policy discussion and wide dissemination of the study findings. Medical exams and clinical tests were conducted by an able team of doctors provided under the auspices of Dr. Esmat Mansour,Director General, Maternal and Child Health Unit, Ministry of Health and Population. Dr. Maher Mahran, Secretary General of the National Population Council, encouraged us to focus on adolescents as a neglected topic from the early days of the project. Engineer Mohamed Ragab Sharaby, First Undersecretary, Ministry of Education, was instrumental for successful completion of the education component of the study.

A helpful group of donors provided funding and encouragement throughout the planning, fielding, and analysis phases of the project. Early support was provided by the United Nations

Fund for Population Activities Egypt and the Rockefeller Foundation. Major contributions for fielding, analysis, and pilot interventions came from the Canadian International Development Agency (CIDA) and the Development Cooperation Office of the Government of the Netherlands. UNICEF Egypt contributed to the health component of the project, and the International Development Research Center of Canada (IDRC) supported components on adolescent policy and livelihoods. Population Council support is also gratefully acknowledged for filling critical funding gaps and providing international staff collaboration from the Policy Research Division, New York. 


\section{Acronyms}

ASCE - Adolescence and Social Change in Egypt

BMI - body mass index

NCHS - National Center for Health Statistics (United States)

NGO - non-governmental organization

PSU - primary sampling unit

SEM - standard error of the mean

SHIS - Student Health Insurance System

SMR - sexual maturity rating

WHO - World Health Organization 


\section{List of Tables}

\section{Chapter 2: Methodology and Scope of the Study}

Table 2.1: Tanner's sex maturity rating for girls

Table 2.2: Tanner's sex maturity rating for boys

\section{Chapter 3: Characteristics of the Sample}

Table 3.1: Percent distribution of population from 1996 census data and distribution of individuals in all sampled households by background variables

Table 3.2: Percent distribution of all adolescents screened, randomly selected adolescents, and interviewed adolescents by some demographic characteristics

Table 3.3: Percent distribution of adolescents subsampled for health component by selected background variables

Table 3.4: Percent distribution of sampled parents by selected background variables

Table 3.5: Distribution of eligible households by different components comprising socioeconomic status index constructed for study

\section{Chapter 4: Health Profile of Egyptian Adolescents}

Table 4.1: Mean body weight, height, and BMI of adolescent boys by age 't 26

Table 4.2: Mean body weight, height, and BMI of adolescent girls by age 26

Table 4.3: Percentage of adolescents classified as inappropriately nourished according to height-for-age and BMI-

for-age, by selected background characteristics 29

Table 4.4: Percent distribution of anemia among adolescents by selected background characteristics 32

Table 4.5: Prevalence of Parasitic Diseases by selected background characteristics. 34

Table 4.6: Median age of menarche (life-table) by selected background variables 38

Table 4.7: Comparison of age at menarche in girls from previous studies in Egypt with the ASCE survey 39

Table 4.8 Girls’ Breast Development Stage By Age

Table 4.9 Girls Pubic Hair Development Stage By Age

Table 4.10: Boys Pubic Hair Development Stage By Age

Table 4.11: Boys' Genital Development Stage By Age

Table 4.12: Comparison of survey sample of Egyptian adolescents with USA population as a standard 42

Table 4.13: Growth spurt stage by background variables

Table 4.14: Dietary habits among adolescents, percentages

Table 4.15: Percent distribution of adolescents' consumption of fruits and vegetables by selected background characteristics

Table 4.16: Percent distribution of adolescents' consumption of different kinds of bread by selected background characteristics 45

Table 4.17: Percent distribution of adolescents by their copsumption of salted foods, sweets, \& soft drinks 46 Table 4.18: Percent distribution of adolescents according to tea drinking, by selected background characteristics

Table 4.19: Percent distribution of smoking among adolescents, their peers, and peers offering cigarettes, by selected background characteristics

Table 4.20: Percent distribution of current smoking among adolescent boys

Table 4.21: Smoking among parents of all adolescents

Table 4.22: Gamma correlation between ever tried smoking and background variables and chronic diseases by selected back ground characteristics

Table 4.24 Parents' report of where their adolescents usually go when ill Table 4.25: Parents' and adolescents' reports of usual service provider and service provider used for the most recent illness in the previous month 


\section{Chapter 5: Education Profile of Egyptian Adolescents}

Table 5.1: Percent distribution of in-school children and adolescents aged $6-19$ by selected background variables

Table 5.2: The number of girls enrolled/100 boys in school by selected background characteristics

Table 5.3: Distribution of out-of-school adolescents, classified as dropouts or those who never attended, by selected background variables

Table 5.4: Attitudes and previous experience of adolescents who never attended school in regard to literacy classes, by selected background variables

Table 5.5: Scholastic achievement as indicated by school exam results and achievement tests in Arabic and mathematics, percents, by selected background variables

Table 5.6: Interrelationships between scholastic achievement and health status

Table 5.7: Differentials in the school experience of adolescents enrolled in general education system or vocational schools, by selected background variables

answers), by selected background characteristics 87

Table 5.9: Percent distribution of adolescents' perspectives on the value of education, by selected background

characteristics

Table 5.10: Percent distribution of parents' reactions to high/low scholastic achievement

based upon adolescents' reports, by selected background variables

Table 5.11: Factors related to school as a socializing agent, by selected background variables

\section{Chapter 6: Employment Profile of Egyptian Adolescents}

Table 6.1: Percent of working adolescents by selected background variables

Table 6.2: Percent of adolescents in unpaid and paid employment by selected background variables

Table 6.3: Education attainment of adolescents by selected background variables

Table 6.4: Median age at first work among adolescents 15-19

Table 6.5: Percent of adolescents unsatisfied with current paid job by reason and by selected background variables

Table 6.5: Mean earnings per month among working adolescents, by selected variables

Table 6.6: Percent distribution of working and nonworking adolescents by selected background variables

Table 6.7: Percent distribution of working adolescents by selected background variables

Table 6.8: Interrelationships between work status and health of adolescents in Egypt

\section{Chapter 7: Agents of Socialization}

Table 7.1: Percent of adolescents who express opinions openly to their families and their families' reactions, by selected background variables

Table 7.2: Percent of adolescents who communicate problems to their parent(s) and percent who report their families depend on them, by selected variables

Table 7.3: Percent of adolescents who observe violence between their parents or among siblings always or sometimes, by selected background variables

Table 7.4: Percent of adolescents hit last month, percent hit by a family member, percent who hit someone last month, percent who hit a family member, by selected variables

Table 7.5: Percent of adolescent exposure to peers, by selected background variables

Table 7.6: Percent communication with peers, by selected background variables

Table 7.7: Dynamics of the peer group, by selected background variables

Table 7.8: Percent of adolescents who feel capable of helping family and friends and percent who have

leadership qualities by selected background variables

Table 7.9: Prevalence of negative emotions among adolescents by selected background variables

Table 7.10: Differentials in expressing anger, by selected background variables

Table 7.11: Percent satisfaction with life among adolescents and their expectations for the future, by selected background variables

Table 7.12: Interrelationships between the psychological profile of adolescents, family/peer support, perception of health status, and stage of biological maturation

Table 7.13: Adolescent reports of activities during the previous day

Table 7.14: Percent distribution of adolescents according to sports activity

Table 7.15: Percent of adolescents responding that they left the house yesterday, for three activities

Table 7.16: Percent reporting that they did domestic chores the prevous day

Table 7.17: Percent of adolescent girls' and boys' exposure to various media

Table 7.18: Comparison of television viewing (entertainment shows), listening to radio, and reading

Table 7.19: Adolescent role models: Who do you admire or hope to be like when you grow up? 


\section{Chapter 8: Transitions to Marriage and Reproductive Roles}

Table 8.1: Knowledge of fertile period among married adolescents

Table 8.2: Percent of never-married girls aged 16-19 and married women who believe a 15-year-old girl can

withstand pregnancy

Table 8.3: Percent distribution of unmarried adolescents' views on the meaning of family planning, by

background characteristics

Table 8.5: Percent of adolescents aged 16-19 who have knowledge of specific contraceptive methods (of those

who report knowing about family planning)

8.6: Percent reporting knowledge of sexually transmitted infections, unmarried girls and boys aged 16-19 152

Table 8.7: Percent of adolescents who believe adolescents should be provided information on reproductive

health topics, and ranking of appropriate sources and timing of provision

Table 8.8: Percent of girls aged 13-19 circumcised by background characteristics

Table 8.9: Percent of married and never-married adolescents who have been circumcised and believe

circumcision is necessary

160

Table 8.10: Management of menstruation: reaction to menarche, hygienic practices, monitoring cycles, reaction to menstrual pains

Table 8.11: Sharing tasks: Percent of adolescents who think tasks should be done by men alone, by women alone, or shared

Table 8.12: Percent of adolescents aged 16-19 who think roles should be shared, by education

Table 8.13: Percent of adolescents aged 16-19 who think household-related decisions should be made by the

husband alone, the wife alone, or be shared

Table 8.14: Percent of adolescents aged 16-19 who think decisionmaking should be shared, by education and

sex

Table 8.15: Gender role attitudes and contemporary issues in adolescents aged 16-19: Percent agreeing wit following staments Table 8.16: A husband should decide what to do with money left over after household needs are met: Percent $\begin{array}{ll}\text { agreeing, by selected variables } & 167 \\ \text { Table } & 168\end{array}$ Table 8.17: A girl should be circumcised before she is married: Percent agreeing by selected variables $\quad 168$ Table 8.18: Mean age suitable for marriage, as reported by adolescents and parents Table 8.19: Mean age suitable for females and males to marry, as reported by girls and boys, by selected variables

Table 8.20: Desirable age difference between husband and wife by own reported education among adolescents aged 16-19 170 Table 8.21: Percent of boys and girls aged 16-19 mentioning qualities sought in future spouse 171 Table 8.22: Percent of never-married adolescents aged 16-19 who understand the meaning of "esma (women's right to divorce) in the marriage contract $\quad 172$ Table 8.23: Percent approval of divorce among never-married adolescents aged 16-19 and married women 174

\section{Chapter 9: Ever-Married Adolescent Females in Egypt}

Table 9.1: Region-specific prevalence rates of all identified ever-married adolescents aged 16-19 178

Table 9.2: Age-specific prevalence of all ever-married adolescent women identified $\quad 178$

Table 9.3: Percent comparison of highest education level attained by married and never-married adolescent females aged 16-19

Table 9.4: Main reasons for school dropout among married adolescents who attended school 180

Table 9.5: Mean age of drop out among married adolescents by reason for drop out 181

Table 9.6: Reasons for never attending school among married adolescents $\quad 181$

Table 9.7: Mean of reported age and ideal age at marriage among married adolescent women 182

Table 9.8: Living arrangements of married adolescents following marriage 184

Table 9.9: Percent of married adolescents reporting shared decision-making with their husbands, by selected

background variables

Table 9.10: Percent of married adolescents reporting yes on questions regarding other gender dynamics between married women and their husbands 187 Table 9.11: Married adolescents' ideal number of children and role in family planning decisions, by selected background variables

Table 9.12: Current physiologic condition of ever-married adolescents

Table 9.13: Timing of first antenatal visit among currently pregnant women

Table 9.14: Main reason for first antenatal visit among currently pregnant women

Table 9.15: Pregnancy outcomes among married adolescents with past pregnancy history

Table 9.16: Location of delivery of most recent pregnancy

Table 9.17: Who assisted at delivery of most recent pregnancy

Table 9.18: Current breastfeeding status among adolescents with births within 2 years 


\section{Appendix IV: Quality of the Data}

Table 1: Response rate, the number of adolescents successfully interviewed, and the number originally selected by type of instrument, sex of respondent and urban/rural type of residence

Table 2: The differentials in response rates among adolescents randomly selected for the core individual interview by selected background variables 


\section{List of Figures}

\section{Chapter 4: Health Profile of Egyptian Adolescents}

Figure 4.1: Comparison of Egyptian Boys' BMI and WHO/NCHS Reference Data. Page Figure 4.2: Comparison of Egyptian Girls' BMI and WHO/NCHS Reference Data. 28

Figure 4.3: Percent Distribution of Anemia by Severity and Sex. 31

Figure 4.4: Prevalence of Anemia by Age and Sex. 33

Figure 4.5: Prevalence of Anemia by Age and Residence. 33

Figure 4.6: Types of Parasites Among Infected Adolescents. 35

Figure 4.7: Anemia Prevalence Among Those With Parasites. 36

Figure 4.8: Probability of Menarche by Age and Socioeconomic Status. 39

Figure 4.9: Probability of Menarche by Age and Residence. 40

Figure 4.10: Boys' Reasons for Starting to Smoke. 49

Figure 4.11: Girls' Reasons for Starting to Smoke. 50

Figure 4.12: Adolescents Perceptions About Their Health Status. 51

Figure 4.13: Percent Distribution of illness among Adolescents, by Sex. 52

\section{Chapter 5: Education Profile of Egyptian Adolescents}

Figure 5.1: Total Enrollment Rates for Egypt. 63

Figure 5.2: Enrollment Rates by Sex. 63

Figure 5.3: Employment Rates by Socioeconomic Status. 63

Figure 5.4: Enrollment Rates by Region of Residence. 64

Figure 5.5: Total Enrollment Rates, by Age and Sex. 67

Figure 5.6: Cohort Enrollment Rates, by Socioeconomic Status. 67

Figure 5.7: Cohort Enrollment Rates, by Region of Residence. 68

Figure 5.8: Percent of Dropouts by Age 11, 14, and 17 among Boys Who Ever Attended School, 70

by Cohort.

Figure 5.9: Percent of Dropouts by Age 11, 14, and 17 among Girls Who Ever Attended School, 70

by Cohort.

Figure 5.10: Percent of Dropouts by Age 11, 14, and 17 among Adolescents in Urban 71

Governorates Who Ever Attended School, by Cohort.

Figure 5.11: Percent of Dropouts by Age 11, 14, and 17 among Adolescents in Urban Lower 71

Egypt Who Ever Attended School, by Cohort.

Figure 5.12: Percent of Dropouts by Age 11, 14, and 17 among Adolescents in Rural Lower 71

Egypt Who Ever Attended School, by Cohort.

Figure 5.13: Percent of Dropouts by Age 11, 14, and 17 among Adolescents in Urban Upper 71

Egypt Who Ever Attended School by Cohort.

Figure 5:14: Percent of Dropouts by Age 11, 14, and 17 among Adolescents in Rural Upper 71

Egypt Who Ever Attended School by Cohort.

Figure 5.15: Percent of Dropouts by Age 11, 14, and 17 Among Adolescents in Low 72

Sociocconomic Category Who Ever Attended School by Cohort.

Figure 5.16: Percent of Dropouts by Ages 11,14, and 17 Among Adolescents in Middle 72

Socioeconomic Category Who Ever Attended School by Cohort.

Figure 5.17: Percent of Dropouts by Age 11, 14, and 17 Among Adolescents in High 72

Socioeconomic Category Who Ever Attended School by Cohort.

Figure 5.19: Main Reasons for Dropping Out of School, by Socioeconomic Status. 74

Figure 5.20: Main Reasons for Dropping Out of School, by Region of Residence. 74

Figure 5.21: Deprivation From Education: Cohort Percent Who Never Attended School, Total. 76

Figure 5.22: Deprivation From Education: Cohort Percent Who Never Attended School, by Sex. 76

Figure 5.23: Deprivation From Education: Cohort Percent Who Never Attended School by 76

Socioeconomic Status.

Figure 5.24: Percent Never Attended School by Region of Residence. 77

Figure 5.25: Main Reason For Never Attending School, by Sex. 78 


\section{Chapter 6: Employment Profile of Egyptian Adolescents}

Figure 6.1: Distribution of Working Adolescents by Type of Employment.

Figure 6.2: Distribution of Working Adolescents in Unpaid Employment, by Sex. 99

Figure 6.3: Distribution of Working Adolescents in Paid Employment, by Sex. 99

Figure 6.4: Distribution of Working Adolescents in Unpaid Employment, by Age. 99

Figure 6.5: Distribution of Working Adolescents in Paid Employment, by Age. 100

Figure 6.6: Economic Activity Rates by Sex. 101

Figure 6.7: Economic Activity Rates in Unpaid Employment, by Sex 101

Figure 6.8: Economic Activity Rates in Paid Employment, by Sex. 101

Figure 6.9: Distribution of Working Adolescents by the Reason They Started To Work. 105

Figure 6.10: Distribution of Working Adolescents by the Number of Working Hours Per Day. 106

Figure 6.11: Distribution of Working Adolescents by the Number of Working Hours Per Week. 106

Figure 6.12: Distribution of Adolescents Working For Pay by the Extent of Stability of Work. 107

Figure 6.13: Management of Earnings Among Adolescents Working For Pay. 110

Figure 6.14: Distribution of Males Aged 15-19 by School Enrollment and Work Status. 113

Figure 6.15: Distribution of Females Aged 15-19 by School Enrollment and Work Status. 113

\section{Chapter 8: Transitions to Marriage and Reproductive Roles}

Figure 8.1: Unmarried girls' knowledge of a woman's fertile period 145

Figure 8.2: Cumulative probability of a girl getting circumcised by age 157

Figure 8.3: Cumulative probability of a girl getting circumcised, by parents' education 158

Figure 8.4: Cumulative probability of a girl getting circumcised, by socioeconomic status 158

Figure 8.5: Cumulative probability of a girl getting circumcised, by age group 159

\section{Appendix IV: Quality of the Data}

Figure 1: Age distribution of individuals ages 9-20 


\section{Chapter 1}

\section{Advancing Our Understanding of Adolescence in Egypt}

\section{INTRODUCTION}

The adolescent stage of human development is a fairly recent concept, corresponding roughly to the second decade of life. As societies have extended the years of education and skilltraining necessary for participation in adult life, that lengthened transition between childhood and adulthood has come to be recognized as a unique and important period in the life cycle. Adolescence as a discrete stage of life, however, has not always been recognized. Youth in pastoral and agricultural societies typically experienced rather abrupt transitions, with boys and girls expected to take on adult roles soon after reaching puberty. In earlier times in Egypt, girls especially were expected to marry and begin bearing children in the early teens. Most boys entered the occupation of their fathers and thus had a fairly early and predictable integration into adult tasks.

Today Egypt has expanded basic education to reach nearly all children and the requirements of entering into adult roles like work and parenting have become more complex. Larger numbers of young people are spending their teen years in school, job training, an engagement period before marriage, or other forms of preparation for adult roles. Thus a relatively new stage of life is emerging, fraught with a number of special difficulties and opportunities.

Unlike in industrialized countries, where large amounts of research have accumulated on the situation and needs of adolescents, Egypt has a dearth of information on this stage of life. Writers and journalists address the more striking aspects of adolescent experience, like mass fainting in schools, cult music, or susceptibility to extremist movements, but little solid research exists on the experiences of average adolescents. The studies that do exist are usually limited to a small number of cases or to one geographic region of the country. Thus, in the months leading up to the International Conference on Population and Development (held in Cairo in 1994), a group of social scientists began preparing reports that would shed light on the situation of adolescents in Egypt.

The effort was coordinated by the Population Council, Regional Office for West Asia and North Africa, and resulted in a monograph on adolescent marriage (El-Hammamsy 1994), a bibliography of local literature (Population Council 1995), and a growing awareness that more field-based research was needed on this age group. The assumptions that were made locally about adolescence appeared out of step with new realities. For example, while many researchers and development agencies were concerned about the effects on girls of early marriage, that phenomenon seemed from the available evidence to be declining fairly rapidly. Concurrently, a growing number of youth faced the problem of delayed marriage, exacerbated by the high cost of housing and extensive unemployment for graduates. That particular situation was neglected in the literature and by most agencies dealing with youth issues.

Meanwhile, the international literature provided few useful models for thinking about the 
realities of Egyptian adolescents. Most of the literature focused on issues of sexual behavior, unwed pregnancy, and exposure to sexually transmitted diseases. However, in addition to being inappropriate to the conservative milieu in Egypt, the literature also seemed to miss many of the crucial aspects of adolescent life that result either in deprivation or enhanced opportunities in the future, such as the transition out of school, to work roles, and into marital unions. Thus, the Population Council determined that it would pursue a broad-based program of research on adolescence that would be responsive to as wide a range of salient issues as possible.

In order to undertake such a task it was necessary to draw upon expertise from a wide array of actors. In 1995-96, the Council convened a group of scholars and activists in Cairo to advise on the design of a comprehensive national study of adolescence. Several Egyptian institutions (detailed below) were invited to participate in the study and workshops were held to define key terms, set the research objectives, and outline a research strategy. Council colleagues in Kenya and New York contributed ideas and expertise based on their own research and program experience.

This process culminated in a proposal to conduct a major national survey that would address the important aspects of adolescence in Egypt. It would attempt to link the information gained about adolescents to important societal trends - in education, health, employment, and family formation-and thus provide a baseline of data for those conducting development efforts on behalf of adolescents. The program of work became known as Adolescence and Social Change in Egypt (ASCE), and is referred to as such throughout this report.

\section{STUDY OBJECTIVES AND DEFINITION OF TERMS}

The research team agreed early on that they viewed adolescence as a normal and important transitional stage, not a social problem. Much of the international literature on adolescence focuses on sexual behavior, deviance, or rebellion against adults. The ASCE team's understanding of this phase of life is broader: it encompasses all of the critical life decisions and developmental tasks that bridge childhood and adulthood-including when to leave school, decisions about employment, taking increased responsibility for self and family, and choosing a spouse. This holistic approach enables us to examine the linkages among various aspects of adolescent experience. Throughout the report reference is made to the strong associations between school continuation, for example, and other aspects of adolescence. We are convinced that this approach is more fruitful than one focused solely on a problem like early marriage or sexual behavior.

Decisions about an appropriate scope for the study were closely linked to debates within the study team over the operational definition of adolescence itself. Multiple definitions are in use in Egypt (Shafey 1998) and in the international community. The question of definition is further complicated because there is no agreed upon corresponding term in Arabic. (The ASCE researchers finally settled on the Arabic term al nasha', which is employed in the Egyptian constitution to refer to citizens between the stages of childhood and young adulthood.) Some definitions are based on physiological criteria: Adolescence can be 
considered to begin with the onset of physical maturation (puberty). But there are important gender and other variations in the age of onset of puberty, making this a difficult definition to operationalize. Other definitions use an arbitrary beginning point, like age 12 , but define the end point in terms of a social landmark such as reaching legal majority (age 21 in Egypt).

In reality, adolescence has no clearly defined starting or ending point. The research team wanted to explore the various social and cultural understandings of this stage of life without imposing prior categories. They were also interested in the early transition into adolescence and the stages of physical maturation. So in the end the team decided to adopt a working definition of adolescence as the second decade of life, spanning the ages 10 to 19 .

The ASCE team not only wanted to look at adolescence holistically but also to understand the social context in which young people grow to adulthood. This led to an interest in the family as a crucial agent of socialization. Given the rapid social and economic change in recent years, the team posited that the experiences parents had as teenagers would be substantially different from those now experienced by their children. They decided to include an interview with one responsible adult - a mother, father, or other adult guardian - for each adolescent interviewed. This would allow for exploration of parental attitudes and practices toward their adolescent children, as well as a chance to assess intergenerational change in such areas as school attainment, gender relations, and age at marriage. It also provided for some interesting comparisons of the perceptions of two generations on the same event or topic. Examples include answers regarding health service utilization during an illness and whether parents and their adolescents had ever discussed the changes of puberty together.

The survey design that was ultimately developed places a strong emphasis on gender constructions of adolescent experience. The study team posited that adolescence is a period in which many gender-specific messages are consolidated, about appropriate dress and demeanor, mobility, leisure activities, adult goals, and aspirations for the future. Doors of opportunity open for some young people in terms of greater education, skill training, or jobs. Other doors close, as some adolescents prematurely leave behind more carefree days to become wives and then mothers. To capture this variability, both boys and girls were asked a set of identical questions, and additional questions were asked of each group alone. One major objective was to better understand how girls and boys experience adolescence differently, and how those patterns may translate into different opportunities as young people progress toward adulthood.

One significant gender difference in Egypt is in the age at marriage; very few boys marry before age 20 while significant numbers of girls do so. The study team made a decision to include all married adolescent women from screened households in the sample in order to better understand the correlates and later implications of teenage marriage. In addition, the survey analysis looks at patterns of similarity and difference among single adolescent boys and girls, and speculates on their implications.

Another objective of the study was to understand the variability of experience as one moves from early adolescence to later stages. Too often, adolescents of all ages are lumped together for research or policy purposes, thus failing to acknowledge the great strides in physical, 
mental, and emotional capacity teens will make between the ages of 10 and 19 . The study team designed a basic interview instrument for all adolescents and then added several sections for those respondents 16 years of age or older. Older adolescents were asked questions regarding gender role expectations of marriage and their knowledge of reproductive health and physiology. In the beginning, some team members were concerned that younger adolescents would not be able to answer the basic interview questions. But during a field pretest it became clear that the ten to twelve year olds were not only capable of responding to the questions, but that they tended to reply with greater spontaneity and enthusiasm than older age groups. Age became an important variable in the analysis that follows in this report.

In addition to household-level findings, the study team wanted to investigate other important settings where adolescents spend substantial time and receive strong socialization messages. Other components of the study are therefore investigating schools and the experience of schooling on young lives, as well as the role of work and the workplace in shaping attitudes and behavior. However, in the interest of disseminating findings as quickly as possible, only the national household survey results for 9,128 adolescents and their parents are reported here.

\section{INSTITUTIONAL COLLABORATION/THE RESEARCH TEAM}

The ASCE household survey consisted of multiple interview instruments, medical and laboratory exams, a cognitive test, and a 24-hour dietary recall instrument. The success of a national survey this complex would not be possible without close collaboration among many institutions and individuals of diverse talents. The project benefited from the synergy created by its four institutional partners, each of which contributed expertise, commitment to the project goals, and a problem-solving approach to the logistics of a major survey effort. (All individuals participating in the ASCE project are listed in Appendices I and II.) The Cairo office of the Population Council developed the original concept for the project, raised necessary funds, and coordinated the overall activities of a core research team, including final editing of the summary report. Council researchers took responsibility for the study components dealing with gender roles, time utilization, and marriage negotiation among adolescents.

Since health and nutrition were to be major components investigated by the survey, cooperation was sought with the High Institute for Public Health (HIPH) of the Alexandria University. HIPH team members were responsible for the design of sections dealing with health status and health behaviors, including dietary habits, smoking, and drug abuse. They were also responsible for the design of the nutritional component of the study, including the assessment of physical growth using weight and height measurements and a 24-hour food recall method. The HIPH also designed and analyzed laboratory tests covering hemoglobin levels and the detection of parasites. HIPH team members, together with members of the Faculty of Community Medicine at Assiut University, took the responsibility for the training of physicians to implement portions of the health component.

In order to address the important adolescent issues around puberty and reproductive health, 
members of the Faculty of Community Medicine from Assiut University were invited to join the team. They worked closely with HIPH members on the health component, with special responsibility for administering tests of physical maturity, a battery of questions on reproductive health knowledge and practices, and questions related to health service utilization by adolescents. A separate questionnaire was designed for married adolescent women that covered many aspects of reproductive and family life.

The last organization to join in the ASCE collaboration became in many ways the most crucial actor in the survey process. The Social Research Center (SRC) of the American University in Cairo took responsibility for sampling design and implementation, questionnaire design, pretesting, interviewer training, and fielding the survey. Their staff undertook the entry, cleaning, and processing of all survey data, and provided technical support to the entire research team for data analysis, including training on the use of statistical programs. In addition, SRC team members were responsible for the study components dealing with education, employment, and the psychological profile of adolescents.

\section{THIS SUMMARY REPORT}

The data generated by the ASCE survey is both rich and extensive. A series of in-depth monographs are planned on the major topics addressed in the survey. However, in the interest of quick dissemination to policy and program managers, this summary report has been produced for early distribution. It covers all major topics included in the survey, providing descriptive statistics and some analysis of important background variables. While not every survey item is analyzed, the authors have attempted to show the breadth of possibility for future analysis. This means that in some cases, important issues are raised without delving fully into their correlates. Subsequent publications will include multivariate analyses, an indepth look at the interesting sample of boy-girl sibling pairs included in the sample, and linked analyses of the survey with other sources of qualitative and quantitative data on schooling experience, marriage negotiation, and youth livelihoods.

The authors hope that this report will stimulate discussion and further research and suggest many areas for program intervention to improve the lives of young Egyptians. 


\section{Chapter 2}

\section{Methodology and Scope of the Study}

The Adolescence and Social Change in Egypt project has multiple objectives that cut across the socioeconomic, cultural, and health dimensions of adolescent development. Due to lack of information on this particular segment of the population, a national survey that provides baseline data on adolescents was considered an essential step toward filling the data gap. A special sampling design and complex set of instruments were developed to serve the multiple goals of the project.

\section{SAMPLING DESIGN}

The survey sample is a nationally representative, multistage, stratified, probability, cluster sample of adolescents. In the first stage, 101 primary sampling units (PSUs) were selected proportional to population size using the updated census frame compiled by the Central Agency for Public Mobilization and Statistics (see Appendix III for list of sampled PSUs). Only the five frontier governorates were excluded from the study, as only about 1.5 percent of the total population of Egypt lives in these five governorates. In urban areas, PSUs are the smallest administrative units for which the census results are published. These are called shiakhas. In rural areas, PSUs are villages with hamlets and satellites that are administratively linked to them.

The PSUs were stratified by 21 governorates and by urban/rural type of residence within each governorate. Based upon population estimates in 1996, selected PSUs were divided on the maps into partitions. Each partition has a population of approximately 5,000 persons in rural PSUs and 10,000 persons in urban PSUs to allow for the higher heterogeneity in urban areas. One partition was randomly selected from each of the 101 PSUs. A quick count process of housing units in the selected partition was carried out. The selected partition was then divided into smaller well-defined segments, each having approximately an equal number of housing units. In the second stage, two segments were randomly selected from each of the 101 PSUs. The size of segments varied among the different PSUs so as to yield at the end a self-weighted sample of households. All households residing within the well-defined boundaries of the selected segments were screened using a household roster sheet. A total of 13,271 households were successfully screened at this phase of the survey.

Eligible households were then defined as households with at least one member in the age range 10-19 years. The number of eligible households amounts to 7,256 (eligibility rate is 0.547 ). Using the Kish grid, one adolescent (by gender) was randomly selected from each eligible household. This resulted in one boy and one girl being selected from households that contained at least one adolescent of each gender. A total of 9,128 adolescents were successfully interviewed (4,354 boys and 4,774 girls). The number of pairs of siblings successfully interviewed was 2,413. All randomly selected adolescents were eligible for an individual interview using a core instrument. The sample of adolescents is not self-weighted. 


\section{SUBSAMPLES}

All randomly selected adolescents currently enrolled in school between the 5 th grade and the 9th grade and those who dropped out between these two grades were eligible for two achievement tests in Arabic and mathematics. A total of 3,713 eligible adolescents completed the Arabic test and 3,792 completed the mathematics test. A total of 3,682 adolescents completed both tests.

A quarter of the total randomly selected sample of adolescents were systematically subsampled; half the sample (by gender) in 50 PSUs. Subjects in this subsample were eligible for a second interview focusing mainly on health issues. The total size of the subsample is 2,323 successfully interviewed (1,070 boys and 1,253 girls). The adolescents selected in this subsample were also eligible for a complete health examination and urine, stool and blood testing. The subsample, like the original sample of adolescents is not self-weighted.

Since there was an interest among the principal investigators in the phenomenon of adolescent marriage among females, the individual core instrument as well as the health instrument were both administered to all ever-married adolescents identified in eligible households. This process was applied regardless of whether or not the adolescent was randomly selected. The total number of ever-married adolescents successfully interviewed was 317 . The sample of all ever-married adolescents is self-weighted. Only ever-married female adolescents who were randomly selected are included in the individual file and health file. Data on all ever-married female adolescents are managed separately.

On the other hand, in two-parent basic family units only one parent was randomly selected for the responsible adult interview (with a probability of 0.5 ) while in single-parent basic family units, the parent who is a member of the sampled household was interviewed. This strategy was followed to ensure a fair representation of the attitudes of mothers/female caretakers and fathers/male caretakers in regard to a multiplicity of issues related to their children in the age group 10-19. A total of 6,213 responsible adults were interviewed (3,274 males and 2,939 females).

This design resulted in nationally representative samples of adolescents and responsible adults for which all reports remain generalizable and can be disaggregated by region of residence (urban governorates/Lower Egypt/Upper Egypt), type of residence (urban/rural), and by gender.

\section{STUDY INSTRUMENTS AND METHODOLOGY}

In order to fulfill the objectives of the study, several instruments and methodologies were utilized. Face-to-face interviews using a number of structured questionnaires were conducted. Tools for proper assessment of the general health status of adolescents incorporated laboratory testing of urine and stool specimen and accurate measurement of height and weight. A 24-hour recall of nutritional intake and instant readings of the level of hemoglobin in blood were also collected. A complete clinical examination to detect health problems and to record 
different indicators of biological maturation was also successfully implemented, utilizing specially trained physicians of the Ministry of Health and Population.

\section{Structured Questionnaires}

Four distinct structured questionnaires were developed: the roster, the core individual adolescent questionnaire, the health questionnaire, and the questionnaire administered to responsible adults. The following section briefly summarizes the content of each survey instrument.

\section{The Roster}

The roster collected basic demographic information from all 13,271 sampled households on all usual members of the household such as age, sex, marital status, educational attainment, literacy among the group who never attended school, and work status.

\section{The Individual Adolescent Core in Five Parts}

Section I. Education collected information on exact birth date, school ever-attendance, highest stage reached if ever attended, current enrollment status, age when dropped out and reasons for dropping out of school if the event had occurred, school entry age, reasons for neverattendance and attitudes toward literacy classes among never-attendants. For those in preuniversity education at the time of the survey and for the group who ever attended preparatory schools, a battery of questions on different aspects of the school experience was administered. Attitudes toward school, travel to school, school physical conditions and facilities, interaction with teachers and among students, and some indicators of the quality of education were also addressed.

Section II. Economic roles included questions concerning ever-participation in the labor market, current involvement, type of current employment, working hours per day, and work days per week. Special questions were asked of adolescents working for pay in regard to work conditions, work hazards, satisfaction with current job, level of earnings, and management of earnings. Reasons for and age at starting work were asked of all who ever worked.

Section III. Health status focused on health service-seeking behavior, medications taken regularly, exercise, and smoking behaviors. For girls, questions about menstruation and its management were addressed.

Section IV. Social relations and personal traits focused on the adolescent's communication and exchange of support with family members and peers. Questions addressing important aspects of the individual's psychological profile in this transitional phase of life also were included. These are not psychological tests but rather exploratory tools to investigate some positive traits such as self-worth and leadership as well as the prevalence of negative emotions (loneliness, anxiety, fear, guilt). In addition, venues to express anger and the extent 
of satisfaction with life, future expectations, and role model are examined (World Health Organization 1996).

Section V. Time use collected information on activities done during the previous 24 hours, such as studying, work, help in household chores, exposure to the media, and activities during leisure time.

\section{The Health Status and Health-Related Attitudes Questionnaire}

Section I. Health service-seeking behavior focused on the frequency of laboratory testing of urine, stool, and blood in the 12 months preceding the interview. General information on the type of service provider, reason for utilization, and level of satisfaction during a recent illness was also collected.

Section II. Health-related practices collected information on regular intake of vitamins and iron tablets as well as personal and peer experience in regard to tobacco and drug use.

Section III. Dietary habits focused on the number of meals per day; snacks between meals; eating outside the home; consumption of tea and coffee, vegetables, fruits, bread, salt, and so forth.

Section IV. Reproductive health and gender roles gathered data on appropriate age at marriage for boys and girls and justification for it, the incidence of circumcision and the related social context, knowledge of perception of maturational changes, sources of information on these changes, and for girls, management of menstruation.

Adolescents 16-19 years old were asked an additional battery of knowledge and attitudinal questions on reproductive health issues, including sexually transmitted infections (STIs) and family planning, gender roles in the house, sharing tasks and decision-making, divorce, and the marriage contract. Some of the questions regarding circumcision, gender roles, decisionmaking, and divorce were extracted from the 1995 Egyptian Demographic and Health Survey modules that were administered to ever-married women in reproductive age.

Section V. Marriage asked all 16-19-year-old adolescents about the qualities they would seek in their future spouse, the ideal age difference between spouses, and the differences in the educational attainment between spouses. Ever-married female adolescents were asked about their age at marriage as well as that of their husbands, marriage arrangements, living arrangements after marriage, ideal number of children, communication between spouses, and a complete account of pregnancy outcomes.

\section{The Responsible Adult Questionnaire}

Section 1. Household living conditions focused on ownership status and size of the house, house utilities (connection to public water and sewerage systems), ownership of durable goods and assets, occupation of the responsible adult and of the head of the household if not the responsible adult. 
Section II. Attitudes toward education gathered information on the value of education for boys and girls, education aspiration for boys and girls, reasons for school never-attendance or dropout among children of responsible adults, expenditures on education, expenditures on food, and overall monthly expenditures of the household.

Section III. Health covered reports of illnesses and disabilities among adolescents, health service seeking behavior, attitudes towards the health insurance system for school children, and smoking behavior among responsible adults.

Section IV. Attitudes toward marriage and gender roles collected data on communicating information concerning puberty and physical maturation, appropriate age at marriage, attitudes toward female employment and marriage arrangements, and views about contemporary marriage compared to marriage in their generation.

\section{ACHIEVEment Tests}

\section{Arabic}

Three different levels of Arabic tests were developed corresponding to 5th primary and $1 \mathrm{st}$ preparatory, 2nd and 3rd preparatory, and 1 st secondary. The tests did not directly incorporate material from school textbooks. Rather they reflected a comparable level of information and inquiries. The tests were intended to measure specific skills such as comprehension, deduction, literary expression, and grammar.

\section{Mathematics}

The mathematics test contained 20 questions, each divided into 5 sub-items corresponding to grades 4-8. Types of questions included matching, multiple choice, correct/incorrect, sentence equation/completion, and short answers. Respondents enrolled in grade 4 were expected to be able to answer the first of the 5 sub-items; those in grade 5 were expected to be able to answer the first and second of the 5 sub-items; and so forth, with those in grades 8 and 9 expected to be able to answer all one hundred items in one hour. The test was intended to measure specific skills in algebra and geometry; algebraic and computational operations, proof and solving problems in algebra at the three levels of retrieval, comprehension, and application. In geometry visual, verbal, logical, and drawing skills were measured as well as problem solying at the levels of identification, organization, analysis, and deduction.

\section{Assessment of General Health Status}

\section{Laboratory Investigations}

\section{Hemoglobin Determination}

Capillary blood was obtained by pricking the fingertip with a sterile lancet. A drop of blood was collected into a disposable microcuvette and the level of hemoglobin was determined using the HemoCue photometer (HemoCue AB, Ängelholm, Sweden). The HemoCue 
instrument allows the detection of anemia by estimating the hemoglobin level in a sample of blood. It provides accurate results that are comparable to the cyanmethemoglobin method. No processing of the blood specimen is needed, and the results can be read directly without calculation in less than 45 seconds. Moreover, the instrument is portable, which makes it possible to use in the field and quite practical for use in surveys. The only disadvantage of this method is its use of expensive, disposable cuvettes.

Anemia was considered to be present if the hemoglobin value was below $12 \mathrm{~g} / \mathrm{deciliter}$ (dl) for adolescent girls and for adolescent boys aged less than 14, and below $13 \mathrm{~g} / \mathrm{dl}$ for adolescent boys above 14 years of age as proposed by WHO (World Health Organization 1968). Blood specimens were obtained from 1,980 adolescents.

\section{Parasitologic Study}

Each adolescent was provided with two labeled plastic pots and asked to provide a stool sample and a urine sample. Only 1,808 and 1,920 of the studied group were able to comply with this request for the stool and urine samples, respectively.

Stool examination: Fecal samples weighing approximately $300 \mathrm{~g}$ were taken by a specially designed spoon and inserted into containers prefilled with $4 \mathrm{ml}$ of Merthiolate-formaline (MF) solution. Samples were thoroughly mixed in the MF solution and then transported to the laboratory of the High Institute for Public Health. Immediately before examination, Lugol's iodine was added to each collected tube. Mixed direct smears (Dunn 1968) with material drawn from the midpoint of the specimen after thorough remixing were made and examined. All samples were then concentrated by the Merthiolate, iodine, formaldehyde-ether centrifugation method (Allen and Ridley 1970). Specimens were sieved and placed in $15 \mathrm{ml}$ conical graduated centrifuge tubes with $3 \mathrm{ml}$ of diethyl ether, then vigorously shaken and centrifuged. Sediment smears were examined microscopically for parasites.

Urine examination: Ten $\mathrm{ml}$ of thoroughly mixed urine was placed in a plastic bottle containing $10 \mathrm{ml}$ of 0.002 percent carbal fuchsin preservative to bring the total volume to $20 \mathrm{ml}$. Preserved urine was transported to the laboratory of the High Institute for Public Health. Upon examination, urine was centrifuged at $2000 \mathrm{rpm}$. for 15 minutes, and sediment was placed on two slides, covered with a cover glass, and examined microscopically (Richardo, Hassan., Cline, and El-Alamy 1984).

Results of tests on urine and stool samples were provided to the responsible adult of each participating adolescent in the form of a written report. Results of the hemoglobin test, if clinically significant, were reported to the adolescent's responsible adult immediately.

\section{Anthropometric Measurements}

Measurement of weight and height were carried out on 1,999 adolescents according to procedures recommended by Jelliffe (1966). For weight measurement, each subject was measured wearing light cloths and without shoes, using beam balance to the nearest $0.1 \mathrm{~kg}$. Height was determined with the subject's head in the Frankfort plane and without shoes to the nearest $0.1 \mathrm{~cm}$. 
In order to evaluate the nutritional status of the adolescents, the anthropometric indices that were used as recommended by the World Health Organization (WHO) Expert Committee (1995) are height-for-age and body mass index (BMI)-for-age. The United States National Center for Health Statistics/World Health Organization (NCHS/WHO) reference data were used for height-for-age index (WHO 1983). The height-for-age index provides an indication of linear growth retardation and therefore is an indicator of stunting. The cutoff value for stunting during adolescence is below minus two standard deviation $(-2 \cdot Z$ scores $)$ from the median of the reference population.

BMI-for-age (weight $[\mathrm{kg}] /$ height $^{2}[\mathrm{~m}]$ ) is recommended as the best indicator of thinness and overweight in adolescence. The cutoff value for thinness or low BMI-for-age in adolescence is below the 5 th percentile of the reference population (Must, Dallal, and Dietz 1991). For those adolescents at risk of being overweight, the cutoff value is between the 85 th to less than the 95 th percentiles, while for obesity, the cutoff value is above the 95 th percentile.

\section{Dietary Intake}

In order to obtain a quantitative assessment of the dietary intake of adolescents, the 24-hour recall method was used. Each subject was asked to recall all food items and beverages that he/she consumed during the 24 hours preceding the interview. A model of customarily used household measures (glasses, plates, and spoons) was used to collect information on the quantity of food items served. Special emphasis was focused on different kinds of bread consumed, recipes of cooked foods, methods of preparation, and kind of fat used.

Nutrient intakes were evaluated using a modification of the Food Intake Analysis System (FIAS) (University of Texas and US Department of Agriculture, Version 2.3). The FIAS utilizes the current version of the USDA Nutrient Database. The results of the nutrient intake data are not included in this report as the analysis has not yet been completed.

\section{Assessment of Sexual Maturation}

The Tanner scale is a tool to assess the development of secondary sexual characters in males and females, the development of pubic hair for both sexes, genitalia development for males, and breast development for females (Tanner 1975). It is a $1-5$ scale with 1 denoting prepubescence and 5 denoting full adult maturation (see charts below). These ratings are represented pictorially with accompanying text describing each stage. Both male and female doctors were trained in the use of the method for one week in the field, male doctors to assess boys' development and female doctors to assess girls'. During the training, both doctors and the trainers used their observations during examinations to determine the stage of an adolescent's development, compared with the Tanner scale photographs. Each doctor's rating was then compared to that of the trainer; by the end of the training, there was almost no differences between the assessments. During the survey field work, the actual assessments were done during a general physical examination, without informing the adolescent that the assessment was being done or showing them the Tanner scale photographs. Tables 2.1 and 2.2 indicate these stages for both boys and girls: 
Table 2.1: Tanner's sex maturity rating for girls

\begin{tabular}{|c|c|c|}
\hline Stage & Pubic hair & Breasts \\
\hline 1 & None & Preadolescent \\
\hline 2 & $\begin{array}{l}\text { Sparse, lightly pigmented, straight, } \\
\text { medial border of the labia }\end{array}$ & $\begin{array}{l}\text { Breast and papilla elevated as small } \\
\text { mould; areola diameter increased }\end{array}$ \\
\hline 3 & $\begin{array}{l}\text { Darker, beginning to curl, } \\
\text { increased amount }\end{array}$ & $\begin{array}{l}\text { Breast and areola enlarged, no contour } \\
\text { separation }\end{array}$ \\
\hline 4 & $\begin{array}{l}\text { Coarse, curly, abundant, but less } \\
\text { in amount than adult }\end{array}$ & $\begin{array}{l}\text { Areola and papilla form a secondary } \\
\text { mound }\end{array}$ \\
\hline 5 & $\begin{array}{l}\text { Adult feminine triangle, spread to } \\
\text { the medial surface of the thighs }\end{array}$ & $\begin{array}{l}\text { Mature, nipple projects, areola part of the } \\
\text { general breast contour }\end{array}$ \\
\hline
\end{tabular}

\section{Table 2.2: Tanner's sex maturity rating for boys}

\begin{tabular}{|lll|}
\hline Stage & Pubic hair & Genitalia \\
$\mathbf{1}$ & None & Preadolescent \\
$\mathbf{2}$ & Scanty, long, slightly pigmented & Enlarged scrotum, pink texture altered \\
3 & Darker, starts to curl, small amount & Scrotum enlarges, penis longer \\
4 & $\begin{array}{l}\text { Resembles adult type, but less in } \\
\text { quantity, coarse, curly }\end{array}$ & $\begin{array}{l}\text { Scrotum larger, dark; penis larger, with } \\
\text { glans and breadth increased in size }\end{array}$ \\
5 & $\begin{array}{l}\text { Adult distribution, spread to the } \\
\text { medial surface of the thighs }\end{array}$ & \begin{tabular}{l} 
Adult size penis and scrotum \\
\hline
\end{tabular}
\end{tabular}

\section{IMPLEMENTATION OF THE STUDY DESIGN AND DATA COLLECTION}

Implementation of the study design was accomplished through the following three steps:

\section{Pretesting}

When preliminary versions of the structured questionnaires were ready for testing, six experienced interviewers were trained intensively on the objectives and methods of the study. Four locations were chosen for implementation of the pretest. The four locations were selected to represent four distinct settings: an urban middle class locality in Cairo, urban district in Upper Egypt, rural village in Lower Egypt, and a rural village in Upper Egypt. Debriefings were held with the field team throughout the pretest phase. Based on the results of pretesting, the layout and content of the structured questionnaires were modified and field procedures revised.

\section{Training of Field Workers (Data Collectors) and Physicians}

A one-month training course for data collection was held at the Social Research Center in Cairo, after which about 50 of the best trainees from different governorates were selected as interviewers. The training program was divided into sessions of lectures, role-playing, and field training. The lectures covered a comprehensive overview and justification for all questions in each instrument. Also, two full days were devoted to a general orientation on gender issues, psychological development during adolescence, and techniques for interviewing young people. 
A one-week training program was also convened for 30 Ministry of Health and Population physicians from different governorates. The training consisted of a one-day orientation to the objectives of the study, overview of adolescent health issues, and explanation of the field implementation. This was followed by four days of field training in administering adolescent health exams in a government health center. The training covered all procedures required for the comprehensive assessment of general health status, the stages of biological maturation, and the nutritional intake of adolescents.

\section{Coordinating Data Collection for the Health Component}

The interviewers who passed the training program were divided into seven teams. Each team had a supervisor who led the team and ensured that all households residing in the designated segment were screened. Then the supervisor carried out the process of random selection of adolescents from each eligible household roster using the Kish grid. The selection of the responsible adult and preparation of the set of instruments needed for each sampled adolescent and guardian followed. Finally, the supervisor distributed the workload to members of the team and revised the questionnaires completed in the field.

The interviewers were instructed to make three attempts to meet the selected adolescent(s) and the responsible adult. After the third attempt, the respondents were considered among the non-response group. During the screening process, the interviewers explained only briefly the objectives of the study. In the second visit, to selected eligible households, carefully designed confidentiality and informed consent procedures were carried out. A one-page introductory statement was first read by the interviewer and then presented to the head of the household to obtain his/her verbal consent for the interviews of both the responsible adult and adolescent(s). Before interviewing the adolescents, the same introductory statement was presented verbally, emphasizing the voluntary nature of participation. The interviewers carried out the interview with each adolescent in privacy to the best of their capacities.

If the PSU was one of the 50 selected for the health component subsample, the health instruments were also administered to half the interviewed adolescents systematically by gender. When all interviews had been completed in the two segments of each PSU, the completed questionnaires were sent to the central office in Cairo for office editing and coding of open-ended questions.

The supervisor was then instructed to visit the nearest government health facility as designated by the Ministry of Health and Population and make the necessary arrangements to complete the clinical examination on all adolescents who were selected in the health subsample. The selected adolescents, their guardians, and the team of trained physicians responsible for the particular PSU were informed about the exact date for the implementation of this component. On that date, the physicians (at least one male and one female) were present at the health center with all needed equipment and medical materials. The interviewers accompanied sampled adolescents and their parents to the health center and attempted to convey a sense of seriousness and commitment to them. This message was re-emphasized through the study team assurance that the participants would receive the results of the laboratory tests on their urine and stool specimens. All laboratory tests were analyzed at the 
High Institute for Public Health, Alexandria University.

Data collection and implementation of the health component of the survey extended for five months (mid-March to mid-August 1997). The long duration of the fieldwork enriched the sample results by covering part of the academic year as well as the school holiday and ranging over two seasons (spring and summer). As a result, findings related to employment, time use, and nutritional intake average the experience of adolescents rather than restricting them to a particular season.

\section{LESSONS FROM FIELDWORK}

Interviewing adolescents is a unique experience, very different from interviewing adults, particularly if they are as young as 10 years old. Obtaining the parents' consent to interview the adolescent in private was occasionally problematic. While the majority of the adolescents interviewed were positive about this process, took it seriously, and felt a sense of pride about participating, parents were often skeptical about it. The interviewers were instructed to carry out the interviews in total privacy. When a parent insisted on attending, the interviewers used one or more strategies to maintain the privacy of the interview. They reiterated the objectives of the study, gave the parent a blank questionnaire to read, or offered to read the questions to the parent before the interview. Alternatively, interviewers suggested that the parent sit where the interview could be seen but not heard or started with the achievement tests if the adolescent was eligible. In cases where there were several eligible respondents from the same household, one or more interviewers carried out interviews simultaneously. At worst, the interviewers accepted that the parent listened to the first few questions and answers, after which parents usually became convinced of the legitimacy of the survey, or grew bored and left the room.

A problem unique to a survey of adolescents is the relatively high mobility, within the area of residence, of this segment of the population. In-school adolescents are either attending classes or taking private tutoring after school. When they finish their scholastic commitments, they visit or go out with friends or are off buying things (particularly food) for the household. In rural areas and in urban Lower and Upper Egypt, they are very likely to be employed either for pay in workshops or helping parents in the fields without pay. As mentioned earlier, the interviewers were instructed to make three attempts on different days and hours to meet the selected adolescent. After the third unsuccessful attempt, the adolescent in question was considered a nonresponse.

Administering multiple instruments to the same respondent necessitated making more than one visit to the same respondent. Adolescents in the health subsample who were also eligible for the achievement tests were an extreme case. This group was interviewed for the core individual adolescent questionnaire, the health questionnaire, the achievement test in Arabic and the achievement test in mathematics. Collectively, two hours and a half were needed to implement this set of instruments. Allocating such a large amount of time to the interview was difficult for some adolescents because of exhaustion or other commitments.

The successful implementation of the complex health component of the survey is a major 
success story that should be documented. It is the outcome of a high level of coordination between four research institutions on the one hand and the sincere support of high-level executives at the Ministry of Health and Population. Also, the seriousness and commitment of the physicians who were recruited for implementing this component and their sensitivity to the respondents were definitely important assets. Nonetheless, implementation of the health component faced four main problems.

Parents' skepticism (and occasional indifference) was a major obstacle for the field interviewers. Convincing parents and the adolescents themselves to undergo the clinical examination and to give urine and stool specimens was indeed a very difficult task. Accompanying the respondents to the health centers, emphasizing the safety of the procedure, and the presence of a female physician (for girls) were all positive factors in raising the response rate to that particular component of the survey. Later on, returning the results of the laboratory tests to the respondents reinforced the benefits of participation and a sense of the researchers' commitment to them.

In some urban and rural PSUs, the nearest health center designated by the Ministry of Health was still not close enough to the particular sampled segment. Walking a long distance or using a means of transportation were real obstacles in the way of implementing the health component.

In addition, the implementation of the health component in some PSUs coincided with school examinations during the month of May. Both parents and adolescents were reluctant to participate in that component during exam periods, while the survey team could not postpone it due to the potential costs incurred by this delay.

A final issue in connection with the implementation of the health component relates to the absence of paramedical personnel from the medical team. Despite all the efforts exerted by the physicians, the presence of paramedics could possibly have sped up the process, facilitated the work of the team, and minimized the waiting time of the respondents.

\section{THE UNIQUE FEATURES OF THE STUDY}

There are a number of unique features of the ASCE data.

Until the ASCE survey was implemented, there had been no sizable data sets available in the Middle East that would permit an exploration of adolescent socialization in depth, on a nationally representative basis, and across more than one generation. Moreover, because the survey gathered such a comprehensive range of information from adolescents and their parents, the data allow us to assess various aspects of adolescence in Egypt. For example, we are able to look at the relationship between an adolescent's health status and his/her scholastic performance, or the association between gender role attitudes of parents and those of their adolescents.

The ASCE data also provide a rare opportunity to examine responses to the same set of questions from boy and girl pairs residing in the same household. The sampling method 
selected one girl and one boy from each household having eligible adolescents of both sexes. This resulted in a subset of 2,554 boy-girl pairs of adolescents across the national sample. Most but not all of these were sibling pairs, that is, a brother and sister who reside in the same household and share at least one biological parent. Because of the random nature of the selection process, the pairs included both older brother/younger sister and reverse-order pairs. Smaller subsets of pairs are available for some aspects of the survey; for example, 292 pairs were sampled for their knowledge of maturation, and a smaller number of pairs (36) where both adolescents were 16 years and older were asked questions about reproductive health and marriage expectations.

\section{SOME TECHNICAL NOTES}

Topics in this report have been presented using only bivariate analysis; thus potential confounding relationships have not been taken into consideration. For example, what appears to be a negative relationship between educational attainment and the presence of anemia may in fact be confounded by socioeconomic status and residence variables. The discussion presented in the text focuses only on those simple relationships that are thought not to be confounded. More complex relationships will be explored in subsequent publications.

Moreover, because of the sampling design, weighted data were used to obtain the percentages cited throughout this report. However, the Ns presented were obtained from the unweighted data in order to reflect the exact number of responses obtained in the data collection. 


\section{Characteristics of the Sample}

\section{REPRESENTATIVENESS OF THE SURVEY OF ADOLESCENTS IN EGYPT}

Table 3.1 displays the distribution of individuals in all sampled households by sex, age, and type and region of residence and compares this distribution to data of the preliminary results of the 1996 census in Egypt. Only minor differences are observed in the distribution of sampled households by urban/rural type of residence. Outside of the urban governorates, the proportion of urban households in the sample is slightly lower than in the census. This is a result of two main factors. First, the response rates in the ASCE survey for the preliminary screening process were lower in urban than in rural areas. In addition, non-sampling nonresponse was higher in urban than in rural areas due to the higher incidence of unoccupied housing units in urban than in rural areas.

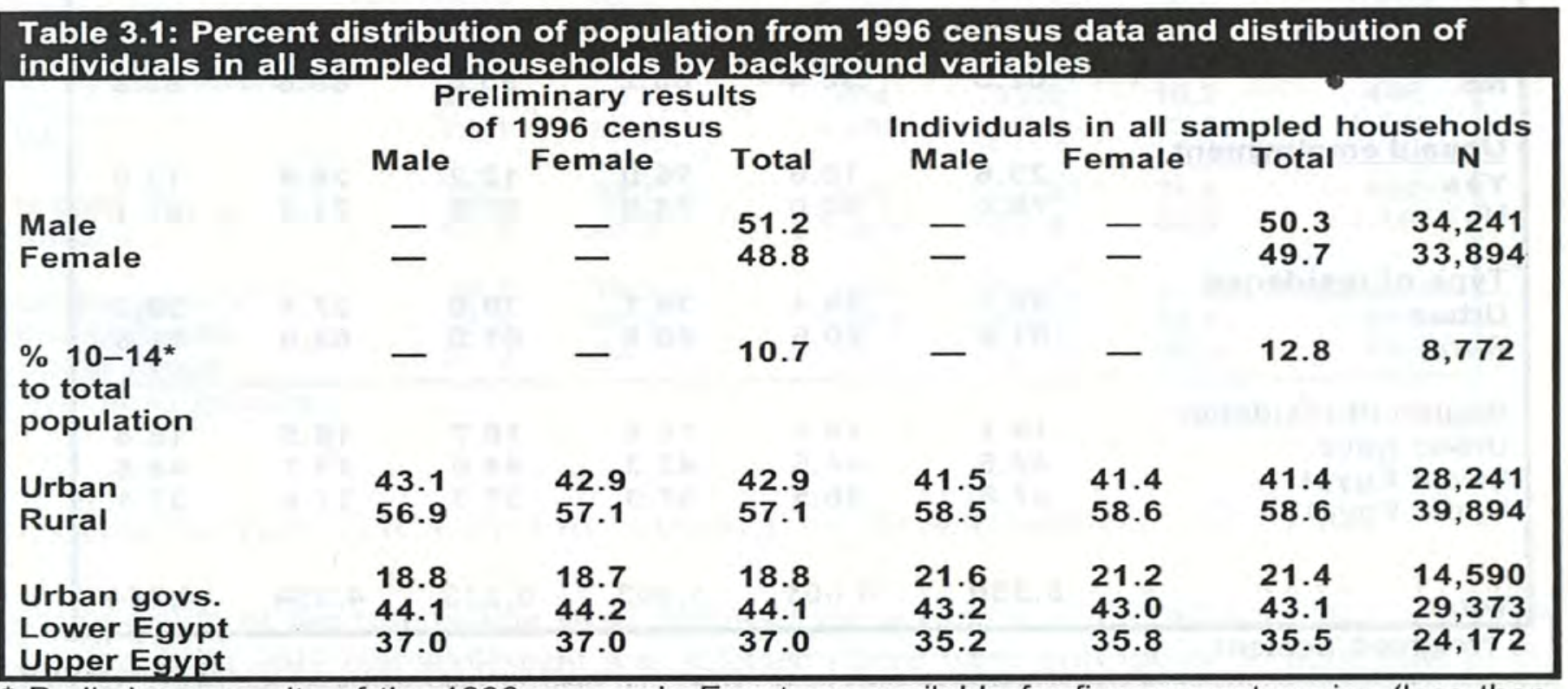

* Preliminary results of the 1996 census in Egypt are available for five age categories (less than $6,6-9,10-14,15-60$, and $60+$, for the two sexes combined).

Table 3.2 attempts to depict any loss in the representation of the population of adolescents in Egypt as we move from the group of all adolescents in sampled households, to the sample of randomly selected adolescents in eligible households and finally to the sample of successfully interviewed adolescents. Table 3.3 displays the same information for the subsample of the health component and the sample subjected to the clinical examination. 


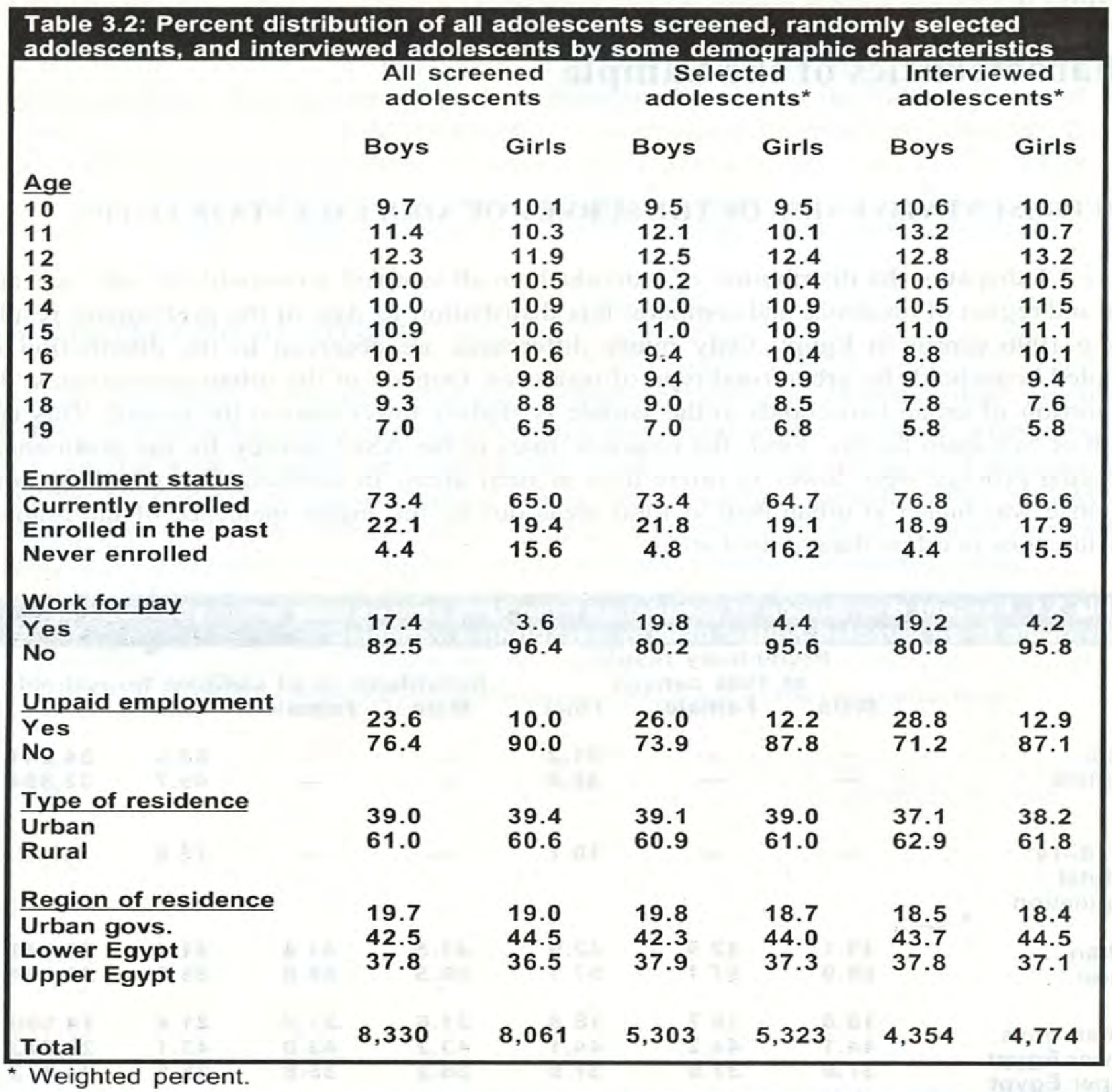

Table 3.2 indicates that the random selection procedure of adolescents by gender using the Kish grid was carried out properly and preserved the main characteristics of the sample of all adolescents in the screened households. Only the proportion of adolescents currently in school was slightly higher than in the screened households. The second process of subsampling, for administration of the health component, under-represented the group aged 18-19. Other than this, only minor deviations are found between the subsample of adolescents and the group that completed the medical examination; mainly in the distribution by urban/rural type of residence and region of residence, particularly among boys. 


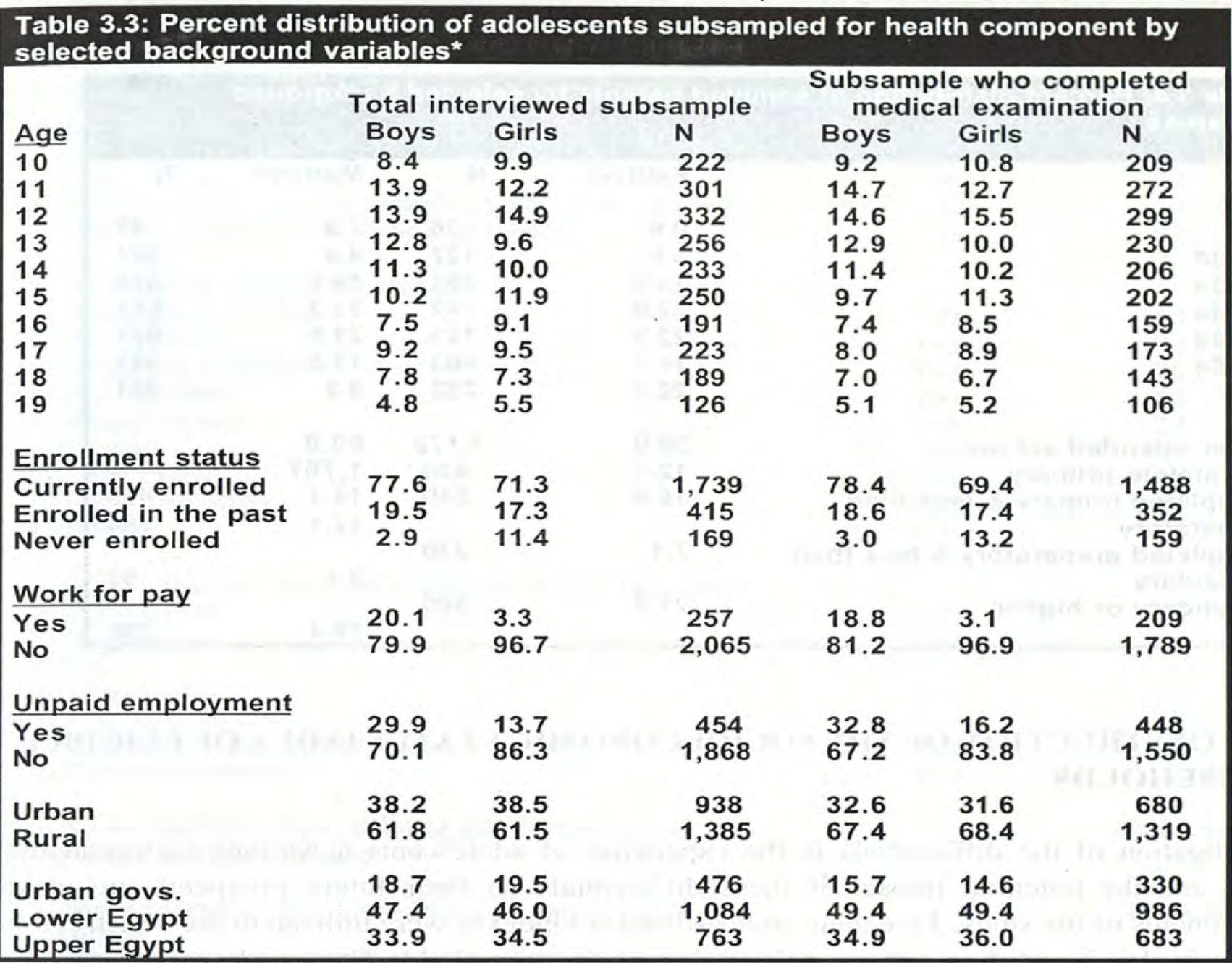

* Weighted percent.

\section{CHARACTERISTICS OF THE SAMPLE OF RESPONSIBLE ADULTS}

The selection of the responsible adult followed the selection of the adolescent(s) in eligible households. If only one adolescent was selected (there were only boys or only girls in the household) one responsible adult was selected. If one adolescent boy and one adolescent girl were selected, one responsible adult was selected if the two adolescents were siblings; if they were not, then two responsible adults were selected unless the same adult was considered the guardian of both.

The results of the survey reveal that 97 percent of all responsible adults interviewed were parents of the adolescent respondent (mothers/fathers). Thus responsible adults are referred to as parents in the following chapters.

Table 3.4 shows the distribution of sampled parents by sex, age, and educational attainment. The mean age of fathers is 47 years and the median is 45 years. The mean and the median ages of mothers are 43 years. One-third of fathers never attended school compared to two-thirds 
of mothers. Only ten percent of the mothers had secondary or higher education compared to 28 percent of the fathers.

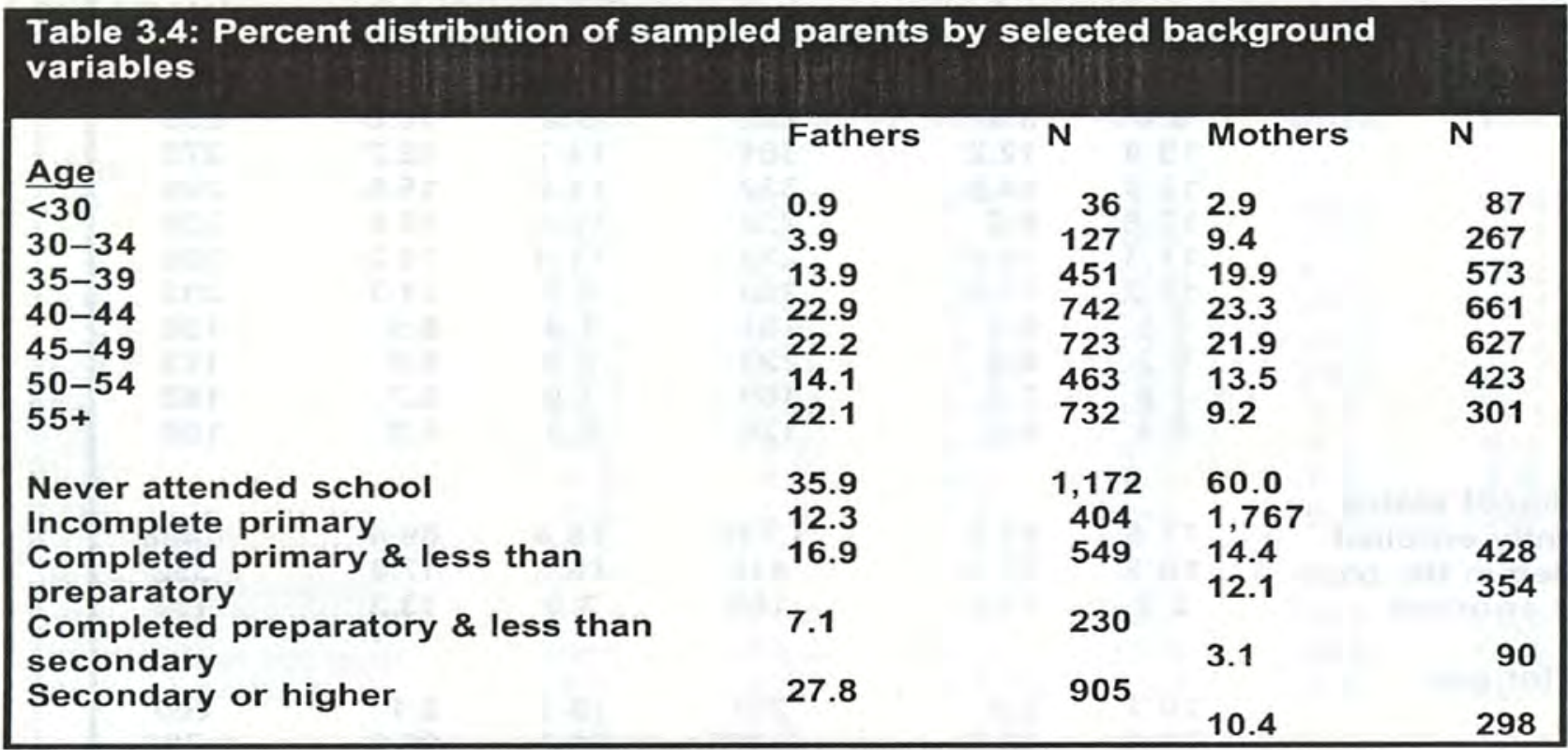

\section{CONSTRUCTION OF THE SOCIOECONOMIC STATUS INDEX OF ELIGIBLE HOUSEHOLDS}

Investigation of the differentials in the experience of adolescents in various socioeconomic levels and the potential impact of these differentials on their future prospects are major components of the study. Five main standardized subindexes were utilized in the construction of the final index of the socioeconomic status of the household. These indexes measure the condition of the housing unit, ownership of durable goods, ownership of assets and means of transportation, mean monthly expenditures on education per adolescent in the household, and mean monthly total expenditures per household member. Components of the indexes are displayed in Table 3.5 .

The weighted values of the components of each of the first three indexes were summed for every household then standardized among all households (the weights are based on the relative frequencies of the presence or absence of each component among sampled households). Also, values of the last two subindexes were standardized among all households. Values of the final index were computed by summation of the five standardized values assigned to each household. The final index is a continuum that was divided into three categories with equal number of eligible households in each, representing the highest, middle and lowest socioeconomic groups in relative rather than absolute terms. The categorical final index is utilized throughout the chapters of the report as a proxy for the socioeconomic status of the household or adolescent involved. 


\section{Table 3.5: Distribution of eligible households by different components comprising}

socioeconomic status index constructed for study ( $N=6,153$ households)

1. Condition of the housing unit

a) Number of bedrooms in the house

b) Access to the public water system in the house

c) Site for preparation of food (kitchen)

$\begin{array}{cc}0 & 16 \\ 1 & 37 \\ 2+ & 47 \\ \text { Yes } & 71 \\ \text { Yes } & 65\end{array}$

2. Ownership of durable goods
a) Cassette recorder
b) Television
c) Washing machine
d) Refrigerator
e) Water heater
f) Heater
g) Telephone
h) Air conditioner
i) Video

Yes

Yes

Yes

Yes

Yes

Yes

Yes

Yes

Yes

$$
\begin{gathered}
68 \\
86 \\
79 \\
56 \\
21 \\
6 \\
19 \\
2 \\
7
\end{gathered}
$$

3. Ownership of assets and means of transportation
a) Motorcycle
b) Truck
c) Car
d) Residence
e) Agricultural land
f) Vacant land for construction
g) Plant/workshop/...

Yes

Yes

Yes

Yes

Yes

Yes

Yes

1
2
5
75
24
1
5

4. Mean monthly expenditures on education per adolescent in household 


\section{Chapter 4}

\section{Health Profile of Egyptian Adolescents}

According to the 1996 Egyptian census, adolescents aged 10-19 comprise 22 percent of the Egyptian population. However, despite the magnitude of this population segment and the variety of problems facing them today, adolescents receive relatively little attention or public investment. Moreover, few studies have attempted to create a health profile of Egyptian adolescents. One reason is undoubtedly that this stage of life has traditionally been assumed to be free of serious health problems. The ASCE researchers have attempted to rectify this situation by gathering nationally representative data from adolescents on their health status and health behaviors in the hope of informing policy and programmatic interventions.

Because health status depends on a series of interrelated behavioral and environmental factors, an ecological approach is necessary to understand morbidity and mortality patterns thoroughly. Individual risk factors can include poor dietary habits, physical activity or inactivity, pregnancy and childbearing, sexual behaviors, crime, and substance abuse. The surrounding environment also plays a critical role in determining health status. This environment comprises family, school, workplace, neighborhood, governmental policies, laws and regulations, and international policies. For example, the amount and quality of food available for consumption at the household level is determined by, among other factors, a household's socioeconomic status as well as by the prices and regional availability of food. These are in turn influenced by national and international economic policies, regulations related to food production and consumption, and national resource availability and allocation.

This chapter describes some aspects of the nutrition and health profile of adolescents in Egypt and explores some of the determinants of adolescent health.

\section{NUTRITIONAL STATUS}

Nutritional status, both past and current, is a key factor in adolescent health, in physical and emotional well being, and in cognitive development. Moreover, nutritional status is an excellent example of a health factor dependent on both individual behaviors and environment. After describing the physical growth status of the sample of boys and girls and the prevalence of nutritional deficiencies, a set of co-factors affecting adolescent's nutrition will be evaluated. In particular, predictors of anemia, undernutrition, and parasitic infection will be examined. Detailed data on food intake were also collected during the study and will be analyzed in subsequent publications.

\section{Growth ASSESSMENT}

Anthropometric measurements (measures of height and weight) are often used during early childhood to assess health status, as they provide important indicators of both short-term and long-term (chronic) problems in nutritional intake and physical health. Despite the accelerated physical changes characteristic of the adolescent period, anthropometry during adolescence has never received the same attention given to earlier periods in childhood. Thus 
there are no well-defined criteria or cut-off values related to specific risk factors. However, the indicators recommended for the assessment of adolescents, derived from anthropometric measures, are stunting; thinness; at risk of overweight; and overweight (World Health Organization 1995). These indicators are explained in further detail below.

Tables 4.1 and 4.2 show the mean body weight, height, and body mass index (BMI) of adolescents by age and sex. BMI is a ratio of weight to height squared [weight $(\mathrm{kg}) / \mathrm{height}^{2}$ $(\mathrm{m})]$ that is used to determine thinness and stunting. Most of the health conditions associated with inappropriate BMI (too high or too low) will not appear until later in life. For example, increased BMI is associated with increased risk of hypertension, the effects of which will probably not appear until later in life. Evaluation of BMI during adolescence can help to identify potential increased risks, in time for the individual to change dietary habits and physical activity practices.

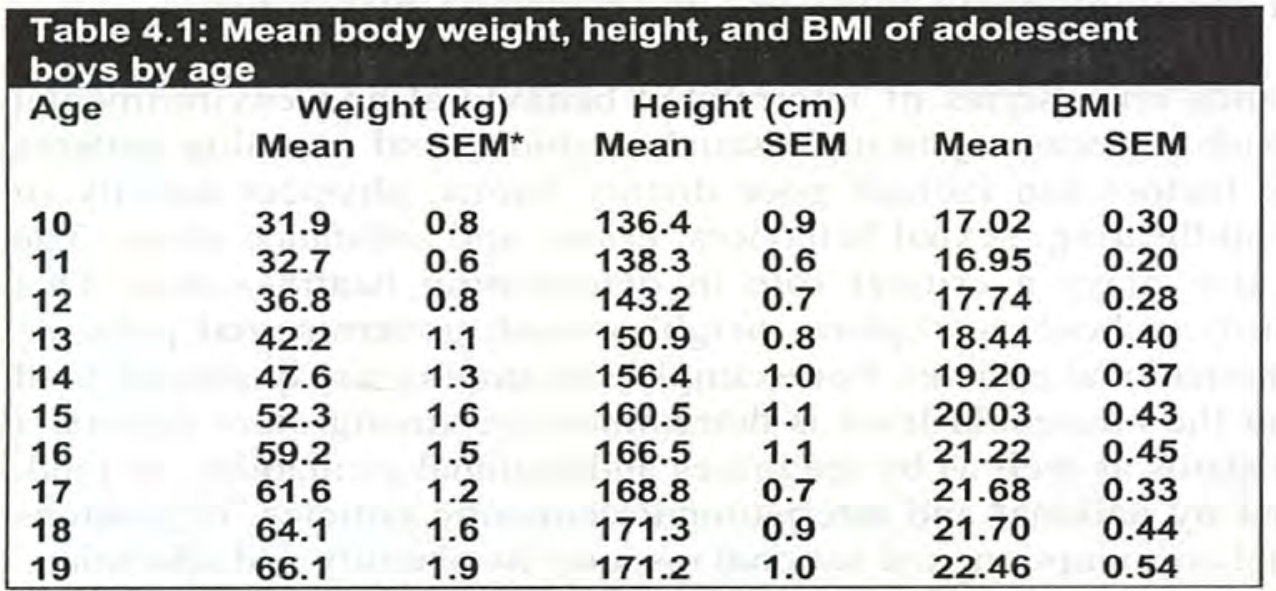

* SEM - standard error of the mean

\begin{tabular}{|c|c|c|c|c|c|c|}
\hline \multirow[t]{2}{*}{ Age } & \multicolumn{2}{|c|}{ Weight (kg) } & \multicolumn{2}{|c|}{ Height $(\mathrm{cm})$} & \multicolumn{2}{|c|}{ BMI } \\
\hline & Mean & SEM* & Mean & SEM & Mean & SEM \\
\hline 10 & 30.5 & 0.5 & 134.5 & 0.6 & 16.76 & 0.22 \\
\hline 11 & 35.4 & 0.9 & 139.2 & 0.8 & 18.13 & 0.38 \\
\hline 12 & 41.3 & 0.8 & 148.2 & 0.7 & 18.58 & 0.25 \\
\hline 13 & 49.1 & 1.1 & 152.2 & 0.7 & 21.06 & 0.43 \\
\hline 14 & 52.8 & 1.1 & 156.0 & 0.7 & 21.65 & 0.39 \\
\hline 15 & 53.6 & 0.9 & 156.4 & 0.7 & 21.87 & 0.34 \\
\hline 16 & 58.6 & 1.2 & 157.7 & 0.6 & 23.46 & 0.46 \\
\hline 17 & 57.6 & 1.2 & 158.4 & 0.7 & 22.90 & 0.41 \\
\hline 18 & 61.6 & 1.5 & 159.2 & 0.7 & 24.26 & 0.55 \\
\hline 19 & 59.8 & 1.4 & 159.6 & 0.7 & 23.43 & 0.47 \\
\hline
\end{tabular}

* SEM - standard error of the mean

As shown, there is a steady increase in the mean weight of boys with the increase in age. Among girls, there is an increase in the mean body weight only until the age of 16 years, after which the mean weight stabilizes and fluctuations are small. Girls are taller than boys during the period between ages 11 and 13, the result of the earlier growth spurt among girls before menarche. After age 14, the increase in mean height is small for girls, whereas boys' mean height increases. As expected, the mean BMI of girls is higher than boys at all ages. 
The median weight and height of the sampled Egyptian adolescents were compared with reference data from the United States National Center for Health Statistics/World Health Organization (NCHS/WHO) (World Health Organization 1983). The median BMI was compared with corrected data from Must et al. (1991) ${ }^{1}$. The median weight-for-age and the median height-for-age of Egyptian adolescent boys are both lower than the medians of the NCHS/WHO reference population (Figure 4.1). The median BMI-for age for Egyptian boys is lower than that of the reference until the age of 15 , after which the difference is negligible.

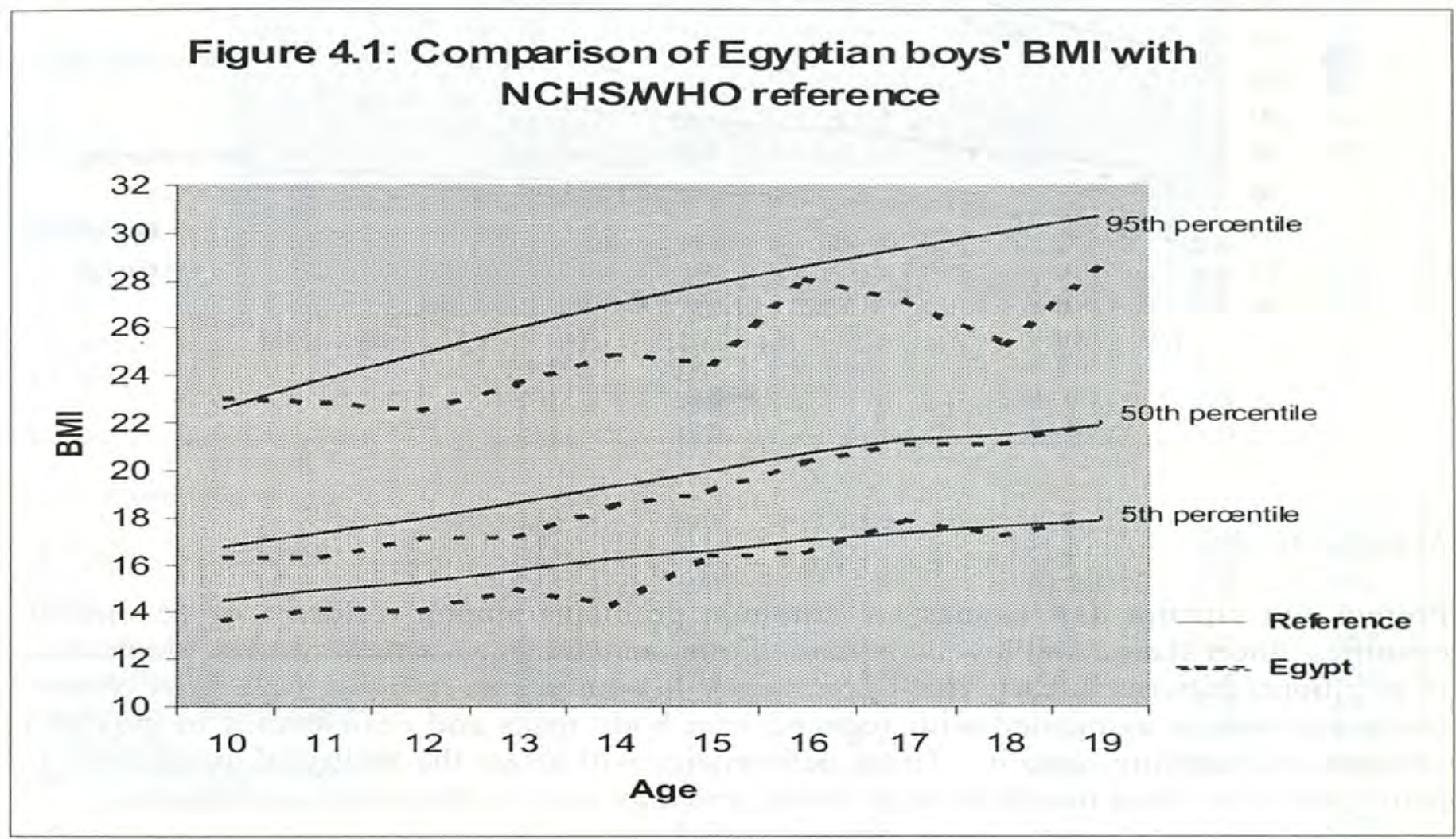

The median height-for-age among Egyptian girls is below the NCHS/WHO reference for all age groups (Figure 4.2). On the other hand, the median weight-for-age of Egyptian girls is lower than those of the reference population until the age of 13 , then it fluctuates until the age of 18, when it stabilizes at a higher level than the reference population. Accordingly, the median BMI for Egyptian girls is higher than the reference population from the age of 13 until the age of 19. These findings suggest that the diet of Egyptian girls' in late adolescence may be contributing to early signs of obesity. Overweight is discussed further below.

\footnotetext{
${ }^{1}$ There is considerable debate in the medical literature about whether or not it is valid to use a reference population from a different region of the world to evaluate nutritional status, as there is some evidence that peoples of different regions have different growth potentials and patterns. While comparison with a reference population from another region may paint an overly bleak picture of the status of Egyptian adolescents, no more appropriate reference data are available.
} 


\section{Figure 4.2: Comparison of Egyptian girls' BMI with NCHS/WHO reference}

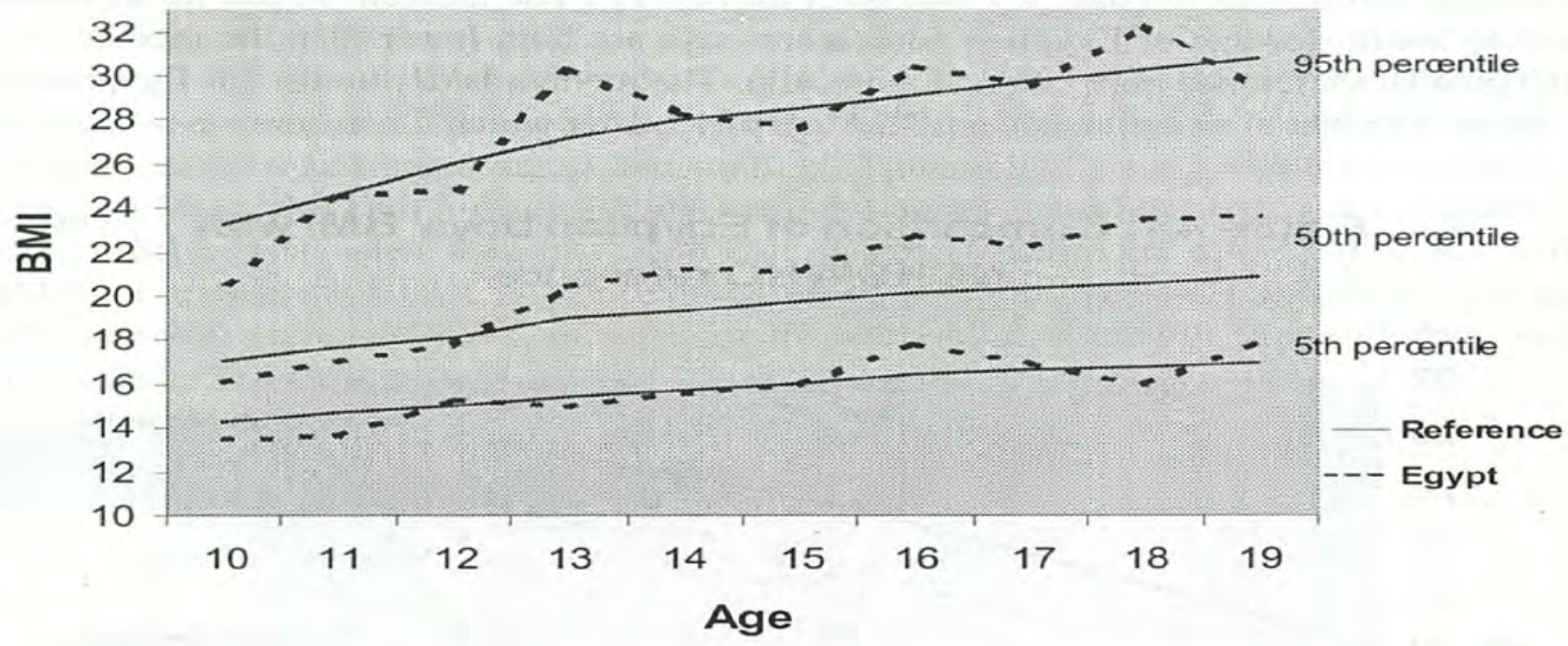

\section{MaLnUtrition}

Protein and vitamin deficiencies are common problems among residents of developing countries. Short stature and low body mass during adolescence are the cumulative outcomes of nutritional patterns in early life. Short stature in adolescents resulting from prior chronic under-nutrition is associated with reduced lean body mass and deficiencies in muscular strength and working capacity. These deficiencies will affect the ability of adolescents to participate in the labor market or in the home, and may increase the risks of childbearing.

Four indicators have been used in the present survey to assess adolescent growth status, based on comparisons with reference data taken from a well-nourished population of adolescents. These indicators are:

1. stunting - a ratio of height-for-age less than -2 standard deviations ( $Z$-scores) relative to the reference population;

2. thinness - a BMI-for-age ratio less than or equal to the $5^{\text {th }}$ percentile of the reference population;

3. at risk of overweight - a BMI-for-age ratio greater than or equal to the $85^{\text {th }}$ percentile and less than the $95^{\text {th }}$ percentile of the reference population; and

4. overweight - a BMI-for-age ratio greater than or equal to the $95^{\text {th }}$. percentile of the reference population.

Table 4.3 shows the percentage of Egyptian adolescents who are classified as inappropriately nourished according to comparisons of height-for-age and BMI-for-age indicators with those of the reference population described above.

Stunting: As shown, 17 percent of all adolescents are classified as stunted, nearly 19 percent of boys and 15 percent of girls. Among girls, the level of stunting decreases as age 
increases, while there is no clear pattern among boys. Among boys, the highest proportion of those who are stunted is among $13-15$ year-olds (19.8\%). Stunting is more prevalent among adolescents in the low socioeconomic stratum and those in rural areas and Upper Egypt than those in the high socioeconomic stratum or residing in other areas.

\begin{tabular}{|c|c|c|c|c|c|c|}
\hline Total & $\begin{array}{c}\text { Stunted }^{\star} \\
\% \\
16.6\end{array}$ & $\begin{array}{c}\text { Total } \\
\text { No. } \\
1658\end{array}$ & $\begin{array}{c}\text { Thinness } \\
\% \\
9.3\end{array}$ & $\begin{array}{c}\text { At risk of } \\
\text { over- } \\
\text { weight } \% \\
10.1\end{array}$ & $\begin{array}{c}\text { Over- } \\
\text { weight } \\
\% \\
4.2\end{array}$ & $\begin{array}{c}\text { Total } \\
\text { No. } \\
1968\end{array}$ \\
\hline $\begin{array}{l}\text { Male } \\
\text { Female }\end{array}$ & $\begin{array}{l}18.9 \\
14.5\end{array}$ & $\begin{array}{l}801 \\
857\end{array}$ & $\begin{array}{c}12.5 \\
6.3\end{array}$ & $\begin{array}{c}5.9 \\
14.1\end{array}$ & $\begin{array}{l}3.3 \\
5.1\end{array}$ & $\begin{array}{c}957 \\
1011\end{array}$ \\
\hline \multicolumn{7}{|l|}{ Male } \\
\hline$-10-12$ & 19.3 & $\begin{array}{l}365 \\
288\end{array}$ & $\begin{array}{l}16.1 \\
13.6\end{array}$ & $\begin{array}{l}8.0 \\
3.7\end{array}$ & $\begin{array}{l}2.8 \\
4.1\end{array}$ & $\begin{array}{l}381 \\
305\end{array}$ \\
\hline$-13-15$ & 19.8 & 288 & 13.6 & 3.7 & 4.1 & 305 \\
\hline $\begin{array}{l}-16+ \\
\text { Female }\end{array}$ & 15.8 & 148 & 6.1 & 5.6 & 2.9 & 271 \\
\hline$-10-12$ & 21.2 & 380 & 9.1 & 6.1 & 4.0 & 399 \\
\hline$-13-15$ & 9.6 & 319 & 5.1 & 18.4 & 5.3 & 332 \\
\hline$-16+$ & 8.0 & 158 & 3.5 & 20.9 & 6.6 & 280 \\
\hline \multicolumn{7}{|l|}{ Socioeconomic status } \\
\hline -Low & 20.2 & 474 & 13.2 & 7.7 & 3.1 & 551 \\
\hline -Middle & 15.6 & 552 & 7.1 & 11.0 & 2.8 & 632 \\
\hline -High & 11.7 & 486 & 7.8 & 10.8 & 7.0 & 582 \\
\hline No Schooling/some primary & 18.2 & 355 & 12.1 & 8.5 & 3.3 & 417 \\
\hline Primary/Preparatory & 19.2 & 781 & 11.5 & 7.1 & 3.2 & 845 \\
\hline Preparatory/Secondary & 12.0 & 411 & 6.5 & 13.8 & 6.2 & 461 \\
\hline Secondary & 10.8 & 91 & 2.7 & 17.6 & 5.7 & 176 \\
\hline Intermediate/University & 10.0 & 20 & 2.0 & 12.9 & 5.9 & 69 \\
\hline Urban & 12.7 & 557 & 4.9 & 14.7 & 7.9 & 677 \\
\hline Rural & 18.1 & 1101 & 11.5 & 7.9 & 2.5 & 1291 \\
\hline Urban Governorates & 9.0 & 261 & 3.7 & 17.0 & 7.1 & 328 \\
\hline Lower Egypt & 13.9 & 816 & 6.2 & 10.8 & 4.4 & 967 \\
\hline Upper Egypt & 23.2 & 581 & 16.2 & 6.1 & 2.8 & 673 \\
\hline
\end{tabular}

*Four percent of the observations were flagged and therefore were excluded. Adolescents $>18$ years were excluded as the reference data includes only adolescents 10-18.

Thinness: The body mass index was also used as the basis for assessments of thinness, at risk of overweight, and overweight. An adolescent is classified as thin if her/his BMI-for-age ratio is less than or equal to that of the $5^{\text {th }}$ percentile of the reference population. Table 4.3 shows that the overall prevalence of thinness among Egyptian adolescents is 9 percent. Since 5 percent of the reference population was deemed to suffer from thinness, this prevalence level among Egyptian adolescents is only 4 percentage points higher than would be expected in a well-nourished population. However, more notable are the variations by sex. Egyptian boys less than 16 years are almost 3 times as likely to suffer from thinness than those in the wellnourished reference group. This level of thinness among boys does, however, drop as age increases, with only 6 percent of boys aged 16-19 classified as thin, only 1 percentage point higher than the reference population. 
A similar pattern is found among girls as age increases, although because the level of thinness among girls is lower overall than among boys, the pattern is less dramatic. Nine percent of girls aged 10-12 are found to be thin, a level 4 percentage points higher than expected in a well-nourished population. However, this level drops to less than 4 percent among girls aged 16-19, a level less than that of the reference population.

At risk of overweight: Table 4.3 also shows that 10 percent of Egyptian adolescents are at risk of overweight. An adolescent is classified as at risk of overweight if her/his BMI-for-age is greater than or equal to that of the $85^{\text {th }}$ percentile and less than the $95^{\text {th }}$ percentile of the reference population. In other words, 10 percent of the reference population was deemed to be at risk of overweight. Thus, Egyptian adolescents are at no more risk of overweight than those in the reference population.

Among girls, however, the levels of at risk of overweight are generally higher than those of the reference population, except in the 10-12 age group. Most noticeably, 21 percent of girls aged 16-19 are classified at risk of overweight, twice the expected level. A similar though less dramatic pattern is found among girls classified as overweight. These results are perhaps not surprising given the restrictions often placed on girls' mobility and physical activity as they get older, as well as the decrease in the amount of free time they have to devote to physical activities as their domestic responsibilities increase with age.

Overweight: Finally, the survey found that 4 percent of Egyptian adolescents are overweight, with a BMI-for-age greater than or equal to that of the $95^{\text {th }}$ percentile in the reference population. Since 5 percent of the reference population was deemed to be overweight, the level of overweight found among Egyptian adolescents is slightly less than expected in a well-nourished population.

The overall numbers also mask some important variations by socioeconomic status and region. Thinness is more prevalent in the low socioeconomic group compared to the high socioeconomic stratum, while the reverse is true for the prevalence of at risk of overweight. The impact of socioeconomic level is even more apparent on the prevalence of overweight. The prevalence of overweight is twice as high among adolescents in the high socioeconomic stratum than in the middle and low strata.

Regional variation is also apparent in the levels of these anthropometric indicators. Many more adolescents in rural areas are thin compared to urban areas $(11.5 \%$ versus $4.9 \%)$, and the highest proportion of thin-for-age adolescents is observed in Upper Egypt, where there are more than four times as many thin-for-age adolescents as there are in urban governorates. On the other hand, the prevalence of overweight and at risk of overweight is higher in urban governorates than in either Lower or Upper Egypt.

Analysis of the 24-hour food intake recall data will undoubtedly provide additional insight and suggest specific directions for interventions and policies regarding food security.

\section{Hemoglobin Status}

Nutritional anemia is the most common public health problem in the world today. It is defined as a level of hemoglobin less than that considered normal for the person's age and sex. It is not a disease in itself, but rather a condition related to different diseases and 
disorders, including genetic ones. Iron deficiency anemia is the most common type of nutritional anemia and it can have significant impact on psychological and physical development, behavior, and work performance. It is the result of inadequate iron intake, reduced bioavailability of dietary iron, increased needs for iron, chronic blood loss, and parasitic infections. It affects mainly infants, preschool children, adolescents, and women of childbearing age, particularly pregnant women.

Hemoglobin determination has been used in nutritional surveys as a simple, reliable test for detection of anemia. This method was used in the ASCE survey to determine the prevalence of anemia among Egyptian adolescents. (See Chapter 2)

\section{Prevalence and severity of anemia}

Anemia is classified into three categories áccording to severity: mild [hemoglobin level (Hb) between $10 \mathrm{~g} / \mathrm{dl}$ and the cutoff], moderate $(\mathrm{Hb}$ between $7 \mathrm{~g} / \mathrm{dl}$ and $9.9 \mathrm{~g} / \mathrm{dl}$ ), and severe (Hb less than $7 \mathrm{~g} / \mathrm{dl}$ ). Accordingly, the majority of the adolescents surveyed who were found to have anemia have a mild degree $(84.7 \%$ of boys and $83.0 \%$ of girls who have anemia) (Figure 4.3). Moderate anemia was found among 16 percent of adolescents who have anemia and severe anemia among less than 1 percent of those who have anemia.

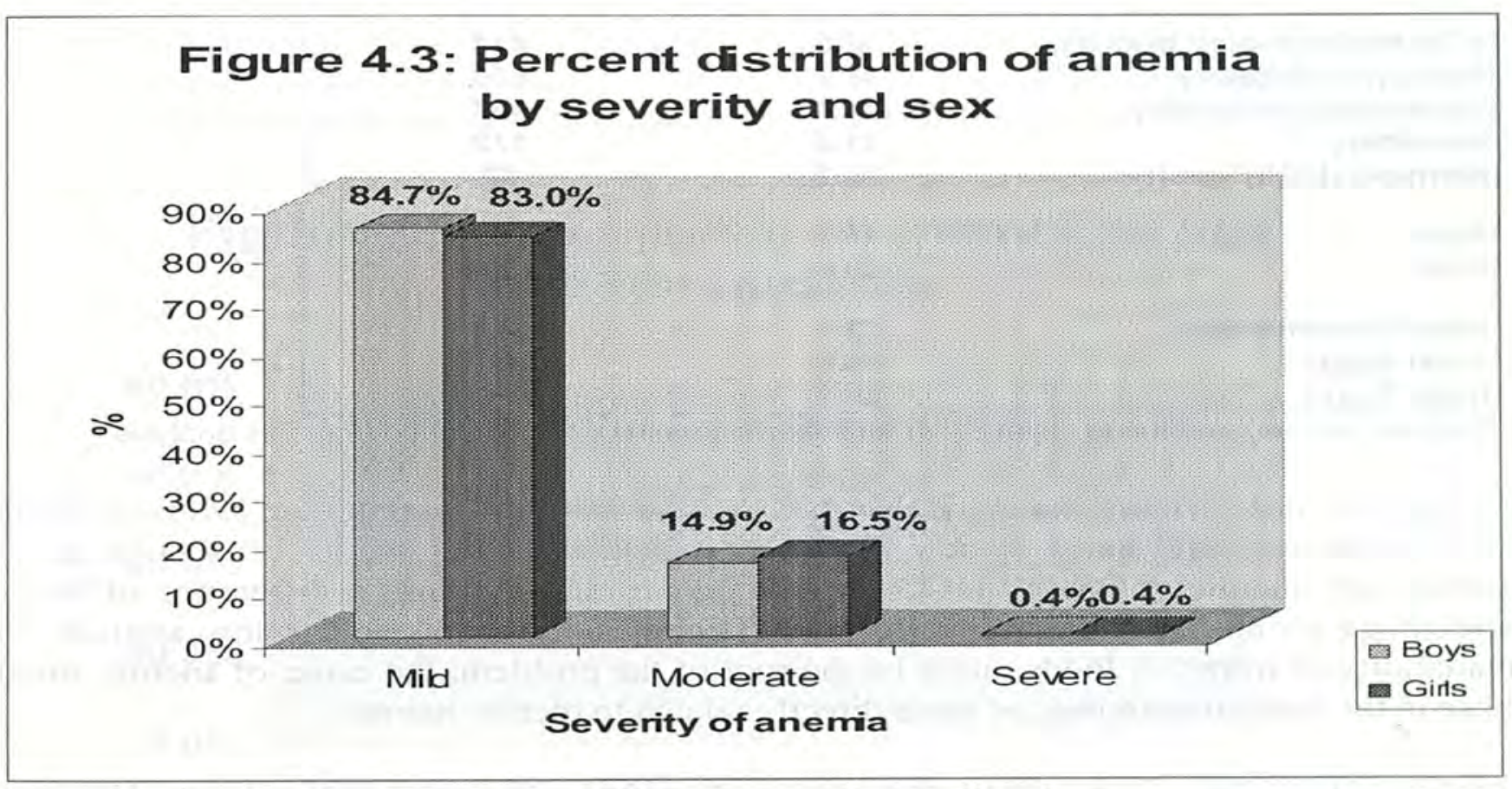

Anemia is considered to be present if the hemoglobin level is below $12 \mathrm{~g} / \mathrm{dl}$ for adolescent girls and boys less than 14 years old, and $13 \mathrm{~g} / \mathrm{dl}$ for adolescent boys 14 years old and above. Based on these cutoffs, the overall prevalence of anemia among adolescents in Egypt is 47 percent (Table 4.4). The mean hemoglobin level among boys less than 14 years is 12.04 $\mathrm{g} / \mathrm{dl}\left(\mathrm{sem}^{2}=0.06\right)$, and for those above 14 years it is $13.41 \mathrm{~g} / \mathrm{dl}(\mathrm{sem}=0.09)$. For girls, the

\footnotetext{
${ }^{2}$ sem $=$ standard error of the mean
} 
mean hemoglobin level is $11.97 \mathrm{~g} / \mathrm{dl}(\mathrm{sem}=0.06)$ for girls less than 14 years, and $11.97 \mathrm{~g} / \mathrm{dl}$ $(\mathrm{sem}=0.08)$ for those above age 14 .

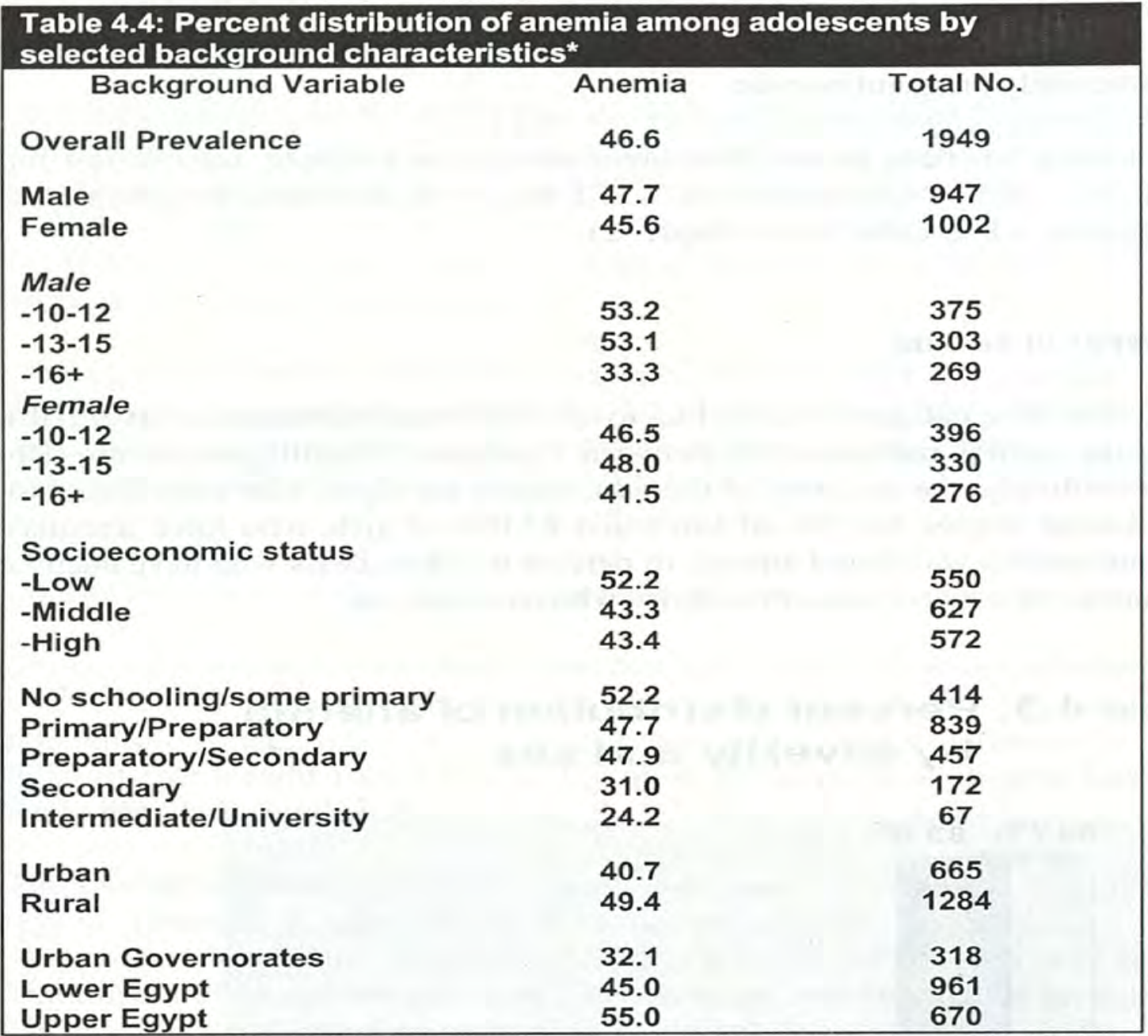

* Pregnant women and those lactating for less than 6 months were excluded from this analysis.

Perhaps the most striking finding is that there is relatively little variation in levels of anemia across socioeconomic status. Nearly 52 percent of adolescents in the lowest socioeconomic stratum are anemic compared to 43 percent in the high stratum, a difference of only 9 percentage points. This suggests that while among adolescents in the low stratum, the availability of iron-rich foods might be the root of the problem, the cause of anemia among those in the high stratum may be more directly related to dietary habits.

Gender differences in the overall prevalence of anemia are almost non-existent. However, differentials are quite evident within each gender across ages among anemic adolescents. For boys, anemia prevalence ranges between 44 and 63 percent until the age of 15; afterwards there is a sharp decline, reaching 18 percent at the age of 19 . A different pattern emerges among girls. At age 10,48 percent of girls are anemic. This declines through age 13 and rises sharply at 14 to 55 percent, probably due to menarche and consequent blood loss. It declines to a low of 33 percent at age 18 but then rises dramatically by age 19 to 49 percent. (Figure 4.4). The cause of the increase in anemia among girls in later adolescence is not clear. What is clear, however, is that girls are not in the best of health as they head into marriage. The additional stresses of pregnancy and lactation will only aggravate their nutritional problems. 


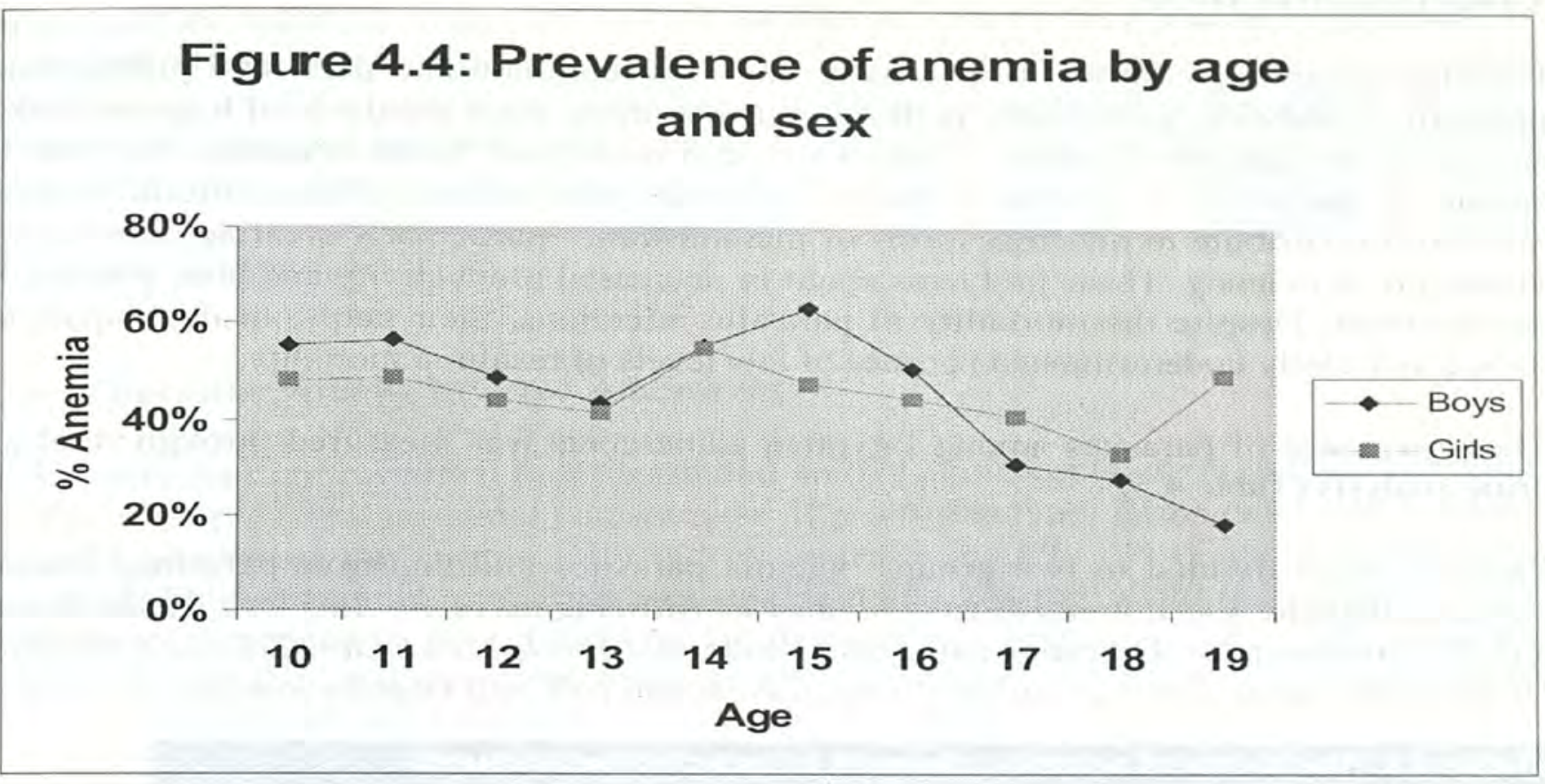

Adolescents from rural areas show a higher prevalence of anemia compared to those in urban areas. The trends of anemia prevalence in urban and rural areas are quite similar in different age groups. Generally, the prevalence of anemia is lower in urban areas for all ages except for

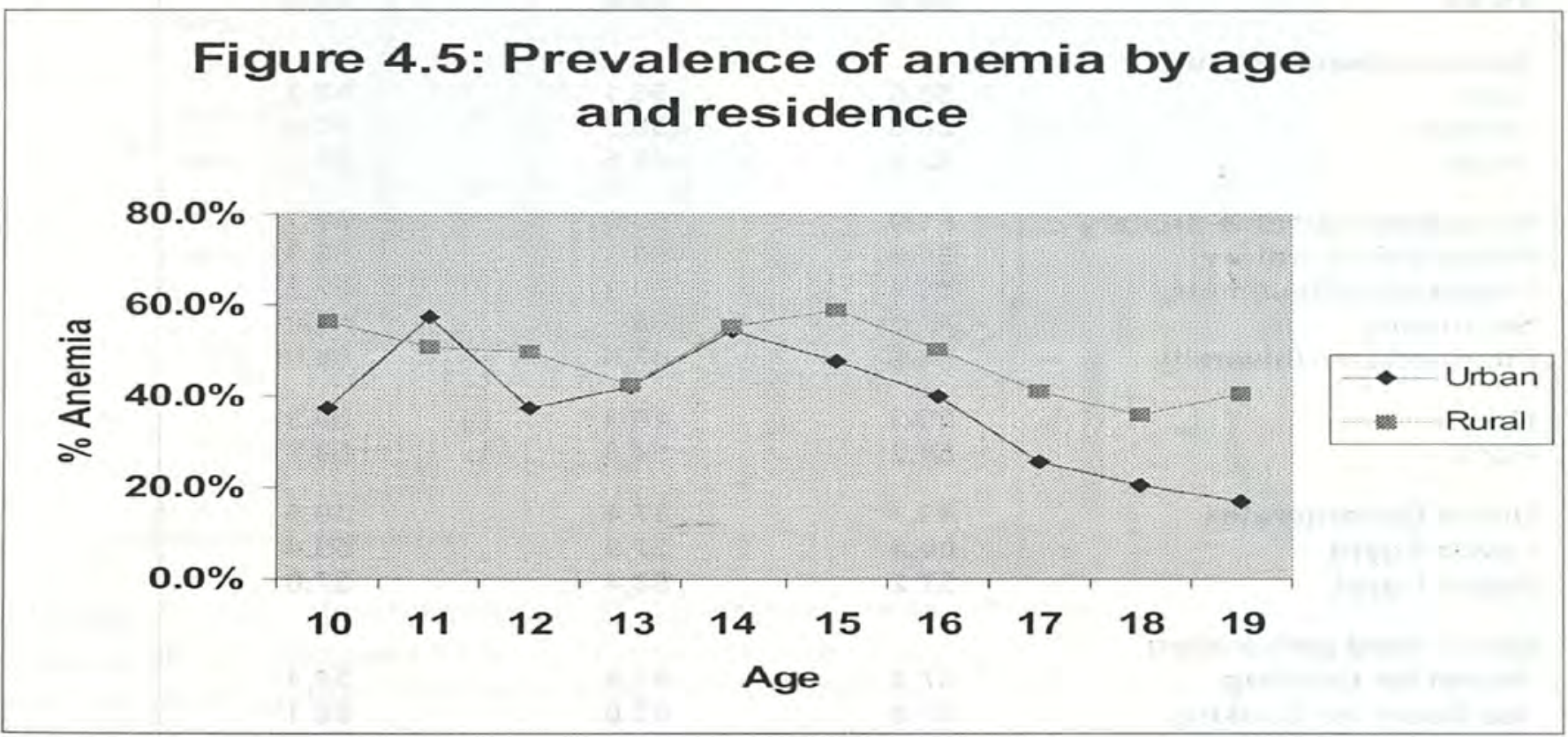

age 11 (Figure 4.5). Regional variation is also significant, being the highest in Upper Egypt and lowest in the urban governorates. This may indicate that economic development is better in urban governorates and Lower Egypt, which may be reflected in better nutrition. 


\section{PARASITIC INFECTIONS}

Parasitic infections continue to be among the most common and persistent public health problems worldwide, particularly in developing countries. Poor standards of hygiene, lack of sanitation services, the shortage of safe water, and inadequate health education facilitate the spread of parasites. Available evidence indicates that several of the enteric parasitic infections contribute to different forms of malnutrition - particularly stunting, anemia, and vitamin A deficiency. These problems result in decreased productivity and poor educational achievement. Despite the morbidity of parasitic infections, their public health impact has been consistently underestimated because of low levels of resulting mortality.

The prevalence of parasites among Egyptian adolescents was measured through stool and urine analysis (Table 4.5).

Parasites were divided in two groups: anemia parasites and digestive parasites. Anemia parasites include: Schistosoma Heamatobium, Schistosoma mansoni, Ancylostoma duodenale, and Trichostrongylus. Digestive parasites include: Ascaris lumbricoides, Trichuris trichiura, Hymenolepis nana, Entamoeba histolytica, Entamoeba coli, and Giardia lamblia.

\begin{tabular}{|c|c|c|c|}
\hline Background Variable & Girls & Boys & Total \\
\hline Overall Prevalence* & 57.4 & 55.5 & 56.2 \\
\hline $\begin{array}{l}10-14 \\
15-19\end{array}$ & $\begin{array}{l}59.6 \\
53.9\end{array}$ & $\begin{array}{l}57.0 \\
52.9\end{array}$ & $\begin{array}{l}58.3 \\
53.4\end{array}$ \\
\hline $\begin{array}{l}\text { Socioeconomic status } \\
\text {-Low } \\
\text {-Middle } \\
\text {-High }\end{array}$ & $\begin{array}{l}58.5 \\
60.6 \\
52.2\end{array}$ & $\begin{array}{l}58.1 \\
59.3 \\
48.5\end{array}$ & $\begin{array}{l}58.3 \\
60.0 \\
50.3\end{array}$ \\
\hline $\begin{array}{l}\text { No schooling/some primary } \\
\text { Primary/Preparatory } \\
\text { Preparatory/Secondary } \\
\text { Secondary } \\
\text { Intermediate/University }\end{array}$ & $\begin{array}{l}61.9 \\
59.9 \\
51.4 \\
47.0 \\
52.6\end{array}$ & $\begin{array}{l}56.0 \\
56.8 \\
53.2 \\
56.5 \\
47.5\end{array}$ & $\begin{array}{l}59.7 \\
58.3 \\
52.3 \\
52.0 \\
50.0\end{array}$ \\
\hline $\begin{array}{l}\text { Urban } \\
\text { Rural }\end{array}$ & $\begin{array}{l}55.3 \\
58.2\end{array}$ & $\begin{array}{l}46.3 \\
59.3\end{array}$ & $\begin{array}{l}50.9 \\
58.7\end{array}$ \\
\hline $\begin{array}{l}\text { Urban Governorates } \\
\text { Lower Egypt } \\
\text { Upper Egypt }\end{array}$ & $\begin{array}{l}43.7 \\
60.8 \\
57.2\end{array}$ & $\begin{array}{l}37.4 \\
57.9 \\
58.4\end{array}$ & $\begin{array}{l}40.5 \\
59.4 \\
57.8\end{array}$ \\
\hline $\begin{array}{l}\text { Site of food preparation } \\
\text {-Room for Cooking } \\
\text {-No Room for Cooking }\end{array}$ & $\begin{array}{l}57.1 \\
57.8\end{array}$ & $\begin{array}{l}51.5 \\
62.6\end{array}$ & $\begin{array}{l}54.4 \\
60.1\end{array}$ \\
\hline $\begin{array}{l}\text { Access to public water supply } \\
\text {-Access } \\
\text {-No access }\end{array}$ & $\begin{array}{l}55.1 \\
60.6\end{array}$ & $\begin{array}{l}52.5 \\
61.5\end{array}$ & $\begin{array}{l}53.9 \\
61.0\end{array}$ \\
\hline $\begin{array}{l}\text { Access to public sewerage fa } \\
\text {-Access } \\
\text {-No access }\end{array}$ & $\begin{array}{l}\text { ies } \\
53.3 \\
58.5\end{array}$ & $\begin{array}{l}45.9 \\
62.2\end{array}$ & $\begin{array}{l}49.7 \\
60.2\end{array}$ \\
\hline
\end{tabular}

* Including E. coli parasite 
Data from the ASCE survey indicates that the overall prevalence of parasitic infections is 46 percent excluding $E$. coli. If $E$. coli is taken into account, the prevalence of infection rises to more than 56 percent. Although $E$. coli is considered non-pathogenic, its presence is indicative of a poor environment. This high prevalence of parasites is due mainly to high prevalence of intestinal parasitic infections $(44.5 \%)$. Both sexes are infected; there is no gender difference in the prevalence of intestinal parasitic infections, though males are more infected with urinary parasites. (See Chapter 5 for more on the association of work status with parasitic infection.)

\section{Types of Parasites Among Infected Adolescents}

The different types of intestinal parasites found among adolescents are presented in Figure $4.6^{3}$. The most prevalent intestinal parasites are of protozoan type; Entamoeba coli is found among 38 percent of the sample followed by Giardia lamblia $(24.1 \%)$ and Entamoeba histolytica $(22.0 \%)$. Helminth parasites were significantly less prevalent: Hymenolepis nana is the most prevalent (3.6\%) followed by Schistosoma mansoni $(2.3 \%)$ and Ascaris lumbricoides (2.1\%). All intestinal parasites except Schistosoma mansoni are food-borne parasites, which are usually associated with low levels of hygiene.

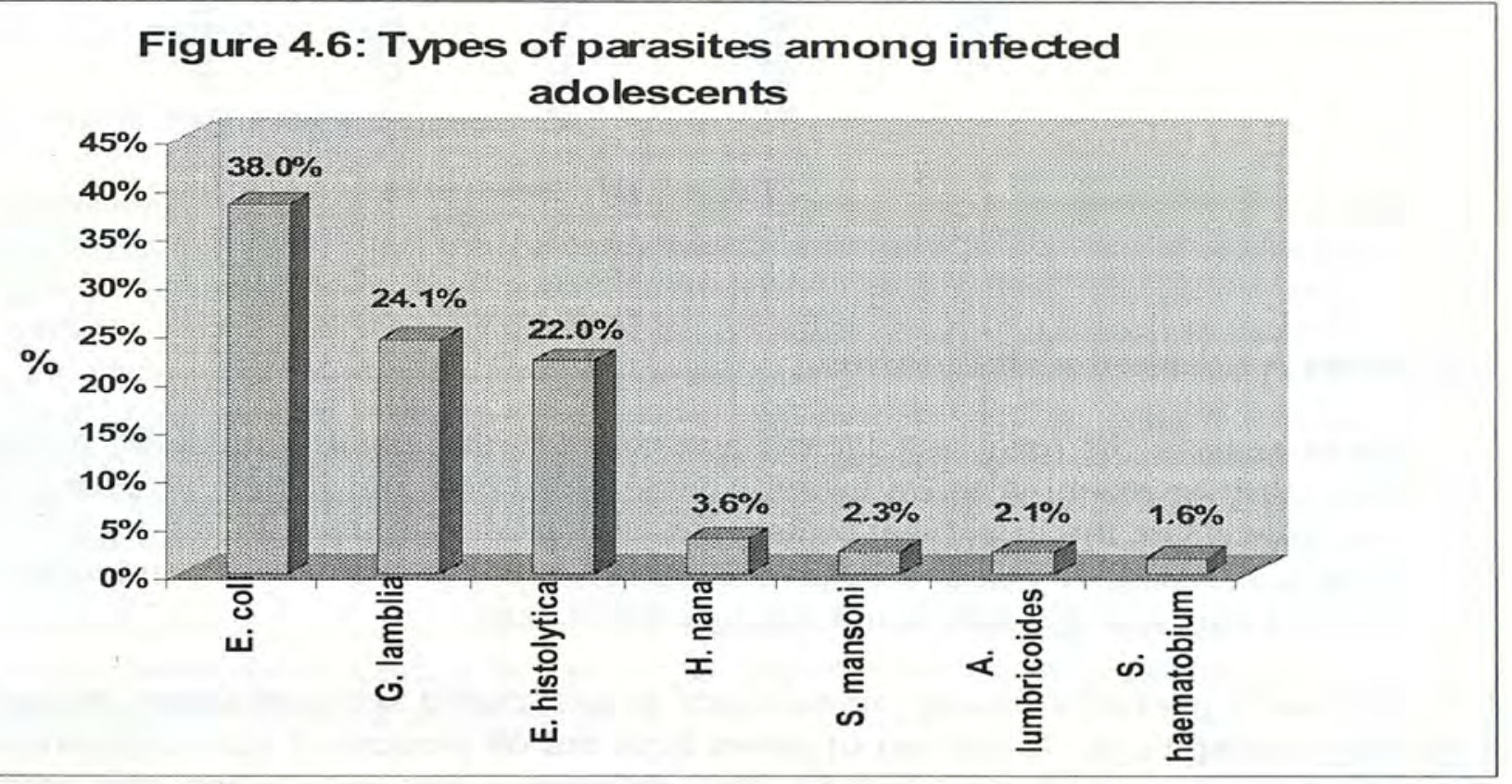

Excluding $E$. coli, about one-third of adolescents who test positive for parasites test are infected with one parasite $(33.6 \%), 10$ percent with two, and 0.5 percent with more than two. There is a slight gender difference with the multiple infections; boys are more infected than girls (table not shown). There were no systematic patterns found among adolescents by age groups.

\footnotetext{
${ }^{3}$ In order to capture the prevalence of schistosoma parasites accurately, a specific test must be used to evaluate stool samples. Since this specific test was not used in the ASCE survey, the prevalence of schistosoma parasites reported here must be considered underestimates.
} 
As shown in Figure 4.7, 47 percent of those infected with parasites also had hemoglobin levels below the cutoff levels for anemia. Anemia was found among 67 percent of those infected with $A$. duodenale, 48 percent with $S$. mansoni, 43 percent with $E$. histolytica and 51 percent with G. lamblia.

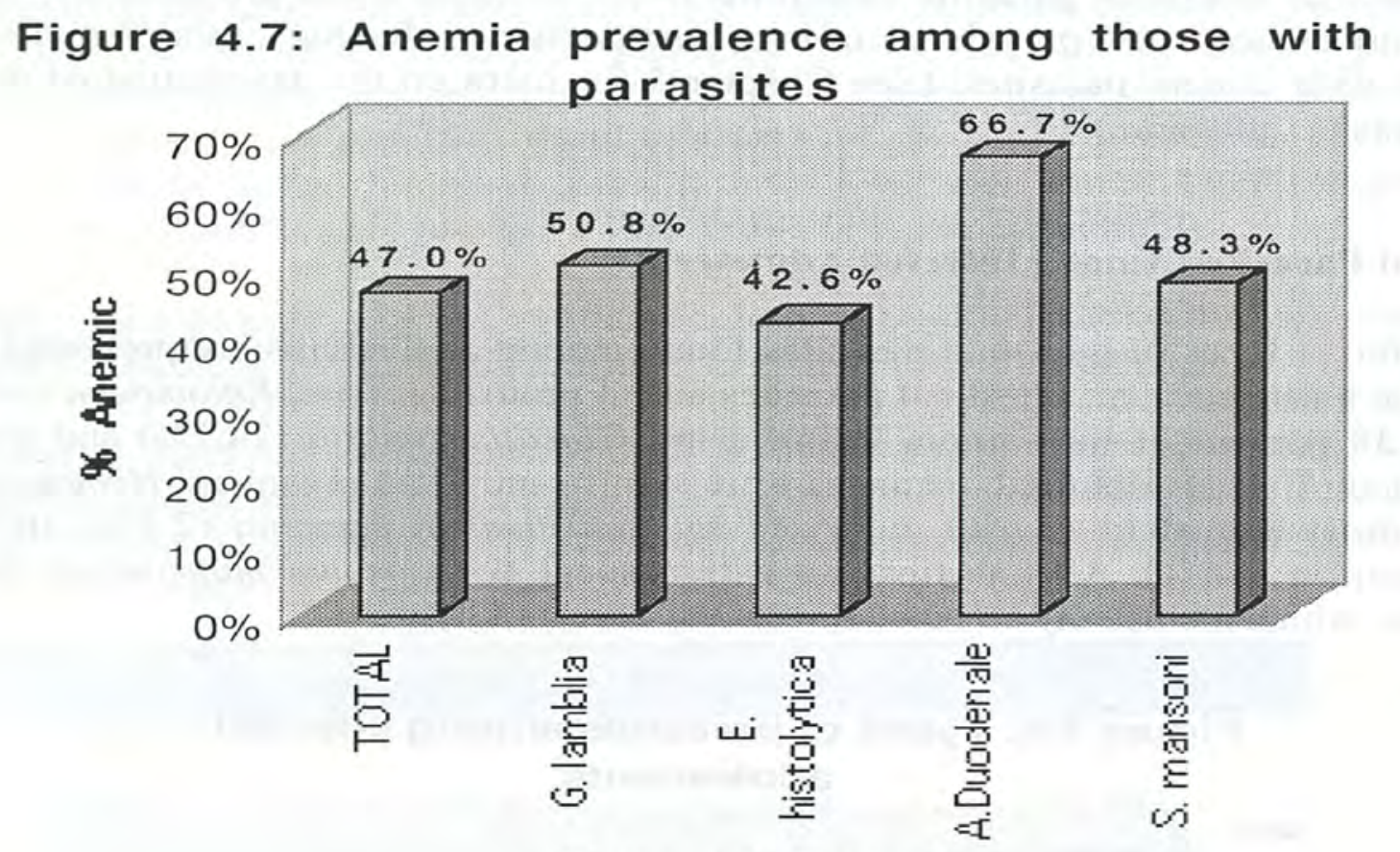

Type of Parasite

\section{Co-factors Associated with Parasites}

In order to analyze the main risk factors associated with parasitic infection, it would have been necessary to examine those health-related behaviors and beliefs affecting sanitation practices as well as the quality of water and sanitation facilities. In the present analysis, environmental risk factors have been considered more important in producing the high prevalence of parasitic diseases found among adolescents.

Infection with parasites among adolescents is associated with residence in rural areas, especially among boys; 46 percent of urban boys but 60 percent of rural boys were infected with at least one parasite (Table 4.5). This difference was not so apparent among girls. Further, parasitic infections are significantly more prevalent in Lower and Upper Egypt $(59.4 \%$ and $57.8 \%)$ than in the urban governorates $(40.5 \%)$.

Parasitic infections are also associated with low socioeconomic status. Adolescents in the low and middle socioeconomic strata are more likely to have one or more parasites than those in the high stratum $(58.3 \%$ and $60.0 \%$ versus $50.3 \%)$. This relationship was confirmed when the association between the site of food preparation and presence of parasitic infections was examined. Adolescents living in households without a kitchen or room for cooking are at higher risk of parasites than those who live in households with these facilities $(60.1 \%$ versus $54.4 \%$ ). 
The negative impact of certain environmental risk factors on adolescent health may be due to lack of access to safe water and sanitation facilities. It was beyond the scope of this study to determine the safety of the water supply and sanitation services in adolescents' homes. As proxy measures, we examined the extent to which the households of adolescents are connected to public water supply and sanitation services. These proxy measures are somewhat problematic, since, for example, public water connections are not always safe and can in fact be subject to more contamination than some private or other local sources. However, the relative safety of public services allows us to get some indication of the exposure of adolescents to unsafe water and sanitation services. As shown in Table 4.5, there is a clear relationship between access to public water and sanitation services and infection with parasitic diseases. Adolescents in households without a connection to public water supply are more likely to be infected by parasites than those who live in households with a connection $(61.0 \%$ versus $53.9 \%)$. Similarly, adolescents without access to the public sewerage system are at significantly higher risk of parasitic infection than those with access to these facilities $(60.2 \%$ versus $49.7 \%)$.

As expected, parasitic infections are associated with a set of variables rather than a single factor. These variables interact with one another to produce this health outcome. While certain factors, such as education, can help to mitigate the effects of a poor environment, inadequate resources undermine the ability of many Egyptian adolescents to protect themselves from parasitic infections.

\section{Determinants of Nutritional Status}

Nutrition-related deficiencies such as stunting and anemia are associated with a number of factors, including residence in rural areas and, as expected, lower socioeconomic status. Adolescents in households in the lowest socioeconomic category are more likely to be anemic, underweight, and stunted compared to those in higher socioeconomic strata. However, the prevalence of anemia among adolescents in the highest socioeconomic stratum is higher than expected and is cause for concern. Adolescents living in rural areas are more likely to be stunted, underweight, and anemic than those living in urban areas. Moreover, adolescents living in Upper Egypt are consistently more likely to be stunted, underweight, and anemic than adolescents living in other areas of Egypt. This association is supported by the fact that people living in rural areas are less likely to have access to infrastructure services and are also more likely to be in low-income families. Although more in-depth analysis is required, such associations should be taken into account when designing interventions to address health problems among adolescents.

\section{SEXUAL MATURATION}

The development of the reproductive and endocrine systems is an important aspect of an adolescent's maturation and growth. On average, sexual development among girls begins at age 8 with the first stages of breast development. Menarche usually occurs between ages 10.5 and 15.5 while the growth spurt usually takes place between ages 9.5 and 14.5. Boys mature sexually somewhat later than girls. Testicular enlargement occurs between ages 10.5 and 13.5 , and their growth spurt and other signs of sexual development among boys usually occur approximately one year after girls. Overall, puberty occurs in humans between ages 8 and 18 years. 
Although sexual maturation varies among individuals, adolescent growth depends on both health and adequate nutrition. Infectious diseases and malnutrition significantly delay the normal growth of adolescents. For example, as a direct consequence of an overall improvement in health and nutrition, a significant reduction of the average age of menarche has taken place in the United States, from age 14.5 at the beginning of the 20th century to 12.5 in the 1990s. Establishing the typical timing of these events among a given population will help physicians and parents to determine when a particular adolescent may require additional medical attention. To this end, the ASCE survey investigated some key maturational markers, including the age of menarche for girls, sexual maturation, and the growth spurt.

\section{Age at Menarche}

The timing of menarche is used as an indicator of the overall timing of adolescence within and among populations. Although spermarche carries equal importance it cannot be assessed as easily with survey questionnaires because it does not seem to be as remarkable an event for boys as menarche is for girls. Therefore the following section concerns menarche only.

Populations vary considerably in their average age of menarche. Research has demonstrated that genetic as well as environmental factors interplay to produce these variations. In the ASCE survey, girls were asked in an interview whether they had started to menstruate and, if yes, at what age. Some researchers believe that self-administered questionnaires are better for obtaining this information and produce more valid results. However, in Egypt, selfadministered questionnaires are not feasible because many adolescent girls cannot read and write. However, in order to increase the validity of the results, girls were asked these questions on three separate occasions, twice by interviewers and once in a clinical examination setting by a female doctor. In almost 98 percent of the cases, the adolescent reported consistently.

Using life table analysis, the median age of menarche for Egyptian girls was determined to be $\mathbf{1 3 . 6 8}$ years (Table 4.6 ). We examined the median age at menarche by region, socioeconomic level, and the educational background of the girl and her parent. The lowest median age of menarche is 13.03 years, reported among girls with parents who have a secondary or above level of education. The highest is 13.94 years, reported among girls living in Upper Egypt. Further, the highest median ages at menarche were found among girls living in households in the low socioeconomic class, in rural areas or in Upper Egypt, and among those with a low level of education (none or only some primary), or whose parent has no education.

\begin{tabular}{|lc|}
\hline $\begin{array}{l}\text { Table 4.6: Median age of menarche (life-table) } \\
\text { by selected background variables }\end{array}$ \\
\hline \multicolumn{1}{|c|}{ Variable } & Median Age \\
Overall median & 13.68 \\
Urban governorates & 13.27 \\
Lower Egypt & 13.71 \\
Upper Egypt & 13.94 \\
Urban & 13.58 \\
Rural & 13.88 \\
Socioeconomic status & \\
-Low & 13.87 \\
-Middle & 13.70 \\
-High & 13.47 \\
Adult Education & \\
-None & 13.82 \\
-Incomplete primary & 13.63 \\
-Primary/any preparatory & 13.66 \\
-Vocational secondary or above & 13.60 \\
-Above secondary & 13.03 \\
\hline
\end{tabular}




\begin{tabular}{|c|c|c|c|}
\hline ASCE Data & $\begin{array}{c}\text { Mean } \\
13.68 \text { (median) }\end{array}$ & $\begin{array}{c}\text { Sample } \\
4774 \\
\text { National sample } \\
\text { (ages } 10-19 \text { yrs.) }\end{array}$ & $\begin{array}{c}\text { Authors } \\
\text { El-Tawila et al., } \\
1999\end{array}$ \\
\hline $\begin{array}{l}\text { Urban Giza } \\
\text { Lower SES* } \\
\text { Middle SES }\end{array}$ & $\begin{array}{l}14.3 \\
13.4\end{array}$ & $\begin{array}{c}1,067 \\
\text { School children } \\
\text { (ages } 10-15 \text { yrs.) }\end{array}$ & $\begin{array}{c}\text { Galal, Harrison, } \\
\text { and Qureshi, } 1991\end{array}$ \\
\hline $\begin{array}{l}\text { Cairo } \\
\text { Well off } \\
\text { Middle class } \\
\text { Rural }\end{array}$ & $\begin{array}{l}12.59 \pm 0.29 \\
13.09 \pm 0.17 \\
13.89 \pm 0.18\end{array}$ & $\begin{array}{c}1,365 \\
\text { School children } \\
\text { (ages } 9-17 \text { yrs.) }\end{array}$ & Atallah, 1977 \\
\hline
\end{tabular}

SES = socioeconomic status

Figures 4.8 and 4.9 present the probability of menarche among Egyptian girls 10-19 years by place of residence and socioeconomic standard. By the age of 16 it is very unlikely that an Egyptian girl has not passed through menarche. However, there are differences in the onset of menarche between girls from high socioeconomic status households compared to those from the lowest status households, and between those residing in urban governorates compared to those in rural areas. These differences in onset can range from 6 to 11 months. This suggests that environmental factors, in nutrition or otherwise, affect the maturation process of Egyptian girls.

Figure 4.8: Probability of menarcle by age and 1.2 socioeconomic status

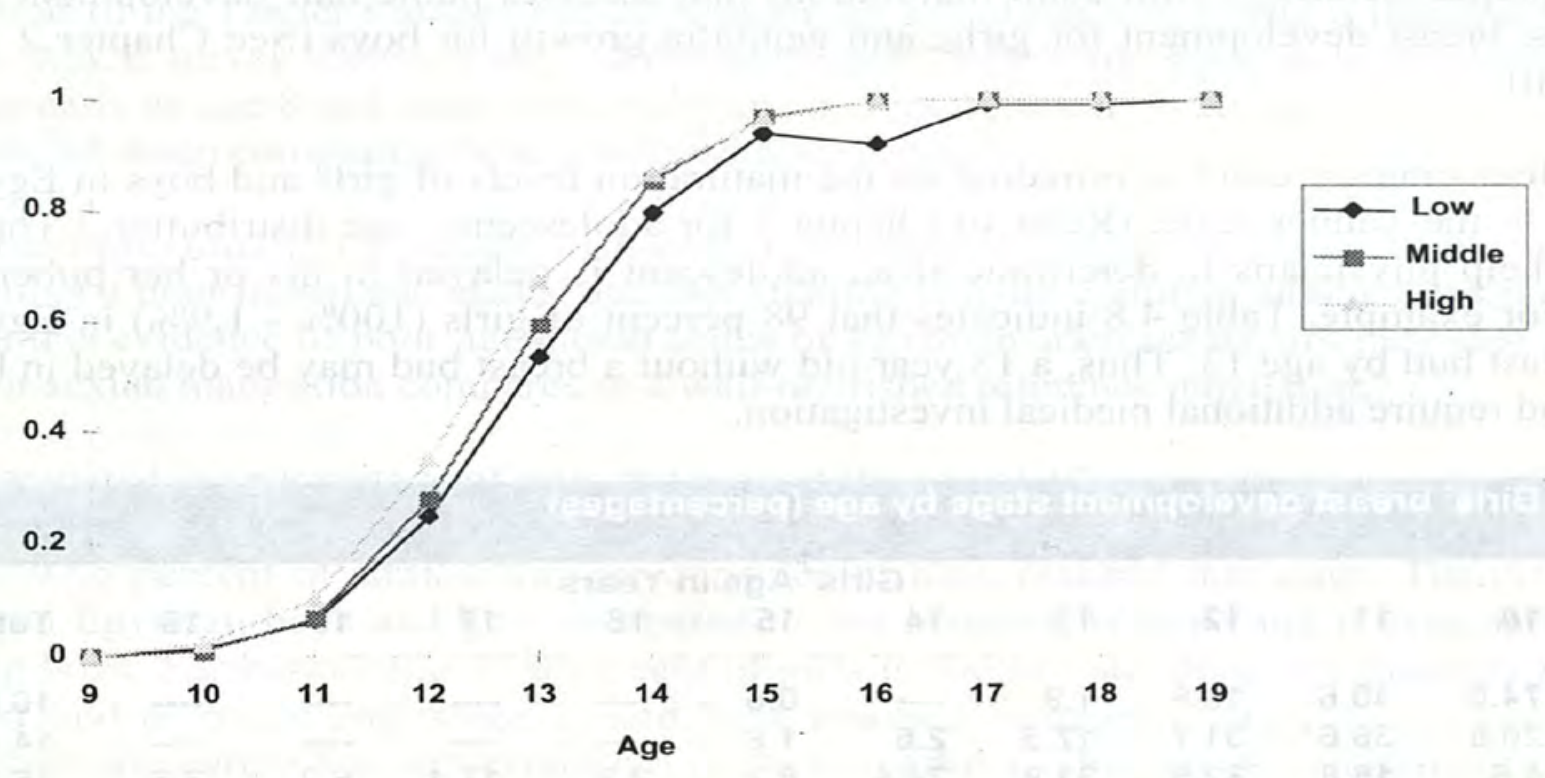


Figure 4.9: Probability of menarche by age and residence

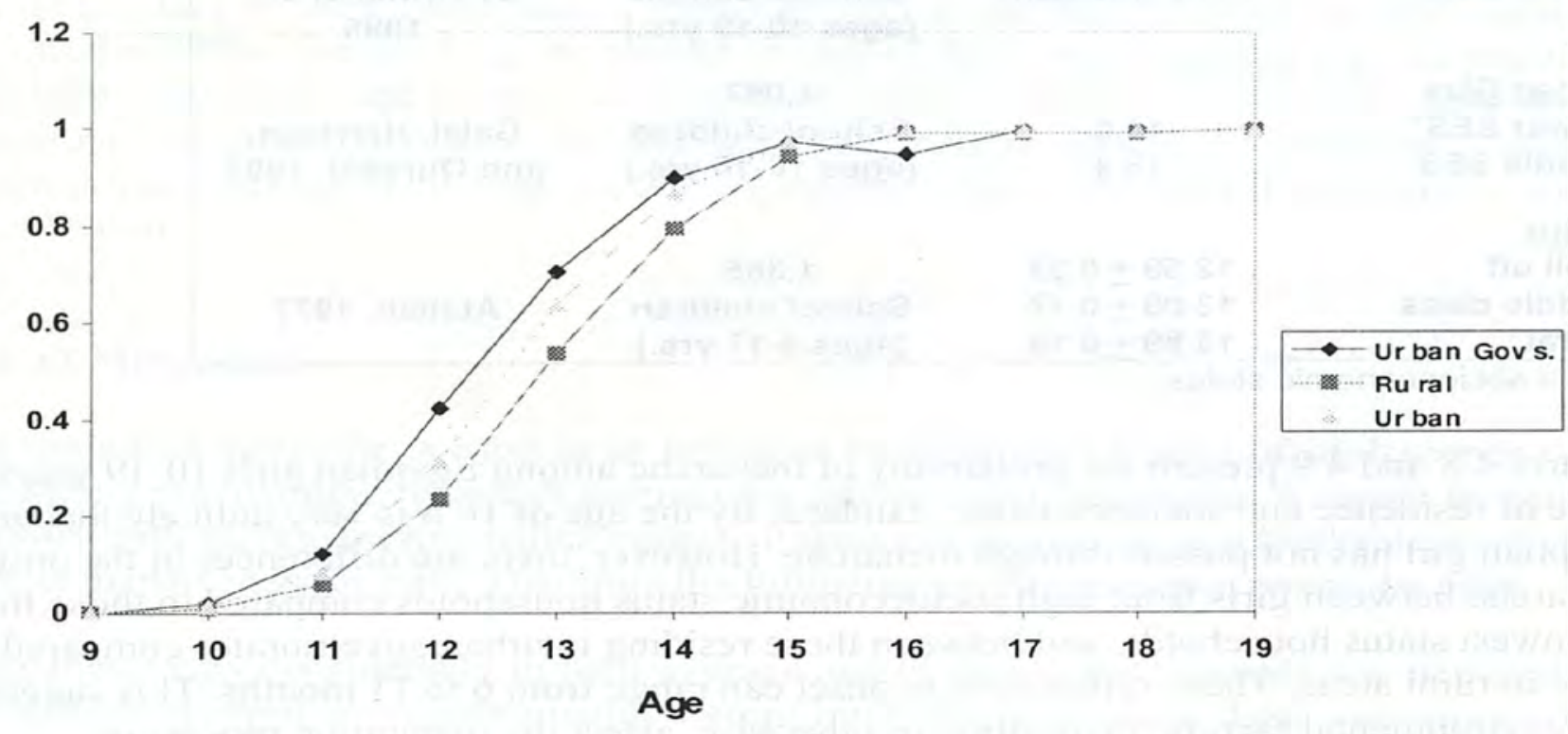

\section{ASSESSMENT OF SEXUAL MATURATION}

To evaluate the maturation process of Egyptian adolescents in terms of sexual development and human growth, Tanner's sex maturity rating scale has been used (Tanner 1975). It is a 1-5 scale $(1=$ prepubescence, $5=$ full adult maturation) that assesses pubic hair development for both sexes, breast development for girls, and genitalia growth for boys (See Chapter 2 for more detail).

The next four tables present information on the maturation levels of girls and boys in Egypt according to the Tanner scale. (Refer to Chapter 2 for adolescents' age distribution.) These data will help physicians to determine if an adolescent is delayed in his or her pubertal process. For example, Table 4.8 indicates that 98 percent of girls $(100 \%-1.9 \%)$ in Egypt have a breast bud by age 13 . Thus, a 13 year old without a breast bud may be delayed in her puberty and require additional medical investigation.

\section{Table 4.8 Girls' breast development stage by age (percentages)}

\begin{tabular}{|c|c|c|c|c|c|c|c|c|c|c|c|}
\hline \multirow[b]{2}{*}{ Stage } & \multicolumn{11}{|c|}{ Girls' Age in Years } \\
\hline & 10 & 11 & 12 & 13 & 14 & 15 & 16 & 17 & 18 & 19 & Total \\
\hline 1 & 74.0 & 40.6 & 13.6 & 1.9 & --- & 0.6 & --- & --- & --- & --- & 16.0 \\
\hline 2 & 20.8 & 36.6 & 31.7 & 17.5 & 2.6 & 1.8 & --- & ---- & ---- & --- & 14.4 \\
\hline 3 & 4.6 & 16.8 & 32.5 & 31.9 & 24.4 & 8.2 & 2.3 & 17.4 & 6.2 & 3.8 & 16.8 \\
\hline 4 & 0.6 & 5.9 & 16.0 & 31.3 & 39.1 & 48.2 & 36.4 & 19.6 & 14.6 & 19.0 & 22.5 \\
\hline 5 & --- & --- & 6.2 & 17.5 & 34.0 & 41.2 & 61.2 & 63.0 & 79.2 & 77.2 & 30.3 \\
\hline
\end{tabular}


Table 4.9 Girls' pubic hair development stage by age (percentages)

\begin{tabular}{|c|c|c|c|c|c|c|c|c|c|c|c|}
\hline \multirow[b]{2}{*}{ Stage } & \multicolumn{11}{|c|}{ Girls' Age in Years } \\
\hline & 10 & 11 & 12 & 13 & 14 & 15 & 16 & 17 & 18 & 19 & Total \\
\hline 1 & 72.8 & 50.5 & 23.5 & 3.1 & 1.3 & 0.6 & $\cdots$ & --- & --- & --- & 19.0 \\
\hline 2 & 25.4 & 33.2 & 37.0 & 20.6 & 6.4 & 2.4 & --- & 0.7 & $\cdots$ & --- & 16.1 \\
\hline 3 & 1.7 & 12.4 & 18.5 & 25.6 & 19.9 & 10.6 & 12.4 & 8.7 & 5.2 & 2.5 & 12.8 \\
\hline 4 & $\cdots$ & 4.0 & 18.1 & 36.3 & 47.4 & 45.3 & 25.6 & 31.9 & 11.5 & 32.9 & 24.3 \\
\hline 5 & --- & $-\cdots$ & 2.9 & 14.4 & 25.0 & 41.2 & 62.0 & 58.7 & 83.3 & 64.6 & 27.9 \\
\hline
\end{tabular}

Table 4.10: Boys pubic hair development stage by age (percentages)

\begin{tabular}{|c|c|c|c|c|c|c|c|c|c|c|c|}
\hline \multirow[b]{3}{*}{ Stage } & \multicolumn{11}{|c|}{ Boys Age in Years } \\
\hline & 10 & 11 & 12 & 13 & 14 & 15 & 16 & 17 & 18 & 19 & Total \\
\hline & & & & & & & & & & & \\
\hline 1 & 92.6 & 86.7 & 76.5 & 39.3 & 31.9 & 16.8 & 4.5 & --- & 1.0 & ---- & 44.0 \\
\hline 2 & 7.4 & 12.8 & 18.8 & 34.6 & 21.5 & 15.3 & 6.4 & 0.9 & 1.0 & 2.9 & 14.7 \\
\hline 3 & & & 4.7 & 20.9 & 30.7 & 32.8 & 17.3 & 18.5 & 14.6 & 7.4 & 14.1 \\
\hline 4 & ---- & ---- & & 3.7 & 14.1 & 28.5 & 50.0 & 34.3 & 38.5 & 16.2 & 14.5 \\
\hline 5 & ---- & 0.5 & --- & 1.6 & 1.8 & 6.6 & 21.8 & 46.3 & 44.8 & 73.5 & 12.7 \\
\hline
\end{tabular}

\section{Table 4.11: Boys' genital development stage by age (percentages)}

\begin{tabular}{|c|c|c|c|c|c|c|c|c|c|c|c|}
\hline \multirow{3}{*}{ Stage } & \multicolumn{11}{|c|}{ Boys Age in Years } \\
\hline & 10 & 11 & 12 & 13 & 14 & 15 & 16 & 17 & 18 & 19 & Total \\
\hline & 81.6 & 71.1 & 63.4 & 31.4 & 20.2 & 13.9 & 2.7 & --- & 4.2 & --- & 36.1 \\
\hline 2 & 18.4 & 25.7 & 28.2 & 32.5 & 27.0 & 15.3 & 2.7 & $\ldots$ & 2.1 & -... & 19.0 \\
\hline 3 & --- & 2.8 & 7.0 & 20.9 & 24.5 & 27.0 & 10.9 & 15.7 & 15.6 & 8.8 & 13.1 \\
\hline 4 & --- & ---- & 0.9 & 13.6 & 25.2 & 29.2 & 42.7 & 28.7 & 22.9 & 8.8 & 14.9 \\
\hline 5 & --- & 0.5 & 0.5 & 1.6 & 3.1 & 14.6 & 40.9 & 55.6 & 55.2 & 82.4 & 16.9 \\
\hline
\end{tabular}

For some of the Tanner's stages, the distribution by age of the ASCE data is incomplete. That is, the ASCE survey included only adolescents ages 10-19 while some girls develop a breast bud as early as age 8 and some boys show an enlarged scrotum by the age of 9 . This must be considered when comparing these results with other research.

As noted previously, 17 percent of Egyptian adolescents are stunted (low height-for-age), indicating a poor nutritional status, and that stunting is more common among boys than girls. Given this evidence of poor nutritional status of Egyptian adolescents, are they also delayed in their sexual maturation compared to a well-nourished reference population?

We compared the percentage of girls and boys at the age of 15 years who have achieved stage 4 on Tanner's scale to girls and boys in the United States (Table 4.12). At the ages listed below 97.5 percent of adolescents are expected to have reached this stage. The difference between Egyptian boys and girls compared to this standard is large and is especially large among boys. Furthermore, only 6 percent of girls in the sample are at sex maturity rating 2 (breast bud or pubic hair stage 2) and have reached menarche, while 10 percent of the reference population has achieved both of these markers. This suggests a general delay in maturation among Egyptian adolescents and requires further investigation. That the ASCE survey did not cover 8 and 9 year old girls could explain some of this observed difference, but certainly not all of it. 
Table 4.12: Comparison of survey sample of Egyptian adolescents with USA

population as a standard

SMR for girls Pubic hair stage 4 (PH4)* $^{*}$
reached

Breast stage 4 (B4)

reached

SMR for boys

Pubic hair stage 4 (PH4)

reached

Genitalia Stage 4 (G4)

reached

\section{Sex Maturity Rating (SMR) \\ Age at which $97.5 \%$ \\ of adolescents \\ reach stage among \\ US population}

\section{$\%$ reaching this \\ stage among \\ Egyptian ASCE sample (weighted)}

72.7

89.6

35.3

62.2

15.4

44.1

53.4

* For $\mathrm{PH} 4,14$ year-old girls were used as a comparison group rather than 15 year-olds.

\section{Growth SPURT}

As previously mentioned, the growth spurt is a remarkable maturational event. We define the growth spurt as the increase in velocity of growth, producing rapid changes in height and weight. The cross-sectional data collected in the ASCE survey does not permit us to comment on the growth spurt except through the maturational indicators available ${ }^{5}$. Thus we cannot compare the ASCE sample to a population reference based on longitudinal data. Table 4.13 examines the growth spurt state of both sexes by selected background variables.

As expected, there is a difference in the pattern of growth spurt between the sexes; only 16 percent of girls in the entire sample have not yet started their growth spurt compared to 55 percent of the boys. Further, there is a large difference between the sexes in the number who have completed their growth spurt, as 59 percent of girls have ended their growth spurt compared to just 13 percent of boys. Between the ages of 10-15, 22 percent of girls have not started the growth spurt compared to 74 percent of boys of the same age group. Socioeconomic status appears to have an impact on the timing of the growth spurt. The highest percent of girls who have not started their growth spurt prevails among those in the low socioeconomic status $(23 \%)$ while the highest percent of girls who have ended their spurt is found among those in the high socioeconomic status $(63 \%)$.

\footnotetext{
${ }^{4}$ The data for the US reference population is taken from longitudinal data while the ASCE data is crosssectional. Therefore, it is not possible to determine the age at which 97.5 percent of Egyptian adolescents would reach the pubertal stages listed in this table.

${ }^{5}$ The World Health Organization recommends using 2 indicators each for girls and boys to determine the stage in the growth spurt. One marker signals the beginning of the growth spurt and one indicating that the peak velocity for height and associated changes have passed. Thus for girls, if breast bud stage 2 (B2) has been reached but menarche has not, this indicates that the adolescent's growth spurt has begun but not ended. If both stage B2 and menarche have taken place, this indicates that the peak velocity of the growth spurt has been completed. Similarly, if neither stage has taken place, this denotes that the growth spurt has not started yet; that is the child is prepubescent. For boys the recommended markers are genital development stage 3 (G3) and adult voice attainment. Because the ASCE survey question regarding voice could have been misinterpreted, we used pubic hair stage 5 (PH5) as the second marker instead.
} 


\begin{tabular}{|c|c|c|c|c|c|c|}
\hline Background Variables & $\begin{array}{c}\text { Not } \\
\text { Started }\end{array}$ & $\begin{array}{l}\text { Girls } \\
\text { Started } \\
\text { But Not } \\
\text { Ended }\end{array}$ & $\begin{array}{l}\text { Ended } \\
\text { Spurt }\end{array}$ & $\begin{array}{c}\text { Not } \\
\text { Started }\end{array}$ & $\begin{array}{c}\text { Boys } \\
\text { Started } \\
\text { But Not } \\
\text { Ended }\end{array}$ & $\begin{array}{l}\text { Ended } \\
\text { Spurt }\end{array}$ \\
\hline Total & 15.9 & 25.7 & 58.5 & 55.0 & 32.3 & 12.6 \\
\hline $\begin{array}{l}10-15 \\
16-19\end{array}$ & $\begin{array}{c}22.2 \\
0.0\end{array}$ & $\begin{array}{c}35.7 \\
0.7\end{array}$ & $\begin{array}{l}42.1 \\
99.3\end{array}$ & $\begin{array}{c}73.8 \\
2.9\end{array}$ & $\begin{array}{l}24.7 \\
53.5\end{array}$ & $\begin{array}{c}1.5 \\
43.6\end{array}$ \\
\hline \multicolumn{7}{|l|}{ Adult Education } \\
\hline -None & 16.6 & 26.9 & 56.5 & 53.2 & 34.2 & 12.6 \\
\hline -Incomplete Primary & 17.0 & 27.0 & 56.0 & 58.6 & 29.7 & 11.7 \\
\hline $\begin{array}{l}\text {-Completed Primary IAny } \\
\text { Preparatory }\end{array}$ & 10.3 & 16.7 & 73.1 & 71.7 & 25.0 & 3.3 \\
\hline $\begin{array}{l}\text {-Voc. Secondary IAbove } \\
\text { Intermediate }\end{array}$ & 13.0 & 23.5 & 63.5 & 62.1 & 22.3 & 15.5 \\
\hline -Secondary + & 13.9 & 39.2 & 46.8 & 50.5 & 38.2 & 11.8 \\
\hline \multicolumn{7}{|l|}{ Socioeconomic status } \\
\hline -Low & 22.9 & 24.2 & 52.9 & 61.8 & 28.4 & 9.8 \\
\hline -Middle & 13.4 & 32.2 & 54.3 & 52.4 & 34.3 & 13.4 \\
\hline -High & 13.2 & 23.9 & 62.9 & 49.9 & 35.6 & 14.5 \\
\hline
\end{tabular}

In sum, the growth spurt starts and ends earlier in girls than in boys as expected. Differences in socioeconomic variables do not appear to have the same effect on both sexes. This suggests that there are other unknown factors that have an impact on boys' growth spurt that have not been considered and need to be investigated further.

\section{HEALTH BEHAVIOR}

\section{DIETARY HABITS}

Adolescence is marked by a level of physical growth and emotional maturation that often results in stress and anxiety. These influence physiological and psychological status, as well as social behavior which in turn affect nutritional behavior. The changing life-styles of adolescents have significant effects on their food habits.

In this survey, information was obtained on the consumption of foods during the day prior to interview that provide fiber and vitamins. Data on foods high in salt, fat, and sugar (chocolates and candy) that are considered harmful to health were also obtained. A more complete picture of dietary habits will be obtained when this data is combined with that from the 24-hour food recall instrument administered to a subsample of adolescents. The data presented here should be viewed as a general indication of adolescent dietary habits. (More details on methods can be found in Chapter 2.)

\section{General Dietary Habits}

Healthy eating habits could be developed during adolescence; however external pressures can influence adolescents to choose foods that do not promote growth and development, and do not help them maintain a healthy body weight. Adolescents generally become more 
independent and mobile during this lifestage; they eat meals outside the home, they share more food with peers, and learn new food habits. General dietary habits among adolescents are presented in Table 4.14. The majority of the adolescents have three meals per day; however the proportion is higher among boys than girls. This difference may be attributed to the higher proportion of girls who report taking snacks.

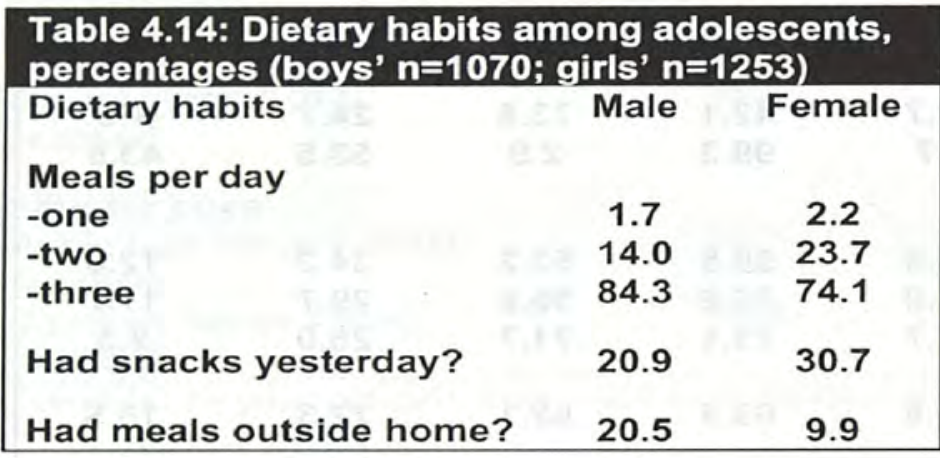

In this survey, about one-fifth of boys report eating meals outside the home, more than twice as many as girls. This is expected, as girls in Egypt are more restricted in their mobility and thus have fewer opportunities to go outside the home environment.

\section{Nutritious Foods}

Fruits and Vegetables: Only about half of girls report that they ate fruits the day prior to the interview, which is slightly higher than boys (Table 4.15). Fruit consumption increases with age and level of education. Moreover, considerably more adolescents consume fruit in urban areas compared to rural areas, and in urban governorates more than in Lower Egypt or in Upper Egypt. Adolescents from households in the high socioeconomic stratum consume significantly more fruits than those in the middle and low strata.

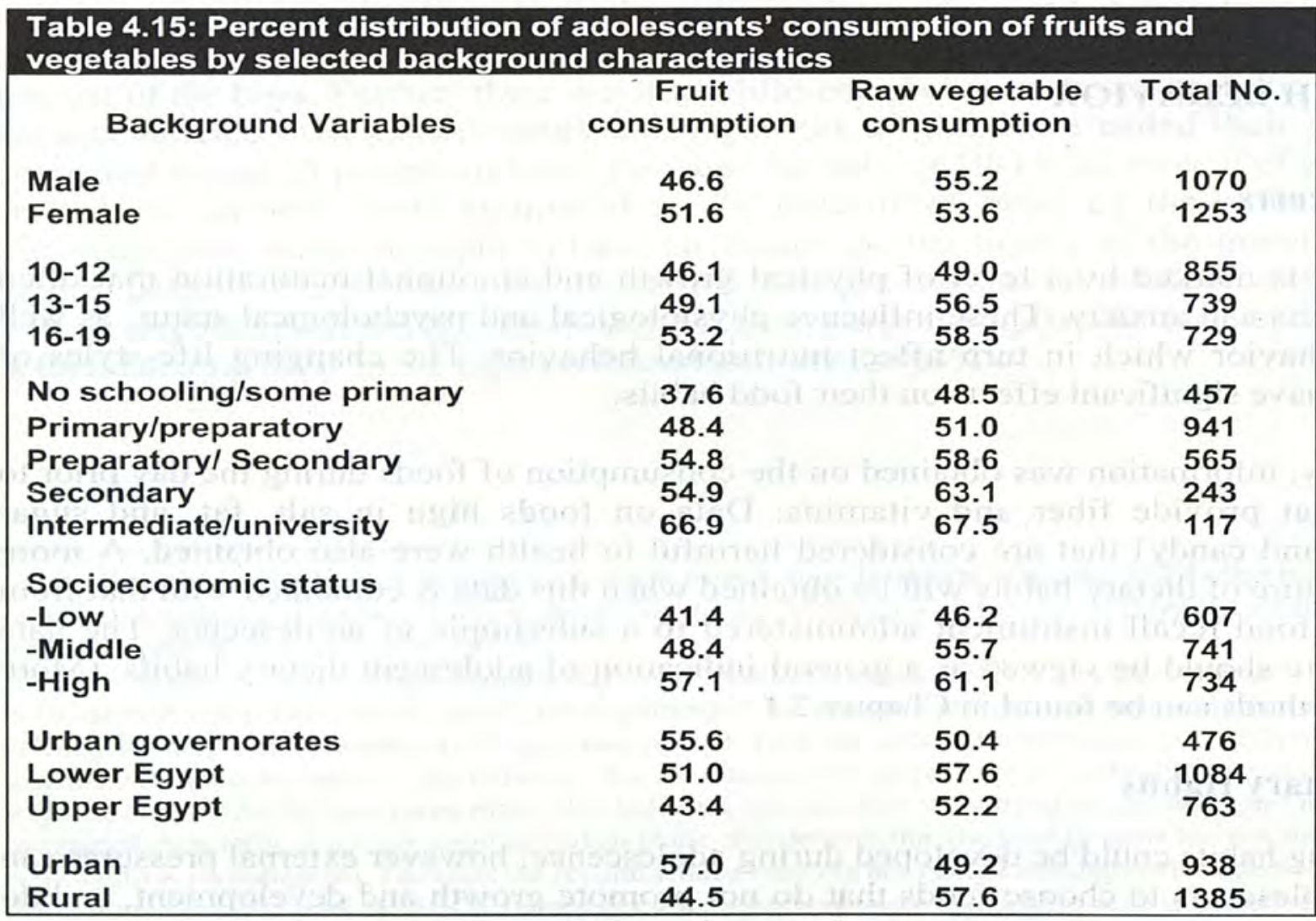


More than half of adolescents and slightly more boys than girls reported eating raw vegetables the day prior to the interview. There is a consistent increase in the proportion of adolescents reporting eating raw vegetables with increases in age, education level, and socioeconomic status. In contrast to fruit consumption, the proportion of adolescents in rural areas consuming raw vegetables is higher than in urban areas and in Lower Egypt more than in Upper Egypt and urban governorates. This may be expected due to the higher availability of raw vegetables in rural areas.

Whole wheat: An excellent source of insoluble dietary fiber is whole grain products such as whole wheat bread. In Egypt, baladi, or unrefined bread ( $85 \%$ extraction rate) is the most popular bread. However, the presence of phytates and bran in the bread inhibits the absorption of dietary iron from plant origin, which may partially explain the widespread prevalence of anemia among adolescents. This effect could be counteracted with ascorbic acid, which is abundant in fresh vegetables and fruits. Table 4.16 shows consumption patterns for Egyptian adolescents.

\begin{tabular}{|c|c|c|c|c|c|}
\hline \multicolumn{2}{|c|}{ Background Variables } & $\begin{array}{l}\text { White } \\
\text { bread \% }\end{array}$ & $\begin{array}{l}\text { Baladi bread } \\
\%\end{array}$ & $\begin{array}{c}\text { Bettao bread } \\
\%\end{array}$ & Total No. \\
\hline \multicolumn{2}{|l|}{ Male } & 12.0 & 88.2 & 4.1 & 1070 \\
\hline \multicolumn{2}{|l|}{ Female } & 11.3 & 88.5 & 5.9 & 1253 \\
\hline \multicolumn{2}{|l|}{$10-12$} & 8.6 & 91.4 & 5.1 & 855 \\
\hline \multicolumn{2}{|l|}{$13-15$} & 11.3 & 88.4 & 5.7 & 739 \\
\hline \multicolumn{2}{|l|}{$16-19$} & 15.6 & 84.6 & 4.3 & 729 \\
\hline \multicolumn{2}{|c|}{ No schooling/some primary } & 6.2 & 85.9 & 10.5 & 457 \\
\hline \multirow{2}{*}{\multicolumn{2}{|c|}{$\begin{array}{l}\text { Primary/preparatory } \\
\text { Preparatory/ secondary }\end{array}$}} & 9.6 & 91.1 & 5.0 & 941 \\
\hline & & 13.5 & 89.4 & 2.3 & 565 \\
\hline \multirow{2}{*}{\multicolumn{2}{|c|}{$\begin{array}{l}\text { Secondary } \\
\text { Intermediate/university }\end{array}$}} & 15.6 & 85.8 & 3.4 & 243 \\
\hline & & 34.4 & 76.1 & --- & 117 \\
\hline \multicolumn{6}{|l|}{ Socioeconomic status } \\
\hline \multirow{2}{*}{\multicolumn{2}{|c|}{$\begin{array}{l}\text {-Low } \\
\text {-Middle }\end{array}$}} & 6.3 & 89.2 & 7.3 & 607 \\
\hline & & 10.2 & 88.8 & 4.3 & 741 \\
\hline \multicolumn{2}{|l|}{-High } & 17.3 & 88.4 & 2.3 & 734 \\
\hline \multirow{3}{*}{$\begin{array}{l}\text { Urban governorates } \\
\text { Lower Egypt } \\
\text { Upper Egypt }\end{array}$} & & 32.0 & 81.8 & --- & 476 \\
\hline & & 7.2 & 94.6 & 0.5 & 1084 \\
\hline & & 6.3 & 83.5 & 14.0 & 763 \\
\hline \multirow{2}{*}{$\begin{array}{l}\text { Urban } \\
\text { Rural }\end{array}$} & & 25.0 & 86.0 & --- & 938 \\
\hline & & 3.4 & 89.9 & 8.2 & 1385 \\
\hline
\end{tabular}

The proportions of boys and girls that reported eating baladi bread are high and quite similar. There is almost no difference in the consumption of unrefined bread among socioeconomic strata. Adolescents in rural areas consumed unrefined bread at slightly higher levels than those in urban areas, while significantly more adolescents in urban areas report consuming white bread than in rural areas. Adolescents in Lower Egypt consume more unrefined bread than urban governorates or Upper Egypt, while those in urban governorates consume more white bread than their counterparts in Lower or Upper Egypt. The latter finding can probably be explained by the greater availability of white bread in urban governorates. Perhaps not 
surprisingly, white bread consumption increases with socioeconomic status as well as with increases in age and education.

A kind of home-made bread, called bettao bread, is consumed in rural Upper Egypt. It is made of wheat flour, corn flour, and fenugreek, and is consumed by 14 percent of adolescents in rural Upper Egypt.

\section{Non-Nutritious Foods}

Salted foods: Sodium is naturally present in various food items such as meat, fish, poultry, and eggs, milk, and milk products. Sodium is added to some foods, like cured meat, frozen vegetables, and potato chips, during processing as baking power, sodium, or monosodium glutamate, or added as salt during preparation or at the table.

Two-thirds of boys and 80 percent of girls prefer salty foods and half as many of both sexes stated that they ate salty foods, like pickles or salted cheeses, the day prior to the interview. When adolescents were asked if they usually add salt to foods, about 31 percent stated they do so (Table 4.17). No difference was found between boys and girls, nor among socioeconomic strata. Adolescents in rural areas add table salt at slightly higher levels than those in urban areas. There is a positive relationship between both age and education and the proportion of adolescents who usually add table salt to their foods.

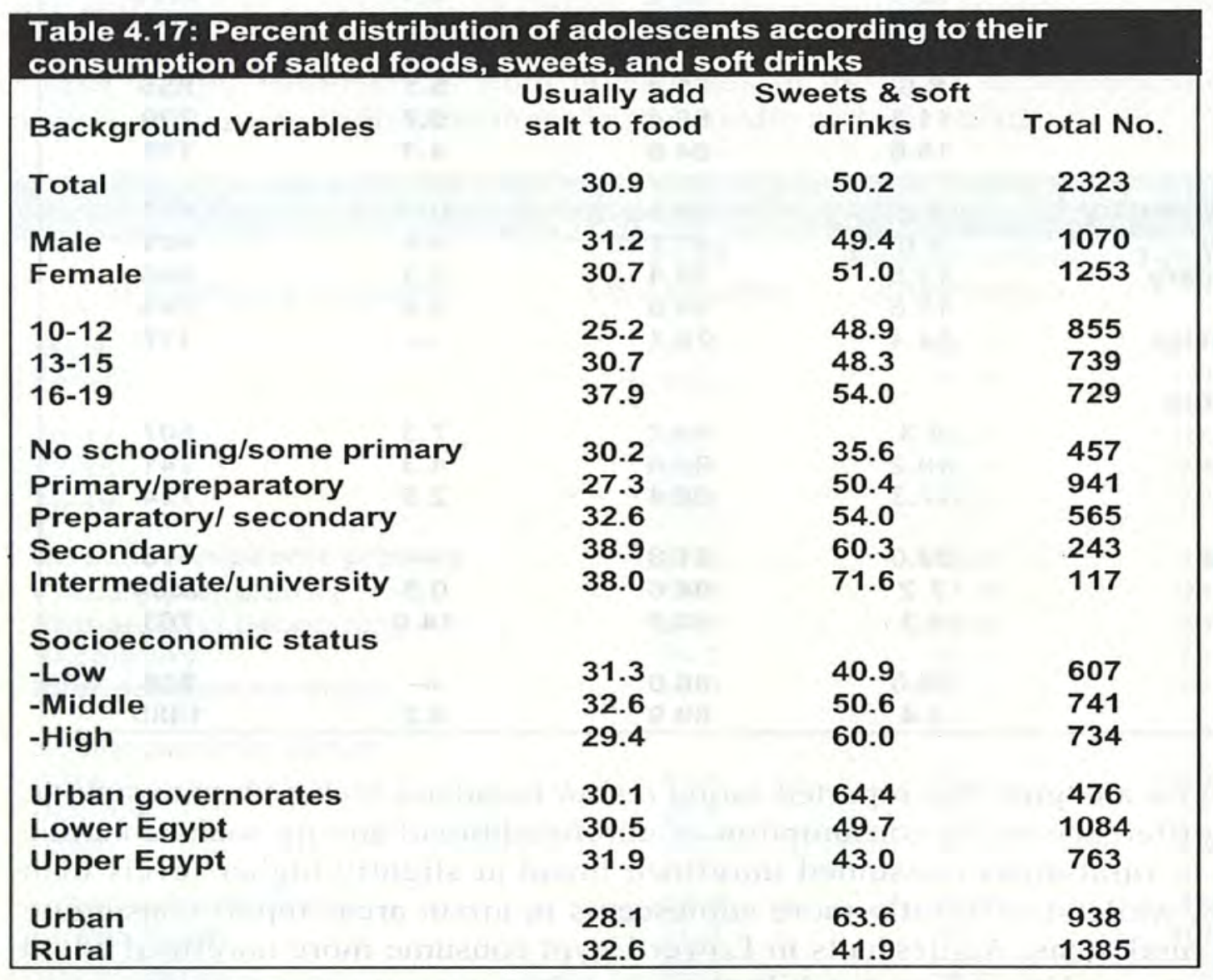

Sweets and soft drinks: Table 4.17 shows that half of the adolescents interviewed reported eating sweets (such as chocolate bars or candy) or soft drinks the day prior to the interview. 
Soft drinks are the most commonly consumed of these foods by adolescents), followed by candy, fruit juice, and chocolate bars and biscuits. There is no difference in consumption by gender; however, there is a difference between age groups. Older adolescents (ages 16-19) consume sweets and soft drinks more than younger adolescents. This may be because older adolescents are more mobile and have more spending money with which to purchase these items for themselves while parents have more control over the diets of their younger children. Consumption of sweets and soft drinks also increases with the level of education, though this may be a function of age, mentioned previously.

The consumption of sweets and soft drinks differs significantly by socioeconomic status. There is a difference in consumption levels of more than 20 percentage points between the lowest and highest socioeconomic level. Consumption also varies by region of residence. Significantly more adolescents in urban areas consume sweets and soft drinks than in rural areas; and in urban governorates compared to Lower and Upper Egypt. This may be due to the greater availability of these food items in urban communities than rural ones.

Drinking tea: One dietary habit widespread among Egyptians regardless of age or social class is the drinking of concentrated tea, particularly after meals. Tea leaves contain a substance called tannic acid, which inhibits the absorption of dietary iron from plants. As most of the dietary iron consumed by Egyptians is of plant origin, the habit of drinking tea after meals is clearly problematic for adequate iron intake (Table 4.18)

\begin{tabular}{|lcccc|}
\hline \multicolumn{5}{l}{$\begin{array}{l}5 \\
\text { Table 4.18: Percent distribution of adolescents according to tea drinking by selected }\end{array}$} \\
\hline \multicolumn{1}{|c}{ Background Variables } & Drink Tea & $\begin{array}{c}\text { Drank Tea } \\
\text { Yesterday }\end{array}$ & $\begin{array}{c}\text { Tea after } \\
\text { meals }\end{array}$ & Total No. \\
Male & 89.2 & 89.4 & 70.3 & 1070 \\
Female & 79.7 & 82.5 & 63.5 & 1253 \\
$10-12$ & 85.9 & 84.6 & 68.3 & 855 \\
$13-15$ & 83.1 & 85.3 & 64.4 & 739 \\
$16-19$ & 83.1 & 88.3 & 68.2 & 729 \\
No schooling/some primary & 86.6 & 86.6 & 80.9 & 476 \\
Primary/preparatory & 88.7 & 85.5 & 65.5 & 931 \\
Preparatory/ secondary & 88.5 & 85.6 & 63.8 & 574 \\
Secondary & 90.3 & 90.4 & 58.0 & 234 \\
Intermediate/university & 94.1 & 79.6 & 55.8 & 107 \\
Socioeconomic status & & & & \\
-Low & 87.7 & 89.0 & 77.1 & 607 \\
-Middle & 82.9 & 86.4 & 70.7 & 741 \\
-High & 84.1 & 81.2 & 53.8 & 734 \\
Urban governorates & 81.9 & 78.4 & 55.1 & 476 \\
Lower Egypt & 83.1 & 86.9 & 69.3 & 1084 \\
Upper Egypt & 86.8 & 88.6 & 69.7 & 763 \\
Urban & 81.1 & 80.1 & 56.9 & 938 \\
Rural & 86.0 & 89.4 & 72.4 & 1385 \\
\hline
\end{tabular}

Table 4.18 shows that most adolescents drink tea. More boys drink tea than girls and consequently more boys drink tea after meals, but there is little difference in consumption among age groups. Adolescents in rural areas, in Upper Egypt, and in the low socioeconomic 
class drink tea more than those in other areas and socioeconomic classes, and there is a significant decrease in drinking tea after meals as adolescents' education rises.

Further analysis will be conducted on the nutritional habits and status of adolescents to determine how interventions should be targeted.

\section{SMOKING}

The harmful effects of smoking have motivated a number of countries to develop policies and programs to reduce ill health and death from tobacco use. These include smoke-free environments and restrictions on the availability, sale, and advertising of tobacco. However, these programs and policies vary markedly among countries and are not always successful in discouraging young people from smoking. In Egypt, taxes on tobacco have been increased many times and advertising has been restricted in mass media. However, there is no age restriction on the purchase of cigarettes. Table 4.19 shows the prevalence of smoking among adolescents, their peers, and the extent to which peers have offered cigarettes.

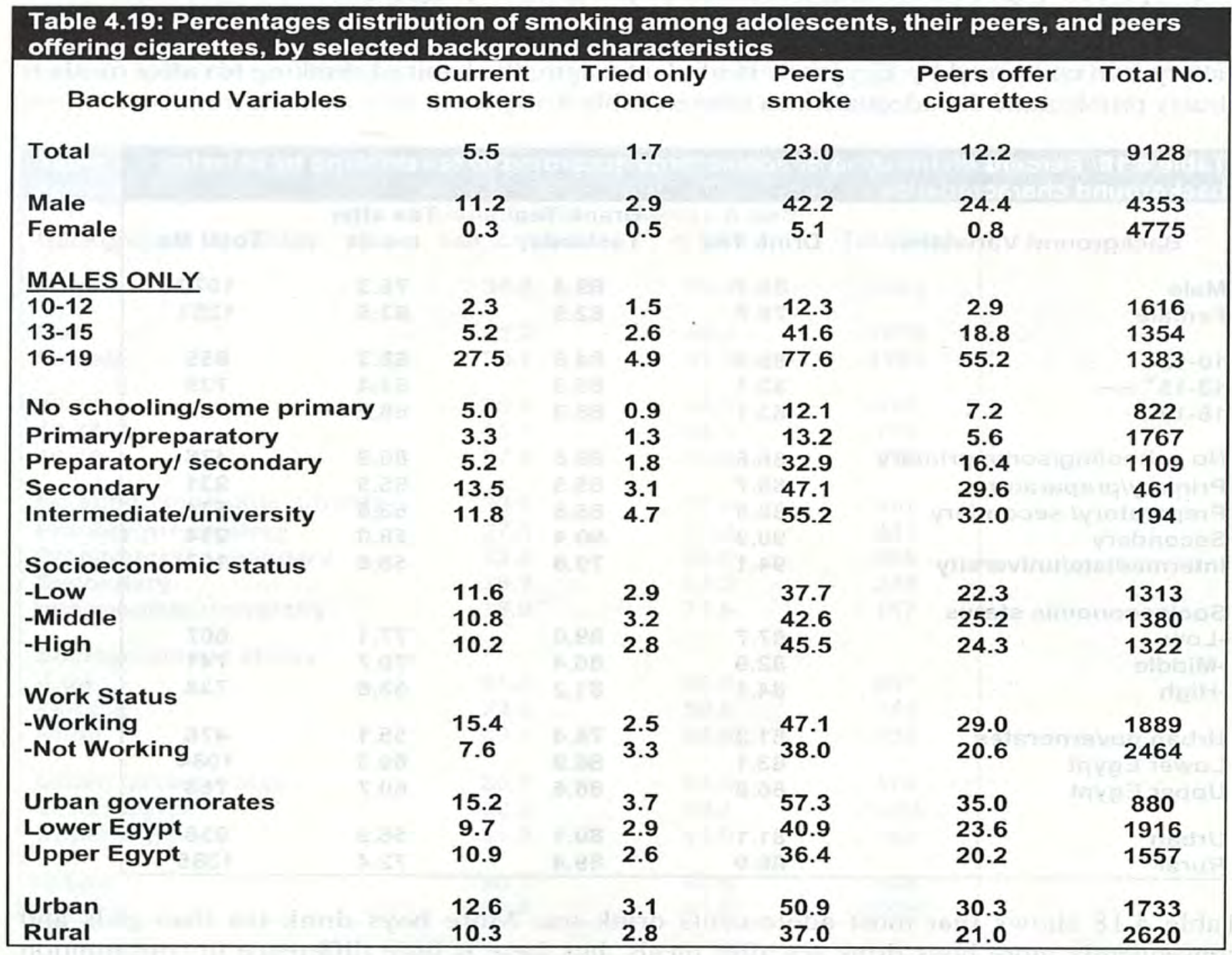


The overall prevalence of smoking among adolescents is nearly 6 percent and an additional 2 percent report having tried smoking only once. Boys report smoking at considerably higher levels than girls $(11.2 \%$ versus $0.3 \%)$, and more boys than girls have tried smoking once.

However, considering that only 11 percent of boys report that they themselves smoke but 42 percent report that their peers smoke, and a similar pattern appears among girls, the levels of smoking reported among our sample are probably underestimates. Because so few girls have reported ever smoking (only 38 girls have ever smoked), much of the following analysis is restricted to boys.

Older boys smoke at significantly higher levels than younger boys, 28 percent of older adolescents compared to 2 percent of boys ages 10-12 and 5 percent of boys ages 13-15. Working boys smoke at levels about twice as high as non-working boys. This is not surprising, as working boys earn money with which to purchase cigarettes, are more exposed to peer influence, and are more frequently away from parental supervision.

Peer group behavior is considered a critical factor in the initiation and maintenance of adolescent smoking. Data shown in Table 4.19 demonstrate the potential for peer influence is high among adolescents in Egypt, particularly among boys. As shown, 42 percent of boys' peers smoke and 24 percent of boys report that their peers have offered them cigarettes. This is particularly evident in the older age group (ages 16-19); more than half of the boys in this age group report that they have been offered cigarettes by their peers.

\section{Reasons for Starting to Smoke}

The reasons adolescents give for starting to smoke confirm the influence of peers in the initiation of smoking. Figure 4.10 shows that 41 percent of boys who ever smoked report that they imitate their friends in smoking and 14 percent report peer pressure as the reason for starting. On the other hand, Figure 4.11 shows that more than one-fifth of girls who ever smoked report that they imitate their parents in smoking. Girls report curiosity as the main reason that they have tried smoking $(43.1 \%)$, while only more than one-quarter of boys state this reason.

\section{Figure 4.10: Boys' reasons for starting to smoke}

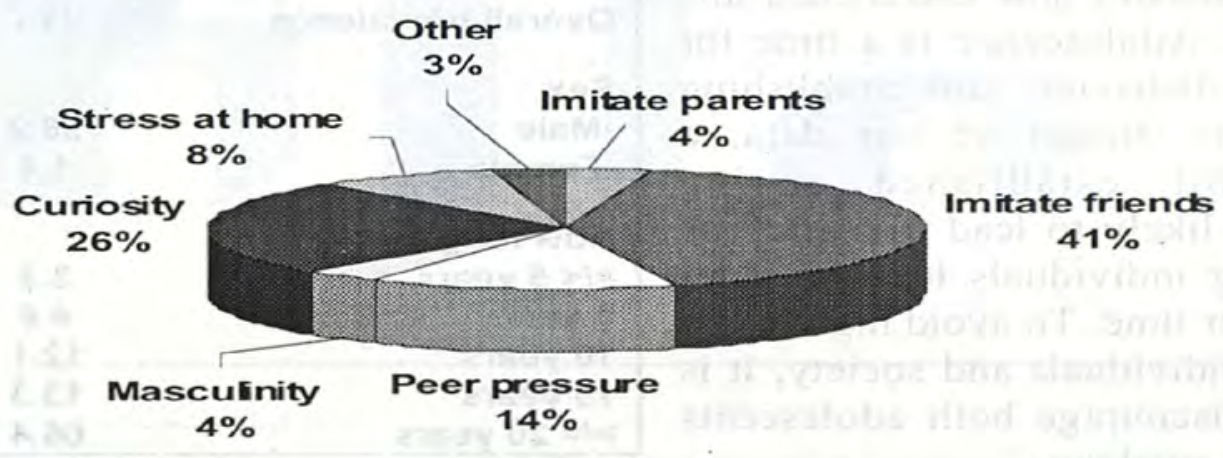




\section{Figure 4.11: Girls' reasons for starting to smoke}

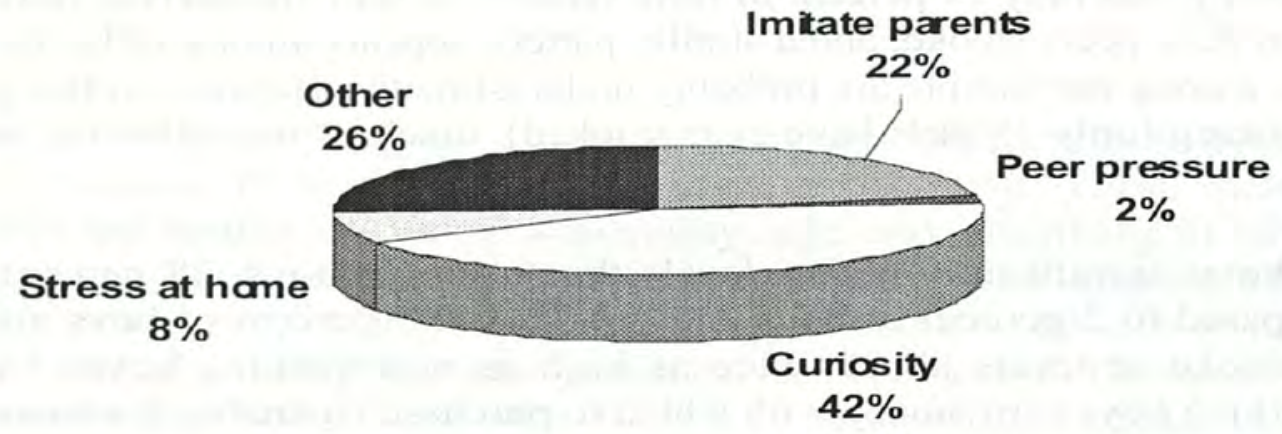

\section{Level of Current Smoking}

To determine the level of smoking among adolescents who reported smoking, adolescents were asked: "How many cigarettes did you smoke the last week?" Thirty-six percent of boys who smoke reported that they did not smoke during the week prior to the survey (Table 4.20).

Table 4.20: Percent distribution of current smoking among adolescent boys $(n=474)$ Cigarettes smoked last week

Boys

Did not smoke

1 cigarette

35.9

10 cigarettes

16.8

50 cigarettes

100-200 cigarettes
20.1

11.5

15.7

\section{Smoking Among Parents}

Thirty-two percent of the parents of the sampled adolescents report that they smoke (Table 4.21). Gender difference in smoking among parents is marked; 59 percent of male adults smoke compared to slightly more than 1 percent of female adults. Two-thirds of parents report that they have smoked for more than 20 years.

The fact that most parents who smoke report having smoked for at least 20 years $(66.4 \%)$ demonstrates how entrenched this habit becomes. Adolescence is a time for trying out new behaviors and establishing life-long habits. Based on our data, a smoking habit established during adolescence is likely to lead to a lifetime habit, exposing individuals to significant health risks over time. To avoid high future costs to both individuals and society, it is important to discourage both adolescents and adults from smoking.
Table 4.21: Smoking among parents of all adolescents

\begin{tabular}{lcc|}
\hline Overall prevalence & $\%$ & No. \\
Sex & 31.7 & 6213 \\
-Male & & \\
-Female & 58.9 & 3274 \\
& 1.4 & 2939 \\
How long smoking & & 1664 \\
$=/<5$ years & 3.2 & \\
5 years & 4.6 & \\
10 years & 12.1 & \\
15 years & 13.3 & \\
$>l=20$ years & 66.4 & \\
\hline
\end{tabular}


The gamma correlation ${ }^{6}$ between having ever smoked cigarettes and selected variables is displayed in Table 4.22. The results emphasize the significant association between ever having smoked cigarettes and work status, having peers who smoke, and having peers who have offered cigarettes. The latter two variables have the strongest correlation with the experience of ever smoking cigarettes. Interestingly, having a parent who smokes is not significantly correlated with an adolescent's smoking.

\section{Table 4.22: Gamma correlation between ever tried smoking and some background} variables

Variable

P. value for $X^{2}$ test

Gamma

Work status

0.000

0.32197

Peers smoke

0.000

0.59754

Peers offer cigarettes

0.000

0.61618

Parent smokes

0.754

$-0.00949$

\section{GENERAL HEALTH}

\section{ADOLESCENTS' PERCEPTIONS OF THEIR PRESENT HEALTH STATUS}

During adolescence, significant psychological development and changes in personal relations and physical maturation can affect one's perception of health. Adolescents were asked to rate their general health status by describing themselves as very healthy, normal, or in poor health compared to others in their age group. Figure 4.12 shows that the majority of adolescents of both sexes consider their health to be normal compared with their peers'. Boys perceive themselves as very healthy more than girls $(30.6 \%$ v. $20.4 \%)$, while a very slight gender difference was found regarding adolescents' perception of being in bad health.

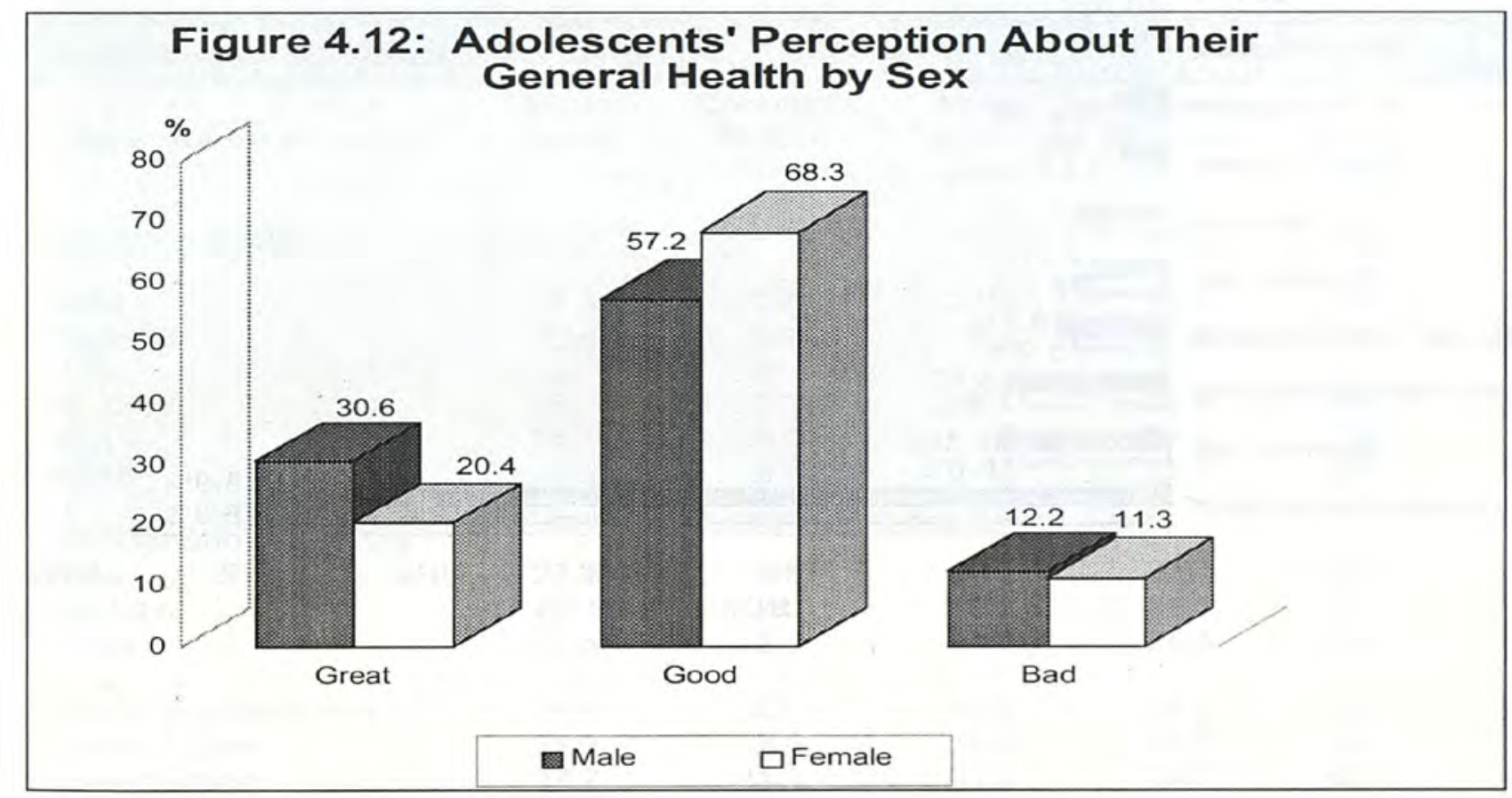

\footnotetext{
${ }^{6}$ The gamma correlation is the appropriate statistic to test for association between 2 nominal variables. The statistic indicates both the magnitude and the direction of association between the variables.
} 


\section{Perceived Health Problems Among Adolescents}

Health problems during adolescence can influence both nutritional status and overall wellbeing. Some health problems among adolescents can be of organic origin and others can originate from stress. The ASCE survey collected information from the responsible adults interviewed on their perceptions of the various health problems experienced by all adolescents $^{7}$ in their households during the month prior to the interview. One-fifth of all adolescents $(20.7 \%)$ were reported to have had an illness during the previous month. As shown in Figure 4.13, the most frequent illness experienced by adolescents are the common cold and cough, with nearly 50 percent of both sexes experiencing this type of illness during the previous month.

Other common ailments include abdominal pain, gastrointestinal complaints, vision/ear/tooth complaints, and rheumatic pain, though these were reported at much lower levels than the common cold and cough. There are no gender differences in the types of illness experienced. However, there are small gender differences in the levels of gastrointestinal complaints, allergies, headaches, and rheumatic pains. Allergies are experienced by 4 percent of adolescents, with boys experiencing them more than girls.

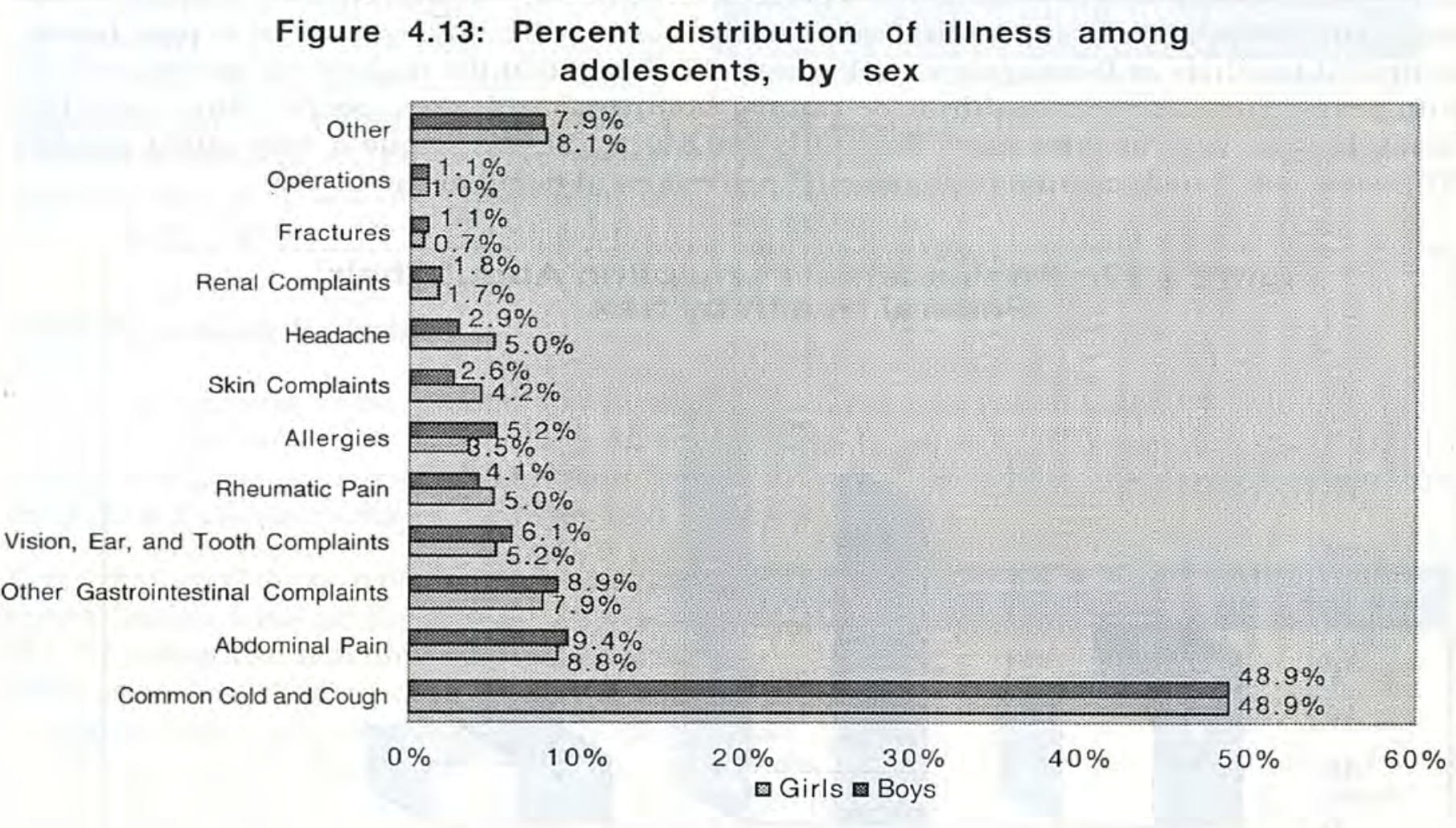

\footnotetext{
${ }^{7}$ Adults were asked to report on all adolescents in their household; thus the $\mathrm{N}$ for these particular findings includes all adolescents in the households of the sampled adolescents.
} 
Physical ailments such as headaches, abdominal pains, and rheumatic pains (pains or aches in the joints) are common complaints among adolescents. These conditions may be of organic origin or may be induced by anxiety and stress that characterize the period of adolescence. Four percent of all adolescents suffered from headaches, as reported by parents, during the month prior to interview, while 10 percent suffered from abdominal pains and 5 percent from rheumatic pains. In general, girls experience these complaints more than boys. Adolescents from the low socioeconomic stratum and those who live in rural areas and in Upper Egypt suffer more from all of these complaints. These higher levels are probably explained by the higher levels of anemia and parasitic infections among these groups, described earlier in this chapter.

\section{Perceptions of Disabilities and Chronic Diseases}

Disabilities among adolescents can interfere with normal life processes. Poor visual acuity, communication disorders, mental retardation, motor impairment, and chronic diseases can interfere with education and scholastic achievement and can lead to school drop out, and minimize opportunities to participate in the labor force. Moreover, disabilities may affect an adolescent's overall health and psychological state. In this survey, responsible adults were asked about disabilities and chronic diseases among the adolescents in their families. It is important to note that the following figures reflect parents' reported perceptions of disabilities and chronic disabilities and are not an accurate measure of actual prevalence. The level of disabilities and chronic diseases perceived among adolescents was reported by parents to be 4 percent. Table 4.23 shows the percent distribution of these adolescents according to disability.

\begin{tabular}{|c|c|c|c|c|c|c|}
\hline Background Variables & $\begin{array}{l}\text { Visual } \\
\text { acuity } \\
\text { problems }\end{array}$ & $\begin{array}{l}\text { Commun- } \\
\text { icative } \\
\text { disorders }\end{array}$ & $\begin{array}{c}\text { Motor } \\
\text { impair- } \\
\text { ment }\end{array}$ & $\begin{array}{l}\text { Chronic } \\
\text { diseases }\end{array}$ & $\begin{array}{l}\text { Mental } \\
\text { retard- } \\
\text { ation }\end{array}$ & Total No. \\
\hline Overall prevalence & 29.7 & 16.4 & 20.6 & 26.3 & 6.7 & 669 \\
\hline Male & 27.4 & 17.0 & 23.0 & 25.3 & 7.3 & 383 \\
\hline Female & 32.9 & 15.7 & 17.5 & 27.6 & 5.9 & 286 \\
\hline $10-12$ & 23.1 & 22.7 & 16.4 & 32.0 & 5.8 & 225 \\
\hline $13-15$ & 36.1 & 10.0 & 21.5 & 24.2 & 7.8 & 219 \\
\hline $16-19$ & 30.2 & 16.4 & 24.0 & 22.7 & 6.7 & 225 \\
\hline Socioeconomic status & & & & & & \\
\hline -Low & 22.1 & 19.8 & 29.3 & 23.4 & 5.4 & 222 \\
\hline -Middle & 27.1 & 17.0 & 18.2 & 29.6 & 8.1 & 247 \\
\hline -High & 41.5 & 12.0 & 14.0 & 25.0 & 6.5 & 200 \\
\hline Urban governorates & 29.1 & 8.7 & 25.2 & 30.7 & 5.5 & 127 \\
\hline Lower Egypt & 31.9 & 15.6 & 18.2 & 25.7 & 8.5 & 306 \\
\hline Upper Egypt & 27.2 & 21.1 & 21.3 & 24.7 & 5.1 & 235 \\
\hline Urban & 33.6 & 10.6 & 20.4 & 27.5 & 7.5 & 265 \\
\hline Rural & 27.2 & 20.3 & 20.8 & 25.5 & 6.2 & 404 \\
\hline
\end{tabular}


Visual acuity problems constitute about 30 percent of the disabilities found among adolescents. One-third of girls and slightly more than one-quarter of boys suffer from this problem. There is a positive association between problems with visual acuity and socioeconomic level; adolescents from the high socioeconomic stratum have significantly higher levels of these problems than those in the lower and middle strata. This relationship probably reflects the fact that adolescents in higher socioeconomic classes are more able and more likely to have their vision screened and their visual acuity problems diagnosed and treated (for example, with glasses). Troubles with visual acuity occur more in urban areas than rural ones, and are slightly more common in Lower Egypt than in urban governorates or Upper Egypt.

Communicative disorders account for 16 percent of the disabilities identified among adolescents in Egypt. An inverse relationship exists between communicative disorders and socioeconomic status; that is, as socioeconomic status increases, the incidence of these disorders decreases. A significant difference also exists between urban and rural areas; adolescents from rural areas suffer twice as much from these problems as those from urban areas. There is also variation by region; the highest proportion of adolescents with hearing/speaking difficulties live in Upper Egypt as compared to those in the urban governorates $(22.1 \%$ compared to $8.7 \%$ ). These differences may reflect a lack of awareness among certain groups of the consequences of recurrent, untreated ear and nose infections in early childhood, or the inability to access or afford treatment for such conditions.

Motor impairment accounts for one-fifth of the disabilities among Egyptian adolescents. (The causes of motor impairment were beyond the scope of the present study.) A significant difference exists among adolescents in different socioeconomic strata. Adolescents from households of low socioeconomic status suffer from more motor disabilities $(29.3 \%)$ than those from middle and high status households (18.2\% and $14.0 \%$ respectively). Adolescents in urban governorates exhibit more motor disabilities than those in Upper Egypt and Lower Egypt, while no differences exist between adolescents in urban and rural areas.

Chronic diseases, such as diabetes mellitus and chronic kidney and heart conditions, constitute 26 percent of the disabilities reported among adolescents. Adolescents from the middle socioeconomic stratum, and the urban governorates are more affected by these diseases.

Mental retardation comprises just 7 percent of all disabilities reported. Adolescents from middle socioeconomic stratum suffer more from this condition than those from the high or low stratum, and those from Lower Egypt more than those in urban governorates and Upper Egypt.

\section{HEALTH SEEKING BEHAVIOR}

\section{Overview of Health Service Providers Available to Adolescents}

Generally speaking, health services in Egypt are provided under four primary institutions: the Ministry of Health outlets $(\mathrm{MoH})$; the Health Insurance System (HIS); university clinics and hospitals under the Ministry of Higher Education; and the private sector. 
Following the enactment of Law 99 in 1992, Egypt's more than 12 million school students now fall under the umbrella of the HIS and are served by a special division called the School Health Insurance System (SHIS). As a large portion of adolescents in the ASCE study are currently enrolled in school, this chapter will give special attention to the SHIS.

The SHIS is arranged in three levels: the primary care doctor, the specialists, and the consultants. The primary care doctor is the gatekeeper to the next level, the specialists, who refer students to consultants if additional care is necessary. The primary care doctor works in one or more schools, while specialists are present in HIS clinics and hospitals located centrally in towns. In some remote rural areas, the rural health unit doctor works for the SHIS as well as for the $\mathrm{MoH}$. (Additionally some doctors have private clinics). School doctors offer both preventive and curative services while only curative services are offered at the other levels. Moreover, the list of drugs available for the SHIS is different at each level, being most restrictive at the primary level and least restrictive at the consultant level in hospitals. Students have access to the SHIS only through schools and pay a nominal amount annually to receive a valid SHIS identification card.

The MoH services are accessible to all population groups through its primary, secondary, or tertiary levels. Referral systems exist in the governmental system but a primary care doctor does not necessarily serve as a gatekeeper to the other levels. All service outlets are open to any client. The list of essential drugs available at the different service levels is not as clear as in the SHIS. A student covered by the SHIS is still able to use the MoH outlets at no cost.

In addition, university clinics and hospitals are available to all population groups. Older adolescents, if enrolled in institutions of higher education, might also be covered by the health insurance for university students. Furthermore, older adolescents may hold governmental jobs (e.g., nurses work immediately after graduating from secondary technical schools), and would thus be covered by the HIS for government employees.

The private sector has no structure or levels of care and is accessible to anyone who can pay.

This brief description of health service providers in Egypt provides a context for interpreting the responses of parents and adolescents to survey questions about their utilization of health services.

\section{Health Services Utilization}

In medical literature, three aspects of health services utilization are investigated: availability, accessibility, and acceptability, from both the users' and the providers' perspective. The ASCE data shed light on health services utilization from the user's perspective only.

Nearly two-thirds of the adolescents surveyed are currently enrolled in schools below the university level and have potential access to the SHIS. Both adolescents and their parents were asked: Where does your child usually go when ill? The question was formulated to allow respondents to list all sites usually approached; this is important in order to capture the variety of service utilization scenarios among users. For example, a child may go to a private doctor for an exam and then go to the SHIS for treatment or alternatively, to a $\mathrm{MoH}$ clinic first and then, if not cured, to another provider. Table 4.24 presents the responses of parents after collapsing all responses into 4 health care provider categories. 
The private sector is reported as the most frequently approached, with 76 percent of parents reporting the use of this provider by their adolescents. Forty-nine percent of parents report

\begin{tabular}{|c|c|c|}
\hline & $\mathbf{N}$ & $\%$ \\
\hline Private Doctor & 4612 & 76.2 \\
\hline Health Insurance System & 2095 & 35.2 \\
\hline Ministry of Health outlets* & 2987 & 49.0 \\
\hline NGO/Mustawsaf & 427 & 7.0 \\
\hline
\end{tabular}

* University Hospitals and Clinics are included with the $\mathrm{MoH}$ outlets that their adolescents use the $\mathrm{MoH}$ outlets and 35 percent report that they utilize the HIS. The least frequently reported provider used by adolescents is the NGO clinics or mustawsafat; only 7 percent of parents report that their adolescents use these facilities.

Nearly 42 percent of parents report that their adolescents usually approach only one provider during an illness and 46 percent use two providers. The median number of service providers visited is two; that is, half of the population visits two or more providers (table not shown).

Table 4.25 presents the responses of both parents and adolescents regarding the sites usually approached for service and, if an adolescent was ill during the previous month, which provider was utilized, if any (called actual use in this section for the sake of clarity).

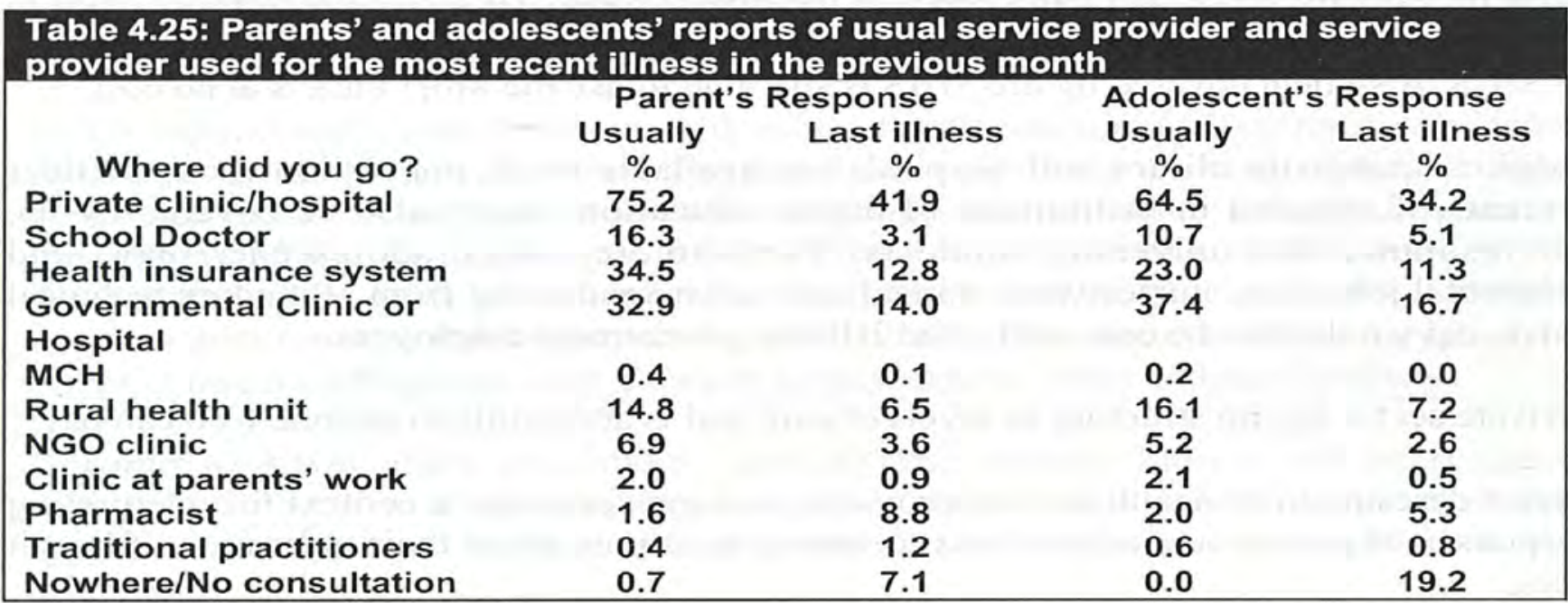

Several patterns emerge from this data. First, there is a large difference in the pattern of 'usual' use and 'actual' use during the most recent illness during the previous month. In particular, both parents and adolescents report much higher usual use of private sector providers than actual use and much lower usual use of pharmacists compared to actual use. In fact, in reporting by both parents and adolescents, adolescents are at least half as likely to have actually used the provider that they report usually using, for all providers with the exception of pharmacists. The data do not permit us to comment on the reasons behind these differences; for example, we do not have information on the severity of the most recent illness, which would have a large impact on the health care seeking behavior as well as on the service provider selected (if any). However, the differences may indicate some sensitivity among the respondents to the perceptions of the interviewer and who reported what they felt to be 'appropriate' answers when describing usual health service use patterns.

Regarding the actual utilization of services, parents and adolescents differ significantly in reported patterns of use. Parents tend to report actual use of the private sector at higher levels 
than adolescents, 42 percent compared to 34 percent. Further, 19 percent of adolescents report that they did not go anywhere when they are ill, while only 7 percent of parents report this. However, the relative ranking of the service provider types is maintained between the groups; that is, both groups report utilizing the private sector, $\mathrm{MoH}$ facilities, and HIS outlets in the same order.

When applicable, the survey also asked parents about health service utilization if they had more than one ill adolescent during the previous month. Table 4.26 presents a number of interesting findings from this data. First, the use of private doctors declines with each event, from 44 percent reporting their use with the first ill adolescent to 26 percent for the third adolescent. There is a corresponding increase in the reported use of pharmacists, from 8 percent for the first ill adolescent to 15 percent for the third. Finally, as the number of ill adolescents increases, more parents report that they did not approach a provider for service, from 7 percent for the first adolescent to 14 percent for the third.

\begin{tabular}{|c|c|c|c|}
\hline $\begin{array}{c}\text { Which service provider was } \\
\text { approached? }\end{array}$ & $\begin{array}{l}\% \text { First ill } \\
\text { adolescent } \\
(\mathrm{N}=2435)\end{array}$ & $\begin{array}{l}\% \text { Second ill } \\
\text { adolescent } \\
(N=475)\end{array}$ & $\begin{array}{l}\% \text { Third ill } \\
\text { adolescent } \\
(\mathrm{N}=103)\end{array}$ \\
\hline Private clinic/hospital & 44.4 & 32.9 & 25.8 \\
\hline School doctor & 2.9 & 2.6 & 4.8 \\
\hline HIS & 12.8 & 14.2 & 15.1 \\
\hline Government clinic/hospital & 13.7 & 14.9 & 10.2 \\
\hline $\mathrm{MCH}$ & 0.0 & 0.2 & 0.0 \\
\hline Rural health unit & 6.6 & 6.2 & 7.0 \\
\hline NGO clinic & 3.6 & 3.8 & 3.8 \\
\hline Clinic at parents' work & 0.7 & 2.0 & 1.6 \\
\hline Pharmacist & 7.7 & 13.1 & 14.5 \\
\hline Nurse & 0.0 & 0.0 & 1.1 \\
\hline Traditional practitioners & 1.0 & 1.4 & 2.7 \\
\hline Nowhere/Self-treatment & 6.5 & 8.9 & 14.2 \\
\hline
\end{tabular}

These observations may be explained by the fact that larger families with greater health care needs may be less inclined to spend money on expensive private services. In addition, having more than one ill adolescent in a short period of time is more likely to occur with acute infections spread among siblings. Since cost is one of the prohibitive features of the private sector, parents can save money by purchasing drugs directly from the pharmacy to treat the second, third, and fourth adolescents instead of seeking consultation with doctors for each.

\section{The SCHOOL Health InSURance System}

As previously mentioned, the SHIS has a primary care clinic inside each school. The number of students in the school determines whether the clinic and doctor responsible is responsible for one school or more than one. If the clinic is to serve two nearby schools, the clinic will be situated in the primary school to make access easier for the younger students. Adolescents in school were asked whether they had a doctor or a nurse available at school; 70 percent report in the affirmative. 
As previously mentioned, the SHIS is available to adolescents enrolled in schools. However, in order to use the system, students must pay 4 LE each fall, after which they receive an identification card to prove their eligibility to use the system. Adolescents were asked whether they have a health insurance identification card; 88 percent of adolescents in school report having one (Table 4.27).

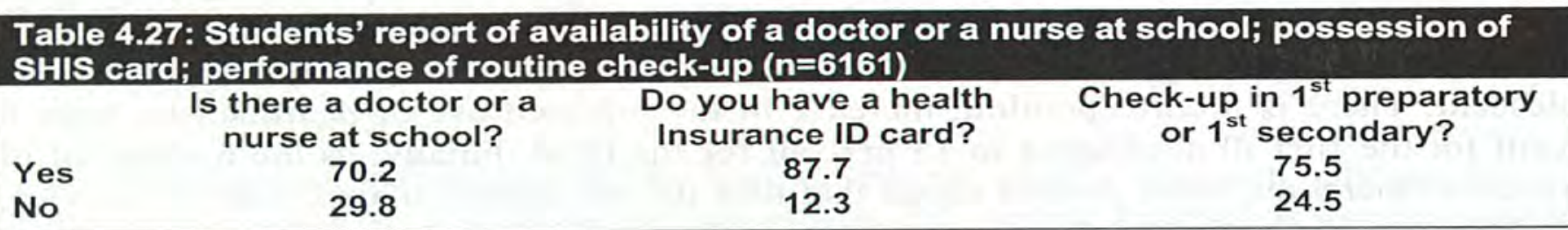

Twelve percent do not have an identification card, possibly due to the students' inability to pay (a client-side reason) or delay in the issuance of the cards (a provider-side reason). Whatever the reason, 12 percent of adolescents who are enrolled in school cannot benefit from the SHIS, while the MoH target is to benefit 100 percent of students. However, threequarters of adolescents who are eligible for an exam report that they have had one.

\section{Adolescents' Reports on Some Preventive and Curative Aspects of the SHIS}

The SHIS provides preventive services as well as curative services. A physical exam for students upon entry into the first preparatory and first secondary is part of this program. Table 4.28 presents adolescents' reports on which preventive procedures were performed during their clinical checkups.

Most of the tests were done in approximately 50 percent of the checkups, with the exception of urine analysis, which was reported more frequently. Height measurement was performed least frequently, with 43 percent of adolescents reporting that this was done. This data suggests that the SHIS is not being as effective as it could be in screening for various medical conditions (such as anemia) among adolescents.
Table 4.28 Procedures performed during clinical check-up, reported by adolescents

Did the doctor:

Do a complete clinical checkup with the stethoscope?

Check vision?

Check your teeth?

Have urine analysis?

Have a stool analysis?

Measure your weight?

Measure your height?

\begin{tabular}{cc}
$\begin{array}{c}\% \text { who } \\
\text { had test } \\
54.4\end{array}$ & $\begin{array}{c}\text { No. } \\
619\end{array}$ \\
& \\
50.8 & 574 \\
45.3 & 512 \\
73.2 & 826 \\
47.5 & 536 \\
57.7 & 652 \\
42.9 & 485 \\
\hline
\end{tabular}

The curative services provided by the SHIS are as important as the preventive. Determining how often these services are being utilized by adolescents helps the providers to estimate the work load for school doctors and specialists and assists in planning. Adolescents were asked: "How many times since the beginning of the school term have you been to the school clinic or been referred to a specialist?" (Table not shown) The median number of visits was 0 and the mean was 1.15 visits. The most striking finding is that more than 52 percent of adolescents enrolled in school report that they have not visited the clinic since the start of the school year. Forty-eight percent have made between 1 and 4 visits since the start of the school year. 


\section{User Satisfaction}

The ASCE survey asked both parents and adolescents about their satisfaction with the available health services, as this is an important indicator for providers. Among the adolescents who report having made at least one visit to the SHIS facilities, 85 percent say they are satisfied with the clinical services offered.

\section{Parents' Perspectives on the SHIS}

A large number of parents, 88 percent, have adolescents currently in school. Fifty-three percent of those parents report that their adolescents utilize the SHIS. The parents of adolescents who do not use the system report being dissatisfied mainly with the providers; that is, 80 percent name reasons such as the unavailability of the doctor, provider carelessness, dissatisfaction with the drugs prescribed, and others.

The remaining 20 percent of non-users name client-related reasons, such as the loss of the identification card, lack of time, or a misunderstanding of the adolescent's eligibility.

Table 4.29 shows that non-use of the system was reported more by female parents of adolescents, rural residents, and those in the high socioeconomic stratum.

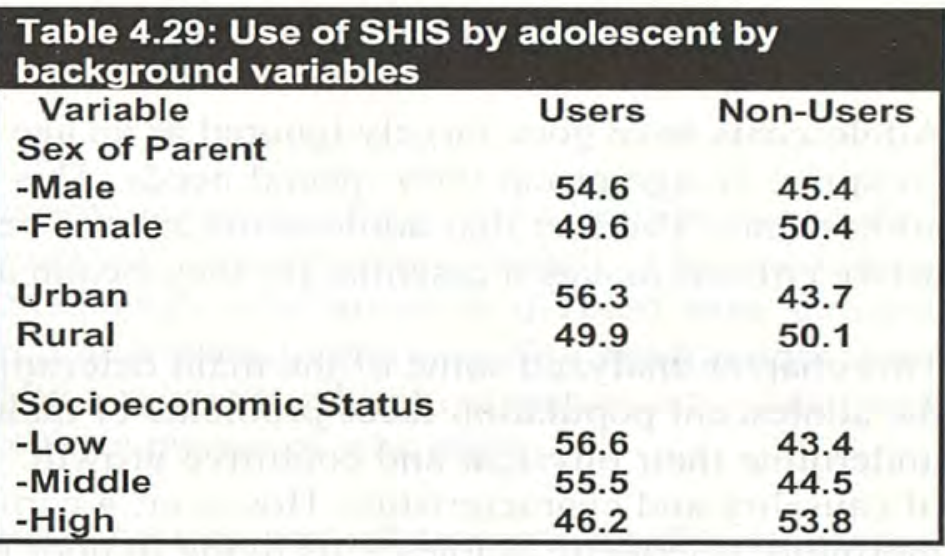

Parents reporting use of the SHIS by their adolescent(s) were asked about their satisfaction with the services provided (Table 4.30). Nearly three-quarters, or 73 percent of parents report being satisfied. This level of satisfaction varies by certain background variables. For example, more satisfaction with the SHIS is found among men, among those in lower socioeconomic strata, and among those who live in Upper Egypt.

\begin{tabular}{|lcc|}
\hline \multicolumn{3}{|c|}{$\begin{array}{l}\text { Table 4.30: Satisfaction with SHIS of parents who report } \\
\text { current use by their adolescent, }\end{array}$ by background variables } \\
\hline Variable & \% Satisfied & \% Dissatisfied \\
TOTAL & 72.7 & 27.3 \\
Female & 69.7 & 30.3 \\
Male & 77.8 & 22.2 \\
Socioeconomic Status & & \\
-Low & 77.4 & 22.6 \\
-Middle & 73.6 & 26.4 \\
-High & 68.1 & 31.9 \\
Rural & & \\
Urban & 72.3 & 27.7 \\
Urban Governorates & 73.9 & 26.1 \\
Lower Egypt & 70.3 & 29.7 \\
Upper Egypt & 71.6 & 28.4 \\
\hline
\end{tabular}


In sum, the availability of different types of health care providers in the market without one umbrella that joins them produces a utilization pattern that can best be described as "mix and match." The private sector is the provider most frequently utilized for adolescent health care, a sector that has no structure, is unregulated in terms of prices, and through which interventions would be impossible. The SHIS is being used by some of the population and has produced a relatively high level of satisfaction among those who use it. However, more than half of the enrolled students report that they have not utilized the SHIS at all during the previous school year. These low levels of use appear to be the result of dissatisfaction with the service providers, a finding that is consistent with other research on the impact of the quality of care on service utilization. However, given the relatively recent introduction of the system, some problems are to be expected. Nonetheless, the SHIS has a clear place in the health service system, as a supplier of both curative services and preventive interventions. Thus it should be developed further, with more attention paid on increasing rates of utilization and user satisfaction.

\section{DISCUSSION AND POLICY IMPLICATIONS}

Adolescents have gone largely ignored as an age group and few have acknowledged that they comprise an age group with special needs. This has had a profound impact on the health of adolescents. The fact that adolescents are the next immediate pool of parents, workers, and active citizens makes it essential for their health and well-being to be as good as possible.

This chapter analyzed some of the main determinants of adolescent health in Egypt. Overall, the adolescent population faces problems of malnutrition, anemia, and parasitic diseases that undermine their physical and cognitive growth. All of these diseases have different patterns of causality and characteristics. However, a common denominator along all these sources of morbidity is evident. Adolescents living in poor households and in rural areas, without access to public water supply and sanitation facilities are disproportionately affected by retardation of physical growth and sexual development, malnutrition, stunting, anemia, and parasitic diseases. They are also less likely to have access to the information and services that could help mitigate the impact of these environmental factors. In general, adolescents in poor households and those living in rural areas seem to suffer the major health and nutritional problems of their age.

However, the fact that anemia prevalence cuts across socioeconomic status indicates that in addition to insufficient availability of iron-rich foods and the existence of other habits (such as tea drinking) that could interfere with iron absorption, perhaps adolescents and/or their parents are not making healthy food choices. Consequently, nutrition education campaigns with carefully defined audiences and targeted messages would be one way to address these nutrition problems. The government should also consider investing in food fortification to address this widespread problem. The nutrition behavior data presented in this chapter, coupled with forthcoming data from the administration of a 24 -hour food recall instrument would be valuable for identifying possible foods for fortification.

To face the challenge of improving adolescent well being, long-term investments in health are needed. Moreover, a serious commitment to support poor families to improve their living conditions is critical to improving the health status of the population. 


\section{Education Profile of Egyptian Adolescents}

The 1971 Egyptian Constitution emphasized the right of all Egyptians to free education at all levels, including university, regardless of gender, geographic location, or socioeconomic status. Education laws issued in 1981 and revised in 1988 govern the implementation of this constitutional right.

This chapter examines the trends in access to education in Egypt and the quality of this education. Differentials in scholastic achievement by gender and socioeconomic status are investigated. Adolescents' assessments of their school experiences are explored together with the social context of education. Finally, the role of school as a socializing agent is highlighted.

\section{ACCESS TO EDUCATION}

The education system in Egypt comprises two pre-university phases, the compulsory phase of basic education (five years of primary and three years of preparatory) followed by three years of noncompulsory secondary education. Secondary education is divided into general secondary and vocational secondary (commercial/industrial/agrarian). The general education system, both public and private, is paralleled by a religious education system introduced and supervised by Al-Azhar. It maintains the same three phases of education.

Table 5.1 displays the distribution of in-school children and adolescents aged 6-19 by the different stages of both education systems. Data collected from every sampled household regarding the educational status of individuals in this age group is utilized. Forty-seven percent of all students enrolled are in general primary education, 24 percent in preparatory, and 7 percent in general secondary. In addition, 12 percent are enrolled in vocational secondary. Students enrolled in Al-Azhar schools at all stages constitute only 6 percent of all students. 


\begin{tabular}{llcc|}
\hline \multicolumn{4}{l}{ Table 5.1: Percent distribution of in-school children and adolescents aged 6-19 by } \\
selected background variables & Boys & Girls & Total \\
\hline General education & 46.9 & 47.1 & 47.0 \\
Primary & 23.4 & 24.5 & 23.9 \\
Preparatory & 6.1 & 7.3 & 6.7 \\
Secondary & 76.4 & 78.9 & 77.6 \\
Total general education & 12.5 & 11.6 & 11.8 \\
Vocational education & & & \\
\hline Al-Azhar education system & 4.3 & 3.0 & 3.7 \\
Primary & 1.9 & 1.5 & 1.7 \\
Sreparatory & 1.1 & 0.5 & 0.8 \\
Total Al-Azhar & 7.3 & 4.0 & 6.2 \\
Higher education & 3.8 & 4.7 & 4.2 \\
Total & 9,018 & 7,756 & 16,774 \\
\hline
\end{tabular}

\section{IN-SCHOOL ADOLESCENTS: ENROLLMENT AND RETENTION}

Data from the ASCE survey provide a cross-sectional portrait of school enrollment in the school year 1996/1997. Enrollment rates are defined as the ratio of individuals of a particular age who are enrolled in school in a given year to all individuals of that particular age. Despite the fact that school entry age in Egypt is 6 years, only 41 percent of all Egyptians are enrolled by that age. The rate increases to 85 percent among 7-year-olds and-stabilizes at a flat peak around 90 percent in the age group 8-11 years. Enrollment rates across successive ages decline significantly after age 11 , coinciding with termination of the first phase of basic education. At age 14, which signals the beginning of the transition from compulsory basic education to noncompulsory secondary education, the enrollment rate is 73 percent. A final sharp drop in enrollment from 57 percent to 39 percent occurs between the ages of 17 and 18 years by the end of the secondary stage and the transition to university.

This pattern of school enrollment holds for both sexes in the five main geographic regions and among all socioeconomic classes. However, great disparities in the level of enrollment exist. The most disadvantaged groups are girls in the low and middle socioeconomic categories, girls in Upper Egypt (both urban and rural) and rural Lower Egypt, and boys in the low socioeconomic category. Household socioeconomic status bears a significant impact on enrollment of its school-age members. Low socioeconomic status of the household has a far more serious impact on girls than on boys.

Figures 5.1-5.4 below show the cross-sectional portrait of enrollment of individuals aged 6-19 years in 1997. Each point on the curve represents the end result of the experience of individuals reporting a certain age who were ever enrolled and who continued their education up to the date of the survey. The nation's dream to achieve universality of education has been partially fulfilled in the primary stage. Enrollment rates in primary schools among boys and girls in the urban governorates and urban Lower Egypt and also among boys in the high and middle socioeconomic categories are above 95 percent. 
Figure 5.1

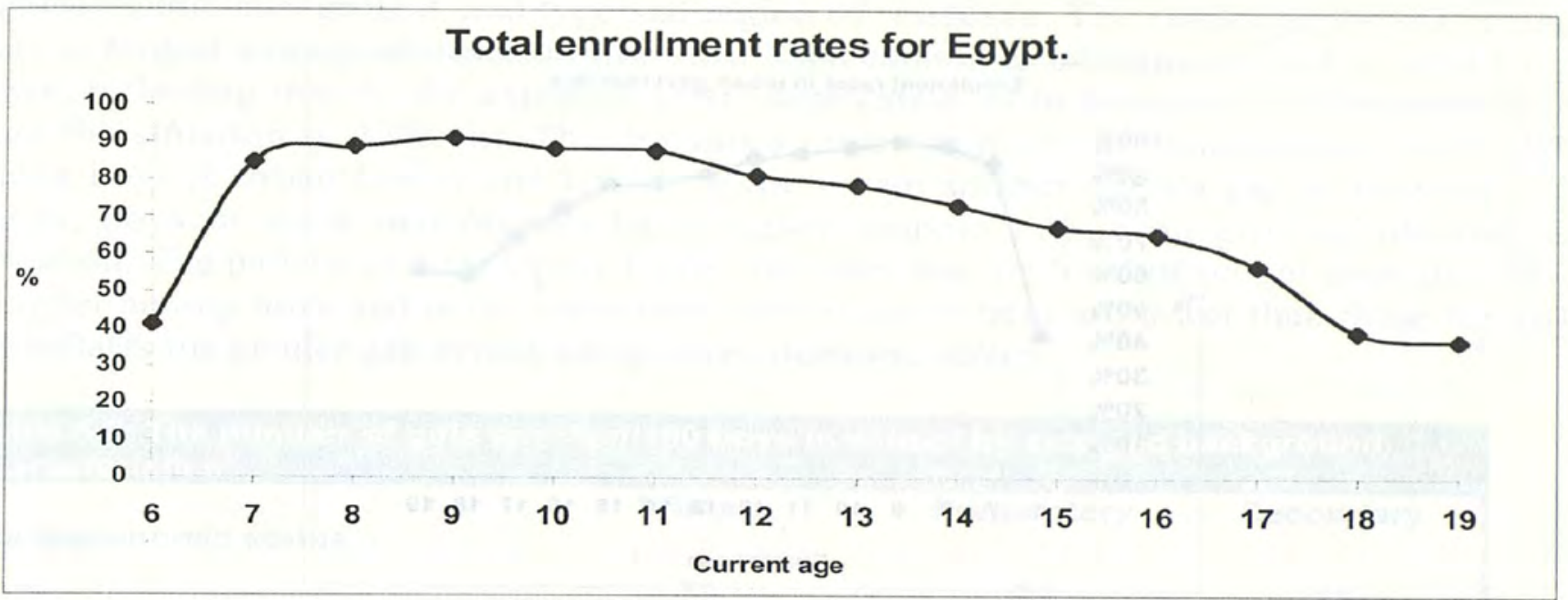

Figure 5.2

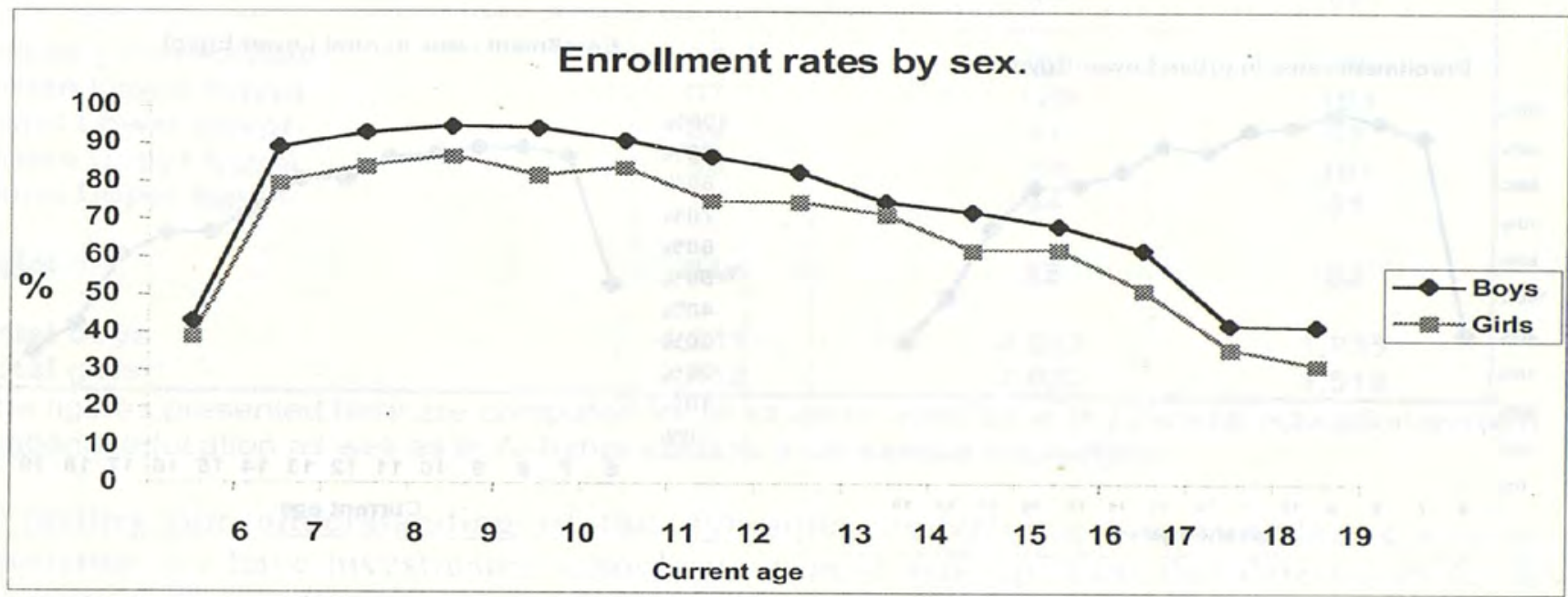

Figure 5.3

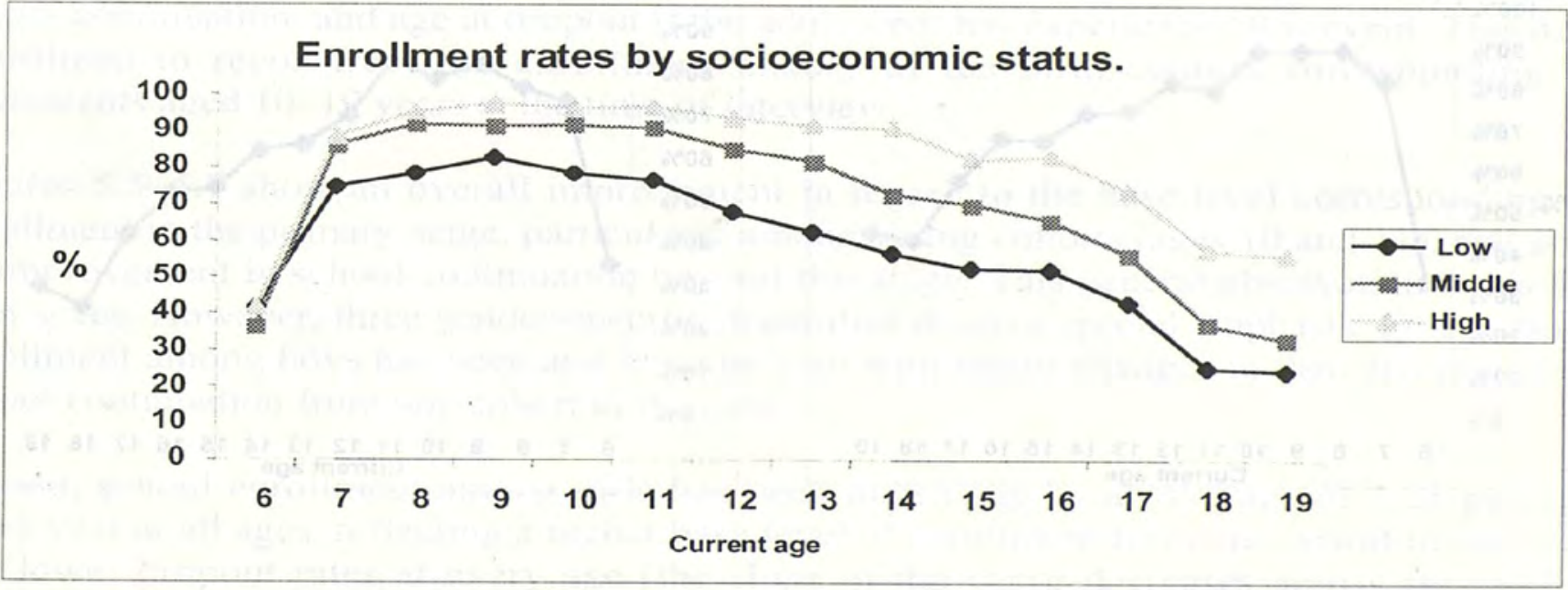


Figure 5.4
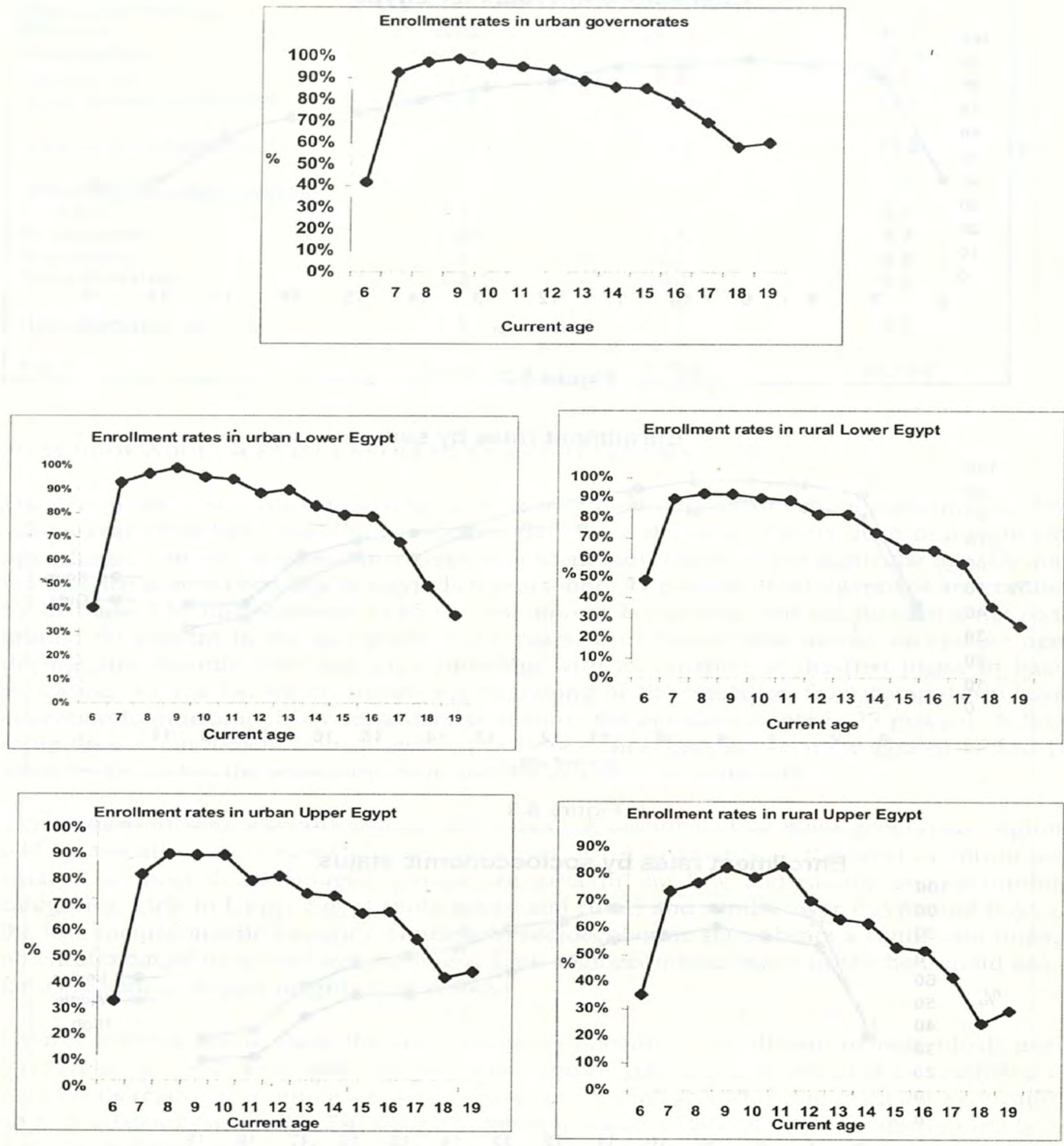
Table 5.2 highlights the gender gap in education in Egypt as of the school year 1996/1997. It provides the number of girls enrolled per 100 boys in school by stage of education, socioeconomic background, and type and region of residence. The gender gap in the primary stage is largest among adolescents from low socioeconomic background and in rural Upper Egypt, reflecting mainly the extent of girls' deprivation from education. In the preparatory stage the situation is different. The dynamics underlying school continuation, particularly among boys in urban Lower and Upper Egypt, create another gender gap in favor of girls; that is, boys in these two regions have higher dropout rates than girls at this stage of education. The pattern in rural Upper Egypt indicates that the level of school ever-attendance is higher among boys and at the same time their dropout rates are lower than those for girls; this inflates the gender gap across successive education stages.

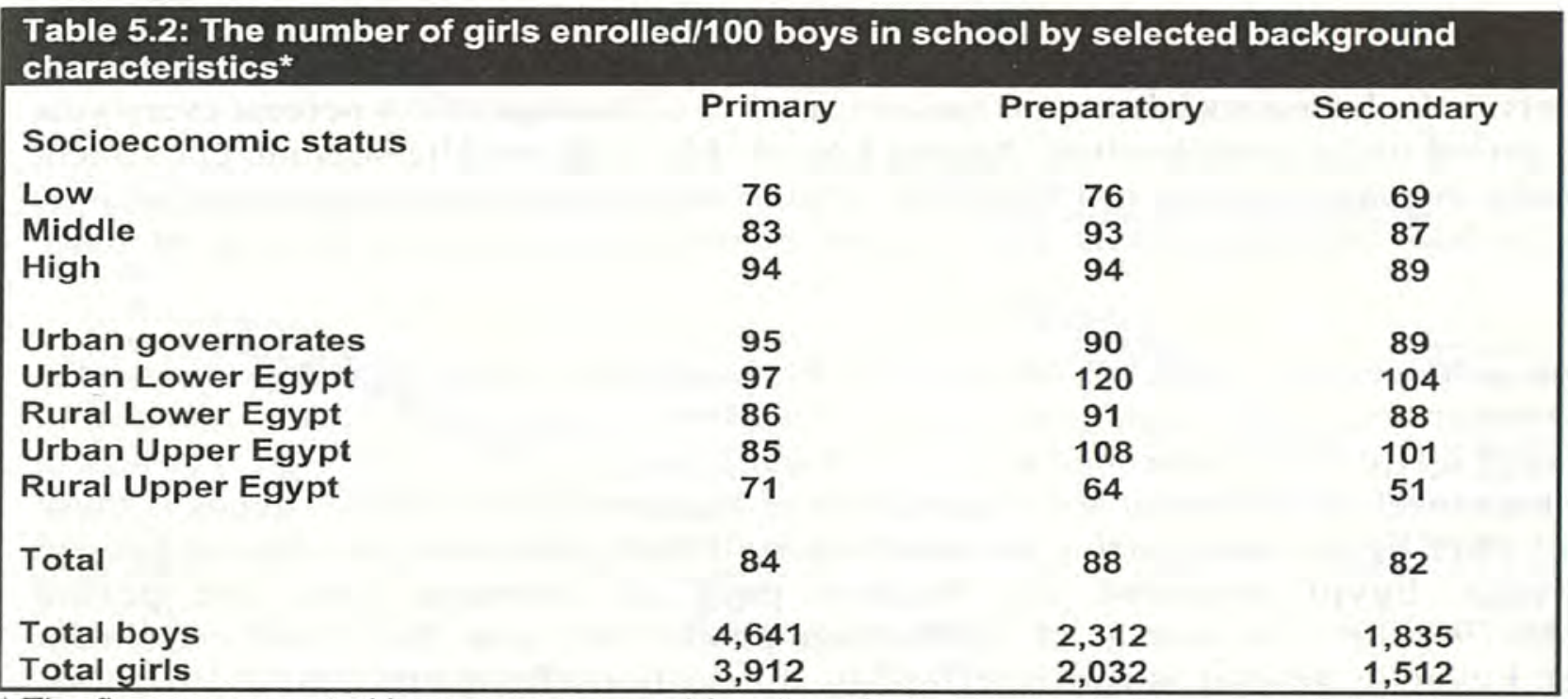

* The figures presented here are computed for all students enrolled in the general education system, vocational education as well as in Al-Azhar schools in all sample households.

To further our understanding of the dynamics underlying this cumulative education experience, we have investigated school retention, a major process that determines the level and pattern of enrollment of each cohort. The individual questionnaire used in the ASCE survey provides useful information concerning school ever-attendance, dropout as opposed to school continuation, and age at dropout if the adolescent has experienced this event. This data is utilized to reconstruct the enrollment history of ten birth cohorts corresponding to adolescents aged 10-19 years at the time of interview.

Figures 5.5-5.7 show an overall improvement in regard to the base level corresponding to enrollment in the primary stage, particularly among young cohorts (ages 10 and 11), and also an improvement in school continuation beyond this stage. This general observation holds for both sexes. However, three gender-specific disparities deserve special emphasis. First, school enrollment among boys has been and remains high with minor changes in their likelihood of school continuation from one cohort to the next.

Second, school enrollment among girls has been increasing by an average of 1.25 percent every year at all ages, reflecting a higher base level of enrollment from one cohort to the next and lower dropout rates at every age (the slope of the curve decreases across successive cohorts). However, a gap of about 10 percentage points exists between enrollment of boys and girls for all cohorts and at all ages. 
Third, school entry for girls seem to be particularly sensitive to contextual factors and fluctuations in the economy. Despite significant improvements in school enrollment of girls, two cohorts of girls in particular seem to have substantially less advantageous positions, those at the ages of 15 and 12 in 1997 . These two cohorts met the criterion of school entry age in $1987 / 1988$ and 1990/1991, respectively, two periods of major macro-level events that had significant bearing on Egyptian society. The first was the effective implementation of the structural adjustment program and economic reform measures in 1987/1988 that encompassed the reintroduction of school fees as a cost recovery measure. The second was the Gulf War in 1990/1991 with its consequential repercussions exacerbated by a massive return migration from both Iraq and Kuwait. Interestingly, the observation concerning the two cohorts aged 15 and 12 in 1997 holds also among adolescent boys and girls in households in the low socioeconomic category.

If we overlook those two particular cohorts aged 12 and 15 in 1997, enrollment of adolescents in the lowest social stratum has increased by an average of 1.4 percent every year over the period under consideration. Among households in the middle stratum, enrollment substantially increased starting in 1985/1986. Among adolescents in the high socioeconomic category, school enrollment was and remains nearly universal until the end of basic education.

Enormous achievement in school continuation beyond basic education is reported in the urban governorates. Eighty-eight percent of 15 and 16 year-olds in this region and also in urban Lower Egypt are still enrolled in school. Rural Lower Egypt has made great strides in both the base level of enrollment and continuation rates, showing very similar trends to those in urban Lower Egypt, emphasizing the completion of basic education. Enrollment rates in rural Upper Egypt recorded the highest pace of increase over the period 1983/1984-1996/1997, an average of 2 percentage points every year. Yet school enrollment in Upper Egypt in general is characterized by fluctuations from one year to the next, particularly in urban Upper Egypt. 

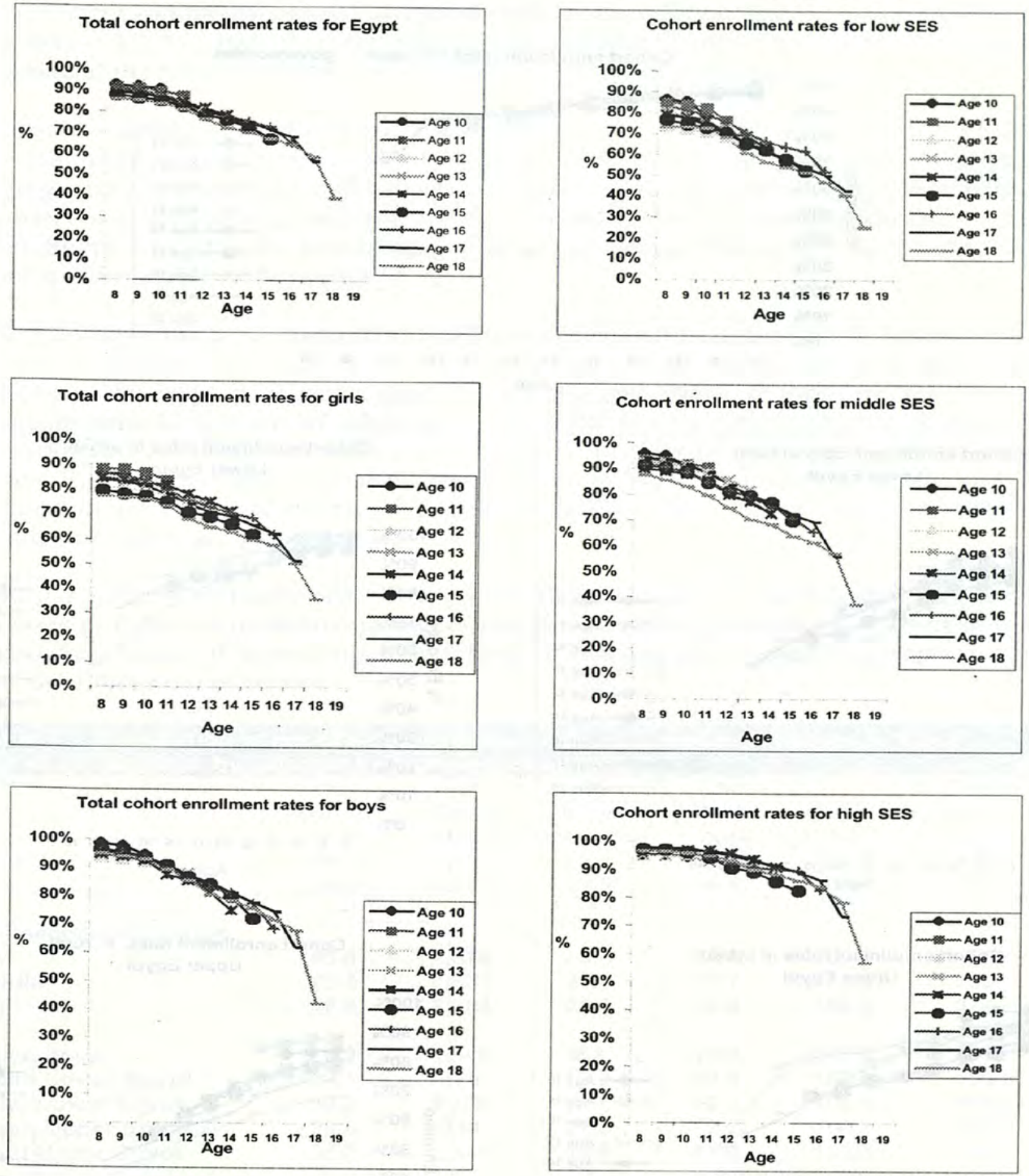
Figure 5.7 Cohort enrollment rates by region of residence

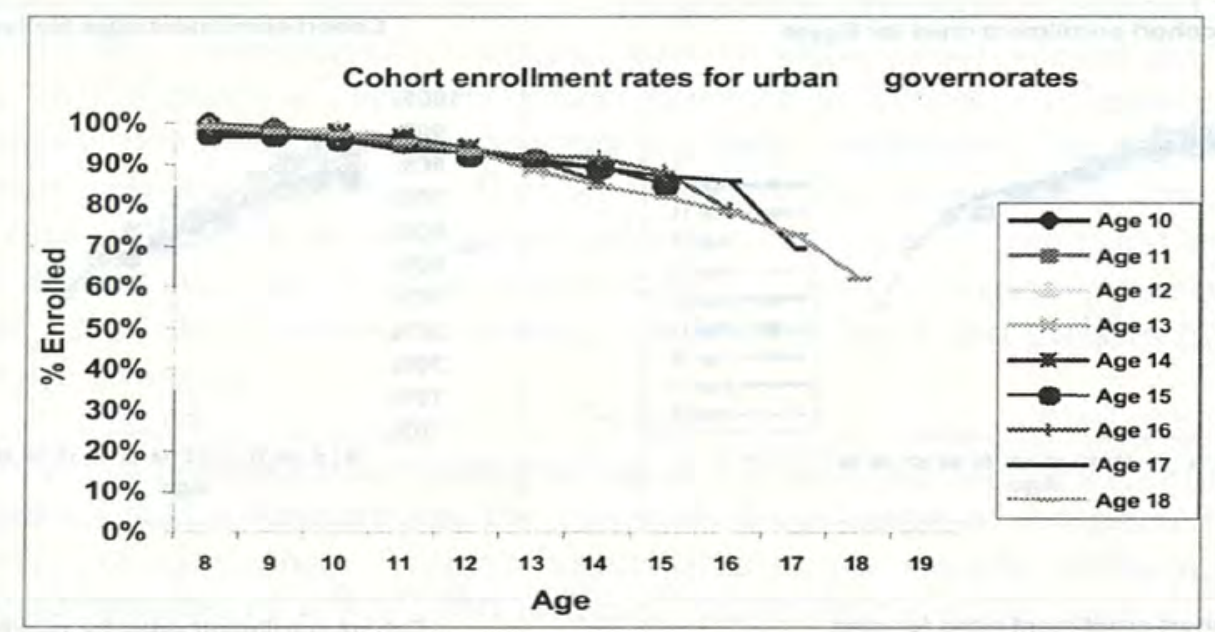

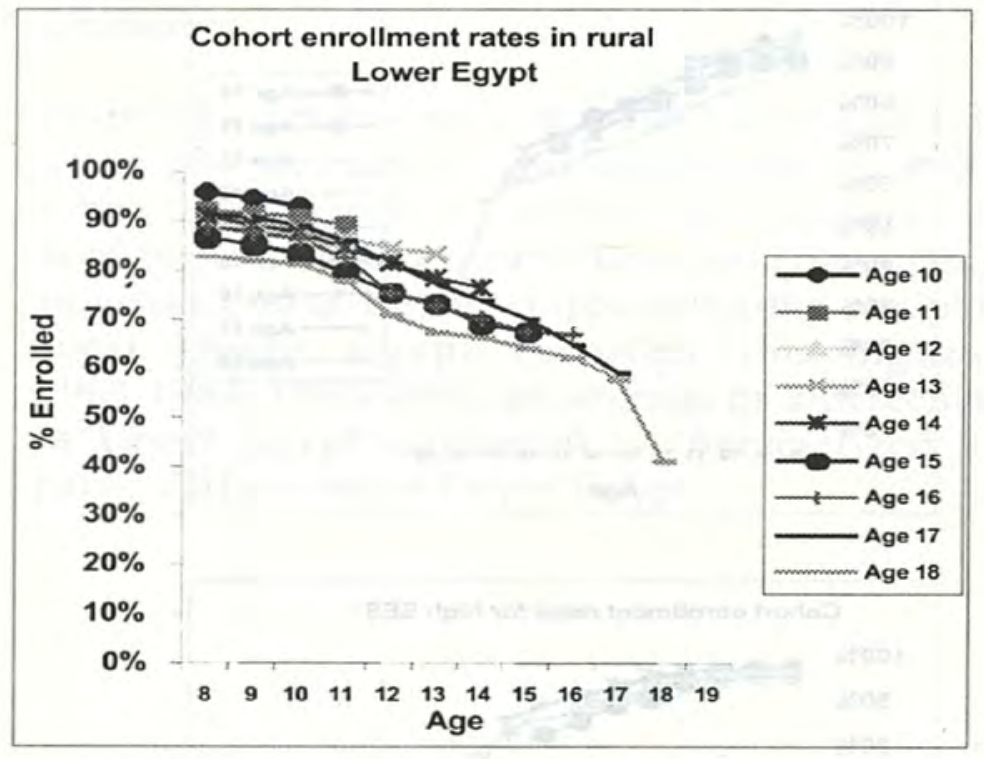

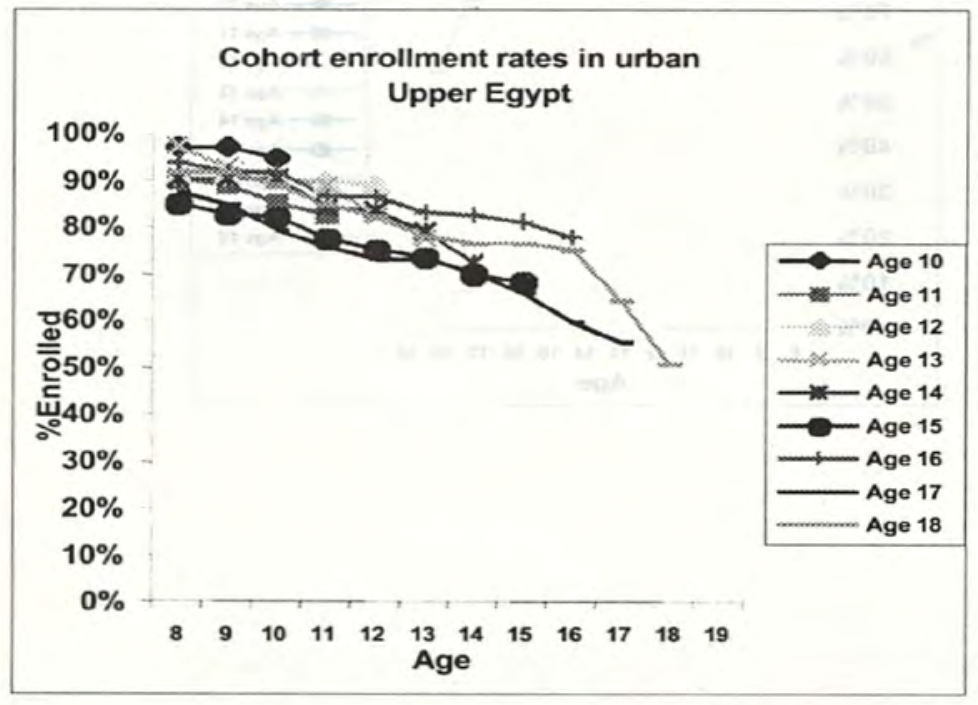

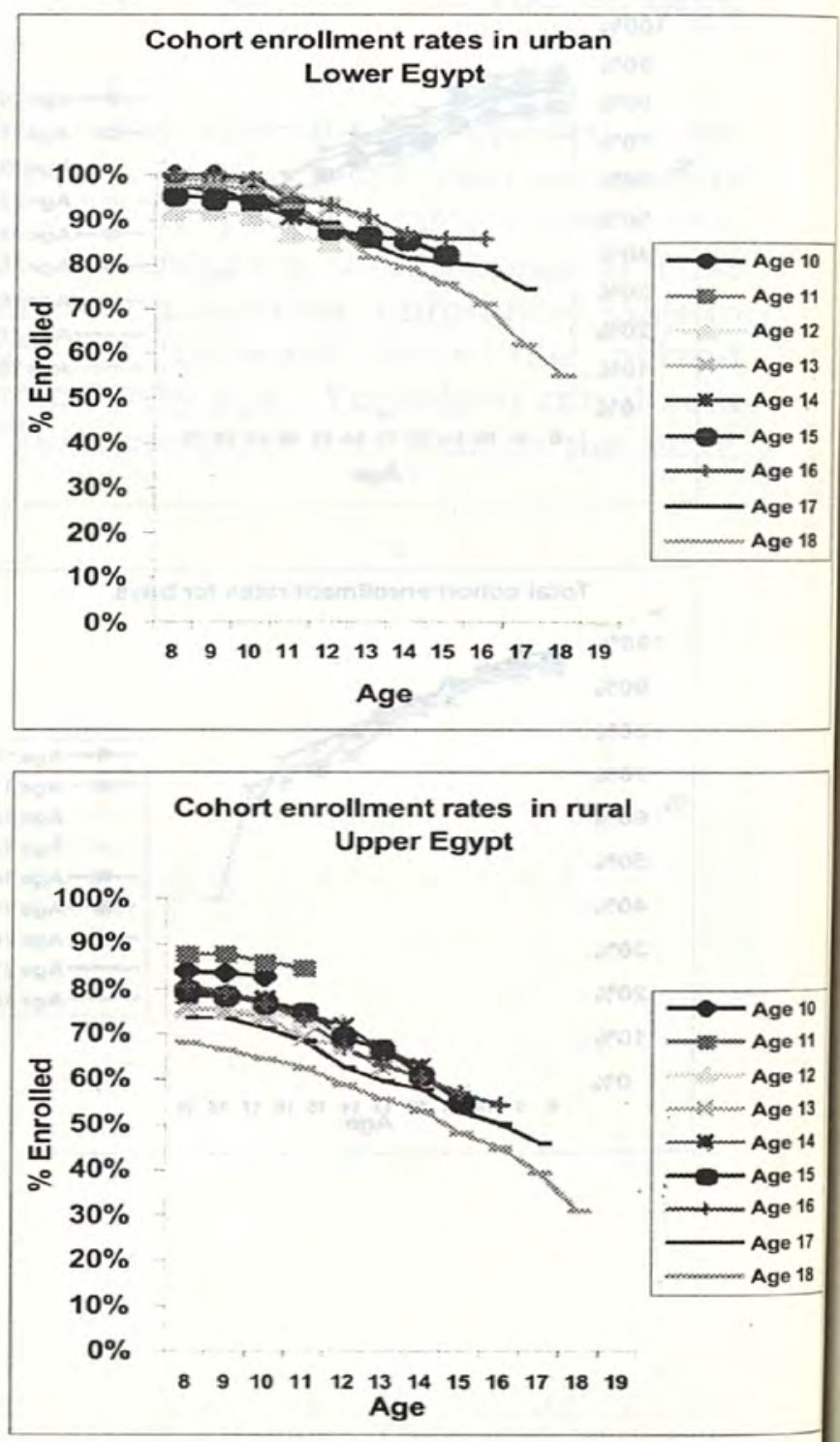


Figures 5.8-5.17 display the percentage of adolescents dropping out by age 11, 14, and 17 for three different cohorts by gender, socioeconomic level, and type and region of residence. The three ages - 11, 14, and 17 - were selected on purpose: Each of the three ages signals the beginning of the transition from one education stage to the next higher stage.

The results emphasize a general decline in dropout rates from one cohort to the next among most subgroups, particularly among girls, adolescents in the low and middle socioeconomic category, and adolescents in rural Lower and Upper Egypt. Deviations from this general trend are observed mainly among boys and among adolescents in the urban governorates and urban Upper Egypt whereby the percentage of dropouts among those who have ever attended school is either stable or fluctuates.

Table 5.3 shows the percentage of out-of-school adolescents, classified as dropouts or those who never attended, by gender, household socioeconomic status, and type and region of residence. One-quarter of boys aged 10-19 and one-third of girls are out of school. Approximately 43 percent of adolescents from the lowest socioeconomic stratum of the population are out of school compared to only 17 percent of adolescents from the highest stratum. Regional variations are also significant; over one-third of adolescents in rural areas, one-third in urban Upper Egypt, 22 percent in urban Lower Egypt, and 19 percent in the urban governorates are out-of-school.

Table 5.3 indicates clearly that as the overall percentage of adolescents out of school decreases in response to improved contextual and economic conditions, a lower proportion misses the chance of ever attending school. Consequently, dropouts comprise a larger segment of those out of school.

Table 5.3: Distribution of out-of-school adolescents, classified as dropouts or those who never attended, by selected background variables

\begin{tabular}{|lcccccc|} 
& $\begin{array}{c}\% \\
\text { Out of } \\
\text { school }\end{array}$ & $\begin{array}{c}\text { Total } \\
\text { sample }\end{array}$ & $\begin{array}{c}\text { Never } \\
\text { attended }\end{array}$ & $\begin{array}{c}\% \\
\text { Drop- } \\
\text { outs }\end{array}$ & $\begin{array}{c}\text { Total } \\
\%\end{array}$ & $\begin{array}{c}\text { Total } \\
\text { out of } \\
\text { school }\end{array}$ \\
Boys & 26.7 & 4,353 & 18.5 & 81.5 & 100.0 & 955 \\
Girls & 34.8 & 4,775 & 45.5 & 54.5 & 100.0 & 1,579 \\
Socioeconomic status & & & & & & \\
Low & 43.0 & 2,676 & 45.6 & 54.4 & 100.0 & 1,074 \\
Middle & 29.5 & 2,831 & 24.3 & 75.7 & 100.0 & 735 \\
High & 16.6 & 2,704 & 21.0 & 79.0 & 100.0 & 374 \\
Urban govs. & 19.2 & 1,840 & 9.2 & 90.8 & 100.0 & 290 \\
Urban Lower Egypt & 22.1 & 885 & 10.0 & 90.0 & 100.0 & 169 \\
Rural Lower Egypt & 33.3 & 3,128 & 29.7 & 70.3 & 100.0 & 934 \\
Urban Upper Egypt & 29.0 & 934 & 27.8 & 72.2 & 100.0 & 241 \\
Rural Upper Egypt & 38.7 & 2,341 & 52.5 & 47.5 & 100.0 & 900 \\
Total & 30.7 & 9,128 & 33.6 & 66.4 & 100.0 & 2,534 \\
\hline
\end{tabular}



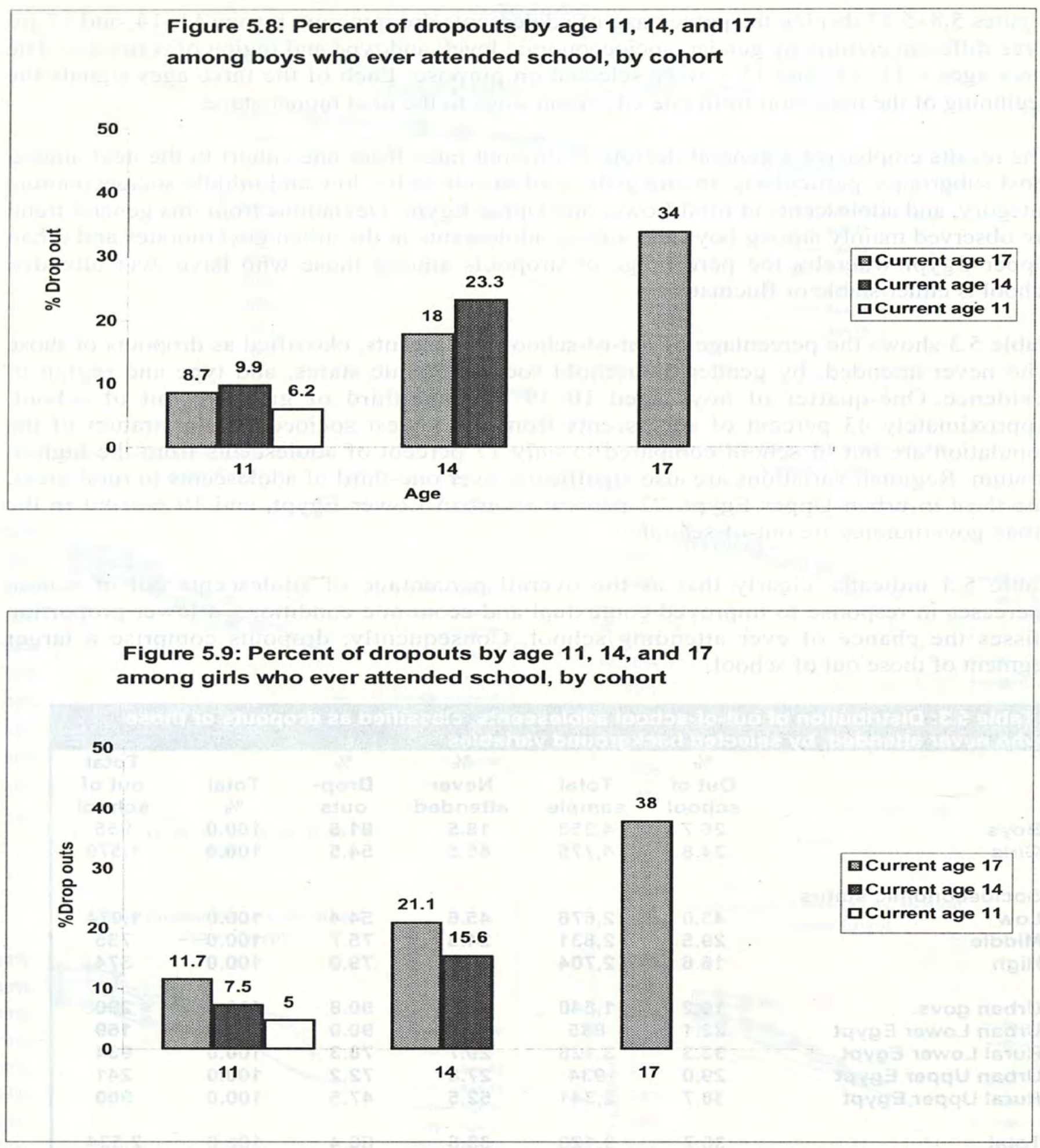

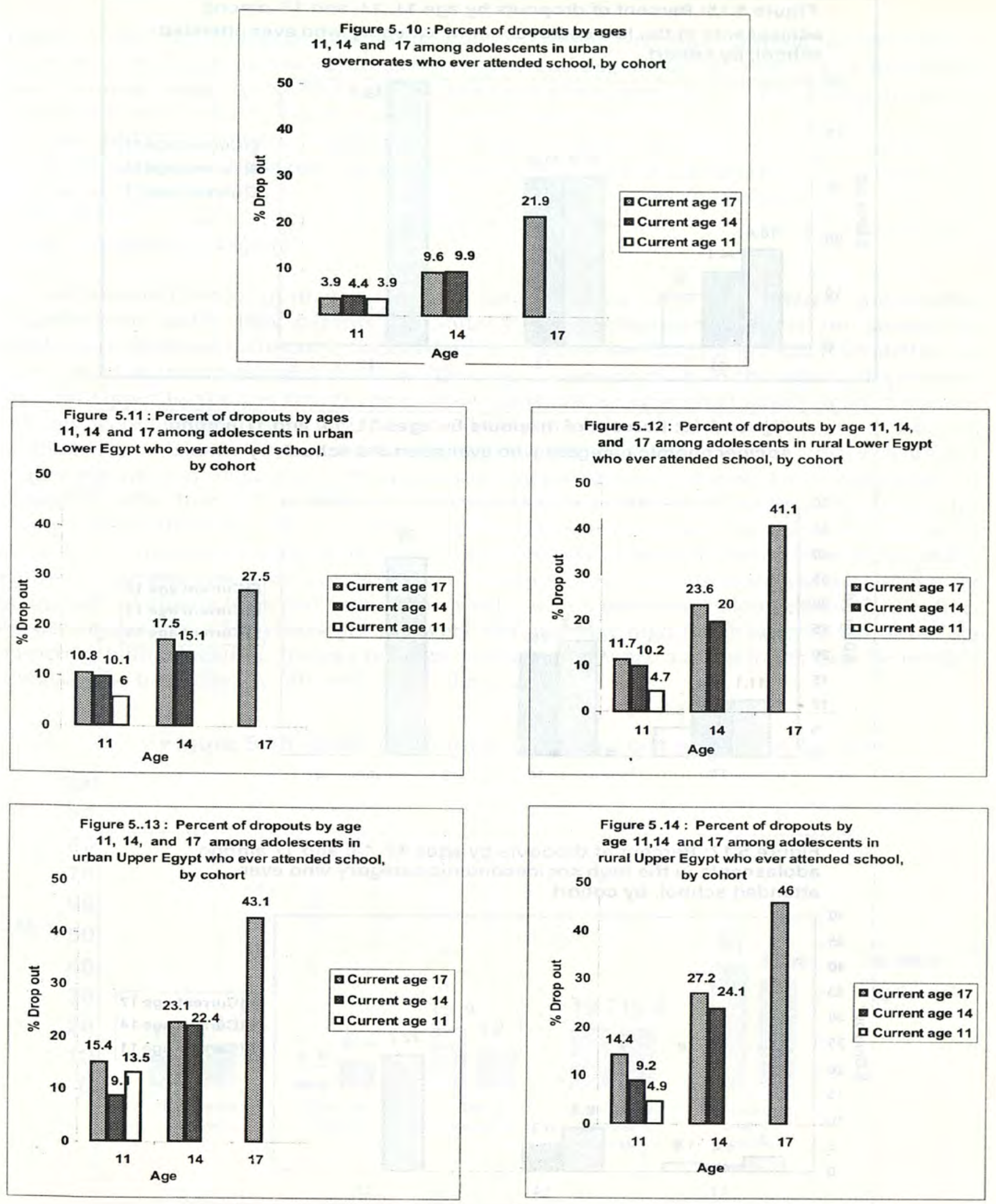

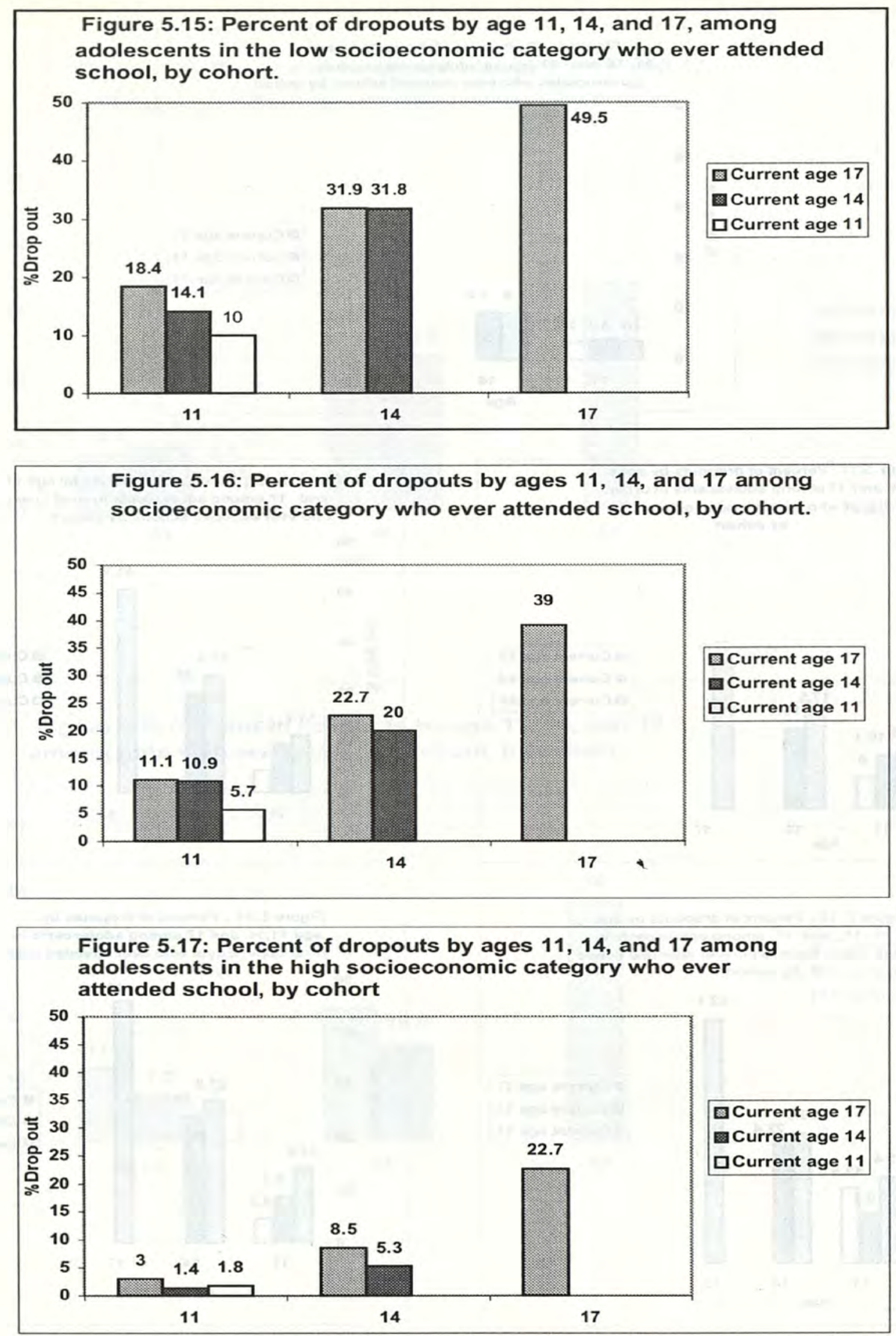


\section{Reasons for Drop Out}

Figures 5.18-5.20 highlight the main reasons underlying the dropout experience of adolescents in Egypt according to gender, type and region of residence, and household socioeconomic status. According to the interviewed adolescents, poor scholastic performance or, in their own words, "not doing well in school" stands out as the main reason for dropping out. This holds among the two sexes in all five regions, regardless of an adolescent's household social and economic status. More than one-third of adolescents who dropped out refer to their poor scholastic performance as the main reason for dropping out. This was mentioned more among boys in the middle and high socioeconomic categories and more outside the urban governorates.

The next reason in order of magnitude is the perceived low value of or interest in education by adolescents and/or their parents, particularly in the urban governorates and among the middle socioeconomic category. School-related reasons for dropout are twofold: dislike of school and bad treatment from teachers. This was expressed most in the urban governorates and rural Upper Egypt and among male adolescents. Those who cited family-related reasons said they were needed to help with household chores, there were family disputes, or a parent had died. These factors have a negative impact on girls' school continuation more than boys in all regions and regardless of household socioeconomic status. Only one-tenth of adolescents who dropped out referred to the lack of economic means as the main reason for leaving school. However, the poor economic resources of the household may exert influence on the scholastic performance of its school-age children through their nutritional status or the quality of education they receive. Work and marriage were rarely stated as main reasons for leaving school among boys and girls, respectively, which undermines long established beliefs and stereotypes about Egyptians placing work and marriage high in the order of major factors competing with education. Instead the data suggests that work and marriage may be options for those who have already left school for other reasons.

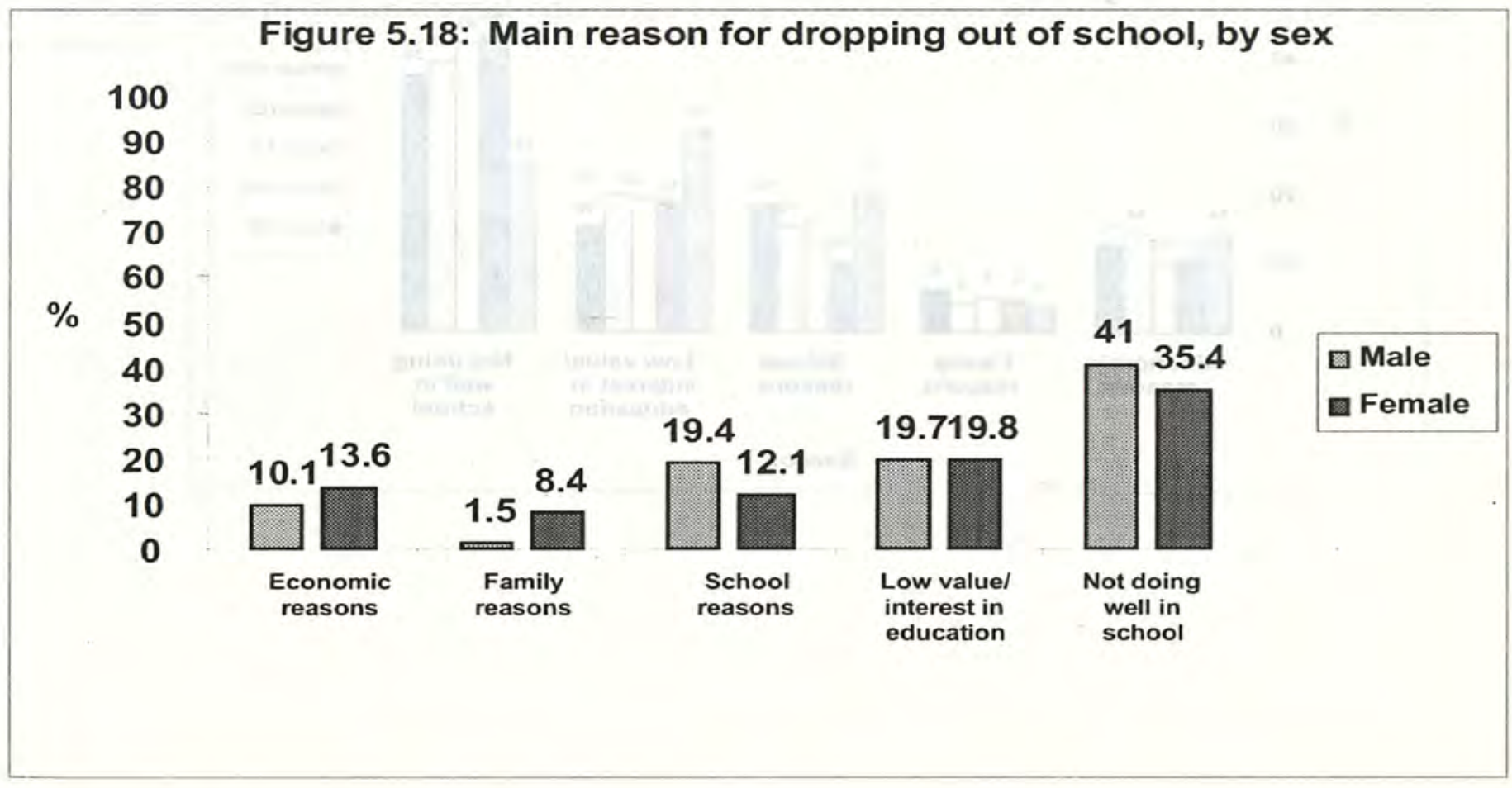


Figure 5.19: Main reason for dropping out of school, by socioeconomic status

60

50

40 -

$\% \quad 30$

20
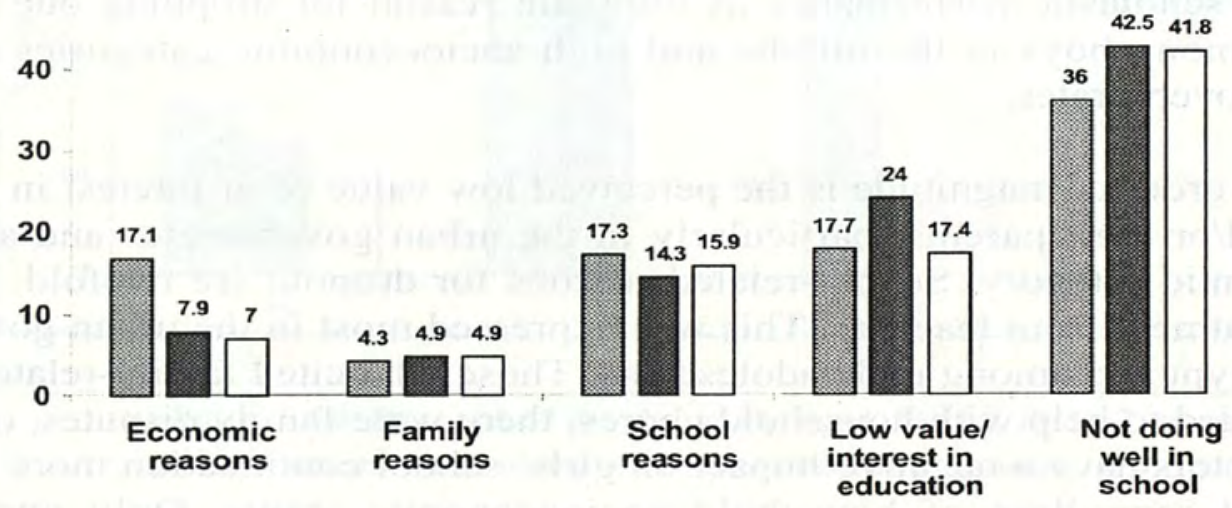

Reason

Figure 5.20: Main reasons for dropping out of school, 60 by region of residence

50

40

$\% \quad 30$

20

10

$\mathbf{0}$
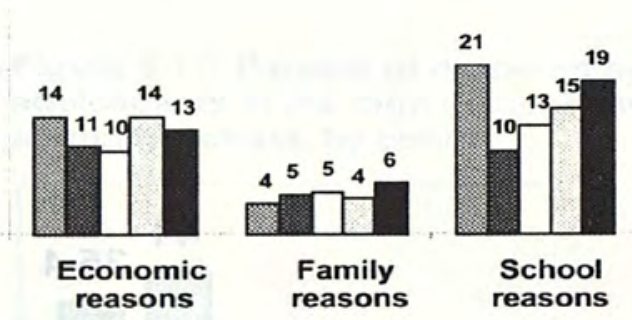

29

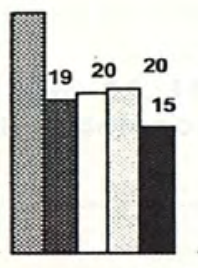

Low value/ iinterest in

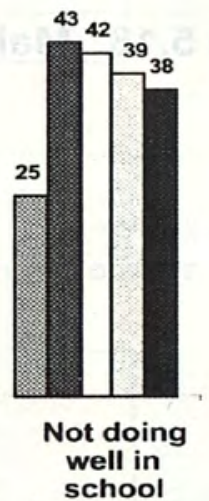

EUrban Govs. aUman LE QRURal LE QUßran UE aRural UE

Reason 
The percentage of any cohort that never attended school is a major parameter in determining the base level of enrollment of that group. Overall, the percentage of adolescents who have been deprived from attending school has declined (Figure 5.21). However, the decline was neither smooth nor systematic.

Among male adolescents, the percentage declined from around 5 percent to 1.5 percent with a small notch at age 12. The percentage of females who have never attended school declined from a high level of 21 percent among 19-year-olds to 13 percent among the youngest cohort. Two deviant cohorts are easily identified at the ages of 12 and 15 years as highlighted in the previous section (Figure 5.22).

The percentage of adolescents who did not get a chance to go to school is stable among households in the high socioeconomic category $(2 \%-4 \%)$. School never-attendance has declined by two-thirds in the middle category (from $12 \%$ to $4 \%$ ) and by one-half in the lowest stratum of the population (from $26 \%$ to $13 \%$ ) (Figure 5.23 ).

Being deprived of education is becoming an increasingly rare phenomenon in the urban governorates (about $1 \%$ among the young cohorts). This is also the case in urban Lower Egypt except again for the two ages 12 and 15 years. The percent of adolescents who-have never attended school declined from 16 percent to 4 percent in rural Lower Egypt. No trend is detected in urban Upper Egypt. However, in rural areas of the region the decline proceeded, stabilized, and even reversed its direction (again for the cohort at age 12), then continued to decline. Between the oldest and youngest cohorts, the percent of adolescents who have never attended school declined from 30 percent to 15 percent in rural Upper Egypt (Figure 5.24).

Despite significant improvements in enrollment, girls in rural Upper Egypt are still being deprived of education. The results estimate that one-third of girls aged 10-11 years were denied their right to obtain formal education compared to others of the same age in the rest of the country. 

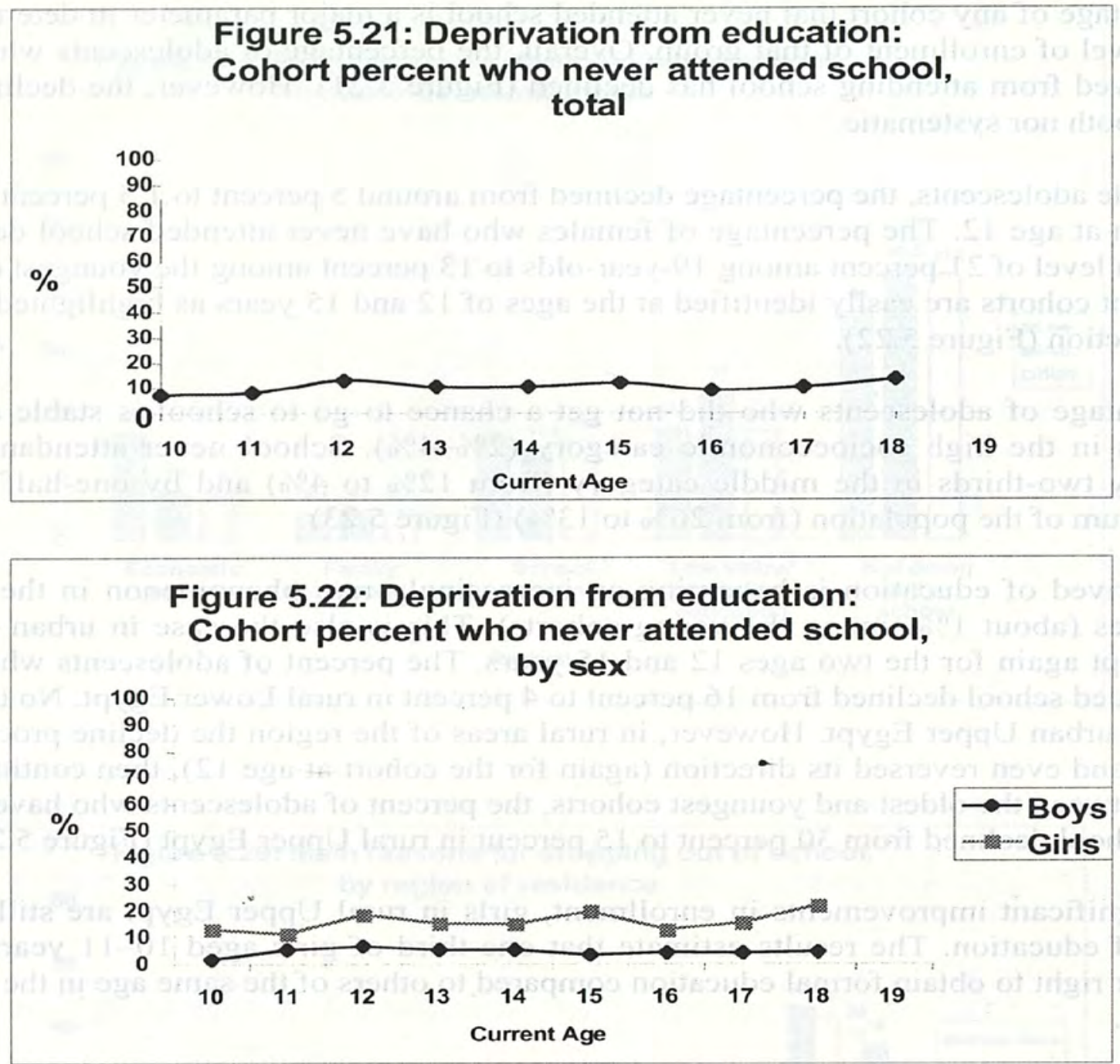

Figure 5.23: Deprivation from education: Cohort percent who never attended school, by

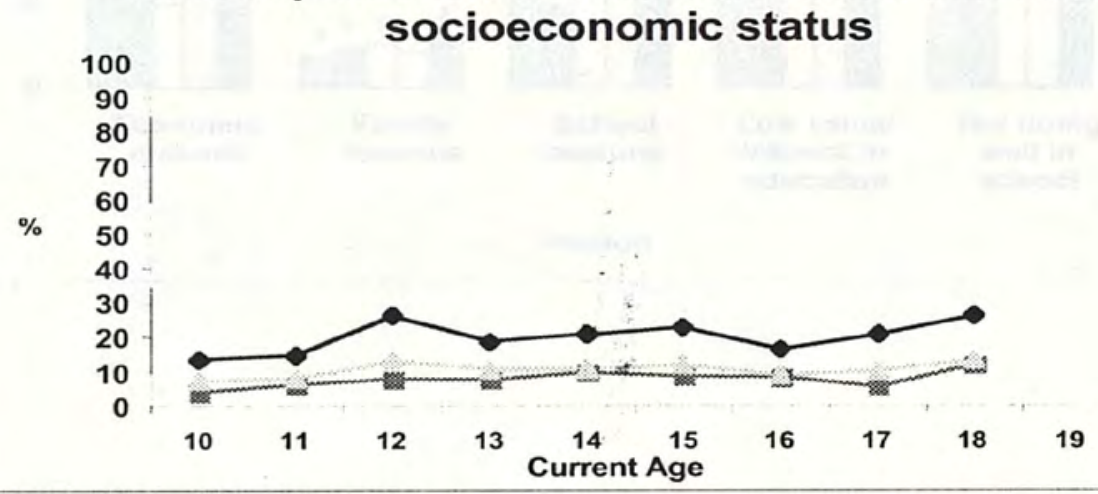


Figure 5.24: Education deprivation: Cohort percent who never attended school, by region of residence
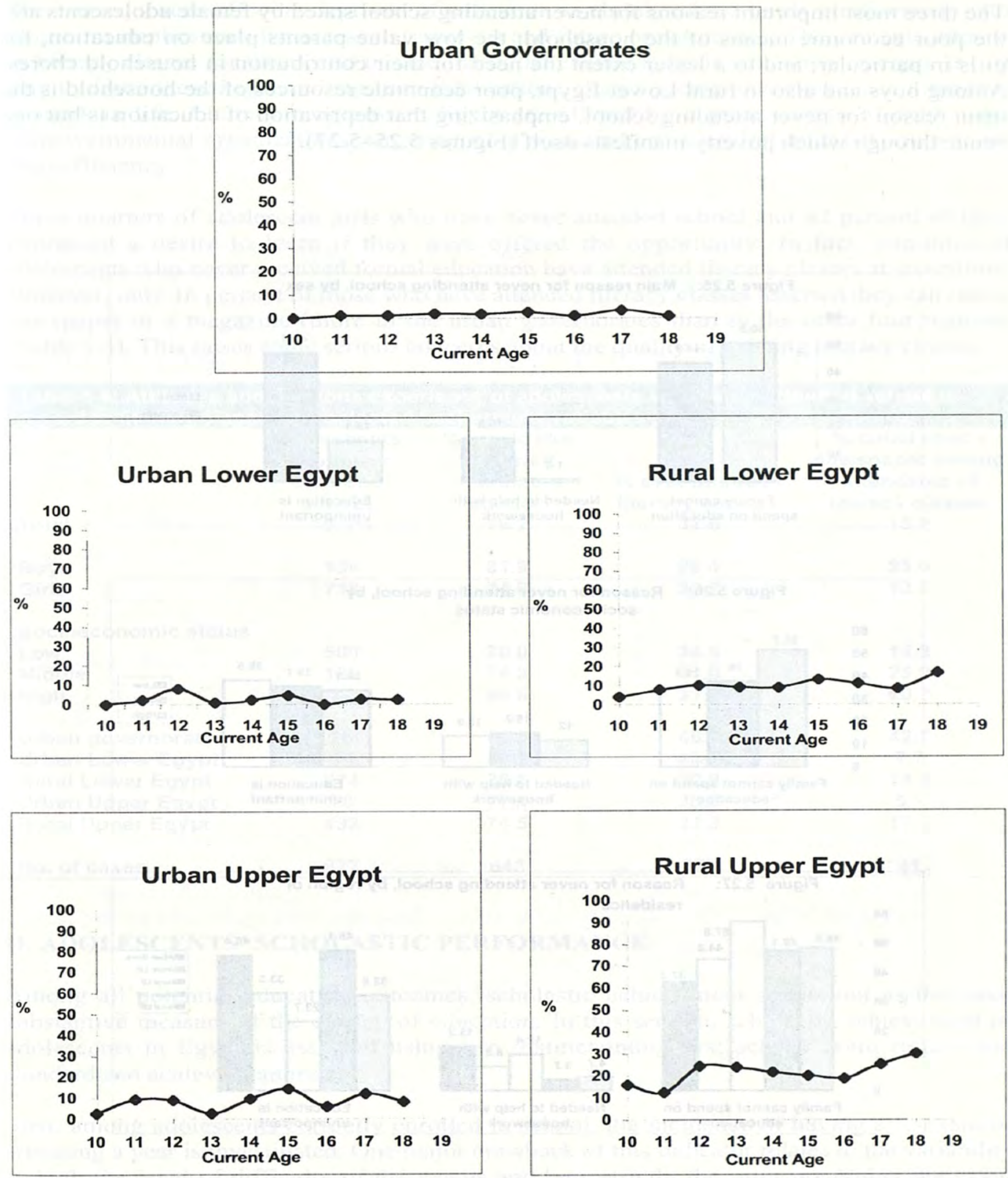


\section{Reasons for Never Attending School}

The three most important reasons for never attending school stated by female adolescents are: the poor economic means of the household; the low value parents place on education, for girls in particular; and to a lesser extent the need for their contribution in household chores. Among boys and also in rural Lower Egypt, poor economic resources of the household is the main reason for never attending school, emphasizing that deprivation of education is but one venue through which poverty manifests itself (Figures 5.25-5.27).
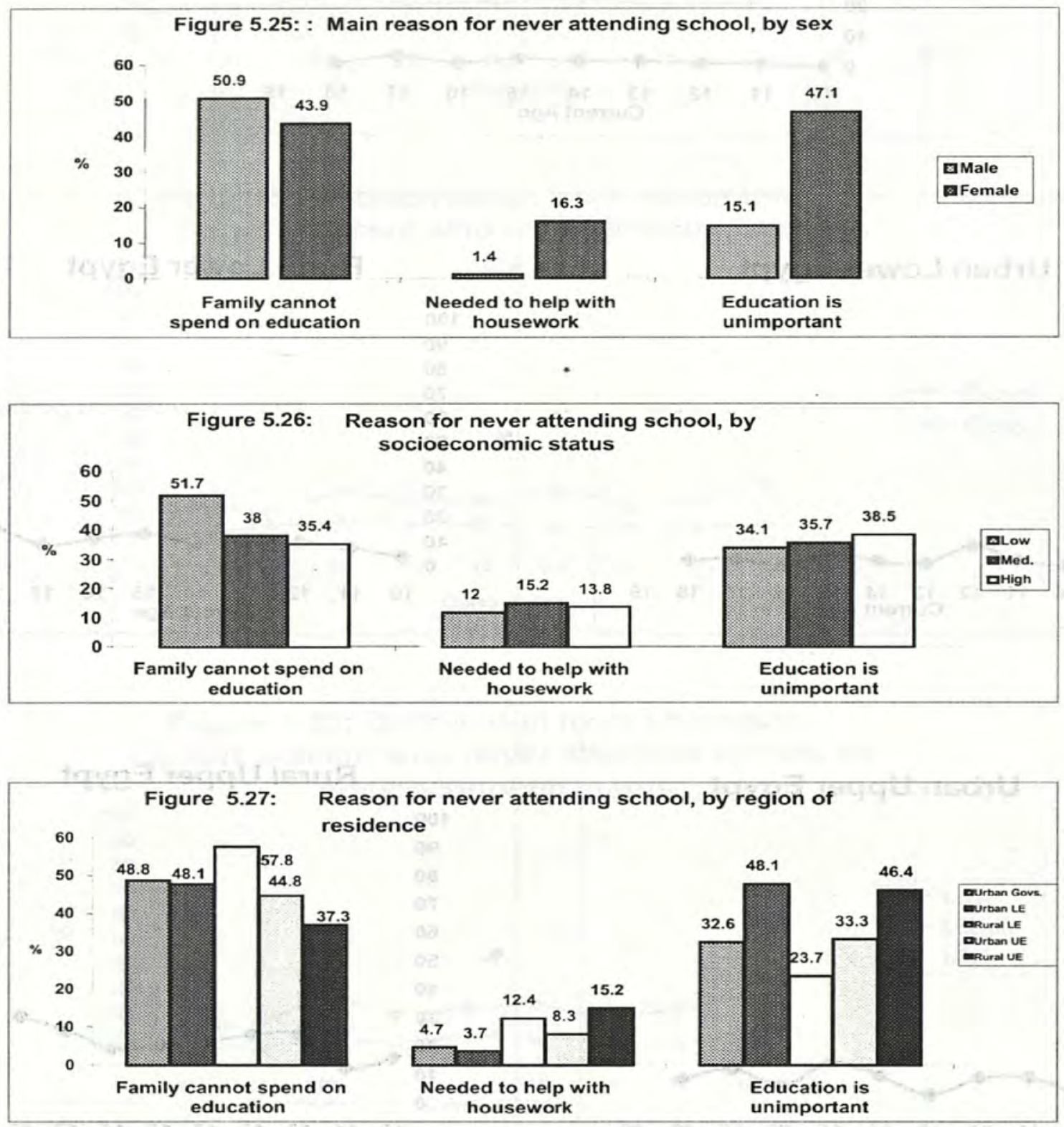


\section{Literacy Classes}

The consequences of being deprived of education in childhood are rarely ameliorated, with long-term implications for access to resources and future opportunities. The strategic interest in literacy classes for those who missed the initial chance at basic education emerges as one way to dilute these negative long-term implications, regain access to resources, and improve chances in life. Literacy programs in Egypt are offered by a great variety of public and nongovernmental organizations, targeting rural areas in particular, but little is known about their efficiency.

Three-quarters of adolescent girls who have never attended school and 82 percent of boys expressed a desire to learn if they were offered the opportunity. In fact, one-third of adolescents who never received formal education have attended literacy classes at some time. However, only 16 percent of those who have attended literacy classes asserted they can read a newspaper or a magazine (more in the urban governorates than in the other four regions) (Table 5.4). This raises some serious concerns about the quality of existing literacy classes.

\begin{tabular}{|c|c|c|c|c|}
\hline Total & $\begin{array}{l}\text { Adolescents } \\
\text { who never } \\
\text { attended } \\
\text { school } \\
10.3 \%\end{array}$ & $\begin{array}{l}\text { \% would like } \\
\text { to learn if } \\
\text { offered the } \\
\text { chance } \\
76.2\end{array}$ & $\begin{array}{c}\% \text { ever attended } \\
\text { literacy classes } \\
32.6\end{array}$ & $\begin{array}{c}\% \text { could read a } \\
\text { newspaper among } \\
\text { attendants of } \\
\text { literacy classes } \\
16.2\end{array}$ \\
\hline Boys & 159 & 81.9 & 28.4 & 25.0 \\
\hline Girls & 718 & 74.8 & 33.7 & 13.8 \\
\hline \multicolumn{5}{|c|}{ Socioeconomic status } \\
\hline Low & 500 & 70.0 & 34.8 & 14.9 \\
\hline Middle & 185 & 74.3 & 31.0 & 25.0 \\
\hline High & 77 & 80.6 & 31.2 & 20.7 \\
\hline Urban governorates & 26 & 60.0 & 46.7 & 42.7 \\
\hline Urban Lower Egypt & 14 & 88.9 & 44.4 & 7.7 \\
\hline Rural Lower Egypt & 274 & 79.6 & 30.0 & 14.4 \\
\hline Urban Upper Egypt & 70 & 77.4 & 36.9 & 5.1 \\
\hline Rurai Upper Egypt & 493 & 74.5 & 32.3 & 17.1 \\
\hline No. of cases & 877 & 643 & 275 & 41 \\
\hline
\end{tabular}

\section{ADOLESCENTS'SCHOLASTIC PERFORMANCE}

Among all potential education outcomes, scholastic achievement stands out as the most substantive measure of the quality of education. In this section, scholastic achievement of adolescents in Egypt is assessed using two distinct indicators; school exam results and standardized achievement tests.

First, among adolescents currently enrolled in school, the incidence of having a re-exam or repeating a year is investigated. One major drawback of this indicator relates to the variability in both the level of difficulty of the exams and how strictly the rules governing the exam grading process are observed. The variability incurred by these two sources is significant between schools and sometimes within the same school. Also, a certain degree of under- 
reporting is anticipated given the embarrassment associated with such reports. However, despite the elements of subjectivity and lack of standardization ingrained in this indicator, it remains an important measure that cannot be overlooked.

In addition, the ASCE survey administered standardized achievement tests in Arabic and mathematics to randomly selected adolescents currently enrolled in grade 5 of the general primary school system, in grades 1, 2, or 3 of the general preparatory school system, or in their first year of the general secondary school system. The same tests were also administered to adolescents who dropped out of school after finishing any of the aforementioned grades. Not only were the tests standardized, but the rules for grading them were also strictly and uniformly implemented. Results of the achievement tests are utilized as a more objective measure of scholastic performance. While these results avoid many of the drawbacks of the first measure based on school results, they have their own inherent biases. The household context differs completely from the school setting as far as administration of achievement tests is concerned. The interviewers were instructed to make every effort in their capacities to ensure an atmosphere of seriousness as well as privacy for the interviews and the tests and to observe the time for both. Overall, the high response of adolescents to these tests and the support and encouragement received by their families are two important factors in favor of the good quality of the results.

\section{SCHOOL ExAM RESULTS}

Table 5.5 shows the distribution of adolescents currently enrolled in the general school system between 5 th primary and 1 st secondary according to their reported school exam results and their demographic and socioeconomic characteristics.

Sixty-one percent of this group has never failed an exam in any subject; one-quarter have had re-exams, which they passed; and 15 percent have had to repeat a year (because they failed the re-exam).

Boys, working adolescents, members of female-headed households, and residents of Lower and Upper Egypt have poor scholastic performance (had a re-exam and/or repeated a year) compared to other groups of adolescents. The lack of economic resources available to a household seems to be strongly correlated with lower achievement of its adolescents enrolled in school. Students from low socioeconomic status households are less likely to have always passed their exams, compared to students from high status households $(50 \%$ and $72 \%$, respectively). Also, they are twice as likely to have repeated a year compared to the more well-off students ( $21 \%$ and $10 \%$, respectively).

\section{Achievement Tests}

School exam results provide indications of the differentials in scholastic achievement but only in the direction of poor performance. Results of the achievement tests administered in the ASCE survey highlight the differentials in the direction of excellent performance as well as poor performance in both absolute and relative terms. Since we are interested in examining the differentials and correlates of poor/good achievement in relative terms, results of the achievement tests were standardized according to the subject of the exam and the different school grades. Then, these results were classified into three categories: good (Z-scores greater 
than +1$)$, average ( $Z$-scores in the range -1 to +1$)$ and poor (Z-scores less than -1$)$. No attempt has been made here to assess the absolute level of scholastic achievement.

Based on the overall level of performance of sampled adolescents, 60 percent of the adolescents who took the Arabic test received an "average" grade, 22 percent received "poor," and 18 percent were classified as "good." No gender differentials are observed, an interesting finding given that language ability is usually thought to be stronger among girls.

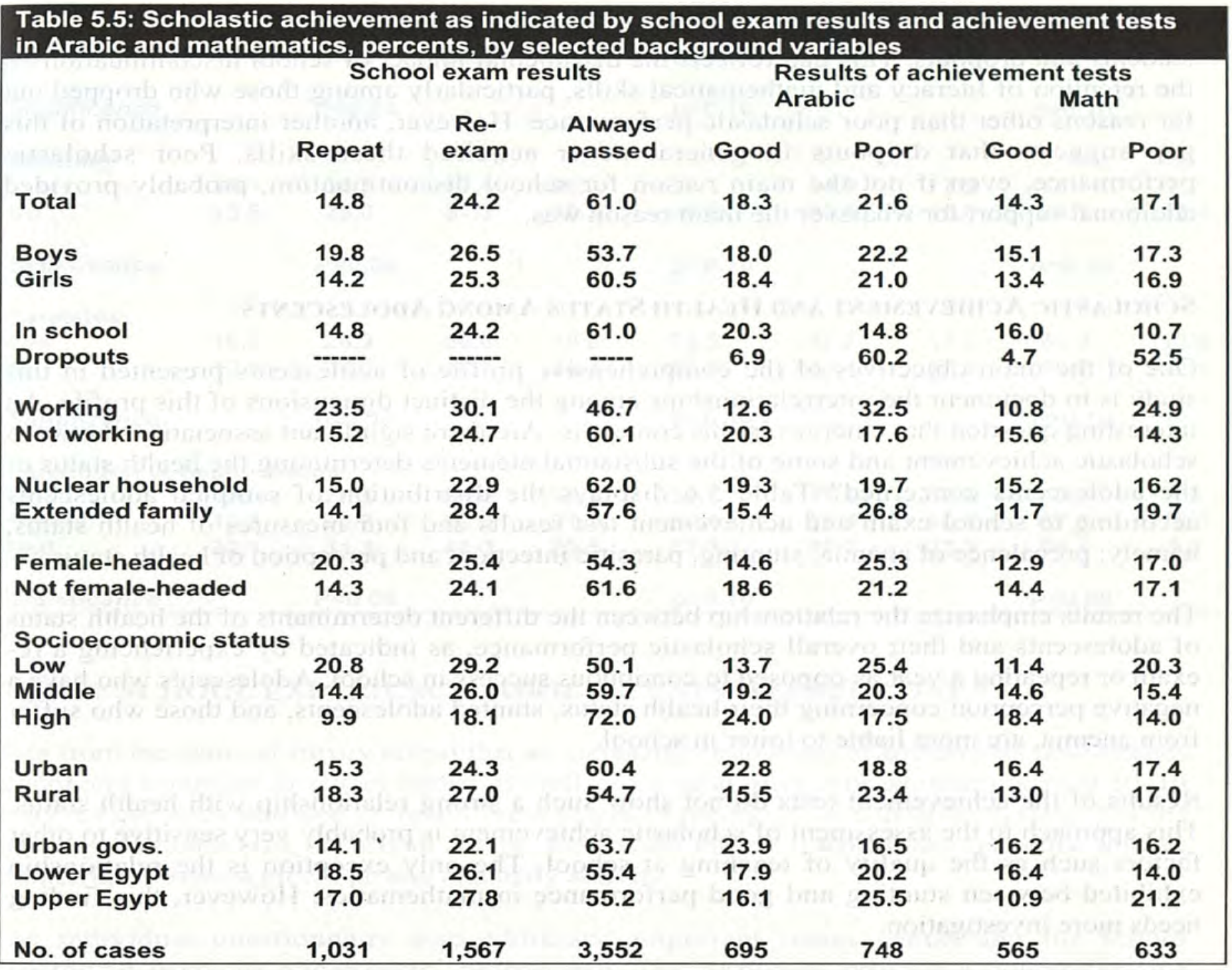

Working adolescents, residents of Upper Egypt and rural areas, and adolescents from low economic status households, female-headed, and extended family households present themselves as likely candidates among the poor achievers in Arabic. On the other hand, coming from a high economic status household and residence in the urban governorates have a positive impact on scholastic achievement in Arabic.

In mathematics, 69 percent were evaluated as "average," 17 percent as "poor," and 14 percent as "good." The differentials in scholastic achievement in mathematics are less pronounced compared to Arabic. Region of residence, work status, and household economic situation 
seem to have the strongest impact on the level of achievement in mathematics while minor gender differences are observed.

The small gender differentials in the results of the achievement tests among this Egyptian population are remarkable. They suggest that the differentials often seen in other societies in mathematics achievement are probably the result of cultural attitudes conveyed to teachers, parents, and students rather than the consequence of innate aptitudes.

Findings from the survey emphasize the large gap in scholastic achievement between enrolled students and dropouts. This gap reflects the detrimental impact of school discontinuation on the retention of literacy and mathematical skills, particularly among those who dropped out for reasons other than poor scholastic performance. However, another interpretation of this gap suggests that dropouts in general never acquired these skills. Poor scholastic performance, even if not the main reason for school discontinuation, probably provided additional support for whatever the main reason was.

\section{Scholastic Achievement and Health Status Among Adolescents}

One of the main objectives of the comprehensive profile of adolescents presented in this study is to document the interrelationships among the distinct dimensions of this profile. An interesting question that emerges in this context is: Are there significant associations between scholastic achievement and some of the substantial elements determining the health status of the adolescents concerned? Table 5.6 displays the distribution of sampled adolescents according to school exam and achievement test results and four measures of health status, namely: prevalence of anemia, stunting, parasitic infection, and perception of health status.

The results emphasize the relationship between the different determinants of the health status of adolescents and their overall scholastic performance, as indicated by experiencing a reexam or repeating a year as opposed to continuous success in school. Adolescents who have a negative perception concerning their health status, stunted adolescents, and those who suffer from anemia, are more liable to loiter in school.

Results of the achievement tests do not show such a strong relationship with health status. This approach to the assessment of scholastic achievement is probably very sensitive to other factors such as the quality of teaching at school. The only exception is the relationship exhibited between stunting and good performance in mathematics. However, this finding needs more investigation. 


\begin{tabular}{|c|c|c|c|c|c|c|c|c|c|}
\hline & \multirow{2}{*}{\multicolumn{3}{|c|}{ School exam results }} & \multicolumn{6}{|c|}{ Results of achievement tests } \\
\hline & & & & & Arabic & & & lathematics & \\
\hline & Repeat & $\begin{array}{l}\text { Re- } \\
\text { exam }\end{array}$ & $\begin{array}{l}\text { Always } \\
\text { passed }\end{array}$ & Poor & Average & Good & Poor & Average & Good \\
\hline \multicolumn{10}{|l|}{ Anemia } \\
\hline Yes & 15.5 & 30.5 & 54.0 & 22.4 & 59.8 & 17.8 & 18.0 & 70.2 & 11.8 \\
\hline No & 15.1 & 24.9 & 60.0 & 20.5 & 58.2 & 21.3 & 16.3 & 67.9 & 15.7 \\
\hline Significance & & $P=0.04$ & & & $p>0.10$ & & & $p>0.10$ & \\
\hline \multicolumn{10}{|l|}{ Stunting } \\
\hline Yes & 16.1 & 36.5 & 47.4 & 26.8 & 58.3 & 14.9 & 17.2 & 75.1 & 7.7 \\
\hline No & 13.8 & 25.0 & 61.3 & 19.3 & 60.2 & 20.6 & 15.6 & 69.1 & 15.4 \\
\hline Significance & & $P=0.00$ & & & $p>0.10$ & & & $p>0.10$ & \\
\hline \multicolumn{10}{|l|}{ Parasites } \\
\hline Yes & 16.5 & 26.9 & 56.6 & 18.6 & 63.2 & 17.7 & 17.3 & 69.8 & 12.9 \\
\hline No & 13.3 & 28.0 & 58.7 & 24.4 & 55.5 & 20.1 & 17.0 & 70.2 & 12.8 \\
\hline Significance & & $p>0.10$ & & & $p>0.10$ & & & $p>0.10$ & \\
\hline \multicolumn{10}{|c|}{ Perception of health status } \\
\hline Great & 15.6 & 27.8 & 56.6 & 22.8 & 56.1 & 21.1 & 18.6 & 73.4 & 8.0 \\
\hline Normal & 13.3 & 26.7 & 60.0 & 21.1 & 60.1 & 18.9 & 15.9 & 67.3 & 16.8 \\
\hline Bad & 22.1 & 31.9 & 46.0 & 20.5 & 62.3 & 17.2 & 22.3 & 68.4 & 9.2 \\
\hline Significance & & $P=0.00$ & & & $p>0.10$ & & & $P=0.08$ & \\
\hline
\end{tabular}

\section{THE SCHOOL EXPERIENCE: ADOLESCENTS'PERSPECTIVE}

Data from the national survey reveal that an increasing proportion of adolescents now attends school and continues in school longer as well. Sixty-nine percent of adolescents aged 10-19 years are currently enrolled in the different stages of the Egyptian education system. For the majority of adolescents, the school environment is the milieu in which they spend the longest uninterrupted time segment on any one daily activity.

The individual questionnaire also addressed important issues concerning the school experience from the adolescents' perspective. The responses provide a comprehensive assessment by the adolescents based upon their attitudes toward school, school proximity, school physical condition and facilities, personal support at school, and the quality of teaching. This assessment is restricted only to adolescents enrolled in general primary, preparatory and secondary schools, as well as the secondary vocational education system (Table 5.7). Students enrolled in higher education or in Al-Azhar schools are excluded from this analysis. 
Responses to the following five questions are combined to assess an adolescent's overall attitude toward school:

-Do you like your school?

-In your opinion, is your school clean?

-Do you like the school system and the level of discipline exercised there?

-Are all students treated equally in your school?

-Does anything bother you about school?

A positive attitude is ascertained if the adolescent responded affirmatively to the first four questions and added in response to the last question "nothing in particular bothers me about school." On the whole 47 percent of eligible adolescents report a positive attitude toward school. No gender differences are observed. Positive attitudes are more likely to be reported by students enrolled in basic education, rural students, students in Lower and Upper Egypt, and members of households in the low socioeconomic category. The least positive about their schools are students enrolled in general secondary and students in the urban governorates.

\section{TrAVEL TO SCHOOL}

The length of time required to travel to school is used as a proxy for the concomitant effort exerted, regardless of the means of transportation utilized, and the level of difficulty exercised daily to attend school. Eighty-two percent of adolescents in general and vocational education take less than a half hour daily to go to school (one way). No gender or urban/rural differentials are observed concerning this particular aspect of the school experience. The stage of education is the most significant determinant of school proximity. More than 90 percent of students enrolled in basic education take less than one half hour to go to school. This finding is consistent with the previous results concerning increasing enrollment and school continuation particularly in basic education. However, school accessibility decreases considerably as students proceed to general secondary $(75 \%)$ or vocational schools $(54 \%)$. Smaller regional and socioeconomic differentials are also observed. A longer period of time is required to reach school in the urban governorates as compared to Lower and Upper Egypt. This may reflect the wider spectrum of schools available in the urban governorates.

\section{School Physical Conditions and Facilities}

The availability of certain facilities at school such as play yards and toilets and the physical condition of these facilities as well as of classrooms, is no doubt one important dimension of the overall school experience. A high proportion (95\%) of eligible adolescents report having a play yard without reference to the exact size of it. Also, 91 percent report having a library at school and 93 percent report having extracurricular activities. Less positive responses were obtained concerning other school facilities. One-quarter of the respondents report that the water supply is frequently cut and a similar proportion report unclear blackboards or bad lighting in class. Unclean toilets are reported by 40 percent, while slightly more than onethird report broken windows or crowding on desks. Broken desks in class are reported by 56 percent. Only urban/rural and regional differentials are significant; better physical conditions and facilities of schools are reported in rural areas and in Lower and Upper Egypt. 


\section{Nonacademic Services and Interaction with Teachers and Peers}

Adolescents in school have greater exposure to and interaction opportunities with nonfamily adults and peers than their out-of-school counterparts. The personal support and counseling they receive at school from doctors, social workers, teachers, and their fellow students not only reflect upon their psychological development and communication skills but also have the potential to have an impact on their scholastic achievement and attitudes toward school. Data from the national survey can be utilized to evaluate the extent of and differentials in personal support at school.

Seventy-three percent of the respondents report that their current school has a doctor or a nurse. Large differentials are observed in this indicator. The presence of a doctor or a nurse at school varies from 64 percent in basic education to 89 percent in secondary schools and from 64 percent in schools where adolescents from low status households are enrolled to 79 percent in schools where adolescents from high status households are enrolled. Ninety-three percent of adolescents in urban areas report having a doctor at school compared to only 57 percent in rural areas. A gap of the same magnitude exists between the urban governorates and Upper Egypt.

The same pattern of differentials exists in regard to the presence of a social counselor at school, however, a larger overall proportion $(86 \%)$ has a social counselor at school.

Only one-third of eligible adolescents report positively on the interaction with and personal support from teachers and peers at school. This group was positive about students' attitudes toward each other, like most of the teachers at school, and emphasize their teachers' encouragement for expression of opinion and their involvement and support in solving students' personal problems. In contrast to the professional support from a doctor or a social counselor, teacher and peer support is reported highest in basic education and least in general secondary schools. It is higher in rural areas and Lower and Upper Egypt than urban areas and the urban governorates and relatively low among adolescents from high-status households.

\section{The Quality of Education}

The quality of education is usually measured by education outcomes in terms of scholastic achievement and acquisition of professional and life skills. Among the correlates of the quality of education often cited in the literature are classroom density, teacher/student scholastic interaction, and private tutoring.

The majority of the sample report that teachers often respond to students' questions in class (94\%). However, only 68 percent reported that it always happened. This positive interaction is higher in the basic education stage, rural areas, and in Upper Egypt compared to other regions or stages of education.

The median class size is 43 students. Low class density, defined as less than 43 students per class, is more prevalent in vocational schools than in basic or general secondary schools, in rural areas more than urban, and in Lower Egypt more than in Upper Egypt or the urban governorates. The percent of students reporting taking private tutoring is higher wherever class density is relatively higher and also when a lower level of teacher/student scholastic 
interaction is reported. No direct or systematic relationship is established between class density and interaction in the classroom.

\begin{tabular}{|c|c|c|c|c|c|c|}
\hline & $\begin{array}{l}\% \text { having } \\
\text { positive } \\
\text { attitude } \\
\text { toward } \\
\text { school }\end{array}$ & $\begin{array}{l}\% \text { taking } \\
\text { less than } \\
\text { half hour } \\
\text { to travel } \\
\text { to school }\end{array}$ & $\begin{array}{c}\% \text { reporting } \\
\text { positive } \\
\text { interaction } \\
\text { with } \\
\text { teachers } \\
\text { and peers }\end{array}$ & $\begin{array}{c}\% \text { in } \\
\text { low } \\
\text { density } \\
\text { classes }\end{array}$ & $\begin{array}{c}\% \\
\text { taking } \\
\text { private } \\
\text { tutoring }\end{array}$ & $\begin{array}{c}\text { \% reporting } \\
\text { teachers } \\
\text { always } \\
\text { answer } \\
\text { students' } \\
\text { questions }\end{array}$ \\
\hline Total & 47.3 & 81.6 & 29.5 & 50.3 & 54.0 & 68.3 \\
\hline $\begin{array}{l}\text { Boys } \\
\text { Girls }\end{array}$ & $\begin{array}{l}46.9 \\
48.0\end{array}$ & $\begin{array}{l}81.7 \\
81.6\end{array}$ & $\begin{array}{l}29.6 \\
30.5\end{array}$ & $\begin{array}{l}53.4 \\
46.9\end{array}$ & $\begin{array}{l}50.5 \\
57.8\end{array}$ & $\begin{array}{l}67.2 \\
69.4\end{array}$ \\
\hline $\begin{array}{l}\text { Basic education } \\
\text { Secondary } \\
\text { Vocational }\end{array}$ & $\begin{array}{l}52.2 \\
29.3 \\
42.2\end{array}$ & $\begin{array}{l}91.3 \\
75.3 \\
54.1\end{array}$ & $\begin{array}{l}32.6 \\
20.0 \\
27.2\end{array}$ & $\begin{array}{l}40.4 \\
54.0 \\
80.1\end{array}$ & $\begin{array}{l}51.8 \\
84.0 \\
44.0\end{array}$ & $\begin{array}{l}70.2 \\
65.8 \\
63.3\end{array}$ \\
\hline \multicolumn{7}{|l|}{$\begin{array}{l}\text { Socioeconomic } \\
\text { status }\end{array}$} \\
\hline Low & 54.1 & 78.5 & 32.6 & 51.9 & 42.7 & 70.3 \\
\hline Middle & 45.1 & 82.6 & 29.8 & 48.4 & 53.8 & 66.4 \\
\hline High & 44.1 & 83.1 & 26.3 & 50.3 & 64.3 & 66.7 \\
\hline $\begin{array}{l}\text { Urban } \\
\text { Rural }\end{array}$ & $\begin{array}{l}36.1 \\
55.5\end{array}$ & $\begin{array}{l}81.7 \\
81.6\end{array}$ & $\begin{array}{l}21.7 \\
35.9\end{array}$ & $\begin{array}{l}43.8 \\
54.9\end{array}$ & $\begin{array}{l}66.4 \\
45.1\end{array}$ & $\begin{array}{l}64.8 \\
70.7\end{array}$ \\
\hline $\begin{array}{l}\text { Urban govs. } \\
\text { Lower Egypt } \\
\text { Upper Egypt }\end{array}$ & $\begin{array}{l}33.5 \\
49.6 \\
52.8\end{array}$ & $\begin{array}{l}75.4 \\
82.9 \\
83.7\end{array}$ & $\begin{array}{l}19.6 \\
29.8 \\
36.3\end{array}$ & $\begin{array}{l}45.1 \\
53.8 \\
48.9\end{array}$ & $\begin{array}{l}68.1 \\
59.4 \\
38.8\end{array}$ & $\begin{array}{l}59.4 \\
67.9 \\
73.9\end{array}$ \\
\hline No. of cases & 2,680 & 4,701 & 1,688 & 2,857 & 3,188 & 3,901 \\
\hline
\end{tabular}

\section{THE SOCIAL CONTEXT OF EDUCATION: VIEWS OF TWO GENERATIONS}

In addition to the national education indicators and adolescents' perspectives on schooling, it is important to situate what the school means within the community and the family. The social context of education - which includes perceived value of education by parents and their children, adolescents' aspirations for continuation, and their parents' aspirations for them - is an important factor influencing whether or not adolescents go to school and how long they stay enrolled. This context, along with the measurements provided above, help to complete the educational profile of adolescents.

\section{Educational aspirations}

Parents, both mothers and fathers, perceive the importance of education (Table 5.8). Ninetynine percent of parents report that education is necessary and important for boys, while 93 percent report that it is necessary and important for girls. Parents in rural areas, in Upper Egypt, in low-status households, and with less than a primary certificate place less importance on educating girls than other groups. About half of the adults did not give a 
specific response and left it up to the adolescent instead. Among the group who provided specific responses, mothers had lower education aspirations compared to fathers, and both had slightly lower aspirations for girls.

\begin{tabular}{|c|c|c|c|c|}
\hline \multirow{2}{*}{ 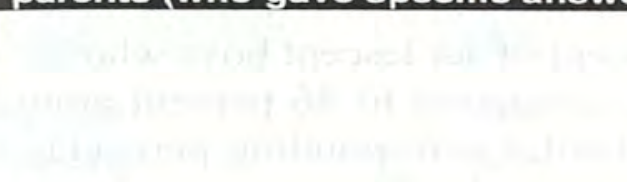 } & \multicolumn{2}{|c|}{$\begin{array}{l}\text { Parents who believe } \\
\text { boys/girls should } \\
\text { continue to university }\end{array}$} & \multicolumn{2}{|c|}{$\begin{array}{l}\text { Adolescents who aspire } \\
\text { to continue to university } \\
\text { level }\end{array}$} \\
\hline & Boys & Girls & Boys & Girls \\
\hline Total & 84.2 & 70.0 & 72.6 & 69.5 \\
\hline Repeat & - & - & 46.1 & 39.6 \\
\hline Re-exam & - & - & 64.3 & 58.0 \\
\hline Neither & - & - & 86.1 & 81.4 \\
\hline $\begin{array}{l}10-14 \text { years } \\
15-19 \text { years }\end{array}$ & - & - & $\begin{array}{l}76.4 \\
64.4\end{array}$ & 73.3 \\
\hline & & & & \\
\hline $\begin{array}{l}\text { Male } \\
\text { Female }\end{array}$ & $\begin{array}{l}85.9 \\
81.8\end{array}$ & $\begin{array}{l}71.1 \\
68.5\end{array}$ & E & - \\
\hline No schooling/less than primary & 73.7 & 55.5 & - & \\
\hline Primary/less than preparatory & 87.0 & 69.1 & - & - \\
\hline Preparatory/less than secondary & 92.0 & 84.6 & - & - \\
\hline Secondary & 96.8 & 86.0 & - & - \\
\hline University & 98.2 & 95.5 & - & - \\
\hline Working & - & - & 59.7 & 58.0 \\
\hline Nonworking & - & - & 73.3 & 65.3 \\
\hline \multicolumn{5}{|l|}{ Socioeconomic status } \\
\hline Low & 68.3 & 50.2 & 63.6 & 55.3 \\
\hline Middle & 85.2 & 68.8 & 70.6 & 68.6 \\
\hline High & 93.3 & 84.0 & 83.5 & 81.4 \\
\hline Nuclear & 86.0 & 73.1 & 74.2 & 70.4 \\
\hline Extended & 77.5 & 58.5 & 67.6 & 66.5 \\
\hline Female-headed & 79.4 & 64.1 & 68.4 & 67.2 \\
\hline Not female-headed & 84.5 & 70.5 & 73.0 & 69.8 \\
\hline Urban & 90.0 & 83.4 & 80.1 & 78.7 \\
\hline Rural & 78.6 & 57.1 & 68.0 & 62.5 \\
\hline Urban governorates & 92.8 & 88.2 & 84.2 & 83.4 \\
\hline Lower Egypt & 86.0 & 68.3 & 71.6 & 69.0 \\
\hline Upper Egypt & 74.9 & 56.8 & 67.8 & 61.3 \\
\hline No. of cases & 2,917 & 3,009 & 3083 & 2826 \\
\hline
\end{tabular}

Parents' opinions on the highest level of education that girls and boys should reach is highly correlated with the parents' own educational attainment, type and place of residence, region of residence, household socioeconomic status, and type of household. Highly educated parents, residents of urban governorates, higher-status households, and nuclear households had higher educational aspirations for their young members compared to other groups. 
On the other side, adolescents' educational aspirations among those currently enrolled are quite high. A minority ( $2 \%$ ) say they would only like to continue in school until the end of preparatory, the end of the stage of basic education required by law in Egypt. More respondents $(27 \%)$ say they wanted to finish secondary school or above intermediate, and 70 percent say they want to finish university.

Aspiration is directly related to achievement. Eighty-six percent of adolescent boys who have never failed a subject express a desire to finish university compared to 46 percent among adolescent boys who have repeated at least one year of school. Corresponding percentages among adolescent girls are 81 percent and 40 percent, respectively. The lower aspirations expressed by older adolescents probably reflect a more realistic view of their own scholastic performance and ability. Moreover, a large proportion of older adolescents is already enrolled in vocational school, hence they have less access to university education. Nonworking adolescents have higher educational aspirations than working adolescents. Residents of urban areas and the urban governorates are also found to have higher aspirations than those in rural areas and in both Lower and Upper Egypt. The higher the socioeconomic background of the adolescent, the higher the educational aspirations.

Among adults who specified a particular level of education as ideal, there is a high overlap between parents' and adolescents' educational aspirations; 79 percent among the boys and 74 percent among the girls. A lower proportion constitutes those parents whose aspirations are lower than their children's (12\% for girls and 6\% for boys). About 13 percent of parents have higher aspirations for their children than the adolescents have for themselves. Two-thirds of parents who left this decision up to their adolescents have adolescents with university level aspirations and one-third have adolescents with below university level with no gender differential.

\section{The VAlue of Education}

Adolescents form an opinion of the value of education through different channels, such as what they perceive in their own communities, from the media, from the school itself, and from their parents and siblings. A high proportion of adolescents, 42 percent, believes that the value of education is in acquiring social status. Thirty-seven percent think it is important simply to learn to read and write, while an equal proportion say it would help them to deal with life's problems (33\%) and help them find a respectable job (32\%). Only 6 percent associated education with higher financial status or a well-paid job (Table 5.9).

Those who believe that social status is the value of education have higher achievement levels, and slightly more of them are boys. This category includes slightly more nonworking than working adolescents, more adolescents from the urban governorates and Lower Egypt than from Upper Egypt, and more from higher to middle socioeconomic groups than lower. Of those who say they only see education as an opportunity to gain reading and writing skills, many more are from rural than urban areas (41.9\% versus $29.5 \%$ ) and more are younger than older (41.3\% versus $28.4 \%$ ). They are also more concentrated in Upper Egypt, followed by Lower Egypt and then by the urban governorates, and more of them are among lower to middle socioeconomic groups. 
Table 5.9: Percent distribution of adolescents' perspectives on the value of education, by selected background characteristics

\begin{tabular}{|c|c|c|c|c|c|}
\hline & $\begin{array}{l}\text { Social } \\
\text { status }\end{array}$ & $\begin{array}{c}\text { Find respectable } \\
\text { job }\end{array}$ & $\begin{array}{l}\text { Deal with } \\
\text { life } \\
\text { problems }\end{array}$ & $\begin{array}{c}\text { Gain } \\
\text { reading/ } \\
\text { writing } \\
\text { skills }\end{array}$ & $\begin{array}{c}\text { Better } \\
\text { financia } \\
\text { status }\end{array}$ \\
\hline Total & 42.0 & 31.8 & 33.1 & 36.8 & 6.4 \\
\hline Repeat & 33.0 & 30.9 & 31.4 & 43.4 & 5.8 \\
\hline Re-exam & 38.6 & 31.1 & 31.9 & 39.2 & 5.9 \\
\hline Neither & 46.2 & 32.5 & 34.2 & 33.8 & 6.7 \\
\hline Boys & 44.4 & 36.0 & 30.0 & 34.8 & 8.3 \\
\hline Girls & 39.3 & 27.2 & 36.8 & 39.2 & 4.2 \\
\hline $10-14$ years & 40.5 & 32.6 & 28.9 & 41.3 & 5.1 \\
\hline $15-19$ years & 44.8 & 30.5 & 41.1 & 28.4 & 8.9 \\
\hline Working & 36.3 & 35.6 & 30.1 & 41.4 & 7.1 \\
\hline Nonworking & 43.7 & 30.7 & 34.1 & 35.5 & 6.2 \\
\hline \multicolumn{6}{|l|}{$\begin{array}{l}\text { Socioeconomic } \\
\text { status }\end{array}$} \\
\hline Low & 36.9 & 35.6 & 28.2 & 41.3 & 8.9 \\
\hline Middle & 42.4 & 29.9 & 34.1 & 37.7 & 5.6 \\
\hline High & 47.4 & 31.6 & 36.8 & 31.2 & 5.6 \\
\hline Nuclear & 42.7 & 32.1 & 34.3 & 35.5 & 6.3 \\
\hline Extended & 39.7 & 31.2 & 29.4 & 41.1 & 6.8 \\
\hline Female-headed & 42.1 & 34.5 & 35.9 & 34.1 & 4.4 \\
\hline Not female-headed & 42.0 & 31.6 & 32.9 & 37.1 & 6.6 \\
\hline Urban & 45.4 & 31.5 & 36.5 & 29.5 & 5.4 \\
\hline Rural & 39.7 & 32.1 & 30.8 & 41.9 & 7.1 \\
\hline Urban govs. & 48.5 & 31.9 & 36.1 & 24.2 & 6.4 \\
\hline Lower Egypt & 45.5 & 28.8 & 37.8 & 35.2 & 7.8 \\
\hline Upper Egypt & 34.0 & 35.6 & 25.8 & 46.0 & 4.7 \\
\hline No. of cases & 2,384 & 1,787 & 1,906 & 2,095 & 344 \\
\hline
\end{tabular}

As for those who find education helpful in dealing with life's problems, more of them are female than male, and many more of them are older than younger (41.1\% versus $28.4 \%$ ). Further, many more of them are from the urban governorates $(36.1 \%)$ and Lower Egypt $(37.8 \%)$ than from Upper Egypt $(25.8 \%)$ and more are in higher socioeconomic groups than lower. Among those who value education as a way to get a respectable job, more are boys than girls, and slightly more are working than non-working.

The benefits of education for boys most commonly cited by parents are improving one's chances of finding any job (62\%), dealing better with life $(41 \%)$, and being well-cultured $(32 \%)$. The benefits for girls cited are being a better mother $(48 \%)$, dealing better with life $(41 \%)$, and knowing how to read and write $(28 \%)$.

One of the ways parents transfer their attitudes about education to their children is through their reactions to the high and low grades received by their school children (Table 5.10). 
Seventy percent of adolescents say their parents encourage them when they get good grades and 23 percent say their parents actually give them some kind of reward. There is no gender differential between these responses, but encouragement seems to be given more to older adolescents and reward more to younger adolescents.

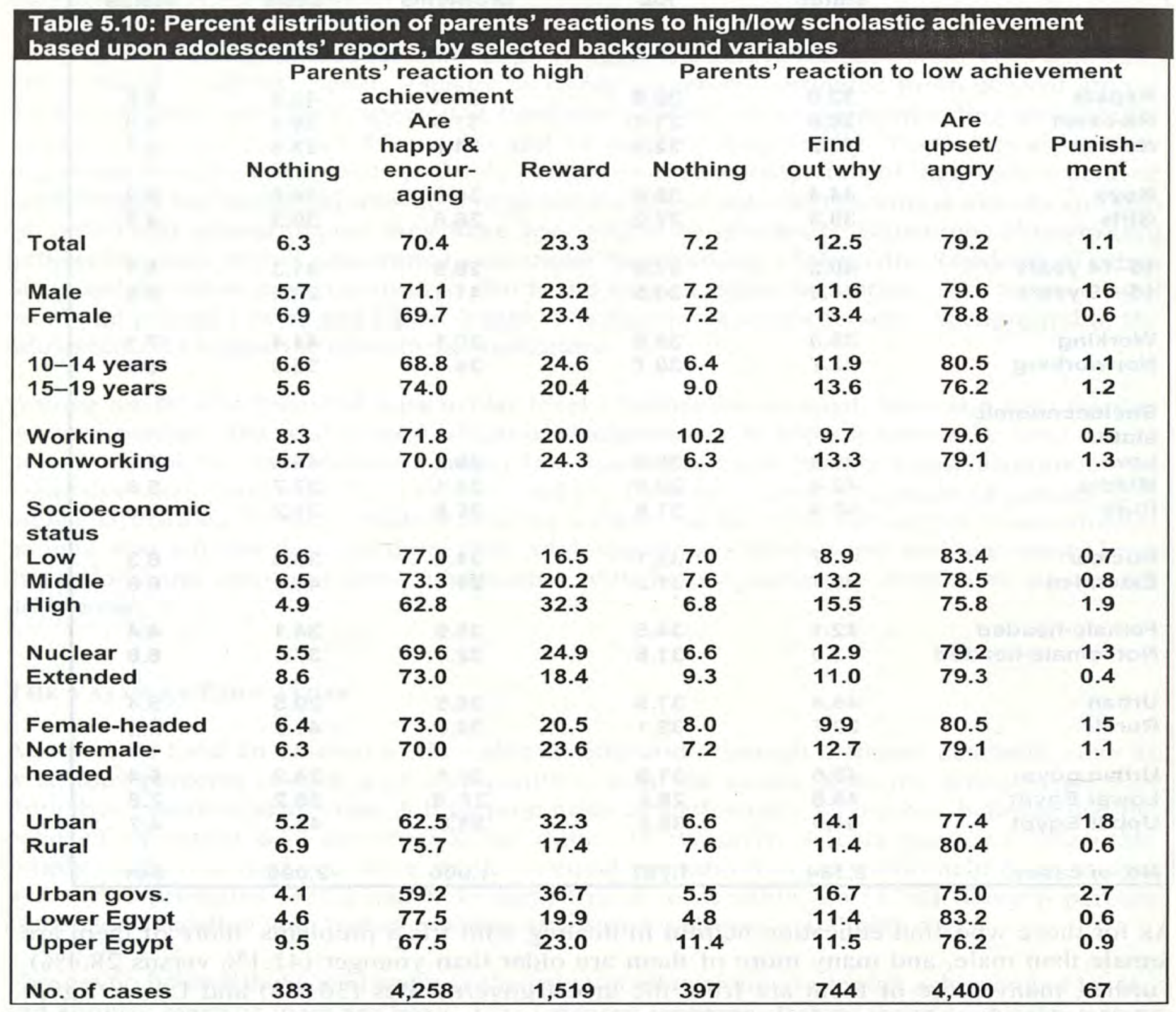

More working adolescents report parental indifference than nonworking adolescents, who seem to get more reward. There are large urban/rural and regional differentials, as rural adolescents report receiving more encouragement while urban adolescents receive more reward. This may all be associated with socioeconomic status as the higher-status adolescents are more likely to receive reward and the lower-status adolescents to receive encouragement. There are slight differences by type of household; that is, extended families and femaleheaded households give more encouragement and less reward. Relatively high levels of no responses from parents are recorded among Upper Egypt and extended families. 
In the case of low grades, 79 percent of adolescents report that their parents get angry, 13 percent say their parents try to find out what the problem is, and 1 percent punish their children. Only some regional and socioeconomic status variations are apparent as more adolescents from the urban governorates say parents try to find out why, while more from Lower Egypt report parents getting angry, and more from Upper Egypt report that their parents do nothing. Low socioeconomic status is related more to a reaction of anger while middle and high socioeconomic status is related to an attempt to understand why.

\section{The School as a Socializing Agent}

The school also influences the community around it and transmits certain values to its students as part of their socialization process. Several different variables were selected merely as indicators of the kinds of values the school may be conveying to adolescents (Table 5.11). The first is the extent of exposure to the opposite sex. Forty-one percent of adolescents currently in school report having mixed classes, this being more common in rural areas than urban (52.8\% and 23.2\%, respectively) and highest in Upper Egypt (49.2\%). Exposure to the opposite sex seems to decrease with age, as younger adolescents report mixed classes more than adolescents aged 15-19 years (53.3\% and $15.3 \%$, respectively). The low overall percentage in mixed classes reflects the relatively low prevalence of mixed schools and the fact that not all mixed schools have mixed classes as well.

Unequal treatment in school may introduce a sense of injustice in the world to the adolescent at a young age. One example of this can be differences in treatment by gender. Among adolescents currently in mixed schools, however, not many $(12.4 \%)$ seem to have the perception that the school discriminates in treatment between boys and girls. There is a large differential by age in this, as twice as many older than younger adolescents $(20.7 \%$ and $10.8 \%$, respectively) report unequal treatment by gender. This also seems to be more common in the urban governorates $(18.8 \%)$ than in Lower and Upper Egypt $(13.3 \%$ and $10.0 \%$, respectively). Differences in treatment that are not gender-based (for example, discrimination based on socioeconomic status) seem to be more common (23.4\%). Age was again a factor as older adolescents report this more than younger. There are also urban/rural and regional differentials as adolescents in urban areas $(28.3 \%)$ report this more than adolescents in rural areas (19.6\%), and Lower and Upper Egypt (23.9\% and 19.7\%, respectively).

Certain classroom practices can also affect the personality of the student and ingrain certain values in them. One example is the extent to which the teacher encourages students to voice their opinions. More than two-thirds of adolescents currently in school say this often or always happens in their class. Younger adolescents report this more than older. There are also some regional and urban/rural differentials. More adolescents from rural areas and Lower and Upper Egypt report this than adolescents from urban areas and the urban governorates. 


\begin{tabular}{|c|c|c|c|c|c|c|c|}
\hline & $\begin{array}{c}\% \\
\text { In mixed } \\
\text { classes }\end{array}$ & $\begin{array}{l}\text { In mixed } \\
\text { schools } \\
\text { reporting } \\
\text { gender- } \\
\text { based } \\
\text { unequal } \\
\text { treatment }\end{array}$ & $\begin{array}{c}\text { Reporting } \\
\text { non-gend } \\
\text { er-based } \\
\text { unequal } \\
\text { treatment }\end{array}$ & $\begin{array}{l}\text { Reporting } \\
\text { teachers } \\
\text { encour- } \\
\text { age } \\
\text { students' } \\
\text { opinions }\end{array}$ & $\begin{array}{l}\text { Able to } \\
\text { express } \\
\text { own } \\
\text { opinion } \\
\text { freely in } \\
\text { class }\end{array}$ & $\begin{array}{l}\text { Reporting } \\
\text { class } \\
\text { cooper- } \\
\text { ates and } \\
\text { like each } \\
\text { other }\end{array}$ & $\begin{array}{c}\text { Reporting } \\
\text { teachers } \\
\text { hit } \\
\text { students } \\
\text { in class }\end{array}$ \\
\hline Total & 41.0 & 12.4 & 23.4 & 69.4 & 54.9 & 86.7 & 54.1 \\
\hline Boys & 41.9 & 11.9 & 22.8 & 71.5 & 59.4 & 87.6 & 61.4 \\
\hline Girls & 39.9 & 13.1 & 24.0 & 67.2 & 49.8 & 85.8 & 46.1 \\
\hline $10-14$ years & 53.3 & 10.8 & 20.6 & 72.2 & 54.8 & 87.0 & 60.7 \\
\hline $15-19$ years & 15.3 & 20.7 & 29.7 & 63.2 & 53.3 & 86.2 & 38.9 \\
\hline Working & 45.2 & 11.6 & 20.8 & 72.4 & 56.3 & 87.5 & 58.9 \\
\hline Nonworking & 39.7 & 12.7 & 24.1 & 68.5 & 54.4 & 86.6 & 52.6 \\
\hline \multicolumn{8}{|l|}{$\begin{array}{l}\text { Socioeconomic } \\
\text { status }\end{array}$} \\
\hline Low & 46.1 & 11.3 & 20.9 & 72.9 & 56.9 & 88.1 & 57.4 \\
\hline Middle & 41.2 & 12.7 & 24.8 & 68.1 & 53.7 & 86.5 & 56.0 \\
\hline High & 37.0 & 14.3 & 24.4 & 67.9 & 54.0 & 85.5 & 40.6 \\
\hline Nuclear & 39.0 & 13.5 & 24.5 & 68.7 & 54.3 & 86.2 & 53.4 \\
\hline Extended & 46.9 & 9.7 & 19.5 & 71.7 & 56.4 & 88.4 & 56.0 \\
\hline Female-headed & 37.0 & 15.4 & 26.2 & 66.0 & 52.4 & 84.3 & 54.8 \\
\hline $\begin{array}{l}\text { Not Female- } \\
\text { headed }\end{array}$ & 41.4 & 12.2 & 23.1 & 69.7 & 55.1 & 87.1 & 53.9 \\
\hline Urban & 23.2 & 16.3 & 28.3 & 60.5 & 51.3 & 83.3 & 49.9 \\
\hline Rural & 52.8 & 11.4 & 19.6 & 75.3 & 57.2 & 89.0 & 56.9 \\
\hline Urban govs. & 19.5 & 18.8 & 28.1 & 55.4 & 47.7 & 80.8 & 44.2 \\
\hline Lower Egypt & 43.7 & 13.3 & 23.9 & 75.1 & 55.3 & 88.4 & 58.3 \\
\hline Upper Egypt & 49.2 & 10.0 & 19.7 & 69.9 & 58.0 & 87.9 & 54.0 \\
\hline No. of cases & 2,548 & 446 & 1,432 & 4,270 & 3,382 & 5,320 & 3,338 \\
\hline
\end{tabular}

If the student feels he or she is able to stand up in class and express an opinion freely, this may indicate some measure of how the classroom situation can help to build self-confidence. Fifty-five percent of adolescents currently in school say they often or always do this. This is indicative of individual character, but also of the perception of the classroom setting as one that is not hostile or intimidating.

Eighty-seven percent of adolescents currently in school see their classmates as generally cooperative with each other and liking each other. Some urban/rural and regional differentials are also observed.

Finally, classroom practices may teach students to resort to aggression to resolve conflicts or to express anger or punishment. Among adolescents in school, 54 percent say that hitting by teachers always or often happens in the school. Males report this more than females $(61.4 \%$ versus $46.1 \%$ ), and younger adolescents more than older (60.7\% versus $38.9 \%)$. Hitting 
students in class occurs more in rural areas (56.9\%) than in urban areas $(49.9 \%)$. Aside from becoming part of the learning experience of adolescents, hitting in class and the fear and tension it creates have potential negative consequences on the psychological development of adolescents in school.

\section{DISCUSSION AND POLICY IMPLICATIONS}

Over the last 10-15 years, accessibility to the basic education system in Egypt has significantly increased. According to the findings from the ASCE survey, the decline in the proportion of adolescents who never attended school is mainly due to the improvement in school enrollment of girls, adolescents from poor households, and residents of Upper Egypt. The proportion of girls who never attended school dropped from 21 percent among 19-yearolds to 13 percent among the youngest cohort aged 10 in 1997. Comparable figures for adolescents from poor households are 26 percent and 13 percent, and for adolescents in Upper Egypt, the figures are 30 percent and 15 percent.

In the school year $1996 / 1997$ net enrollment in primary education among 8-11-year-olds was around 90 percent. Enrollment among this age group provides a better representation of net enrollment in primary education than the conventional 6-10 year age group. Despite the fact that parents are required by the law to register their children in primary education at the age of 6 , less than half abide by the law. A significant proportion of parents delays registering their children until the ages of 7 or 8 . Concomitant to the rise in enrollment, over 90 percent of students enrolled in basic education reported taking less than one half-hour to travel to school (one way) with no urban/rural differentials.

Lack of economic resources, reported by half of those who never attended school, remains the major cause underlying the deprivation of education for some groups. Increasingly, this group is becoming more selective, comprising only children who are most vulnerable to contextual fluctuations in the economy and at the household level, namely the poor and girls in rural Upper Egypt. One-third of girls aged 10 in rural Upper Egypt and 13 percent of boys and girls in the same age who belong to households in the lowest socioeconomic stratum of the population have never attended school.

The results of the ASCE survey emphasize a general decline in dropout rates from one cohort to the next among most subgroups, particularly girls (in the primary and preparatory stages), adolescents in the low socioeconomic category (in primary only), and adolescents in rural Lower and Upper Egypt. Deviations from this general trend are observed mainly among boys and among adolescents in urban areas whereby the percent of dropouts among those who ever attended school is either stable or shows some increase. Among interviewed adolescents aged 14 in 1997 who ever attended school, 16 percent of the girls and 23 percent of the boys had dropped out.

Collaboration among key actors (the state, schools, NGOs, and parents) is deemed necessary for serious improvement to be achieved. NGOs, in particular those working closely with the population in poor communities, can play a major role. Raising awareness among parents in regard to both the importance of education (of girls in particular) and the necessity of obtaining basic official documents for their children, emphasizing early registration of children in primary schools, encouraging those who were late to register, and establishing daycare centers for children 3-5 years old in these communities to prepare both parents and 
children for a smooth transition to enrollment in primary education are some of the measures that can be implemented. School administrators in these communities should be instructed to show some degree of flexibility and cooperation with parents who are mostly illiterate and apprehensive of dealing with government officials, even in schools.

Nevertheless, the state and the policies of the Ministry of Education remain the key actor. Raising the upper limit of age for enrollment in primary schools from 8 to 10 years is a necessary first step. More importantly, providing literally free education for the vulnerable groups is a prerequisite to close the file on deprivation from education.

The cost of education is not only confined to school tuition. It encompasses the cost of the school uniform, needed stationary, and daily allowance (or the cost of a snack), in addition to private tutoring. The percent of students reporting taking private tutoring is higher wherever class density is relatively higher and also where a lower level of teacher/student scholastic interaction is reported. Overall, 52 percent of students in basic education resort to private tutoring.

While waiving school fees and providing students with a safe and nutritious school meals in selective locations fall in the domain of state policies, schools and NGOs can also play an important role. Emphasizing good teaching and close monitoring of the scholastic performance of this group is essential since poor achievement combined with lack of economic means provide strong justification for school dropout, which is the case in Egypt.

According to the interviewed adolescents, poor scholastic performance stands out as the main reason for dropping out. This holds among the two sexes, in all five regions, and regardless of the social and economic status of the household of the adolescent interviewed. Since inschool adolescents who come from poor households are also more likely to be poor achievers due to less than ideal health status or other social or economic barriers, they end up being more likely to drop out. Over one-third of adolescents who dropped out referred to their poor scholastic performance as the main reason for dropping out. This finding is consistent with another result emphasizing the link between educational aspiration and scholastic achievement. More than eighty percent of adolescents who never failed a subject expressed a desire to finish university, compared to 42 percent among adolescents who repeated at least once. Otherwise, differentials in aspirations by gender were minor. Next in order of magnitude, one-fifth of dropouts referred to low value/interest in education by the adolescent and/or parents as the main reason for leaving school, followed by school reasons and lack of economic resources, especially among respondents in the low socioeconomic category.

School-related reasons for dropout combine dislike of school and teachers' bad treatment. Bad treatment by teachers was expressed most in urban areas and among male adolescents. On the whole only half of eligible adolescents reported a positive attitude toward school. Large differentials were also observed in regard to the presence of a doctor/nurse and a social counselor at school. The presence of a doctor or a nurse at school is highest in urban areas and in general secondary schools and much lower in rural areas and in basic education schools. The same pattern of differentials exists in regard to the presence of a social counselor at school.

Only one-third of eligible adolescents reported positively on the interaction and personal support from teachers and peers at school. This group was positive about students' attitudes toward each other, liked most of the teachers at school, and emphasized teachers' 
encouragement for expression of opinion and their involvement and support in solving students' personal problems. Contrary to the more professional support from a doctor or a social counselor, support from teachers and peers is reported highest in basic education and least in general secondary schools. It is higher in rural areas and Lower and Upper Egypt than urban areas and the urban governorates and relatively low among adolescents from high status households.

Family-related reasons for school dropout encompass help needed in household chores, family disputes, and death of either parent. These factors impact negatively on girls' school continuation more than boys in all regions, and regardless of the socioeconomic status of the household. Work and marriage were rarely stated as main reasons for leaving school among boys and girls, respectively. The data suggest that work and marriage may be options for those who have already left school for other reasons.

The results emphasize the relationship between the different determinants of the health status of adolescents and their overall scholastic performance, as indicated by experiencing reexam/repeat a year as opposed to continuous success in school. Adolescents who have a negative perception concerning their health status, those who suffer from anemia, and those who are growth-stunted are more liable to loiter in school.

A high proportion of adolescents, 42 percent, believes that the value of education is in acquiring social status. Only 6 percent associated education with higher financial status or a well-paid job. One of the ways in which parents transfer their attitudes about education to their children is through their reactions to high and low grades received by their schoolchildren. Ninety-three percent of adolescents in school said their parents encouraged them or actually gave them some kind of reward when they got good grades. There was no gender differential between these responses. In the case of low grades, 79 percent of adolescents reported their parents being angry, 13 percent said their parents tried to find out what the problem was, and 1 percent punished them.

The school also influences the community around it and transmits certain values to its students as part of their socialization. Exposure to the opposite sex in a healthy environment supportive of gender equality is an important dimension of the school experience. Forty-one percent of adolescents currently in school reported having mixed classes, this being more so in rural than urban areas. Only 12 percent seem to have the perception that the school discriminates in treatment between boys and girls. There is a large differential by age in this, as twice as many older than younger adolescents reported unequal treatment by gender. This also seemed to be more common in the urban governorates than in Lower and Upper Egypt, and in favor of girls in all cases.

Unequal treatment in school that is not gender-based seemed to be more common $(23.4 \%)$ which may introduce a sense of injustice into the world of the adolescent at a young age. Age was again a factor as older adolescents reported this more than younger. There were also urban/rural and regional differentials as adolescents in urban areas reported this more than adolescents in rural areas and Lower and Upper Egypt.

Certain classroom practices can also affect the personality of the student and ingrain certain values in him or her. One example is the extent to which the teacher encourages student opinion. More than two-thirds of adolescents currently in school said this sometimes or always happened in their classes. If the student feels he/she is able to stand up in class and 
express an opinion freely, this may indicate some measure of how the classroom situation can help to build self-confidence. Half of the adolescents currently in school said they often or always do this. This is indicative of both individual character, but also the perception of the classroom setting as one that is not hostile or intimidating.

Finally, classroom practices may teach students resorting to aggression to resolve conflicts or express anger or punishment. Among adolescents in school, 54 percent report the phenomenon of teachers hitting students. Males reported this more than females, and younger adolescents more than older. Hitting students in class occurs more in rural areas than in urban areas. Aside from becoming part of the learning experience of adolescents, hitting in class and the fear and tension it creates have potential negative consequences on the psychological development of adolescents in school.

As all key actors pull together to ensure universality of school enrollment and completion of at least basic education among boys and girls in Egypt, serious concerns exist in regard to the impact that the current school environment and the quality of education offered to students have on scholastic achievement, school continuation, and the values transmitted to them. Research on the different dimensions of input from the school environment and education is imperative. Evaluation of the education inputs and their link to education outcomes is a necessary step for the design of school interventions specially tailored to deal with specific issues. 


\section{Chapter 6}

\section{Economic Roles of Adolescents}

If childhood is characterized by dependence, and one mark of adulthood is autonomy, then becoming economically active is a major transitional step from childhood to adulthood. The timing of this transition is crucial, since premature entry into work roles may rob a child of the chances for normal development of his or her potential and have harmful effects on health and psychological wellbeing. There is a well-known relationship between educational deprivation and early entry into the work force. On the other hand, delayed entry into workroles, either because of a shortage of jobs or cultural factors hindering employment, may also have a negative effect on young people by souring their outlook on the future or hindering their ability to achieve autonomy.

The transition to work roles is one area where gender differences are often quite stark. This is true in Egypt, with boys both more likely to suffer from very early economic activity and more likely to benefit from work opportunities as they approach full adulthood. For these reasons it is an important area of study, as well as a landmark in the lives of many individuals. Investigation of the level of activity among adolescents, their work conditions, and the relevance of their labor force participation to their psychological development, health status, and educational attainment is of utmost significance.

This chapter aims to document the current experience of Egyptian adolescents in the labor market. We have defined work to include both unpaid and gainful employment in all sectors including agriculture. Gainful employment encompasses any work from which an individual earns income. It includes work for cash (paid work) as well as self-employment. Unpaid work is defined as help in an income-generating activity, for which an individual does not receive payment. Other less formal types of unpaid work, such as household chores, that do not generate income, are not considered. Responses to the following three questions in the ASCE survey were utilized to identify working adolescents in unpaid work, paid work, and selfemployment, respectively:

1. Currently (during the week preceding the survey), do you regularly help anyone in his/her work without getting remuneration, for example, on a farm or in a business?

2. Currently (during the week preceding the survey), do you work for cash as an employee?

3. Currently (during the week preceding the survey), do you carry out activities or make anything on your own from which you earn income (self-employed)?

\section{ADOLESCENTS' PARTICIPATION IN ECONOMIC ACTIVITIES: CURRENT EXPERIENCE}

Findings from the survey show that 44 percent of adolescents aged 10-19 in Egypt have ever worked, be it for cash, in self-employment, or by helping others in their work without pay. On the whole, one-third of sampled adolescents $(32 \%)$ report current involvement in economic activities during the week preceding the interview. One-fifth were regularly 
engaged in unpaid employment during the week preceding the survey while 12 percent have paid jobs and 2 percent identify themselves as self-employed. These reported figures include 2 percent of adolescents involved in both paid and unpaid employment and 2 percent that are self-employed and also engaged in other types of economic activities. It is worth mentioning that the two latest laws regulating child labor in Egypt, issued in 1981 and 1996, have excluded work in the agricultural sector and domestic services from work activities that are governed by the law. Findings from this survey reveal that 67 percent and 28 percent respectively of adolescents' unpaid and gainful employment is concentrated in agriculturalrelated activities.

\section{Figure 6.1:Distribution of working adolescents by type of employment.}

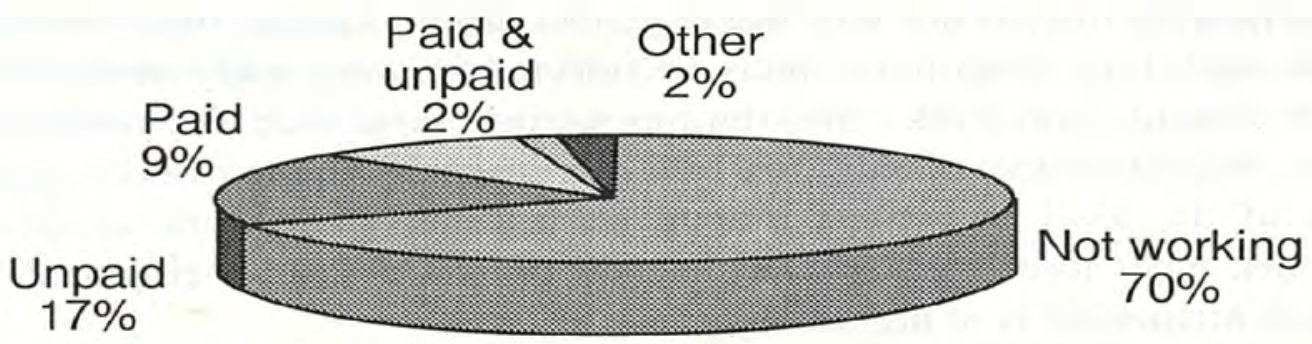

\section{PROFILE OF WORKING ADOLESCENTS}

This section attempts to draw the demographic profile of working adolescents; age and gender differentials as well as urban/rural and regional variations are considered. Subsequently, interrelationships between work status and educational attainment are examined. Finally, the age of the adolescent at initial entry into the labor market is addressed together with the main reason underlying such an important decision.

\section{Age and Gender Differentials}

Before 1996, there was an inconsistency between the Education Law 139/1981 and the Labor Law 136/1981 in Egypt; the former defined education as mandatory up to age 14, while the latter legalized work starting at age 12. In 1996, a new labor law was passed regulating child labor and rectifying this inconsistency. Child labor below the age of 15 was banned and training of children was totally prohibited before the age of 12 . However, as in all developing societies, the reality is that underage work exists, and therefore needs to be better understood. Similarly, the problems of finding work for older, out-of-school adolescents require careful analysis.

Age and gender differentials are quite evident among economically active adolescents in Egypt (Figures 6.2-6.5). Almost one in every two male adolescents and one in every six 
females are engaged in economic activities. Girls constitute one-third of unpaid employment but only one-fifth of paid employment among adolescents in Egypt.

Figure 6.2:Distribution of working adolescents in unpaid employment, by sex.

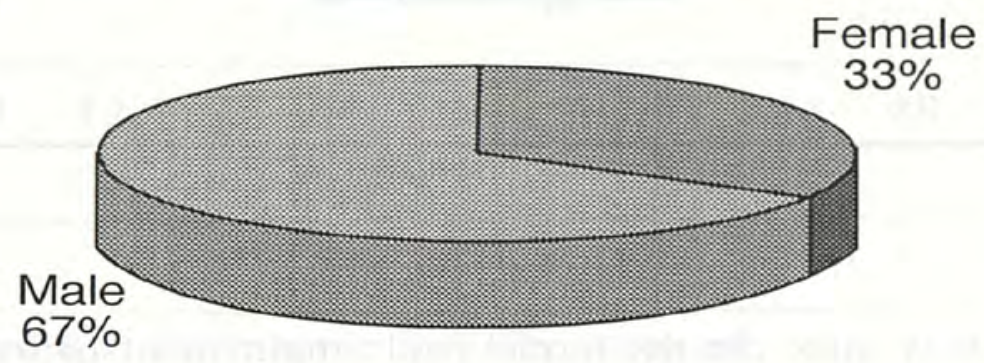

Figure 6.3:Distribution of working adolescents in paid employment, by sex.

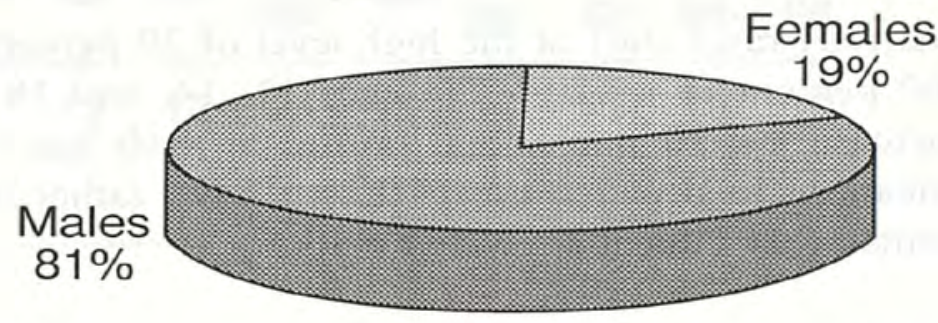

Figure 6.4:Distribution of working adolescents in unpaid employment by age.

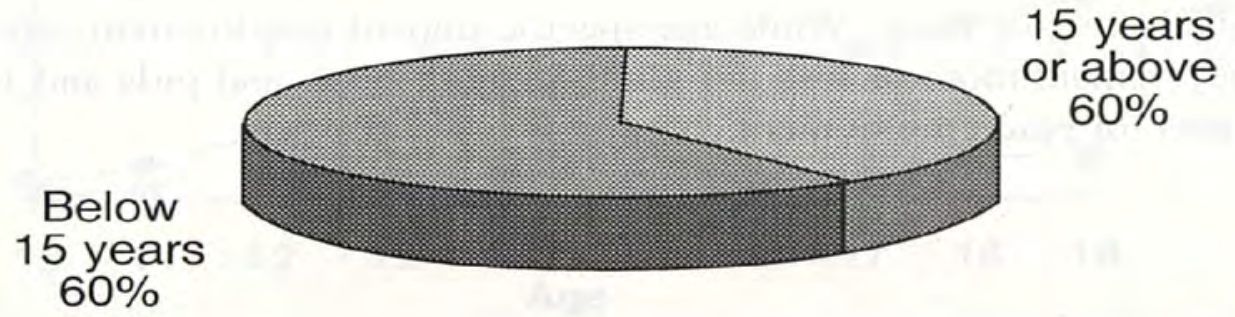




\title{
Figure 6.5:Distribution of working adolescents in paid employment by age.
}

\author{
Below \\ 15 years \\ $35 \%$
}

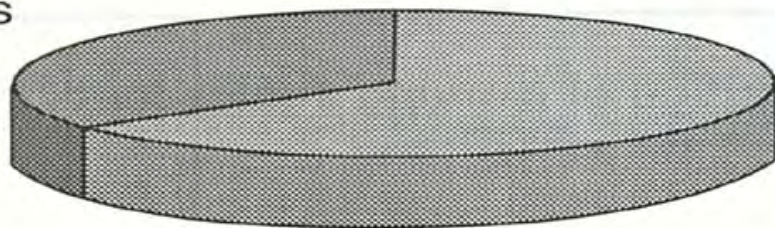

15 years

or above

$65 \%$

As Figures 6.6-6.8 show quite clearly, formal paid employment patterns of girls and boys diverge as they grow older. While few boys or girls are in paid work in the ages 10-12, by age 19 employment rates for boys have risen to nearly 40 percent, while employment rates for girls remain under 10 percent.

Among economically active adolescents, 52 percent are under the minimum legal age for work. More specifically, 60 percent of adolescents in unpaid employment and 35 percent of those in paid employment are below age 15 .

Among adolescent boys, activity rates start at the high level of 29 percent at age 10 and rise systematically to reach 60 percent at age 19 . The ages 11,14 , and 18 are clear transition points: Activity rates increase by 10 percentage points at each age. These ages do not conform to the age specifications as declared by the Labor Law; rather, they correspond to well-defined transition points in the education system.

For girls, the profile of activity rates is starkly different. Girls at age 10 are less likely to be economically active than boys ( $13 \%$ compared to $29 \%)$. Activity rates among girls increase from 13 percent to 19 percent throughout adolescence. It is worth noting that while biological and physical growth are closely linked to increased participation of male adolescents in the labor market, increasing with increasing age, such a relationship does not exist among adolescent girls.

Paid employment among boys and girls increases systematically throughout adolescence though at much higher rates for boys. While age-specific unpaid employment rates show an irregular pattern, they remain more or less the same for both boys and girls and higher than the corresponding rates for paid employment. 
Figure 6.6: Economic activity rates, by sex

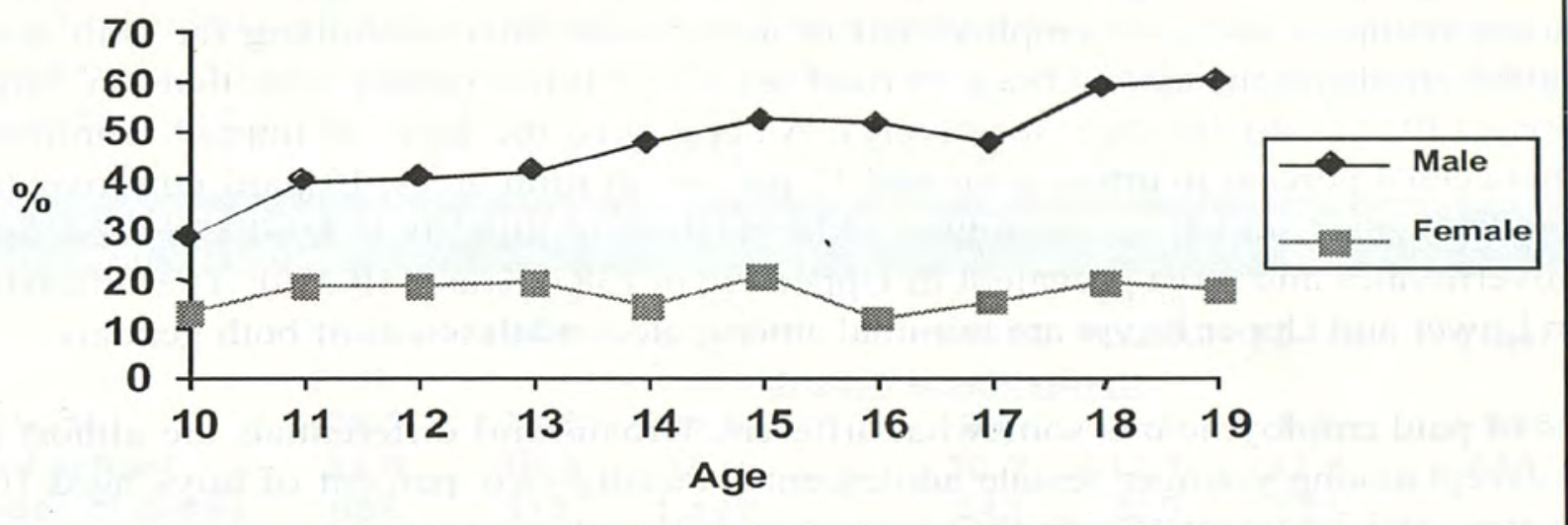

Figure 6.7: Economic activity rates in unpaid employment, by sex

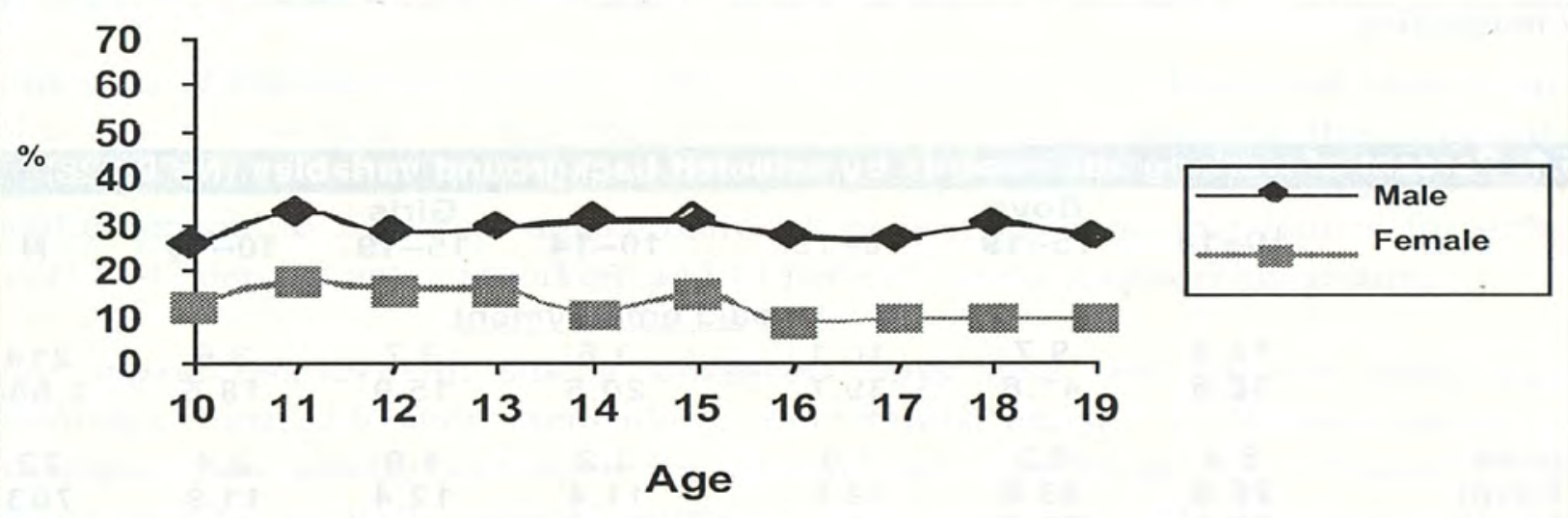

Figure 6.8: Economic activity rates in paid employment, by sex

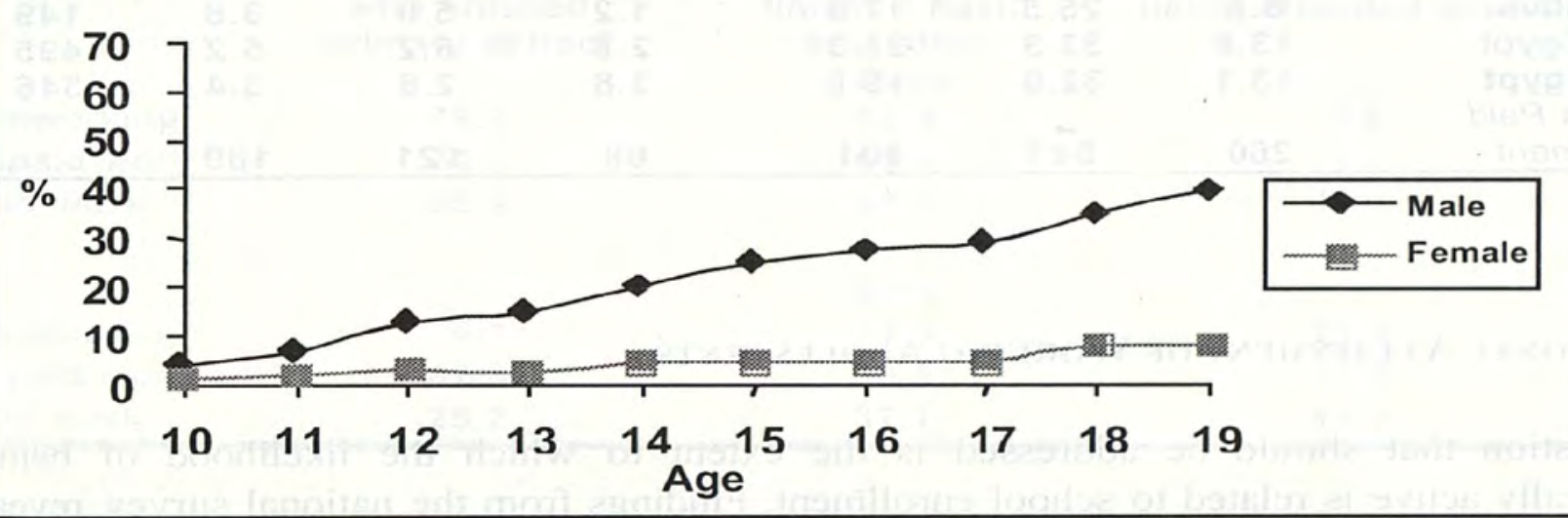


Table 6.1 highlights the significance of urban/rural as well as regional differentials in engagement in unpaid and paid employment of adolescents after controlling for both sex and age. Unpaid employment among boys in rural areas is 4 times greater than that for boys in urban areas (39.7\% and 10.1\% respectively). Among girls, the level of unpaid employment ranges between 4 percent in urban areas and 19 percent in rural areas. Unpaid employment in rural areas is higher among younger than older adolescent girls. It is least prevalent in the urban governorates and most prevalent in Upper Egypt (38.1\% and 19.3\%). The differentials between Lower and Upper Egypt are minimal among older adolescents of both genders.

The case of paid employment is somewhat different. Urban/rural differentials are almost nonexistent except among younger female adolescents. Twenty-two percent of boys aged 10-19 in urban areas and 3 percent of girls are engaged in paid employment. The urban governorates have the lowest paid employment rates among boys (particularly before age 15) while no obvious differences exist between Lower and Upper Egypt irrespective of age. These findings suggest that there is both a supply of working boys in urban areas of Lower and Upper Egypt and a demand for this supply in the labor market, and that these two forces are actively interacting.

\begin{tabular}{|c|c|c|c|c|c|c|c|}
\hline & $10-14$ & $\begin{array}{c}\text { Boys } \\
15-19\end{array}$ & $10-19$ & $10-14$ & $\begin{array}{c}\text { Girls } \\
15-19\end{array}$ & $10-19$ & $\mathbf{N}$ \\
\hline & \multicolumn{7}{|c|}{ Unpaid employment } \\
\hline $\begin{array}{l}\text { Urban } \\
\text { Rural }\end{array}$ & $\begin{array}{l}10.5 \\
38.5\end{array}$ & $\begin{array}{c}9.7 \\
41.6\end{array}$ & $\begin{array}{l}10.1 \\
39.7\end{array}$ & $\begin{array}{c}3.6 \\
20.5\end{array}$ & $\begin{array}{c}3.7 \\
15.9\end{array}$ & $\begin{array}{c}3.6 \\
18.5\end{array}$ & $\begin{array}{c}219 \\
1,550\end{array}$ \\
\hline $\begin{array}{l}\text { Urban govs. } \\
\text { Lower Egypt } \\
\text { Upper Egypt } \\
\text { Cases in Unpaid }\end{array}$ & $\begin{array}{c}5.4 \\
26.6 \\
39.0\end{array}$ & $\begin{array}{c}8.3 \\
33.6 \\
36.2\end{array}$ & $\begin{array}{c}7.0 \\
29.8 \\
38.1\end{array}$ & $\begin{array}{c}3.2 \\
11.4 \\
21.6\end{array}$ & $\begin{array}{c}1.9 \\
12.4 \\
15.3\end{array}$ & $\begin{array}{c}2.4 \\
11.9 \\
19.3\end{array}$ & $\begin{array}{c}72 \\
793 \\
904\end{array}$ \\
\hline Employment & 686 & 512 & 1,198 & 342 & 229 & 571 & \\
\hline & \multicolumn{7}{|c|}{ Paid employment } \\
\hline $\begin{array}{l}\text { Urban } \\
\text { Rural }\end{array}$ & $\begin{array}{l}13.5 \\
11.8\end{array}$ & $\begin{array}{l}29.4 \\
32.3\end{array}$ & $\begin{array}{l}21.6 \\
20.5\end{array}$ & $\begin{array}{l}1.0 \\
4.1\end{array}$ & $\begin{array}{l}4.8 \\
6.7\end{array}$ & $\begin{array}{l}2.8 \\
5.2\end{array}$ & $\begin{array}{l}358 \\
632\end{array}$ \\
\hline $\begin{array}{l}\text { Urban govs. } \\
\text { Lower Egypt } \\
\text { Upper Egypt } \\
\text { Cases in Paid }\end{array}$ & $\begin{array}{c}6.0 \\
13.8 \\
13.1\end{array}$ & $\begin{array}{l}25.5 \\
33.3 \\
32.0\end{array}$ & $\begin{array}{l}17.9 \\
23.3 \\
19.8\end{array}$ & $\begin{array}{l}1.2 \\
2.8 \\
3.8\end{array}$ & $\begin{array}{l}5.9 \\
8.2 \\
2.6\end{array}$ & $\begin{array}{l}3.8 \\
5.2 \\
3.4\end{array}$ & $\begin{array}{l}149 \\
495 \\
346\end{array}$ \\
\hline Employment & 260 & 541 & 801 & 68 & 121 & 189 & \\
\hline
\end{tabular}

\section{Educational Attainment of Working Adolescents}

One question that should be addressed is the extent to which the likelihood of being economically active is related to school enrollment. Findings from the national survey reveal that more than one-fourth of males in school and 36 percent of those out of school are 
engaged in unpaid employment. The situation among the girls emphasizes the relationship even more. Out-of-school female adolescents are three times as likely to be involved in unpaid employment compared to female adolescents enrolled in school (22.6\% versus $8.0 \%$ ). Boys who are not enrolled in school are six times as likely to be gainfully employed as their peers who are (53.5\% versus $8.7 \%$ ). Interestingly, among girls, the chances are even higher, 11 times as likely (Table 6.2).

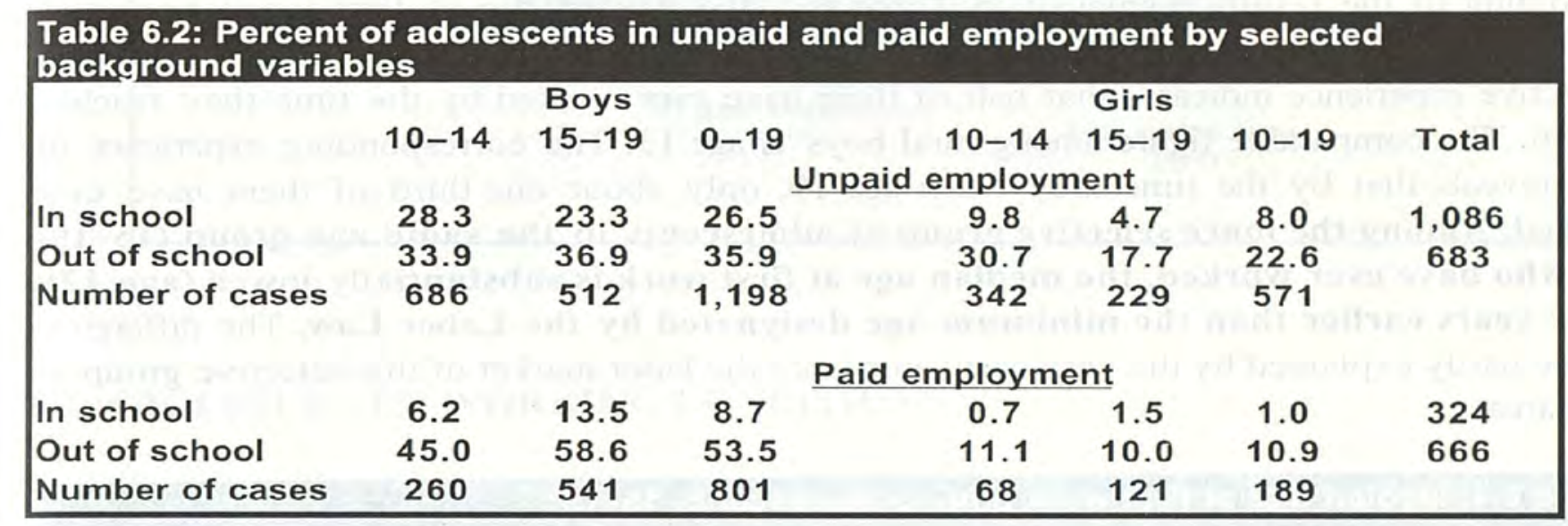

Exploration of the interrelationships between employment and educational attainment among adolescents is essential for the design of special programs targeting this segment of the population. Table 6.3 indicates that 7 percent to 10 percent of working boys never attended school compared to 2 percent among nonworking boys. Comparable figures for girls are 37 percent to 42 percent among working and 11 percent among nonworking groups.

While unpaid employment among adolescent boys does not threaten their educational attainment compared to their nonworking counterparts, unpaid employment among girls and paid employment among both sexes are detrimental. Only 56 percent of boys working for cash completed primary school compared to 79 percent of the nonworking group. Comparable figures for girls are 25 percent and 74 percent among those working for cash and those not working, respectively.

\begin{tabular}{|c|c|c|c|}
\hline betrither & $\begin{array}{l}\text { Age } 10-14 \text { years } \\
\text { who finished } \\
\text { primary school }\end{array}$ & $\begin{array}{c}\text { Age } 15-19 \text { years who } \\
\text { finished basic } \\
\text { education } \\
\text { Boys }\end{array}$ & $\begin{array}{l}\text { Age 10-19 years who } \\
\text { never attended school }\end{array}$ \\
\hline Nonworking & 79.0 & $\overline{92.9}$ & 1.6 \\
\hline Unpaid work & 74.0 & 65.4 & 7.1 \\
\hline \multirow[t]{2}{*}{ Paid work } & 55.9 & 50.1 & 10.4 \\
\hline & & Girls & \\
\hline Nonworking & 74.1 & 71.3 & 11.2 \\
\hline Unpaid work & 47.8 & 30.5 & 37.0 \\
\hline Paid work & 25.2 & 37.7 & 41.7 \\
\hline
\end{tabular}


Among older adolescents, 93 percent of nonworking boys and 71 percent of nonworking girls have completed basic education compared to 66 percent of boys and 30 percent of girls in unpaid employment and 50 percent of boys and 38 percent of girls in paid employment.

\section{Age at Entry into the Labor Force}

According to the results displayed in Table 6.4, the median age at first work among all adolescents age 15-19 is age 17.6. Among boys in this age group residing in urban areas, their collective experience indicates that half of them have ever worked by the time they reached age 16. The comparable figure among rural boys is age 13. The corresponding experience of girls reveals that by the time they reach age 19, only about one-third of them have ever worked. Among the more selective group of adolescents in the same age group (15-19) but who have ever worked, the median age at first work is substantially lower (age 12), three years earlier than the minimum age designated by the Labor Law. The difference can be partly explained by the very early entry into the labor market of this selective group in rural areas.

\section{Table 6.4: Median age at first work among adolescents 15-19}

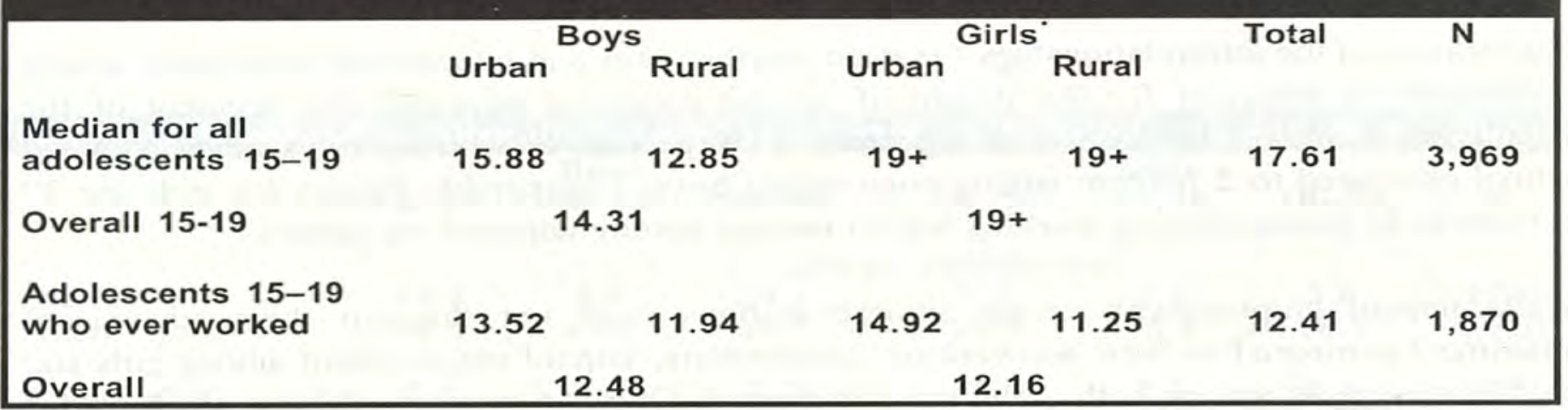

\section{REASONS FOR STARTING WORK}

Investigation of the reasons for starting work among adolescents with current or past exposure to employment is essential for the assessment of this experience (Figure 6.9). Over one-third of adolescents who have ever worked mention their families' need for their unpaid help as the main reason for starting to work, particularly among younger adolescents, females, and residents of rural areas. The second most important reason for starting work is to provide income for the family (19\%). This reason is important especially among older adolescents and residents of rural areas and of Lower Egypt. There are no differences between the two sexes. Covering their own needs (9\%) and gaining experience $(6 \%)$ are reported more among older adolescents, males, and residents of urban areas.

Poor scholastic performance and having a lot of spare time, mentioned by 5 percent and 16 percent of working adolescents, respectively, point indirectly to a probable sequence of events underlying the entry of adolescents into the labor market by emphasizing the consequential nature, rather than the deterministic role, of a decision taken to start working. 
Figure 6.9:Distribution of working adolescents by the reason they started to work

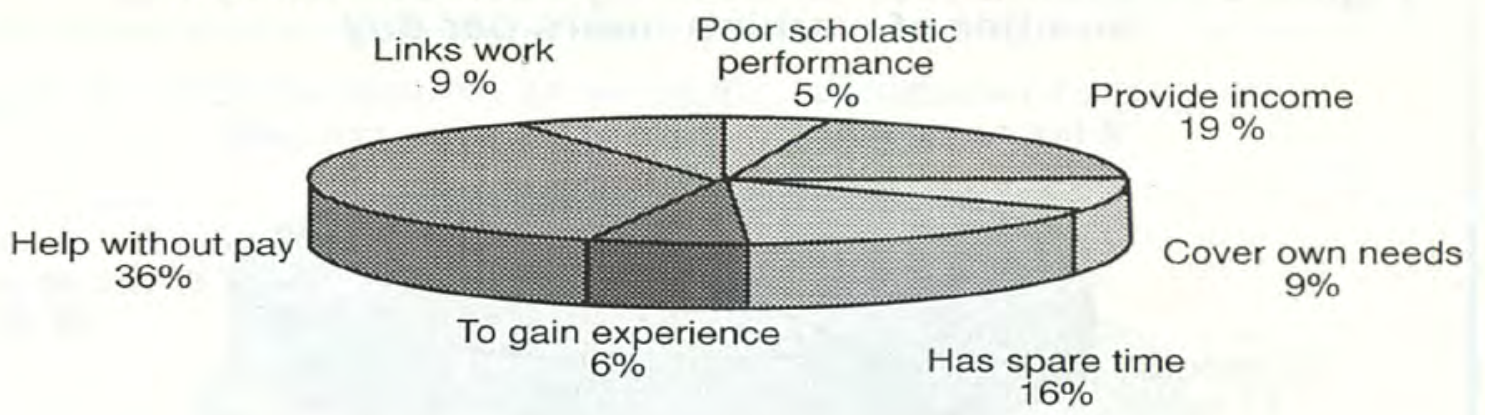

\section{ADOLESCENTS' WORKING CONDITIONS}

The high prevalence of employment among adolescents in Egypt and their early entry into the labor market justify a thorough examination of the work environment as well as working adolescents' responses to this environment.

\section{Working Days Per Week and Hours Per Day}

Reports obtained from adolescents engaged in paid or unpaid employment during the week before the interview indicate that 44 percent of them work less than six days per week, 17 percent work exactly six days, while 39 percent do not take days off from work (Figure 6.10). While the age and sex of the working adolescent are not determining factors of the number of working days per week, the type and region of residence seem to be more important: Working adolescents residing in rural areas or in Upper Egypt are more likely not to take days off compared to adolescents working in urban areas or in Lower Egypt.

For working adolescents, the Labor Law set a maximum number of working hours per day at six hours to be interrupted with breaks for meals and rest. Of all working adolescents, 58 percent work six hours or less per day while 42 percent work long hours exceeding the number designated by the law ( $17 \%$ work $7-8$ hours per day and $25 \%$ work 9 hours or more) (Figure 6.11). The number of working hours per day is dependent on all demographic factors: Male adolescents, those in the age group 15-19, and residents of urban areas are more likely to work long hours compared to their female counterparts, younger adolescents, and residents of rural areas or Upper Egypt. The most disadvantaged group, adolescents working long hours (more than 6 hours per day) and not taking days off, comprises 16 percent of all working adolescents. About 80 percent of this group are males. 
Figure 6.10:Distribution of working adolescents by the number of working hours per day

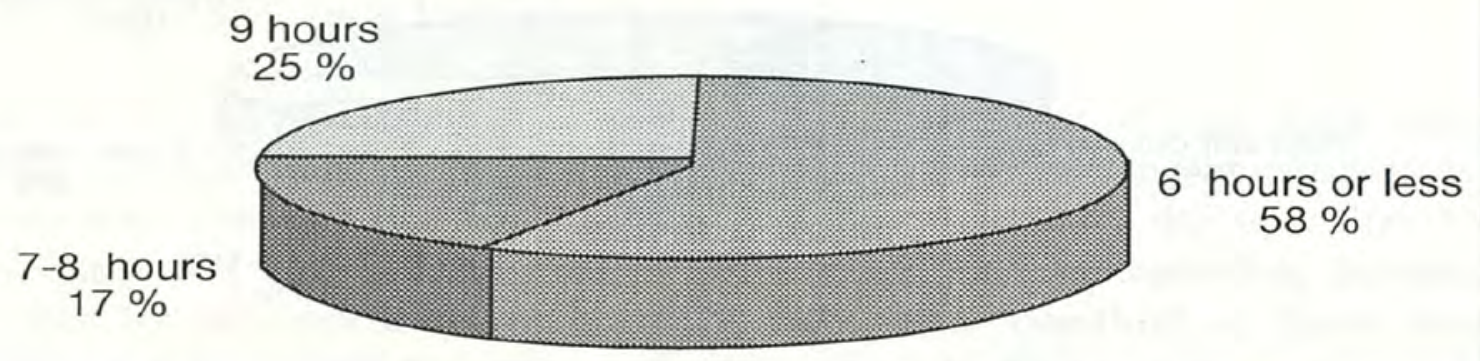

Figure 6.11: Distribution of working adolescents by the number of working days per week

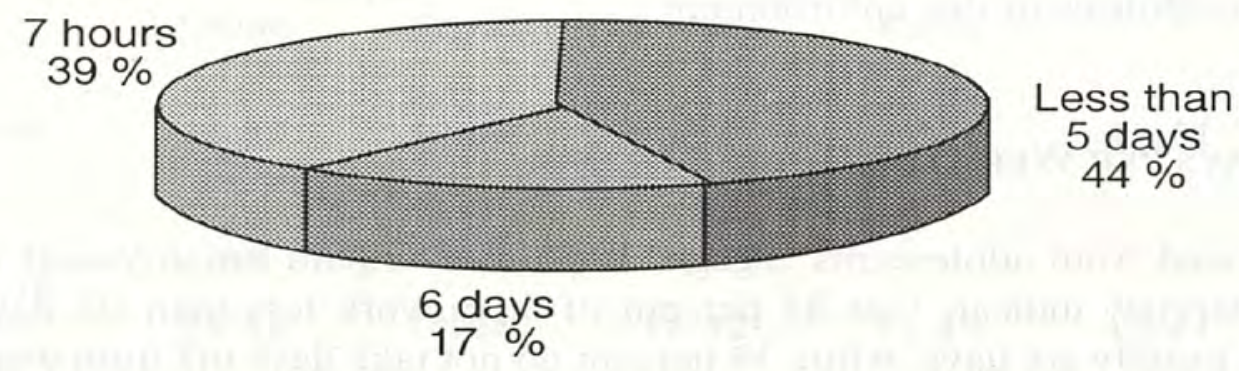

\section{STABILITY OF WORK}

One-third of adolescents working at the time of interview report they had worked for less than four months over the preceding 12 months and one-fifth report working 4-10 months. On the other hand, about half mention having worked 10-12 months. Among working adolescents, those who are younger and residents of rural areas or Upper Egypt are more likely to report shorter duration of work during the 12 months before the survey. Reports of longer duration of work are more prevalent among girls, older adolescents, and residents of urban areas or Lower Egypt.

Among adolescents engaged in paid employment, 50 percent report having stable (all year) jobs, one-quarter have seasonal jobs, and one-quarter are involved in irregular (unstable) types 


\section{Figure 6.12:Distribution of working adolescents pay by the extent of stability of work.}

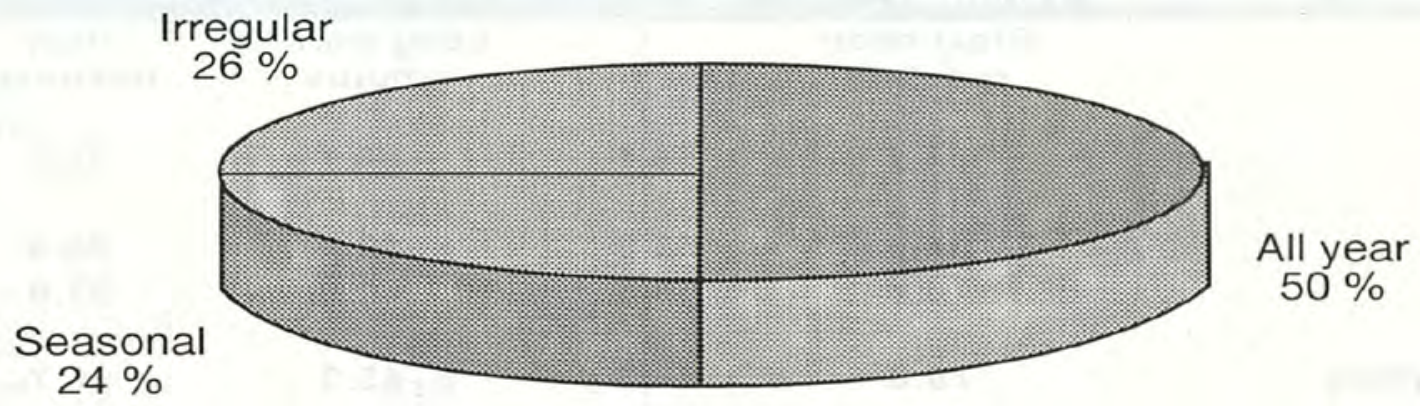

of rural areas and Upper Egypt are more likely to be engaged in unstable paid jobs. Seasonal work is more likely to be taken by younger adolescents and residents of rural areas.

\section{WORK HAZARdS}

Adolescents' work becomes a real concern if associated with hazards that might have grave physical or psychological consequences. This concern is emphasized in the Labor Law issued in 1996. Adolescents aged 15 and 16 are forbidden from working in certain jobs that are considered either immoral or hazardous to health. One-third of adolescents who have paid jobs report involvement in activities that are potentially dangerous, such as using sharp tools, working near or with fire or extreme heat, standing, sitting, or working on something high off the ground, and others. Of this group, 90 percent are males and half of them are less than 17 years of age. Engagement in dangerous paid jobs is more likely to occur in urban areas.

\section{Satisfaction with Current Paid Job}

Two-thirds of adolescents working for cash report being content with their current work and desire to continue in it. One-fifth resent their jobs and express a wish not to continue. The third group, comprising 15 percent of paid working adolescents, express inconsistent views. This conflict of attitudes probably reflects their aspirations for better jobs (if contented but do not want to continue in the same job) or a strong need for the remuneration from work (if not contented but still would like to continue).

Table 6.5 displays the percent unsatisfied with their current paid job by reason for dissatisfaction and the demographic characteristics of the respondent. Two-thirds of this group mention the great effort exerted at work as one of the reasons for dissatisfaction. This reason was mentioned more among females, younger adolescents, and residents of rural areas and Upper Egypt. Fifty-four percent complain about their low pay. Again females, older adolescents, and residents of Lower and Upper Egypt emphasize this complaint. Forty-seven percent are dissatisfied with their long working hours. This is expressed more among females 
and residents of rural areas and Lower Egypt. Bad treatment at work is cited by about onethird of dissatisfied adolescents working for cash. Younger adolescents working for cash and residents of urban areas and Upper Egypt are more likely to complain of bad treatment at work.

\begin{tabular}{|c|c|c|c|c|}
\hline & $\begin{array}{l}\text { Great effort } \\
\text { required }\end{array}$ & Low pay & $\begin{array}{l}\text { Long working } \\
\text { hours }\end{array}$ & $\begin{array}{c}\text { Poor } \\
\text { treatment }\end{array}$ \\
\hline Total & 67.1 & 54.1 & 46.7 & 30.7 \\
\hline Boys & 64.9 & 53.0 & 42.9 & 30.4 \\
\hline Girls & 76.4 & 58.3 & 62.5 & 31.9 \\
\hline $10-14$ years & 70.8 & 47.5 & 45.0 & 46.7 \\
\hline 15-19 years & 65.3 & 57.3 & 47.6 & 23.0 \\
\hline Urban & 41.6 & 42.6 & 33.7 & 41.6 \\
\hline Rural & 76.8 & 58.4 & 51.7 & 26.6 \\
\hline Urban govs. & 44.4 & 27.8 & 36.1 & 36.1 \\
\hline Lower Egypt & 66.8 & 57.1 & 49.8 & 28.1 \\
\hline Upper Egypt & 74.8 & 56.5 & 44.3 & 33.9 \\
\hline Number of cases & 155 & 112 & 107 & 67 \\
\hline
\end{tabular}

The higher level of dissatisfaction among working girls compared to boys is worth highlighting: It may reflect a higher concentration of working girls in jobs requiring relatively high levels of effort while working boys have a more variable distribution across job categories. On the other hand, the dissatisfaction of working girls may also reflect a psychological tension between their work status and traditional norms saying that work for girls is inappropriate.

\section{REMUNERATION}

\section{LEVEl of EARnings}

Data from the ASCE survey reveal that the mean monthly earnings from gainful employment among adolescents 10-19 years old amount to 122 Egyptian pounds (LE) (approximately US\$36).

One-fifth of this group of adolescents earns more than LE 175 per month. Table 6.5 provides evidence to the significant differentials in the mean earnings per month by all demographic characteristics of earners. The mean monthly remuneration is 130 and 88 Egyptian pounds per month among males and females respectively. Adolescents $15-19$ years old make twice as much money as those 10-14 years old (LE 148 and LE 76). Adolescents working in the urban governorates earn as much as LE 164 per month on average, roughly 60 percent higher than their counterparts from Lower and Upper Egypt. 


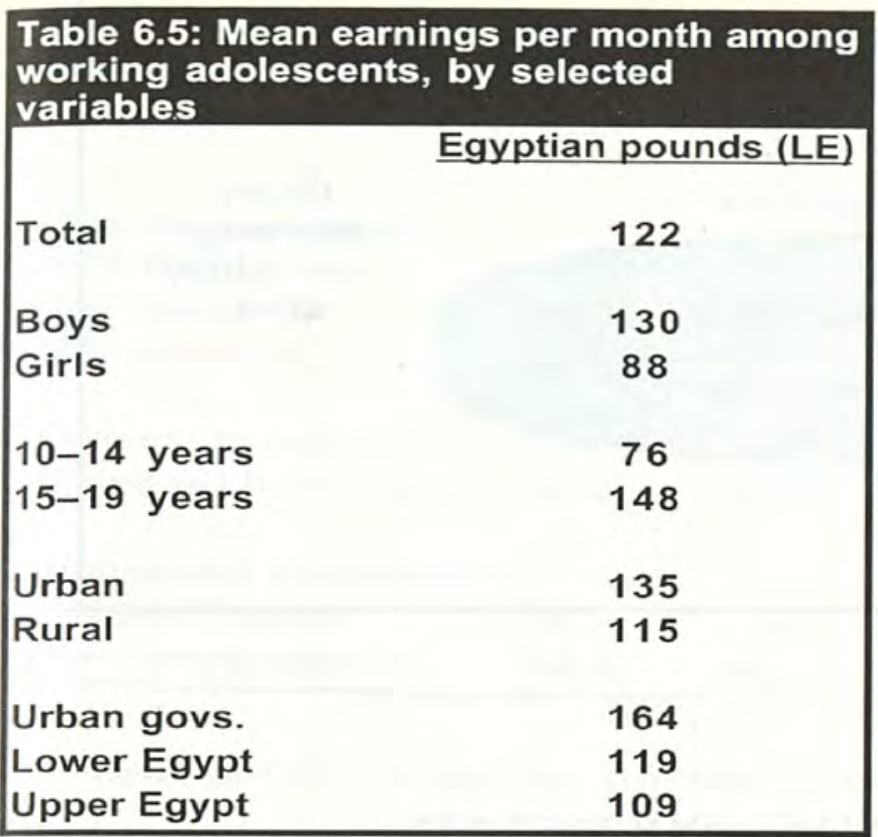

\section{Management of EARnings}

The way adolescents engaged in gainful employment manage their earnings is an important aspect of their work experience (Figure 6.6). One-fifth of this group of working adolescents keeps all earnings for themselves. This is more likely to occur among females and residents of urban areas, particularly the urban governorates.

Forty percent provide all of their earned income to their families and 40 percent share their earnings with their families. Apparently in the latter two cases, being economically active is a matter of livelihood not only for the adolescents but also for for entire families. Providing all earnings to the family is more likely to be the case among working females than males, among younger than older adolescents, and among those living in rural areas. Sharing income with the * family is more prevalent among working males than females. It is more likely in urban than rural areas and among older adolescents.

Economically active female adolescents who provide fully or partially for their family are twice as likely to give their earnings to their mother than to their father. Among working males there is no clear trend in who receives their contributions.

How working adolescents manage their earnings reflects to a large extent the reasons underlying their involvement in gainful employment. Working adolescents who retain part of their earnings for themselves are more inclined to mention as reasons for starting to work: covering their own needs, having spare time, gaining experience, and liking work. On the other hand, 50 percent of working males and 70 percent of females who do not keep any earnings for themselves refer to providing for the family as the main reason for starting to work. Gaining experience or liking work is rarely mentioned among this group. 


\section{Figure 6.13:Distribution of earnings among adolescents}

working for pay

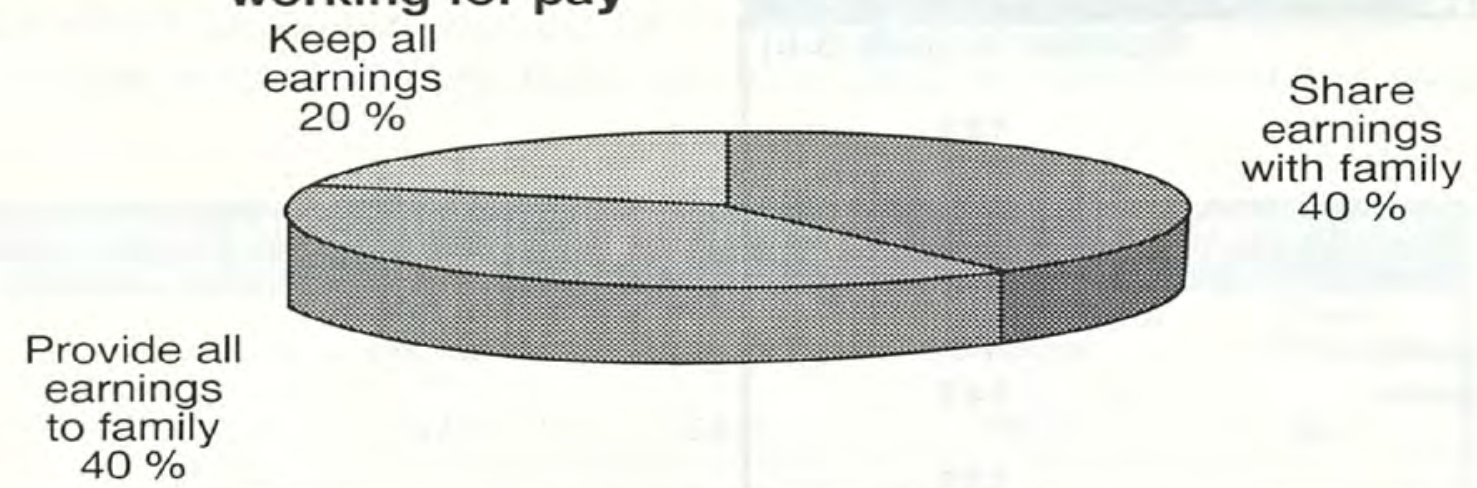

\section{PROFILE OF HOUSEHOLDS OF WORKING ADOLESCENTS}

Investigation of the characteristics of the households of working adolescents is crucial in understanding the environment and circumstances surrounding and/or determining early entry into the labor market. Household size and composition, social resources, and economic status of the household are central issues in this regard.

\section{Household Size AND Composition}

About 11 percent of all sampled adolescents are members of households that consist of less than five members while half belong to households of 5-7 members and over one-third live in large households with at least 8 members.

Table 6.6 displays the distribution of adolescents by work status and household size and composition. The results indicate a higher concentration of working adolescents, both paid and unpaid, in large households, particularly among working females. Fifty-four percent of female adolescents in unpaid employment and 43 percent in paid employment come from very large households compared to one-third only of the nonworking group.

Seventy-three percent of all adolescents surveyed live in nuclear households and 27 percent are members of extended households that accommodate members beyond the parent/nevermarried child relationship. Adolescents engaged in unpaid employment, especially girls, are more likely to belong to extended rather than nuclear households, compared to nonworking adolescents or those working for cash. Among the group of adolescents working for pay, the higher concentration in large households and in extended households is less pronounced compared to adolescents in unpaid employment. However, there is an indication of a slightly higher prevalence of paid employment among adolescents, both males and females, in nuclear households headed by an adult female compared to the nonworking group. 


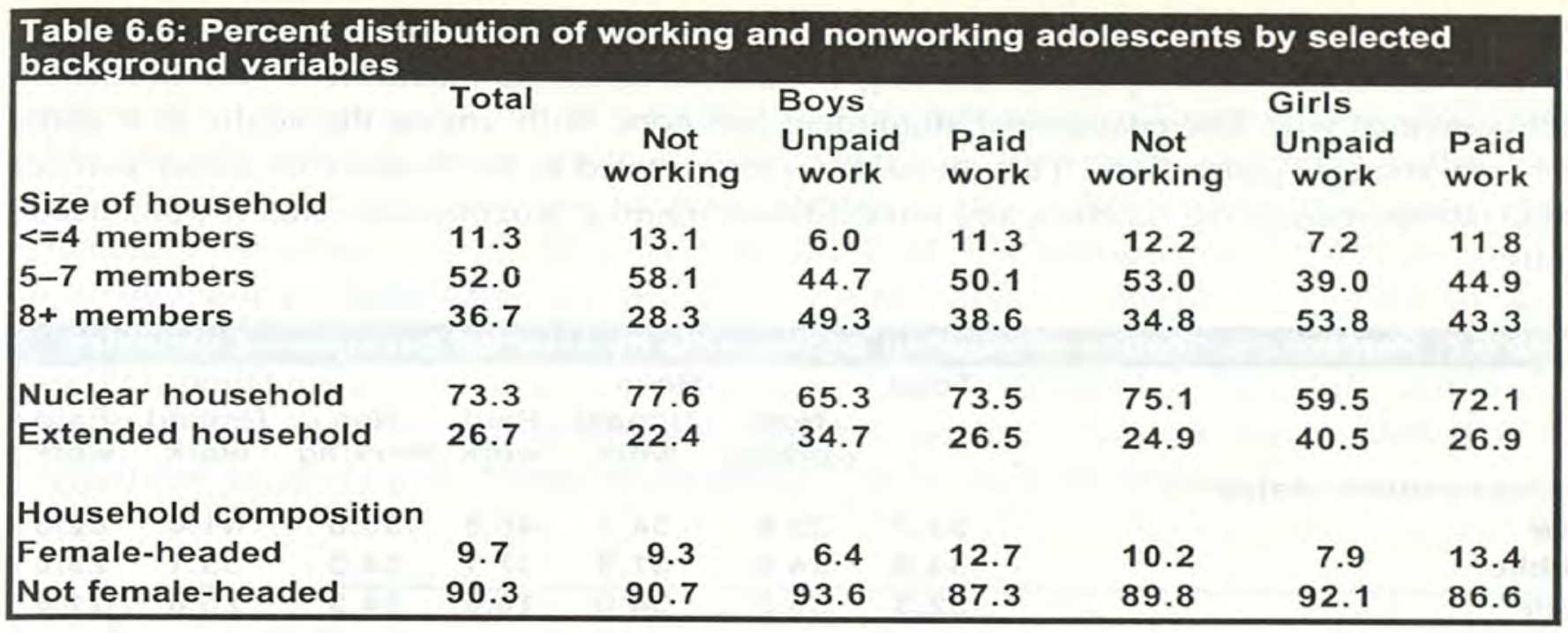

\section{Socioeconomic Status of the Household}

Early engagement in the labor market for adolescents is usually the exception rather than the norm. The economic resources available to the household as well as the social capital acquired by adult household members are anticipated to have a strong bearing on this significant event in an adolescent's life. The economic index computed from the household data divides sampled adolescents into thirds according to the value of this index assigned to their households. While nonworking adolescents maintain a uniform distribution, the working group displays a higher concentration in poorer households.

Table 6.7 emphasizes the significant concentration in the lowest economic category among male adolescents working for pay $(46.8 \%)$, and especially among female working adolescents in unpaid and paid employment $(41.4 \%$ and $62.6 \%$, respectively). Table 6.5.2 also highlights the interrelationships between work experience and the social resources of the household as measured by the education attainment of male and female guardians of adolescents.

While less than half of the fathers of nonworking adolescents are illiterate or have less than a primary certificate, three-quarters to 86 percent of fathers of working boys and girls respectively have this low level of education. Thirty-six percent to 42 percent of the nonworking group have fathers with at least a secondary certificate while only 7 percent to 12 percent of the working adolescents have fathers with a similar level of education. Similar conclusions are reached when the educational attainment of mothers is considered.

Three-quarters of mothers of nonworking adolescents are illiterate or have less than a primary certificate. Comparable figures among working boys and girls are 92 percent and 95 percent. On the other hand, 2 percent to 4 percent of mothers of working adolescents have at least secondary certificate compared to 13 percent to 16 percent among mothers of nonworking girls and boys. Observed differentials in the social resources available to the household by sex of the working adolescent are not as striking as they are when the economic status of the household is considered. 
These results emphasize what is already stressed in the literature on poverty and strategies to alleviate its negative consequences. Lacking or limited economic resources at the household level combined with low educational attainment and poor skills among the adults in it spills over into younger generations. This situation is exacerbated in the absence of social policies tied to income-generating schemes and rehabilitation/training programs directed toward needy adults.

\begin{tabular}{|c|c|c|c|c|c|c|c|}
\hline \multirow{3}{*}{ Socioeconomic status } & \multirow[t]{3}{*}{ Total } & \multicolumn{3}{|c|}{ Boys } & \multicolumn{3}{|c|}{ Girls } \\
\hline & & $\begin{array}{l}\text { Non } \\
\text { working }\end{array}$ & $\begin{array}{l}\text { Unpaid } \\
\text { work }\end{array}$ & $\begin{array}{l}\text { Paid } \\
\text { work }\end{array}$ & $\begin{array}{l}\text { Non } \\
\text { working }\end{array}$ & $\begin{array}{l}\text { Unpaid } \\
\text { work }\end{array}$ & $\begin{array}{l}\text { Paid } \\
\text { work }\end{array}$ \\
\hline & & & & & & & \\
\hline Low & 33.7 & 29.8 & 34.1 & 46.8 & 30.6 & 41.4 & 62.6 \\
\hline Middle & 34.0 & 34.6 & 31.9 & 37.1 & 34.6 & 33.1 & 25.6 \\
\hline High & 32.3 & 35.6 & 34.0 & 16.0 & 34.8 & 25.6 & 11.8 \\
\hline \multicolumn{8}{|l|}{ Education of fathers } \\
\hline $\begin{array}{l}\text {-Illiterate or less than primary } \\
\text { certificate }\end{array}$ & 55.7 & 43.0 & 75.6 & 78.2 & 49.4 & 82.4 & 86.2 \\
\hline $\begin{array}{l}\text {-Primary certificate } \& \text { less than } \\
\text { preparatory certificate }\end{array}$ & 6.0 & 5.9 & 6.2 & 5.9 & 6.1 & 5.8 & 5.5 \\
\hline $\begin{array}{l}\text {-Preparatory certificate \& less than } \\
\text { secondary }\end{array}$ & 8.3 & 9.5 & 6.2 & 7.7 & 8.9 & 4.8 & 0.9 \\
\hline -At least secondary certificate & 30.0 & 41.5 & 12.1 & 8.3 & 35.6 & 7.1 & 7.3 \\
\hline \multicolumn{8}{|l|}{ Education of mothers } \\
\hline $\begin{array}{l}\text {-Illiterate or less than primary } \\
\text { certificate }\end{array}$ & 80.3 & 73.6 & 91.0 & 92.2 & 75.6 & 95.0 & 94.3 \\
\hline $\begin{array}{l}\text {-Primary certificate } \& \text { less than } \\
\text { preparatory certificate }\end{array}$ & 6.1 & 6.7 & 5.0 & 4.4 & 7.0 & 4.5 & 2.1 \\
\hline -Preparatory certificate \& less than & 3.4 & 3.6 & 1.6 & 1.1 & 4.8 & 0.5 & - \\
\hline -At least secondary certificate & 10.2 & 16.1 & 2.5 & 2.3 & 12.6 & - & 3.5 \\
\hline
\end{tabular}

\section{OUT-OF-SCHOOL AND OUT-OF-WORK ADOLESCENTS}

According to the formal definition of unemployment, Egyptian adolescents above the age of 15 who have the ability and the desire to work and are actively seeking it but cannot find it should be considered unemployed. The ASCE survey did not investigate the two dimensions of the desire and the active search for work. Hence, obtaining an estimate of the actual level of unemployment among this segment of the population is not possible ${ }^{1}$. However, we can explore the profile of older, out-of-school adolescents to better understand their situation.

To identify the potential target population for interventions focusing on education, training, and apprenticeship for adolescents, the following three criteria are incorporated: age 15 or above, not enrolled in the formal education system, and not working.

\footnotetext{
'Youth unemployment is one topic of a labor force analysis currently underway in Egypt (Population Council, forthcoming).
} 
Only 6 percent of boys aged 15 or above are not enrolled in school and not working, compared to 34 percent of the females in the same age group (Figures 6.14-6.15). Finding jobs does not seem to be a major problem among out-of-school adolescent males. Work conditions and pay for boys are far more serious issues to be considered. Among eligible females, the situation is very different. One-third of this group, aged 15-19, are neither in school nor economically active. Other research has uncovered large ratios of female applicants to job openings among this age group (Papanek and Ibrahim 1981). Apparently girls 15-19 are in need of education and training programs to develop their skills and improve their future life chances and conditions. More job opportunities are also needed. The data suggest that currently girls devote considerable time to domestic chores.

\section{Figure 6.14:Distribution of males aged 15-19 by school enrollment and work status.}

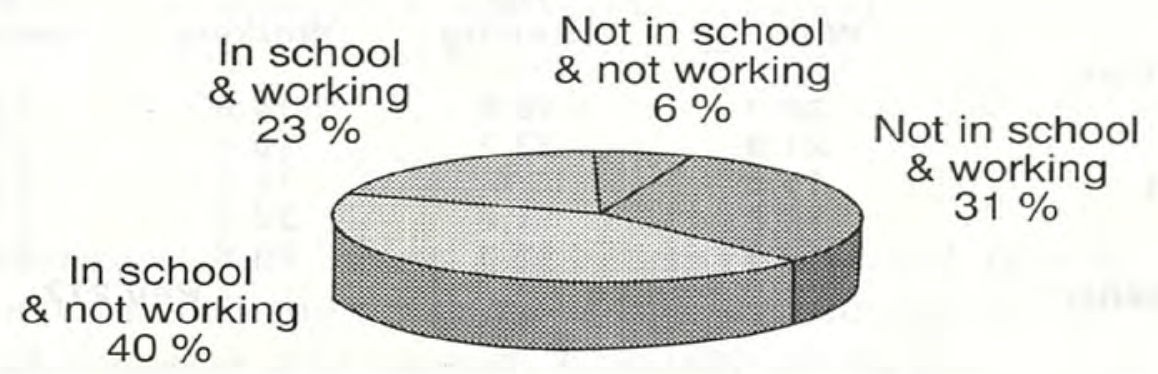

Figure 6.15:Distribution of females aged $15-19$ by school enrollment and work status.

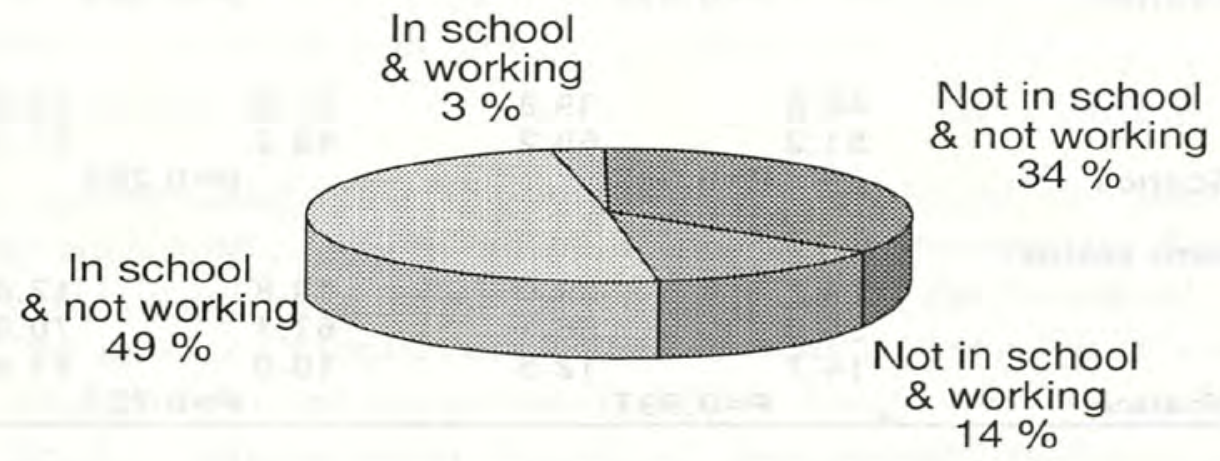

\section{HEALTH STATUS OF WORKING ADOLESCENTS}

Investigation of the health status of working adolescents is essential for the design of interventions targeting this particular group of the population. Issues of special concern include biological maturation, stunting, anemia, parasite infestation, and perception of health 
status. Table 6.8 displays the distribution of working and nonworking adolescents by selected health status indicators.

Working boys are ahead of the nonworking group in regard to biological maturation. The proportion of working boys in the stages of middle or late adolescence or who are fully mature is 53 percent compared to 34 percent among the nonworking group of boys. Furthermore, working boys show higher levels of parasitic infestation compared to their nonworking counterparts. This result suggests that either as a result of their lower socioeconomic status or their work status, working boys have higher exposure to potential sources of parasitic infection. Boys in paid or unpaid employment in agriculture are at higher risk of infection during work. Those in nonagricultural economic activities rely heavily on cheap unhealthy meals while at work.

\begin{tabular}{|c|c|c|c|c|}
\hline \multirow[b]{3}{*}{ Biological maturation } & \multicolumn{2}{|c|}{ Boys } & \multicolumn{2}{|c|}{ Girls } \\
\hline & Working & $\begin{array}{c}\text { Not } \\
\text { working }\end{array}$ & Working & $\begin{array}{c}\text { Not } \\
\text { working }\end{array}$ \\
\hline & & & & \\
\hline Prepubescent & 25.0 & 43.8 & 14.9 & 13.6 \\
\hline Early adolescent & 21.9 & 22.2 & 16.3 & 17.1 \\
\hline Middle adolescent & 16.8 & 9.6 & 17.7 & 11.8 \\
\hline Late adolescent & 16.8 & 11.6 & 22.3 & 24.0 \\
\hline Full maturation & 19.5 & 12.8 & 28.8 & 33.5 \\
\hline Statistical significance & \multicolumn{2}{|c|}{$P=0.00$} & \multicolumn{2}{|c|}{$P=0.212$} \\
\hline Stunting & & & & \\
\hline Stunted & 20.5 & 18.2 & 18.7 & 13.5 \\
\hline Not stunted & 79.5 & 81.8 & 81.3 & 86.5 \\
\hline Statistical significance & \multicolumn{2}{|c|}{$P=0.084$} & \multicolumn{2}{|c|}{$P=0.000$} \\
\hline \multicolumn{5}{|l|}{ Anemia } \\
\hline Anemic & 51.6 & 47.4 & 55.6 & 49.1 \\
\hline Not anemic & 48.4 & 52.6 & 44.4 & 50.9 \\
\hline Statistical significance & \multicolumn{2}{|c|}{$P=0.924$} & \multicolumn{2}{|c|}{$P=0.611$} \\
\hline \multicolumn{5}{|l|}{ Parasites } \\
\hline Infected & 48.8 & 39.8 & 51.8 & 42.8 \\
\hline Not infected & 51.2 & 60.2 & 48.2 & 57.2 \\
\hline Statistical significance & \multicolumn{2}{|c|}{$P=0.003$} & \multicolumn{2}{|c|}{$P=0.284$} \\
\hline \multicolumn{5}{|l|}{ Perception of health status } \\
\hline Great & 29.2 & 29.9 & 13.8 & 17.4 \\
\hline Normal & 55.6 & 56.1 & 67.1 & 70.8 \\
\hline Bad & \multirow{2}{*}{\multicolumn{2}{|c|}{$P=0.997$}} & 19.0 & 11.8 \\
\hline Statistical significance & & & \multicolumn{2}{|c|}{$P=0.727$} \\
\hline
\end{tabular}

The prevalence of stunting is substantially higher among working girls than nonworking. The health profile of working girls supports the argument that working girls are more likely to come from poor households. Since stunting is a process that begins in early childhood, we can be fairly confident that stunting is intrinsic to living conditions, though it may be exacerbated by work status. 


\section{CONCLUSION}

About one-third of adolescents, one in every two males and one in every six females report current involvement in economic activities, mostly in unpaid work. More than half of these adolescents are under the minimum legal age for work, 60 percent in unpaid employment and 35 percent in paid employment. However, the majority of unpaid work and one-third of paid work is concentrated in agricultural-related activities, which are excluded from the two latest laws regulating child labor in Egypt.

Working conditions of economically active adolescents are less than ideal. Nearly half of working adolescents work seven or more hours per day, exceeding the maximum number of working hours permitted by law, with one-quarter of those working nine or more hours per day. In addition, about 40 percent of working adolescents work seven days per week, not taking days off from work. Notably, almost one-fifth of all working adolescents work long hours and do not take days off.

Moreover, one-third of working adolescents report being exposed to potential hazards, such as using sharp tools or being exposed to fire or extreme heat. If the hazards of working in agricultural-related activities were also considered, a much higher level of involvement in unsafe work activities would be found.

The findings demonstrate the strong link between household poverty and adolescents' participation in economic activities. There is a significant concentration of working boys and girls in the lowest socioeconomic category, especially among girls in both unpaid and paid work and among boys working for pay. Furthermore, while less than half of the fathers of nonworking adolescents are illiterate or have less than a primary certificate, the fathers of 75 percent of working boys and 85 percent of working girls have this low level of education. Moreover, working girls have significantly lower levels of education themselves and higher levels of stunting compared to their nonworking peers. Adolescents' own reports confirm the link between poverty and their working status: The two most important reasons that adolescents report for starting work were their families' need for their unpaid help and their families' need for their income.

This analysis shows clearly that the disadvantages conferred by inadequate economic resources in the household combined with low educational attainment and poor skills among adult members are transmitted to the adolescent generation in the household. This situation is exacerbated in the absence of social policies tied to income-generating schemes and training/ rehabilitation programs directed toward needy adults. Policymakers must take into account the potential for the intergenerational transfer of disadvantage when designing policies and programs to address the needs of adolescents.

These results also help to identify the potential target population for interventions focusing on education, training and apprenticeship. Only 6 percent of adolescent boys aged 15 or above are not enrolled in school and not working, compared to 34 percent of girls in the same age group. Finding jobs does not seem to be the problem among out-of-school adolescent boys. For them, work conditions and remuneration for boys are far more serious issues to be 
considered. However, the large numbers of older adolescent girls who are neither in school nor engaged in any economic activity demonstrates that additional training and work opportunities may be welcome among this group. While domestic chores undoubtedly occupy some of their time, additional opportunities would give them the option to gain both trade and personal skills, economic resources, and would also potentially increase their selfesteem and abilities to negotiate within their families.

Finally, any policies and programs targeting adolescent economic activity should take into account the significant differences in the work profile by age and gender. Thus, disaggregating adolescents by age and gender is critical in creating policy and program strategies to assist adolescents through their transitions to productive adult work roles. The next chapter explores agents of socialization that contribute to adolescents' orientation toward the world and their psychological wellbeing. 


\section{Chapter 7}

\section{Agents of Socialization}

As a child grows into the second decade of life, the circle of influential people around him or her expands. Whereas in childhood it is parents, siblings, other family members, and perhaps teachers who have the most influence, adolescence is a time when peers, workmates, potential marriage partners, and others begin to exert influence. Moreover, adolescents begin a process of self-exploration and gradually establish identities separate from their family and friends. The process by which individuals and institutions contribute to molding the outlook and behavior of young people is called socialization. This chapter will explore some of the agents of socialization affecting adolescents in Egypt. It will focus in particular on family members, friends, and other peers, but will also touch upon the media as a socializing agent. Leisure activities and sports participation are assessed, as well as some of the psychological dimensions of being an adolescent.

\section{THE FAMILY: INTERACTION WITH PARENTS AND SIBLINGS}

During adolescence, parents and their children establish new kinds of relationships with one another. Adolescents begin to express themselves as individuals separate from their parents and with needs and feelings of their own, make decisions about their own lives, and learn to take responsibility for the consequences of those decisions. This process is aided by the extent to which adolescents are connected to and encouraged by their families and the level of mutual support that exists, but also by increased independence (appropriate to their age) and sufficient freedom from parental control.

The ASCE survey investigated these issues, focusing on self-expression and subsequent parental response, exchange of support in terms of communication and openness with the family, as well as conflict or aggression.

\section{Self-Expression and Parental Response}

Adolescents grow up in a family context in which they internalize values, social expectations, and norms for appropriate behavior. Interactions within the family context present to adolescents a range of communication models they can call upon in their future interactions with peers and families as adults. The family can be a source of ongoing support for adolescents, and adolescents can also provide support to their families, whether materially or emotionally. Families show great variability in the level of support they offer and in their responses to adolescents' emerging ideas, opinions, and desires for autonomy. The ASCE survey asked adolescents a number of questions to assess the social environment of the family as it shapes their lives.

Three-quarters of the sample say they generally express their opinions openly to their families (Table 7.1). Older adolescents did this to a larger extent than younger $(84.0 \%$ 
compared to $67.8 \%$ ). Age is more significant than gender: boys are only slightly more assertive than girls, most likely because of reactions of family members, as described below. Adolescents attending school also reported expressing their ideas more than out-of-school adolescents, but working status had no noticeable impact. The urban governorates showed the highest rate for self-expression, followed by Lower Egypt and Upper Egypt, and generally urban areas showed higher rates than rural. Adolescents also seem to be more likely to voice their opinions in nuclear households than extended households, and in female-headed households than in male-headed. Household socioeconomic status is also relevant. Adolescents from high-status households are more likely to speak up compared to those from lower-status households.

\begin{tabular}{|c|c|c|}
\hline Total & $\begin{array}{c}\text { Adolescent expresses } \\
\text { his/her opinions } \\
74.6\end{array}$ & $\begin{array}{l}\text { Family respects } \\
\text { opinions } \\
80.4\end{array}$ \\
\hline $\begin{array}{l}\text { Boys } \\
\text { Girls }\end{array}$ & $\begin{array}{l}77.4 \\
71.9\end{array}$ & $\begin{array}{l}83.3 \\
77.3\end{array}$ \\
\hline $\begin{array}{l}10-14 \text { years } \\
15-19 \text { years }\end{array}$ & $\begin{array}{l}67.8 \\
84.0\end{array}$ & $\begin{array}{l}73.6 \\
87.9\end{array}$ \\
\hline $\begin{array}{l}\text { In school } \\
\text { Out of school }\end{array}$ & $\begin{array}{l}76.2 \\
70.3\end{array}$ & $\begin{array}{l}80.5 \\
80.0\end{array}$ \\
\hline $\begin{array}{l}\text { Working } \\
\text { Not working }\end{array}$ & $\begin{array}{l}74.1 \\
74.9\end{array}$ & $\begin{array}{l}80.4 \\
80.3\end{array}$ \\
\hline $\begin{array}{l}\text { Nuclear household } \\
\text { Extended household }\end{array}$ & $\begin{array}{l}76.3 \\
69.7\end{array}$ & $\begin{array}{l}81.3 \\
77.4\end{array}$ \\
\hline $\begin{array}{l}\text { Female-headed household } \\
\text { Not female-headed household }\end{array}$ & $\begin{array}{l}81.4 \\
73.9\end{array}$ & $\begin{array}{l}80.4 \\
80.4\end{array}$ \\
\hline $\begin{array}{l}\text { Socioeconomic status } \\
\text { Low } \\
\text { Middle } \\
\text { High }\end{array}$ & $\begin{array}{l}71.3 \\
74.7 \\
78.1\end{array}$ & $\begin{array}{l}77.9 \\
80.8 \\
82.5\end{array}$ \\
\hline $\begin{array}{l}\text { Urban } \\
\text { Rural }\end{array}$ & $\begin{array}{l}79.5 \\
71.6\end{array}$ & $\begin{array}{l}82.7 \\
78.8\end{array}$ \\
\hline $\begin{array}{l}\text { Urban govs. } \\
\text { Lower Egypt } \\
\text { Upper Egypt }\end{array}$ & $\begin{array}{l}83.2 \\
73.6 \\
71.5\end{array}$ & $\begin{array}{l}86.2 \\
84.7 \\
71.7\end{array}$ \\
\hline
\end{tabular}

An even larger proportion of adolescents, 80 percent, who expressed their opinions said their parents listened to and respected their opinions. Age is again a deciding factor as older adolescents reported this more than younger $(87.9 \%$ versus $73.6 \%$ ), while school and work status have no impact on variability. There is also a gender differential, as boys report that their families respected their views more than girls, as well as a regional differential, with the highest rates found in Lower Egypt and the urban governorates as compared to Upper Egypt. Of course we would expect these percentages to be relatively high, as the reactions of family members in past interactions has an effect on current behavior: those who receive respect 
when they express their opinions are more likely to continue expressing them, while those who do not receive respect are more likely to stop attempting to make themselves heard.

On the other hand dismissing adolescents' opinions or shutting them out of adult discussions is demoralizing and conveys a negative message. This can affect self-esteem and confidence at a very critical stage in the life cycle and discourage youth from future active participation in decisionmaking. Region of residence, gender, and age of the adolescent seem to be strong determinants of experiencing such a negative reaction to their participation. Upper Egyptian adolescents, girls, and younger adolescents are more likely to report that their opinions are dismissed or that they are shut out from adult discussions (Table 7.1).

\section{Exchange of Support Between Family and Adolescent}

The ASCE survey asked adolescents who they talk to if they experience problems (Table 7.2). Among the crucial times adolescents turn to their families for help is during illness. Almost half of the sample reported they inform only their mother when they feel ill, and about one-third inform both parents. Age, school attendance, and socioeconomic status do not affect communication with the mother on this issue, whereas gender, region of residence, work status, and household composition do. Girls are more likely to tell their mothers while boys are more likely to tell their fathers or both parents. In the urban governorates and urban areas adolescents are more likely to tell their mother about their illness than in Upper and Lower Egypt and rural areas, although Lower Egypt has the highest reporting for telling both parents. Nuclear households seem to strengthen communication with the mother on this issue compared to the extended household context ( $51 \%$ versus $43 \%)$.

Concerning adolescents' problems within the family, one-quarter of the sample say they would not tell their parents, 35 percent say they would go to their mother, and one-fifth would tell both parents. The older the adolescent the less likely he or she is to talk to either parent about such issues. Gender and work status are also important, as girls and nonworking adolescents would tend to involve the mother, whereas boys and working adolescents gravitate toward the father. There are no regional differences for the involvement of mothers, but involvement of fathers in discussing family problems is slightly higher in Upper Egypt and rural areas.

Adolescents tend to avoid their parents when they have problems with friends. Almost half of the sample said they would not tell their parents about their problems with friends. This is higher for males than females. As might be expected, older, out-of-school, and working adolescents also reported this distance from parents more than younger, in-school, and nonworking adolescents.

Adolescents also talk to parents about certain problems they encounter at school or at work. Almost one-third say they would tell only their mother, one-fifth only their father, 24 percent say they would tell neither parent, and a similar proportion would tell both. Gender is a deciding factor here, as more girls would tell their mothers and more boys would tell their fathers. Again, in the urban governorates and urban areas involvement of mothers is higher than in Upper and Lower Egypt and rural areas. 
Another area in which adolescents might turn to parents concerns their reproductive health. This important topic is discussed in Chapter 8 in the context of the transition to adulthood.

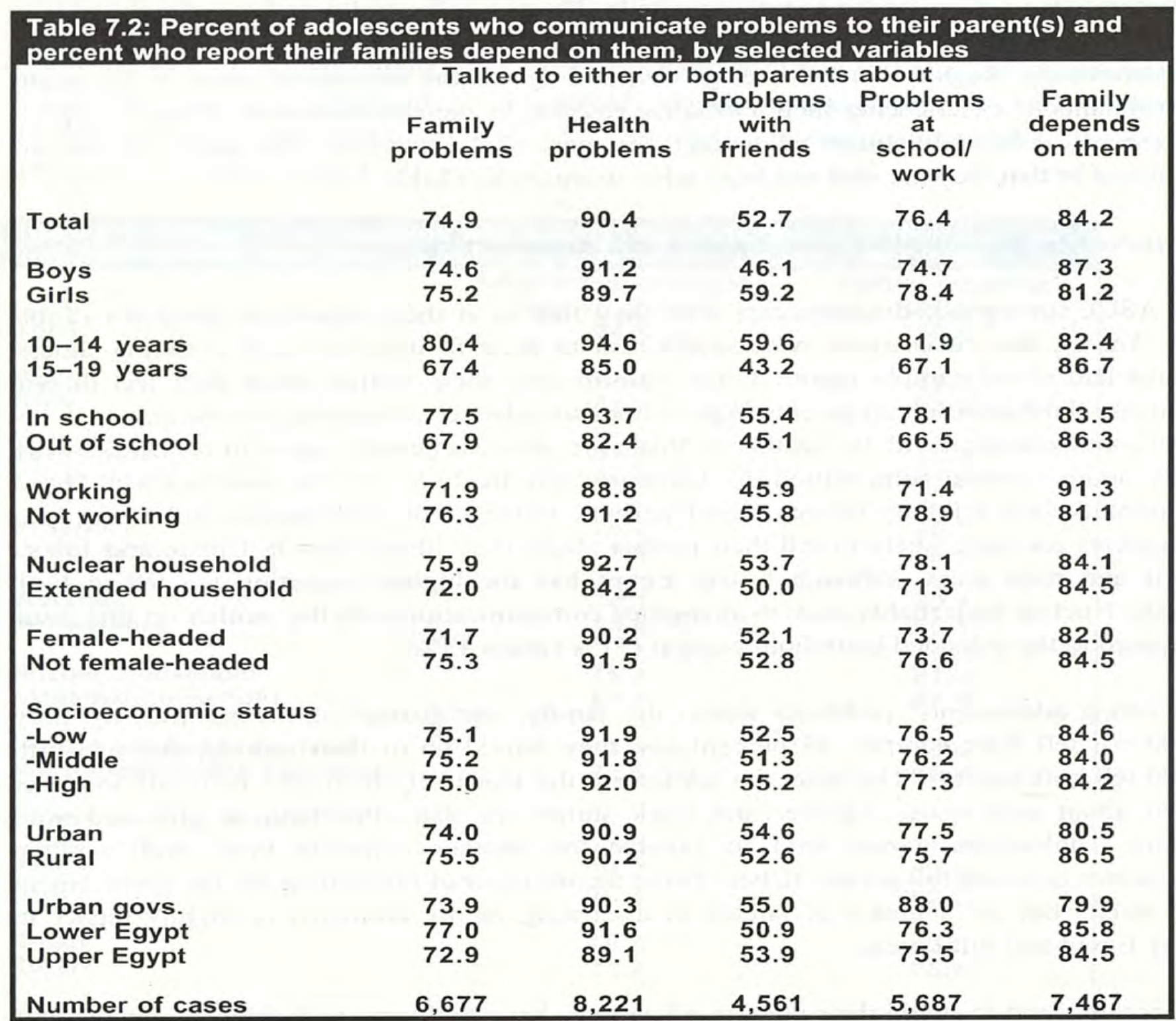

If the family can be seen as a source of help and support for the adolescent, most adolescents also see themselves as sources of support for their families. Eighty-four percent of the sample say they feel their family depends on them for help when they need it. There was a slight gender difference as more boys reported this than girls. Also more working adolescents said their family depends on them for help, and slightly more adolescents in rural areas report this than in urban areas.

The results reveal that indeed as adolescents grow up they become more autonomous. One way of exercising this autonomy is that they are less willing to communicate with their parents about the problems they face with other family members, with friends, or at school/work. More seriously, they become less likely to communicate with parents in regard 
to their health problems. This pattern prevails despite the fact that parents depend more on them and increasingly respect their opinions.

\section{Aggression Among Family Members}

The ASCE survey asked adolescents about their experience with aggression/violence in a number of contexts. No distinction was made regarding the severity of aggression involved; however, the wording of the question referred to hitting (darab) and the use of violence (isti'mal al-'unf). When communication fails among family members, adolescents may see, experience, or initiate acts of aggression. About one-fifth of the sample say they observe violence between their parents. Acts of aggression between parents are slightly more common among adolescents in the lower socioeconomic groups. There is also more parental aggression in rural areas and in Upper Egypt than in urban areas and Lower Egypt (Table 7.3).

\begin{tabular}{|c|c|c|}
\hline 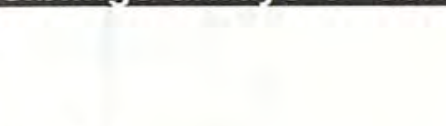 & $\begin{array}{l}\text { Observe violence between } \\
\text { parents always or } \\
\text { sometimes }\end{array}$ & $\begin{array}{c}\text { Observe violence between } \\
\text { siblings always or } \\
\text { sometimes }\end{array}$ \\
\hline Total & 21.5 & 53.3 \\
\hline $\begin{array}{l}\text { Boys } \\
\text { Girls }\end{array}$ & $\begin{array}{l}20.8 \\
22.3\end{array}$ & $\begin{array}{l}50.0 \\
56.7\end{array}$ \\
\hline $\begin{array}{l}10-14 \text { years } \\
15-19 \text { years }\end{array}$ & $\begin{array}{l}23.4 \\
19.1\end{array}$ & $\begin{array}{l}57.0 \\
48.7\end{array}$ \\
\hline $\begin{array}{l}\text { In school } \\
\text { Out of school }\end{array}$ & $\begin{array}{l}20.5 \\
24.2\end{array}$ & $\begin{array}{l}53.3 \\
53.3\end{array}$ \\
\hline $\begin{array}{l}\text { Working } \\
\text { Not working }\end{array}$ & $\begin{array}{l}26.2 \\
19.3\end{array}$ & $\begin{array}{l}54.6 \\
52.7\end{array}$ \\
\hline $\begin{array}{l}\text { Nuclear household } \\
\text { Extended household }\end{array}$ & $\begin{array}{l}21.0 \\
23.1\end{array}$ & $\begin{array}{l}53.5 \\
52.8\end{array}$ \\
\hline $\begin{array}{l}\text { Socioeconomic status } \\
\text {-Low } \\
\text {-Middle } \\
\text {-High }\end{array}$ & $\begin{array}{l}25.9 \\
21.2 \\
18.5\end{array}$ & $\begin{array}{l}56.1 \\
52.3 \\
51.1\end{array}$ \\
\hline $\begin{array}{l}\text { Urban } \\
\text { Rural }\end{array}$ & $\begin{array}{l}18.7 \\
23.3\end{array}$ & $\begin{array}{l}49.1 \\
55.9\end{array}$ \\
\hline $\begin{array}{l}\text { Urban govs. } \\
\text { Lower Egypt } \\
\text { Upper Egypt }\end{array}$ & $\begin{array}{l}13.2 \\
22.1 \\
25.3\end{array}$ & $\begin{array}{l}43.4 \\
54.9 \\
56.5\end{array}$ \\
\hline
\end{tabular}

Cases of aggression between siblings seem to be more common, as 53 percent of the sample reported this sometimes happens in their households. This is slightly more frequent in rural areas and in Upper Egypt than in urban areas, Lower Egypt, or the urban governorates.

A total of about 16 percent of the sample reported being hit in the month prior to the survey, and slightly more than two-thirds of those were hit by either parents or siblings (Table 7.4). Girls report this more than boys and young adolescents more than older ones. This probably 
reflects the more frequent presence of girls and younger adolescents in the household compared to boys and older adolescents, who are generally more autonomous and mobile.

\begin{tabular}{|c|c|c|c|c|}
\hline & $\begin{array}{l}\text { Were hit last } \\
\text { month }\end{array}$ & $\begin{array}{c}\text { Were hit by a } \\
\text { family } \\
\text { member }\end{array}$ & $\begin{array}{c}\text { Hit } \\
\text { someone } \\
\text { last month }\end{array}$ & $\begin{array}{l}\text { Hit a family } \\
\text { member }\end{array}$ \\
\hline Total & 15.6 & 71.7 & 15.2 & 67.8 \\
\hline $\begin{array}{l}\text { Boys } \\
\text { Girls }\end{array}$ & $\begin{array}{l}14.8 \\
16.3\end{array}$ & $\begin{array}{l}52.8 \\
86.6\end{array}$ & $\begin{array}{l}14.9 \\
15.4\end{array}$ & $\begin{array}{l}47.3 \\
86.7\end{array}$ \\
\hline $\begin{array}{l}10-14 \text { years } \\
15-19 \text { years }\end{array}$ & $\begin{array}{c}20.1 \\
9.3\end{array}$ & $\begin{array}{l}71.5 \\
68.4\end{array}$ & $\begin{array}{l}15.9 \\
14.1\end{array}$ & $\begin{array}{l}66.0 \\
70.5\end{array}$ \\
\hline $\begin{array}{l}\text { In school } \\
\text { Out of school }\end{array}$ & $\begin{array}{l}17.0 \\
11.8\end{array}$ & $\begin{array}{l}69.7 \\
74.8\end{array}$ & $\begin{array}{l}16.1 \\
12.6\end{array}$ & $\begin{array}{l}67.7 \\
68.2\end{array}$ \\
\hline $\begin{array}{l}\text { Working } \\
\text { Not working }\end{array}$ & $\begin{array}{l}14.1 \\
16.3\end{array}$ & $\begin{array}{l}63.7 \\
73.4\end{array}$ & $\begin{array}{l}15.5 \\
15.0\end{array}$ & $\begin{array}{l}60.2 \\
71.2\end{array}$ \\
\hline $\begin{array}{l}\text { Nuclear household } \\
\text { Extended household }\end{array}$ & $\begin{array}{l}16.2 \\
13.7\end{array}$ & $\begin{array}{l}71.0 \\
69.8\end{array}$ & $\begin{array}{l}15.7 \\
13.7\end{array}$ & $\begin{array}{l}68.7 \\
64.5\end{array}$ \\
\hline $\begin{array}{l}\text { Female-headed } \\
\text { Not female-headed }\end{array}$ & $\begin{array}{l}17.0 \\
15.4\end{array}$ & $\begin{array}{l}69.9 \\
70.8\end{array}$ & $\begin{array}{l}16.6 \\
15.0\end{array}$ & $\begin{array}{l}67.3 \\
67.8\end{array}$ \\
\hline $\begin{array}{l}\text { Socioeconomic status } \\
\text {-Low } \\
\text {-Middle } \\
\text {-High }\end{array}$ & $\begin{array}{l}16.2 \\
15.9 \\
14.2\end{array}$ & $\begin{array}{l}65.0 \\
73.6 \\
74.8\end{array}$ & $\begin{array}{l}14.0 \\
14.8 \\
17.0\end{array}$ & $\begin{array}{l}68.2 \\
65.7 \\
70.7\end{array}$ \\
\hline $\begin{array}{l}\text { Urban } \\
\text { Rural }\end{array}$ & $\begin{array}{l}16.4 \\
15.1\end{array}$ & $\begin{array}{l}65.7 \\
74.1\end{array}$ & $\begin{array}{l}17.1 \\
13.9\end{array}$ & $\begin{array}{l}63.4 \\
71.1\end{array}$ \\
\hline $\begin{array}{l}\text { Urban govs. } \\
\text { Lower Egypt } \\
\text { Upper Egypt }\end{array}$ & $\begin{array}{l}14.3 \\
14.9 \\
17.0\end{array}$ & $\begin{array}{l}56.9 \\
72.6 \\
74.6\end{array}$ & $\begin{array}{l}17.4 \\
13.8 \\
15.7\end{array}$ & $\begin{array}{l}60.6 \\
67.8 \\
71.8\end{array}$ \\
\hline Number of cases & 1,361 & 945 & 1,343 & 882 \\
\hline
\end{tabular}

Working adolescents report being hit less frequently by their parents compared to nonworking adolescents. Again this probably reflects working adolescents' less frequent presence in the household, but could also corroborate existing ethnographic evidence that wage earning increases status within the household. There are very slight regional or socioeconomic differences among adolescents being hit by their parents. However, more adolescents in rural areas report being hit by their siblings than in urban areas, as did residents of Upper Egypt and those in the middle and high socioeconomic groups.

Aggressive behavior is sometimes initiated by the adolescent; 15 percent of adolescents report that they hit someone last month. Girls report hitting their siblings much more than boys do, while boys hit people other than siblings, such as peers. Working adolescents are more aggressive with people other than siblings and non-working adolescents are more aggressive with siblings. This can be partially explained by the fact that non-working youth may spend 
more time at home and in interaction with siblings. Sibling aggression also occurs in Upper and Lower Egypt more than in the urban governorates, and in rural more than in urban communities.

The proportion of adolescents who initiated hitting is almost identical to the proportion hit by others. We investigated whether or not these two groups comprised the same people; that is, whether those who experience being hit by others tended to initiate aggression themselves. The data reveal that these are almost totally distinct groups: one that initiates hitting but is not hit by others, and another exposed to hitting without initiating such acts themselves. So rather than a situation of reciprocal violence among adolescents, there appear to be individuals who are passive recipients and other who behave aggressively. Further analysis is needed to understand the profile of these two groups.

\section{PEER RELATIONSHIPS}

\section{FRIENDSHIP}

Peers play an increasingly important role in the psychological and social development of adolescents as they emerge from childhood into teenage years. They spend an increasing amount of time with friends, and the relationships they form with peers are generally more intimate than those they had in childhood. The relationship between the individual and the peer group is more clearly delineated during this stage, and adolescents vary in the extent to which they conform or separate themselves from the values, customs, and fads of the peer culture. The ASCE survey investigated two issues related to peer relationships: friendships and the dynamics of the peer group.

A vast 96 percent of the sample report having at least one friend of the same age group who they can trust with their secrets, but slightly more girls than boys report having no friends at all. Although the size of this figure may not seem surprising, a comparable study conducted in Algeria revealed that up to 20 percent of adolescents responded that they had no friends. This points to the notion that having friends among this age group is not to be taken for granted, and that their absence may be indicative of individual and/or national conditions.

The opportunities for seeing and interacting with friends vary according to gender, age, region of residence, and working status, with gender as the most significant factor. Boys are almost twice as likely to report they are allowed to go out with friends, compared with girls $(67.3 \%$ versus $36.9 \%$ ), while girls are more likely to be limited to exchanging visits with friends in their houses only or not at all.

Older and working adolescents also have more opportunity to go out with friends. Adolescents in Upper Egypt are the most restricted, in that a larger proportion is not allowed to meet with friends at all, followed by Lower Egypt and the urban governorates. Differences according to socioeconomic status are slight, with higher-status groups somewhat less restricted than lower-status adolescents (Table 7.5). 


\begin{tabular}{|c|c|c|c|}
\hline Total & $\begin{array}{l}\text { Allowed to meet } \\
\text { friends and go out } \\
52.0\end{array}$ & $\begin{array}{c}\text { Only allowed to } \\
\text { exchange visits } \\
31.0\end{array}$ & $\begin{array}{l}\text { Not allowed to } \\
\text { meet with } \\
\text { friends } \\
17.0\end{array}$ \\
\hline $\begin{array}{l}\text { Boys } \\
\text { Girls }\end{array}$ & $\begin{array}{l}67.3 \\
36.9\end{array}$ & $\begin{array}{l}22.4 \\
39.6\end{array}$ & $\begin{array}{l}10.4 \\
23.6\end{array}$ \\
\hline $\begin{array}{l}10-14 \text { years } \\
15-19 \text { years }\end{array}$ & $\begin{array}{l}42.9 \\
64.7\end{array}$ & $\begin{array}{l}36.9 \\
22.8\end{array}$ & $\begin{array}{l}20.2 \\
12.5\end{array}$ \\
\hline $\begin{array}{l}\text { In school } \\
\text { Out of school }\end{array}$ & $\begin{array}{l}52.3 \\
51.2\end{array}$ & $\begin{array}{l}30.0 \\
33.8\end{array}$ & $\begin{array}{l}17.7 \\
14.9\end{array}$ \\
\hline $\begin{array}{l}\text { Working } \\
\text { Not working }\end{array}$ & $\begin{array}{l}59.3 \\
48.8\end{array}$ & $\begin{array}{l}27.6 \\
32.5\end{array}$ & $\begin{array}{l}13.1 \\
18.7\end{array}$ \\
\hline $\begin{array}{l}\text { Socioeconomic status } \\
\text { Low } \\
\text { Middle } \\
\text { High }\end{array}$ & $\begin{array}{l}48.6 \\
53.2 \\
55.4\end{array}$ & $\begin{array}{l}35.4 \\
31.2 \\
27.0\end{array}$ & $\begin{array}{l}16.0 \\
15.6 \\
17.6\end{array}$ \\
\hline $\begin{array}{l}\text { Urban } \\
\text { Rural }\end{array}$ & $\begin{array}{l}58.3 \\
48.2\end{array}$ & $\begin{array}{l}23.7 \\
35.5\end{array}$ & $\begin{array}{l}18.0 \\
16.3\end{array}$ \\
\hline $\begin{array}{l}\text { Urban govs. } \\
\text { Lower Egypt } \\
\text { Upper Egypt }\end{array}$ & $\begin{array}{l}61.0 \\
54.1 \\
45.0\end{array}$ & $\begin{array}{l}20.3 \\
35.5 \\
30.9\end{array}$ & $\begin{array}{l}18.7 \\
10.4 \\
24.1\end{array}$ \\
\hline Number of cases & 4,452 & 2,662 & 1,422 \\
\hline
\end{tabular}

Predictably there is substantial exchange of support between adolescents and their friends in terms of talking about problems. About 80 percent of the sample said they talk to their friends about their personal problems and in turn their friends share their problems with them (Table 7.6). There is no gender difference here; the reports are almost exactly the same for boys and girls. More older adolescents than younger, however, report having friendships involving this exchange of support. More in-school adolescents reported this level of involvement with friends than out-of-school adolescents, which is not surprising as in-school adolescents probably have more contact with peers in the first place, and because school provides them with a forum in which to develop social skills.

Confiding in friends is closely linked with a feeling that friends are dependent on the respondent for help and support. In fact 87 percent of the sample report that they feel their friends needed them, and this was common across most groups. The only exception is among younger adolescents, who are less likely to report feeling their friends depend on them compared with older adolescents. 


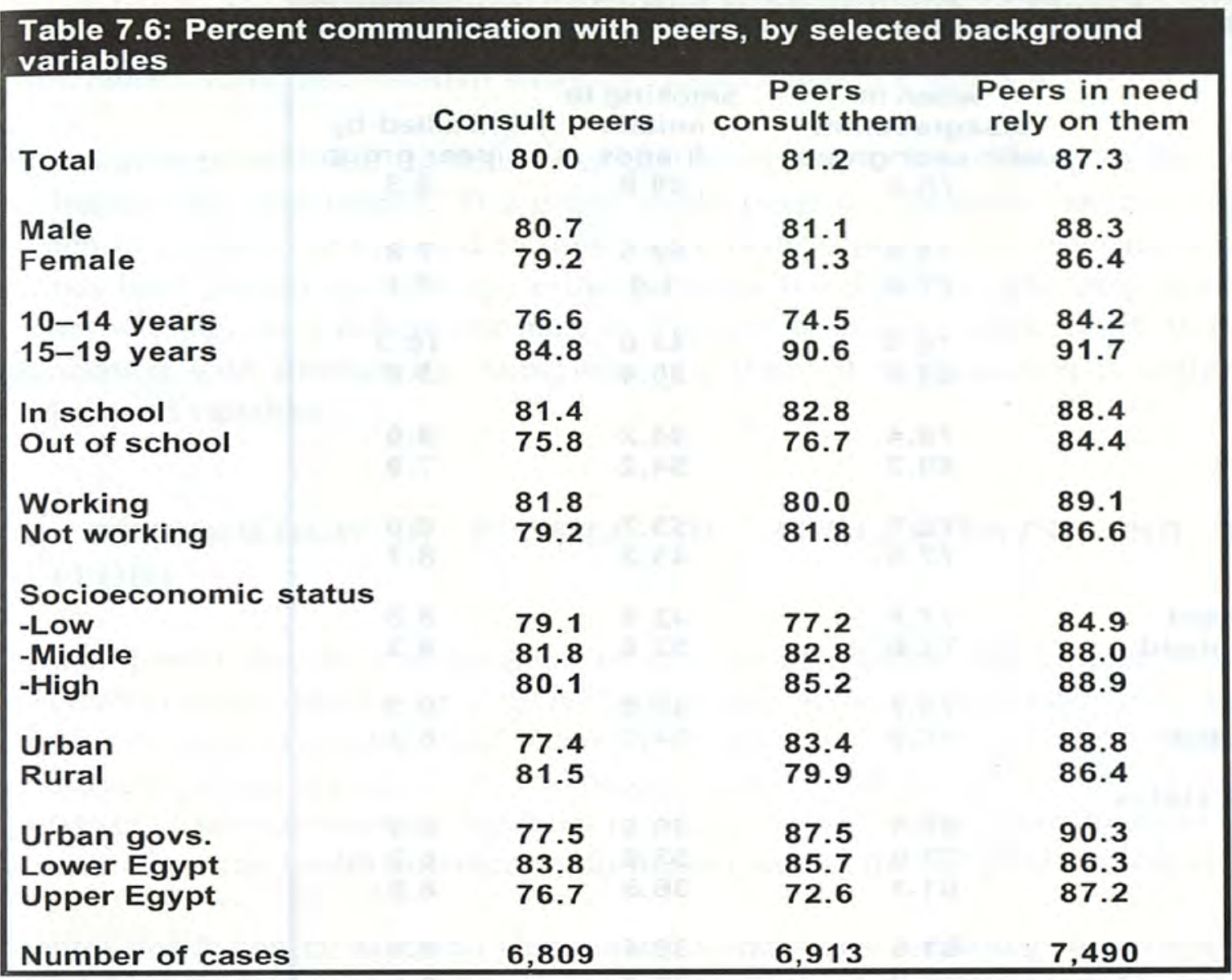

\section{Dynamics of the Peer Group}

When an individual is part of a group, different dynamics come into play depending on the characteristics of the members of the peer group. Just as with the family, there is a constant interchange between the individual personality and the collective. The opinions of the individual can sometimes be dominated by the collective opinion of the group, while at other times an individual can emerge as a leader and dominate within the group. In this context, there may be settings in which adolescents feel intimidated by their friends and restricted from voicing an opinion that may be different from that of the group.

About three-quarters of adolescents say they voice their opinions even when in disagreement to the group (Table 7.7). Girls are slightly more likely to report this than boys. Older adolescents are more assertive than younger with their peers (83.9\% versus $70.4 \%$ ). Interestingly, adolescents in the urban governorates are considerably more likely to voice their opinions even when in disagreement with the group than those in either Upper or Lower Egypt. Socioeconomic status also seems to be related to assertiveness: the higher the socioeconomic level the more likely the adolescent is to voice his/her opinion to the group. Adolescents who are in school and those who live in nuclear households are more likely to voice their opinions than those who are out of school, working, or in extended households. 
Table 7.7: Dynamics of the peer group (in percent), by selected

background variables

\begin{tabular}{lccc} 
Total & with peer group & friends & peer group \\
Male & 76.0 & 49.0 & 8.5 \\
Female & 75.0 & 52.5 & 7.8 \\
10-14 years & 77.0 & 1.4 & 9.1 \\
15-19 years & 70.4 & 44.0 & 10.3 \\
In school & 83.9 & 50.4 & 5.8 \\
Out of school & 78.4 & 44.2 & 8.6 \\
Working & 69.2 & 54.2 & 7.9 \\
Not working & 72.7 & 53.7 & 8.0 \\
Nuclear household & 77.5 & 43.3 & 8.7 \\
Extended household & 77.5 & 47.5 & 8.5 \\
Female-headed & 71.6 & 52.8 & 8.3 \\
Not female-headed & 75.7 & 47.0 & 9.3 \\
Socioeconomic status & 76.0 & 64.5 & 8.4 \\
-Low & & & \\
-Middle & 69.1 & 56.5 & 8.9 \\
-High & 77.0 & 53.6 & 8.2 \\
Urban & 81.1 & 36.8 & 8.0 \\
Rural & 81.6 & 38.4 & 8.8 \\
Urban govs. & 72.5 & 56.8 & 8.2 \\
Lower Egypt & 88.0 & 34.1 & 8.0 \\
Upper Egypt & 74.9 & 57.4 & 8.5 \\
Number of cases & 71.3 & 50.5 & 72.6 \\
& 6,580 & 314 & \\
\hline
\end{tabular}

\section{Voice opinion \\ when in \\ disagreement \\ with peer group}

Male

10-14 years

In school

Working

Nuclear household

Female-headed

Socioeconomic status

-Low

-Middle

Urban

Urban govs.

Lower Egypt

Number of cases

\section{Started smoking to imitate friends}

52.5

44.0

44.2

53.7

47.5

47.0

56.5

53.6

38.4

34.1

57.4

314
Bullied by

peer group

7.8

10.3

5.8

8.6

8.0

8.5

9.3

8.9

8.2

8.0

8.5

722

A person can be influenced by the peer group and acquire values and behavior by emulating friends. One indicator of this peer influence is if an adolescent acquires a habit such as smoking cigarettes because his/her friends do it. The ASCE survey asked several questions related to smoking behavior. Almost one-quarter of respondents say they have friends who smoke. However, only 5 percent of them are female, which could reflect a reporting bias or actual gender differences in behavior. Thus, this may be a better indicator of peer pressure for boys than it is for girls. Older adolescents, working adolescents, residents of urban areas and the urban governorates, and adolescents from high-status households or female-headed households report peers smoking at higher proportions compared to other groups.

Twelve percent of sampled adolescents reported being offered cigarettes by their peers, indicating that friends do exert some pressure on each other. Again this happens more to males, those adolescents who are older, out of school, and working, and residents of urban areas. Of those adolescents who do smoke, 49 percent say they started because their friends also smoked. The results indicate that peer pressure is stronger among older, working, and 
out-of-school adolescents. Also adolescents in rural areas, residents of Lower Egypt and those from lower socioeconomic status or non-female-headed households seem to be more vulnerable. (More discussion of smoking can be found in Chapter 4.)

At a more extreme level, the individual can be victimized by a group of friends who gang up on him/her for any reason. The group might taunt or ostracize him/her because he/she is somehow different or opposed to their ideas. Only 9 percent of the sample report that their friends have ganged up on them in the previous few months. The only noticeable variation comes with age, as this happens more to younger than older adolescents, thus pointing to an association with immaturity. Otherwise this type of victimization is uniform across other background variables.

\section{PSYCHOLOGICAL PROFILE OF ADOLESCENTS AND FAMILY/PEER SUPPORT}

Mental health and the development of a sense of identity are integral components in the assessment of the well-being of individuals, and of adolescents in particular. Evaluation of the status of mental health and identity formation through standardized psychological instruments is beyond the scope and objectives of a multipurpose national household survey. However, a serious attempt has been made to explore, rather than measure precisely, some aspects of mental health and identity formation among the sampled adolescents.

Mental health can be assessed along many dimensions, including the extent of contentment with life and appreciation of support the individual receives from family, friends, and others. Indicators of mental health status include self-worth, body image, self-confidence, and leadership. Other important considerations include how adolescents express anger and the prevalence of negative feelings such as loneliness, anxiety or fear, and guilt. Because adolescence is a period of transition and of intense emotional sensitivity, we can expect to find a certain degree of negative self-image and feelings. However, the psychological profile of Egyptian adolescents that emerged from this survey is not at all bleak.

\section{Positive Attitudes}

\section{Self-Worth}

How do adolescents think of themselves? How highly do they regard their capabilities and their importance to others? A good indication is whether they feel able to help friends and family when necessary. When asked this question, a strong majority of 94 percent respond affirmatively. There are minor variations by gender and type and region of residence. Older adolescents and those in high socioeconomic status households express more feelings of selfworth, in the sense of ability to help others, than younger adolescents or those in lowerstatus households (Table 7.8). 


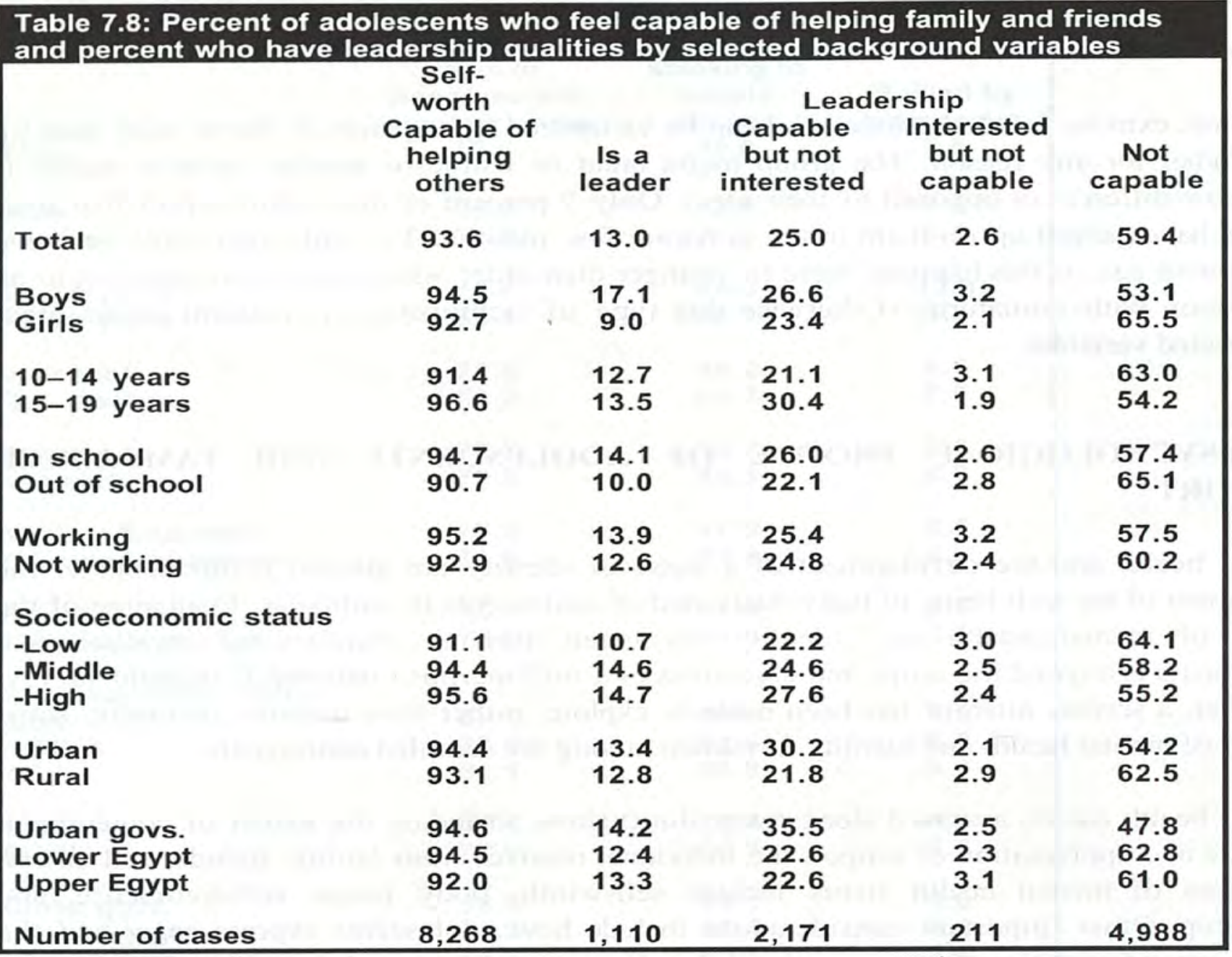

\section{Leadership}

One indicator of self-confidence is whether or not an individual demonstrates leadership qualities in group settings. The ASCE survey tried to assess one aspect of leadership among peers; that is, whether an adolescent decides what the group does, whether the group in fact follows, and whether the adolescent enjoys this role in the group. When defined in these terms, 13 percent of adolescents fall into the category of leader. The only apparent difference seems to be between genders, as more boys than girls fit the description. This gender difference may corroborate the notion that girls are socialized to negotiate with others and build consensus while boys are socialized to take charge and make decisions unilaterally to be carried out by a group.

Other kinds of leaders, who effectively lead the group but report not enjoying the role and those who are capable of leading but are not interested, make up a quarter of the sample. Here, gender made only a slight difference, but age, region of residence, and socioeconomic status had a substantial effect. Older adolescents, adolescents of higher socioeconomic status, and residents of urban areas and the urban governorates are more likely to be part of this 
group than younger adolescents, those in lower socioeconomic groups, those in rural areas and in Upper and Lower Egypt. A minority report wanting to be the leader but not being capable, in the sense that the group does not follow them. And finally, the largest proportion of the sample, 59 percent, report neither interest in nor the ability to lead a group in this manner. Gender and age are found to make considerable differences as more girls than boys and younger than older were part of this category. Socioeconomic status and region were also deciding factors, as adolescents of lower socioeconomic status, from rural areas and Upper and Lower Egypt are more likely to belong to this group than those of higher socioeconomic status and those from urban areas and the urban governorates (Table 7.8).

\section{Negative Emotions}

\section{Body Image}

Numerous physical changes occur during adolescence that may result in feelings of awkwardness or embarrassment of one's body. In some cultures, dissatisfaction with one's body is extensive among adolescents. Twelve percent of Egyptian adolescents report having a negative body image for any reason (Table 7.9). This fairly small proportion is the same for boys and girls. Higher levels of variation are found by type and region of residence, as more adolescents from urban than rural areas, and most from the urban governorates, followed by Upper Egypt and Lower Egypt express concern about their appearance.

\section{Loneliness}

Among the more negative feelings an individual can have are loneliness, fear or anxiety, and a sense of guilt. More than half of the sample admit to sometimes having feelings of loneliness. This is more common among older than younger adolescents. Feelings of loneliness seem to be more common for adolescents in female-headed households, and substantially more common in Lower Egypt and the urban governorates (59.8\% and 60.9\%) than in Upper Egypt $(48.2 \%)$.

\section{Anxiety and Fear}

Fifty-nine percent of the sample report experiencing feelings of fear or anxiety. Girls report this more than boys, and urban adolescents (63.2\%) substantially more than rural adolescents (55.7\%). Surprisingly, adolescents of higher socioeconomic status report experiencing this more than middle to lower-status groups, and working adolescents less than non-working. Finally, Lower Egypt has the lowest rate of fear, followed by Upper Egypt, and the urban governorates $(55.1 \%$ versus $59.4 \%$ and $65.1 \%$ ). There is a striking difference in reporting feelings of fear between in-school and out-of-school adolescents: 62 percent of in-school adolescents report feeling fearful and anxious compared to only 48 percent of those not in school. This may reflect exam pressures and/or the poor treatment that some adolescents, especially boys, report receiving in school. (See Chapter 5). 


\section{Guilt}

A sense of guilt indicates the extent to which people blame themselves for problems or feel that they are not doing enough for those around them and how much they are weighed down by these feelings. Almost 15 percent of adolescents say they frequently feel guilty and 66 percent say they sometimes feel guilty. There is a slight gender differential, showing boys to experience this more than girls, older adolescents more than younger ones, and in-school adolescents more than those not in school. Guilt is most commonly felt by adolescents from Lower Egypt, followed by the urban governorates and Upper Egypt.

\begin{tabular}{|c|c|c|c|c|}
\hline Total & $\begin{array}{c}\text { Negative body } \\
\text { image } \\
12.4\end{array}$ & $\begin{array}{c}\text { Loneliness } \\
55.7\end{array}$ & $\begin{array}{l}\text { Anxietyl } \\
\text { fear } \\
58.6\end{array}$ & $\begin{array}{l}\text { Guilt } \\
81.2\end{array}$ \\
\hline $\begin{array}{l}\text { Boys } \\
\text { Girls }\end{array}$ & $\begin{array}{l}12.1 \\
12.8\end{array}$ & $\begin{array}{l}53.7 \\
57.6\end{array}$ & $\begin{array}{l}56.1 \\
60.9\end{array}$ & $\begin{array}{l}82.6 \\
80.0\end{array}$ \\
\hline $\begin{array}{l}10-14 \text { years } \\
15-19 \text { years }\end{array}$ & $\begin{array}{l}11.1 \\
14.3\end{array}$ & $\begin{array}{l}48.5 \\
65.6\end{array}$ & $\begin{array}{l}59.0 \\
57.9\end{array}$ & $\begin{array}{l}76.5 \\
87.8\end{array}$ \\
\hline $\begin{array}{l}\text { In school } \\
\text { Out of school }\end{array}$ & $\begin{array}{l}12.7 \\
11.8\end{array}$ & $\begin{array}{l}54.0 \\
60.2\end{array}$ & $\begin{array}{l}62.4 \\
48.1\end{array}$ & $\begin{array}{l}83.4 \\
75.4\end{array}$ \\
\hline $\begin{array}{l}\text { Working } \\
\text { Not working }\end{array}$ & $\begin{array}{l}12.1 \\
12.6\end{array}$ & $\begin{array}{l}56.1 \\
55.4\end{array}$ & $\begin{array}{l}53.6 \\
60.8\end{array}$ & $\begin{array}{l}79.6 \\
82.0\end{array}$ \\
\hline $\begin{array}{l}\text { Nuclear household } \\
\text { Extended household }\end{array}$ & $\begin{array}{l}12.7 \\
11.7\end{array}$ & $\begin{array}{l}56.7 \\
52.6\end{array}$ & $\begin{array}{l}59.8 \\
55.1\end{array}$ & $\begin{array}{l}82.4 \\
77.9\end{array}$ \\
\hline $\begin{array}{l}\text { Female-headed } \\
\text { Not female-headed }\end{array}$ & $\begin{array}{l}13.6 \\
12.3\end{array}$ & $\begin{array}{l}64.1 \\
54.7\end{array}$ & $\begin{array}{l}59.5 \\
58.5\end{array}$ & $\begin{array}{l}82.6 \\
81.2\end{array}$ \\
\hline $\begin{array}{l}\text { Socioeconomic status } \\
\text {-Low } \\
\text {-Middle } \\
\text {-High }\end{array}$ & $\begin{array}{l}13.2 \\
11.5 \\
12.2\end{array}$ & $\begin{array}{l}57.2 \\
55.9 \\
54.1\end{array}$ & $\begin{array}{l}57.0 \\
56.8 \\
61.6\end{array}$ & $\begin{array}{l}77.8 \\
82.2 \\
84.3\end{array}$ \\
\hline $\begin{array}{l}\text { Urban } \\
\text { Rural }\end{array}$ & $\begin{array}{l}15.8 \\
10.4\end{array}$ & $\begin{array}{l}57.4 \\
54.6\end{array}$ & $\begin{array}{l}63.2 \\
55.7\end{array}$ & $\begin{array}{l}82.7 \\
80.4\end{array}$ \\
\hline $\begin{array}{l}\text { Urban govs. } \\
\text { Lower Egypt } \\
\text { Upper Egypt }\end{array}$ & $\begin{array}{c}16.4 \\
9.9 \\
13.4\end{array}$ & $\begin{array}{l}60.9 \\
59.8 \\
48.2\end{array}$ & $\begin{array}{l}65.1 \\
55.1 \\
59.4\end{array}$ & $\begin{array}{l}83.4 \\
84.1 \\
75.8\end{array}$ \\
\hline Number of cases & 1,083 & 4,999 & 5,213 & 7,252 \\
\hline
\end{tabular}

\section{EXPRESSING ANGER}

Expression of anger may take on several forms that range from total repression to physical aggression. The way in which a person expresses anger is very telling about what kind of a person he or she is. The ASCE survey asked adolescents what they typically do when they feel angry (Table 7.10). The highest proportion of adolescents say the first thing they do 
when angry is to isolate themselves $(22.6 \%)$. Less introverted and more verbal about it are those who said they find someone with whom to talk, followed closely by those who cry, and those who do nothing.

\begin{tabular}{|c|c|c|c|c|c|c|c|c|}
\hline Total & $\begin{array}{l}\text { Do } \\
\text { nothing } \\
16.3\end{array}$ & $\begin{array}{l}\text { Be } \\
\text { alone } \\
22.6\end{array}$ & $\begin{array}{l}\text { Weep } \\
18.1\end{array}$ & $\begin{array}{c}\text { Talk } \\
\text { about } \\
\text { it } \\
19.9\end{array}$ & $\begin{array}{c}\text { Sleep, } \\
\text { eat, } \\
\text { smoke } \\
4.3\end{array}$ & $\begin{array}{l}\text { Turn to } \\
\text { religion } \\
5.0\end{array}$ & $\begin{array}{c}\text { Use } \\
\text { aggress } \\
\text {-ion } \\
9.4\end{array}$ & $\begin{array}{c}\text { Other } \\
4.0\end{array}$ \\
\hline $\begin{array}{l}\text { Boys } \\
\text { Girls }\end{array}$ & $\begin{array}{l}16.3 \\
16.4\end{array}$ & $\begin{array}{l}29.3 \\
14.9\end{array}$ & $\begin{array}{l}7.3 \\
29.9\end{array}$ & $\begin{array}{l}20.3 \\
19.6\end{array}$ & $\begin{array}{l}4.9 \\
3.8\end{array}$ & $\begin{array}{l}5.9 \\
4.2\end{array}$ & $\begin{array}{l}11.2 \\
7.5\end{array}$ & $\begin{array}{l}4.3 \\
3.7\end{array}$ \\
\hline $\begin{array}{l}10-14 \text { years } \\
15-19 \text { years }\end{array}$ & $\begin{array}{l}20.0 \\
11.9\end{array}$ & $\begin{array}{l}17.9 \\
27.6\end{array}$ & $\begin{array}{l}20.4 \\
16.7\end{array}$ & $\begin{array}{l}20.0 \\
19.9\end{array}$ & $\begin{array}{l}4.5 \\
4.2\end{array}$ & $\begin{array}{l}3.2 \\
7.5\end{array}$ & $\begin{array}{l}9.4 \\
9.3\end{array}$ & $\begin{array}{l}4.6 \\
3.1\end{array}$ \\
\hline $\begin{array}{l}\text { In school } \\
\text { Out of school }\end{array}$ & $\begin{array}{l}15.3 \\
20.1\end{array}$ & $\begin{array}{l}22.3 \\
21.1\end{array}$ & $\begin{array}{l}18.4 \\
20.0\end{array}$ & $\begin{array}{l}20.8 \\
17.6\end{array}$ & $\begin{array}{l}4.7 \\
3.5\end{array}$ & $\begin{array}{l}5.6 \\
3.6\end{array}$ & $\begin{array}{l}9.2 \\
9.7\end{array}$ & $\begin{array}{l}3.8 \\
4.6\end{array}$ \\
\hline $\begin{array}{l}\text { Working } \\
\text { Not working }\end{array}$ & $\begin{array}{l}19.1 \\
15.4\end{array}$ & $\begin{array}{l}25.7 \\
20.3\end{array}$ & $\begin{array}{l}12.6 \\
21.6\end{array}$ & $\begin{array}{l}19.5 \\
20.1\end{array}$ & $\begin{array}{l}3.9 \\
4.5\end{array}$ & $\begin{array}{l}4.5 \\
5.3\end{array}$ & $\begin{array}{c}10.8 \\
8.7\end{array}$ & $\begin{array}{l}3.9 \\
4.0\end{array}$ \\
\hline $\begin{array}{l}\text { Nuclear } \\
\text { household }\end{array}$ & 15.3 & 22.6 & 18.8 & 20.0 & 4.6 & 5.3 & 9.5 & 3.8 \\
\hline $\begin{array}{l}\text { Extended } \\
\text { household }\end{array}$ & 20.2 & 20.1 & 19.1 & 19.6 & 3.5 & 4.2 & 8.8 & 4.6 \\
\hline $\begin{array}{l}\text { Socioeconomic st } \\
\text {-Low } \\
\text {-Middle } \\
\text {-High }\end{array}$ & $\begin{array}{r}\text { tatus } \\
19.0 \\
15.8 \\
13.5\end{array}$ & $\begin{array}{l}19.8 \\
21.9 \\
24.9\end{array}$ & $\begin{array}{l}19.7 \\
19.7 \\
18.2\end{array}$ & $\begin{array}{l}19.1 \\
20.4 \\
20.0\end{array}$ & $\begin{array}{l}4.5 \\
4.1 \\
4.4\end{array}$ & $\begin{array}{l}5.1 \\
4.7 \\
5.2\end{array}$ & $\begin{array}{c}8.6 \\
9.5 \\
10.1\end{array}$ & $\begin{array}{l}4.2 \\
4.0 \\
3.7\end{array}$ \\
\hline $\begin{array}{l}\text { Urban } \\
\text { Rural }\end{array}$ & $\begin{array}{l}11.9 \\
19.4\end{array}$ & $\begin{array}{l}24.2 \\
20.6\end{array}$ & $\begin{array}{l}17.9 \\
19.4\end{array}$ & $\begin{array}{l}21.8 \\
18.8\end{array}$ & $\begin{array}{l}5.4 \\
3.7\end{array}$ & $\begin{array}{l}5.1 \\
5.0\end{array}$ & $\begin{array}{l}9.6 \\
9.2\end{array}$ & $\begin{array}{l}4.2 \\
3.9\end{array}$ \\
\hline $\begin{array}{l}\text { Urban govs. } \\
\text { Lower Egypt } \\
\text { Upper Egypt }\end{array}$ & $\begin{array}{l}8.5 \\
12.6 \\
25.3\end{array}$ & $\begin{array}{l}26.5 \\
21.8 \\
19.9\end{array}$ & $\begin{array}{l}18.4 \\
23.9 \\
13.1\end{array}$ & $\begin{array}{l}21.1 \\
20.6 \\
18.6\end{array}$ & $\begin{array}{l}5.7 \\
4.3 \\
3.7\end{array}$ & $\begin{array}{l}5.5 \\
5.0 \\
4.9\end{array}$ & $\begin{array}{l}9.7 \\
9.1 \\
9.4\end{array}$ & $\begin{array}{l}4.6 \\
2.7 \\
5.2\end{array}$ \\
\hline Number of cases & 1,449 & 1,940 & 1,673 & 1,819 & 375 & 432 & 796 & 356 \\
\hline
\end{tabular}

There is little variation across categories for these reactions. However, almost twice as many males as females isolate themselves and more males than females resort to aggression $(11.2 \%$ versus $7.5 \%$, respectively). Overall, one in ten adolescents resorts to aggression when angry. This may take several forms, such as hitting, breaking things, and shouting at others. Almost equal proportions of males and females say they do nothing, and equal proportions say they talk to someone when they are angry. Females are four times as likely as males to cry when they feel angry, reinforcing gender expectations about the acceptability of crying in society. Younger adolescents are twice as likely as older adolescents to say they do nothing or show no reaction, which can be particularly dangerous as emotions are repressed or bottled up instead of being expressed. Only 5 percent of adolescents report that they turn to religion when angry. 
Given the high overall rates of negative feelings reported, the levels of satisfaction with life and optimism for the future among adolescents are surprisingly high (Table 7.11). We can speculate that family support and/or peer acceptance and understanding may be significant factors in alleviating the consequences of negative feelings. Seventy-one percent of the sample report that they are very satisfied with their lives. This is directly related to socioeconomic status, and inversely related to age. Females report being very satisfied $(69.3 \%)$ somewhat less than males (73.4\%). A negligible proportion of adolescents from any group report not being satisfied with their lives. Given that adolescence is a time of emotional extremes, these seemingly contradictory findings may be the result of adolescents' reconciliation with some of the negative aspects that, from an adolescent's viewpoint, have become a normal part of life.

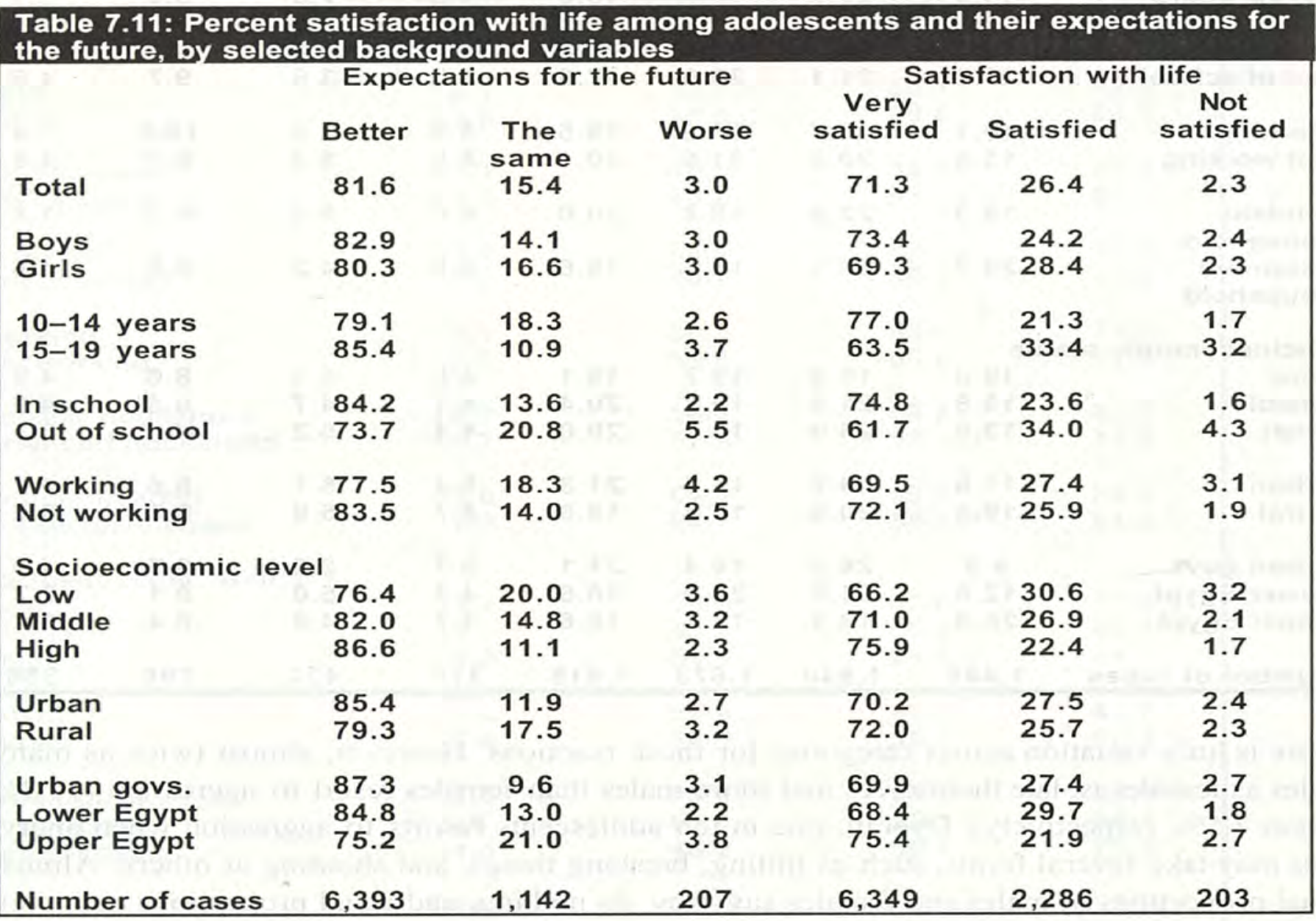

Complementing this high level of satisfaction, a high 82 percent report optimism for the future. Here there is no gender differential, but socioeconomic status is a factor in increased optimism. There is a difference of 10 percentage points between adolescents in low and high socioeconomic status households in optimism toward the future (76.4\% versus $86.6 \%$ ). Interestingly, more of the older adolescents $(85.4 \%)$ are optimistic about the future than are younger adolescents $(79.1 \%)$, more urban adolescents are optimistic than rural adolescents, and more non-working than working adolescents report feeling optimistic about the future. Upper Egyptian adolescents are considerably less optimistic than Lower Egyptians and those 
from the urban governorates.

\section{HEALTH STATUS, MENTAL HEALTH, AND COMMUNICATION WITH FAMILY AND PEERS}

Table 7.12 shows whether or not a link exists between different positive attitudes and negative emotions felt by adolescents on the one hand and the level of communication and interaction with parents and peers. Positive interaction with parents is defined in terms of communicating health problems, problems with other family members and friends, and problems at school or work with either or both parents. Good interaction with peers involves exchange of consultation and support and a lack of acts of taunting and bullying. Also of great interest is the potential impact on mental health of both the perceptions of adolescents concerning their health status and their actual stage of biological maturation.

\section{Table 7.12: Interrelationships between the psychological profile of adolescents,}

family/peer support, perception of health status, and stage of biological maturation

\begin{tabular}{|c|c|c|c|c|c|c|c|c|}
\hline & $\begin{array}{l}\text { Commu } \\
\text { with }\end{array}$ & $\begin{array}{l}\text { ication } \\
\text { rents }\end{array}$ & $\begin{array}{l}\text { Inter } \\
\text { with }\end{array}$ & $\begin{array}{l}\text { tion } \\
\text { eers }\end{array}$ & $\begin{array}{l}\text { Perce } \\
\text { health }\end{array}$ & $\begin{array}{l}\text { ion of } \\
\text { tatus }\end{array}$ & $\begin{array}{r}\text { Sta } \\
\text { biol } \\
\text { matu }\end{array}$ & $\begin{array}{l}\text { of } \\
\text { ical } \\
\text { tion }\end{array}$ \\
\hline & Boys & Girls & Boys & Girls & Boys & Girls & Boys & Girls \\
\hline Self-worth & - & - & $\star \star \star$ & $\star \star \star$ & $\star$ & - & $\star \star \star$ & - \\
\hline $\begin{array}{l}\text { Leadership } \\
\text { qualities }\end{array}$ & - & - & $\star * *$ & $\star * \star$ & $\star \star *$ & - & $\star \star *$ & $\star \star \star$ \\
\hline $\begin{array}{l}\text { Negative body } \\
\text { image }\end{array}$ & - & $*$ & - & - & - & - & * & - \\
\hline Loneliness & ** & * & $\star \star \star *$ & $\star \star \star$ & $\star \star \star *$ & $* * *$ & ** & $\star \star \star$ \\
\hline Anxiety/fear & - & - & - & $\star \star$ & - & - & - & - \\
\hline Guilt & $\star \star$ & - & $\star \star \star$ & $\star \star \star *$ & $\star *$ & * & $\star \star$ & $\star \star \star$ \\
\hline Aggression & * & * & - & - & - & - & - & - \\
\hline $\begin{array}{l}\text { Satisfaction with } \\
\text { life }\end{array}$ & $\star * *$ & $\star * *$ & - & - & $\star \star \star *$ & $\star \star \star$ & - & 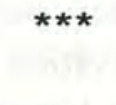 \\
\hline $\begin{array}{l}\text { Optimism/ } \\
\text { pessimism }\end{array}$ & - & - & $\star \star$ & * & - & - & ** & - \\
\hline
\end{tabular}

Positive interaction with peers exerts the most significant impact on the two qualities of selfworth and sense of leadership (as defined previously) in the anticipated direction. A positive perception of health status and experiencing an advanced stage of biological maturation increases feelings of self-worth and sense of leadership, but among boys only. Interestingly, a good communicative relationship with parents has no effect on whether or not an adolescent shows leadership or expresses self-worth.

A negative body image among girls seems to be marginally related to a less than ideal level of communication with parents. Among boys, the more advanced their stage of biological 
maturation, the more likely they are to have a negative body image.

The negative feeling of loneliness is the only aspect of the psychological profile sensitive to family and peer support as well as to health status. Good communication with parents and a positive perception of health status are associated with reduced loneliness. Good interaction with friends is correlated with increased levels of loneliness. This peculiar association is in fact mediated by a third factor, approaching full maturation, which is positively related to good interaction with friends while at the same time is linked to increased sense of loneliness. Similarly, good interaction with friends is related to increased anxiety/fear among girls and increased sense of guilt among boys. These seemingly contradictory associations need further analysis and an in-depth assessment of adolescent mental health. However, the same two negative feelings, fear and guilt also increase as the adolescent approaches full maturation. The only factor that appears to reduce the likelihood of acts of adolescent aggression is good communication with parents.

A positive perception of health status and good communication with parents are related to increased satisfaction with life while positive interaction with peers is linked to increased optimism and more hopeful future expectations. As girls approach maturation they become less rather than more satisfied with their lives. The relationship between boys' maturation and their future expectations is U-shaped. Optimism is highest among prepubescent boys and those who are fully mature. During middle and late adolescence they are far less optimistic about the future.

\section{ADOLESCENTS' DAILY ACTIVITY PROFILE}

Leisure serves an important function in the psychosocial development of adolescents and is an avenue through which important values such as teamwork, responsibility, and creativity are acquired. The definition of leisure used here includes activities that are undertaken once adolescents have completed the obligations of school, employment, and domestic responsibilities. The main distinction between leisure and other activities is that adolescents are more likely to choose their leisure activities, whereas others (teachers, parents, supervisors) dictate their time at school and work and some of their time at home. Leisure activities can include socializing with friends, playing sports and games, watching television and listening to music, working on hobbies, and just "kicking back." The amount of time available to adolescents for leisure and the ways in which they spend their leisure may vary significantly by gender, socioeconomic status, and region of residence, as well as other background variables.

While information exists on the education and work status of Egyptian young people, national data on leisure activities has been lacking until the ASCE survey. The survey team decided to administer a complete activity profile to all single adolescents in the sample. A total of eighteen activities that an adolescent might have undertaken during the previous 24 hours were included in the survey. This section of the report focuses on those activities not related to schooling and employment, since these are covered more fully in other chapters. The focus therefore is on family interaction and use of leisure, including opportunities for movement beyond the home. Because the data collection spanned part of the academic year as 
well as the school holiday and ranged over two seasons, the findings average the experience of adolescents rather than restricting them to a particular season.

\section{Adolescents' Reports of Daily Activities}

Table 7.13 illustrates the activities of 8,811 adolescents as reported for the day before the interview. Media related activities-watching television and listening to the radio-rank highest: 87 percent of adolescents overall report engaging in this activity. Activities that take place around the home and family also rank high in adolescent lives. The strong link between adolescents and their families is especially evident in the percent reporting family-related activities on the previous day: urban governorates $(55.8 \%)$, Lower Egypt $(58.5 \%)$ and Upper Egypt (67.7\%).

Social activities such as walking with friends, playing sports, and visiting other relatives and friends rank third in activities undertaken by adolescents $(55.0 \%)$. The main variation between girls and boys is that reporting social activities for boys $(67.2 \%)$ is significantly higher than that for girls $(43.2 \%)$; the reverse is true for family activities. Twice as many girls as boys report engaging in activities related to home and family.

Religious activities are somewhat more commonly reported among boys, those of higher socioeconomic status, rural residents, and those from Lower Egypt. The most significant difference in reporting religious activities is between in-school $(53.8 \%)$ and out-of-school $(36.9 \%)$ adolescents.

\begin{tabular}{|c|c|c|c|c|c|c|}
\hline & $\begin{array}{l}\text { School- } \\
\text { related }\end{array}$ & $\begin{array}{l}\text { Homel } \\
\text { family }\end{array}$ & $\begin{array}{c}\text { Employ- } \\
\text { ment }\end{array}$ & $\begin{array}{l}\text { Media- } \\
\text { related }\end{array}$ & Social & Religious \\
\hline Total & 35.1 & 61.4 & 23.6 & 86.9 & 55.0 & 49.2 \\
\hline $\begin{array}{l}\text { Girls } \\
\text { Boys }\end{array}$ & $\begin{array}{l}33.5 \\
36.7\end{array}$ & $\begin{array}{l}81.5 \\
40.7\end{array}$ & $\begin{array}{l}11.4 \\
36.3\end{array}$ & $\begin{array}{l}86.8 \\
87.0\end{array}$ & $\begin{array}{l}43.2 \\
67.2\end{array}$ & $\begin{array}{l}41.7 \\
56.9\end{array}$ \\
\hline $\begin{array}{l}10-15 \text { years } \\
16-19 \text { years }\end{array}$ & $\begin{array}{l}38.2 \\
30.8\end{array}$ & $\begin{array}{l}64.2 \\
57.6\end{array}$ & $\begin{array}{l}21.5 \\
26.5\end{array}$ & $\begin{array}{l}86.7 \\
87.2\end{array}$ & $\begin{array}{l}55.0 \\
55.0\end{array}$ & $\begin{array}{l}45.3 \\
54.5\end{array}$ \\
\hline $\begin{array}{l}\text { In school } \\
\text { Out of school }\end{array}$ & $\begin{array}{c}47.5 \\
1.5\end{array}$ & $\begin{array}{l}60.1 \\
65.0\end{array}$ & $\begin{array}{l}17.3 \\
40.7\end{array}$ & $\begin{array}{l}89.8 \\
90.8\end{array}$ & $\begin{array}{l}56.4 \\
51.2\end{array}$ & $\begin{array}{l}53.8 \\
36.9\end{array}$ \\
\hline $\begin{array}{l}\text { Working } \\
\text { Not working }\end{array}$ & $\begin{array}{l}23.3 \\
40.3\end{array}$ & $\begin{array}{l}51.0 \\
66.1\end{array}$ & $\begin{array}{c}69.9 \\
3.1\end{array}$ & $\begin{array}{l}81.5 \\
89.3\end{array}$ & $\begin{array}{l}59.2 \\
53.2\end{array}$ & $\begin{array}{l}49.0 \\
49.3\end{array}$ \\
\hline $\begin{array}{l}\text { Socioeconomi } \\
\text {-Low } \\
\text {-Middle } \\
\text {-High }\end{array}$ & $\begin{array}{r}\text { tus } \\
34.4 \\
32.4 \\
37.3\end{array}$ & $\begin{array}{l}60.2 \\
61.7 \\
61.3\end{array}$ & $\begin{array}{l}28.6 \\
23.2 \\
19.3\end{array}$ & $\begin{array}{l}80.2 \\
89.6 \\
90.8\end{array}$ & $\begin{array}{l}54.7 \\
56.6 \\
53.4\end{array}$ & $\begin{array}{l}45.4 \\
49.8 \\
54.3\end{array}$ \\
\hline $\begin{array}{l}\text { Urban } \\
\text { Rural }\end{array}$ & $\begin{array}{l}36.6 \\
34.1\end{array}$ & $\begin{array}{l}58.6 \\
63.1\end{array}$ & $\begin{array}{l}13.6 \\
69.9\end{array}$ & $\begin{array}{l}91.5 \\
84.1\end{array}$ & $\begin{array}{l}51.3 \\
57.3\end{array}$ & $\begin{array}{l}43.1 \\
52.9\end{array}$ \\
\hline $\begin{array}{l}\text { Urban govs. } \\
\text { Lower Egypt } \\
\text { Upper Egypt }\end{array}$ & $\begin{array}{l}41.4 \\
32.0 \\
35.6 \\
\end{array}$ & $\begin{array}{l}55.8 \\
58.5 \\
67.7 \\
\end{array}$ & $\begin{array}{l}10.7 \\
24.7 \\
28.9\end{array}$ & $\begin{array}{l}92.2 \\
85.8 \\
85.6 \\
\end{array}$ & $\begin{array}{l}49.6 \\
58.3 \\
53.9 \\
\end{array}$ & $\begin{array}{l}43.8 \\
58.3 \\
41.1 \\
\end{array}$ \\
\hline
\end{tabular}




\section{Physical Activities}

Another survey question asked how often and what sports activities were played in the last week, including school-based activities (Table 7.14). It is well documented that regular physical activity improves overall health, promotes mental health, and enhances self-esteem as well as social well-being. Regular physical activity is also associated with decreased risk of cardiovascular disease and premature death.

The ASCE survey shows that the level of sports activity outside school hours is dramatically higher among adolescent boys than adolescent girls (56.5\% versus $5.2 \%$ ). Ball games are the most frequently reported type of games for both sexes, but are played significantly more often by boys $(88.6 \%$ and $51.7 \%)$. For adolescent boys, 32 percent report playing in the streets, followed by youth clubs $(28.0 \%)$ and other clubs $(25.0 \%)$. For adolescent girls, 39 percent of those who report playing sports report playing in schools, followed by clubs $(25.0 \%)$ and at home $(17.2 \%)$. When respondents were asked how many times during the week prior to the survey they played sports, 45 percent of adolescent girls and 24 percent of boys reported not playing at all.

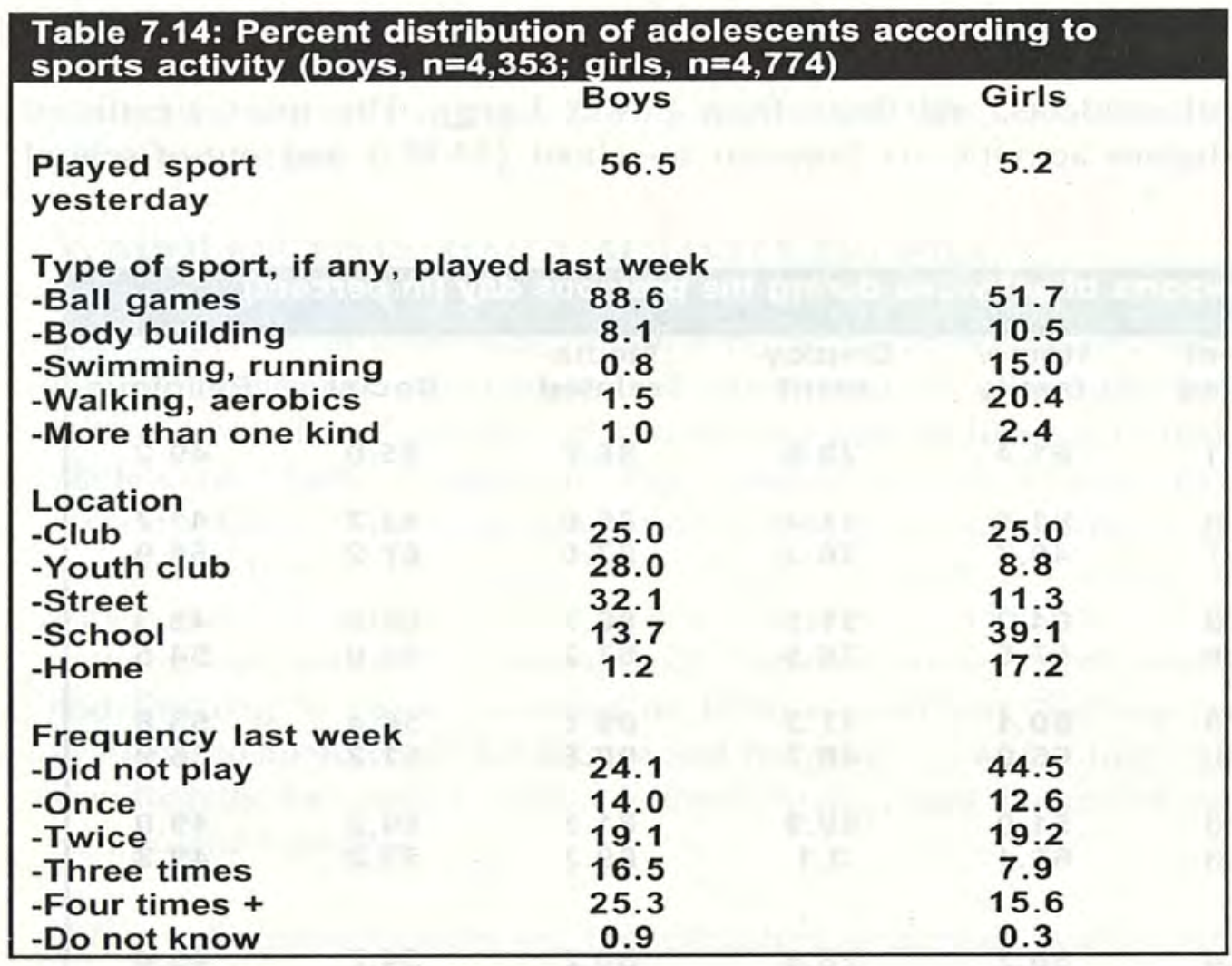

The survey shows the important role of schools in providing girls with opportunities to engage in any type of physical activity and exercise. Boys have other options for pursuing physical activities; they are able to use government-run clubs, NGO-run facilities within the community, and the street. Girls appear to have limited access to these facilities, either because they serve only boys or because girls are restricted from participating by their families. Most likely these two factors are linked, as low demand for girls' sports facilities 
leads to lower investment in girls' sports overall.

\section{Mobility/Leisure}

One expectation regarding mobility in Egypt is that girls would have less opportunity to move freely compared with boys in both rural and urban settings. Possible reasons for this limited mobility include parents' fears for their daughters' safety, cultural beliefs that a girls' place is in the home, and fewer facilities designated for the use of young girls. With regard to mobility outside the home, this survey corroborates that girls are not as likely to visit friends, or relatives or go for a walk as boys (Table 7.15).

Adolescents in Lower Egypt, both boys and girls, reported visiting friends at home more often than those in other regions. There is no difference for girls by age but significant difference for boys, with about 18 percent to 19 percent of girls visiting across all age groups, while the rates of visiting increase for boys from 22 percent to 39 percent as they become older. Boys who are out of school report more visiting activities than those who are in school, but this does not hold true for girls. An interesting finding is that more low socioeconomic level girls report visiting friends yesterday than those in either the middle and higher socioeconomic levels.

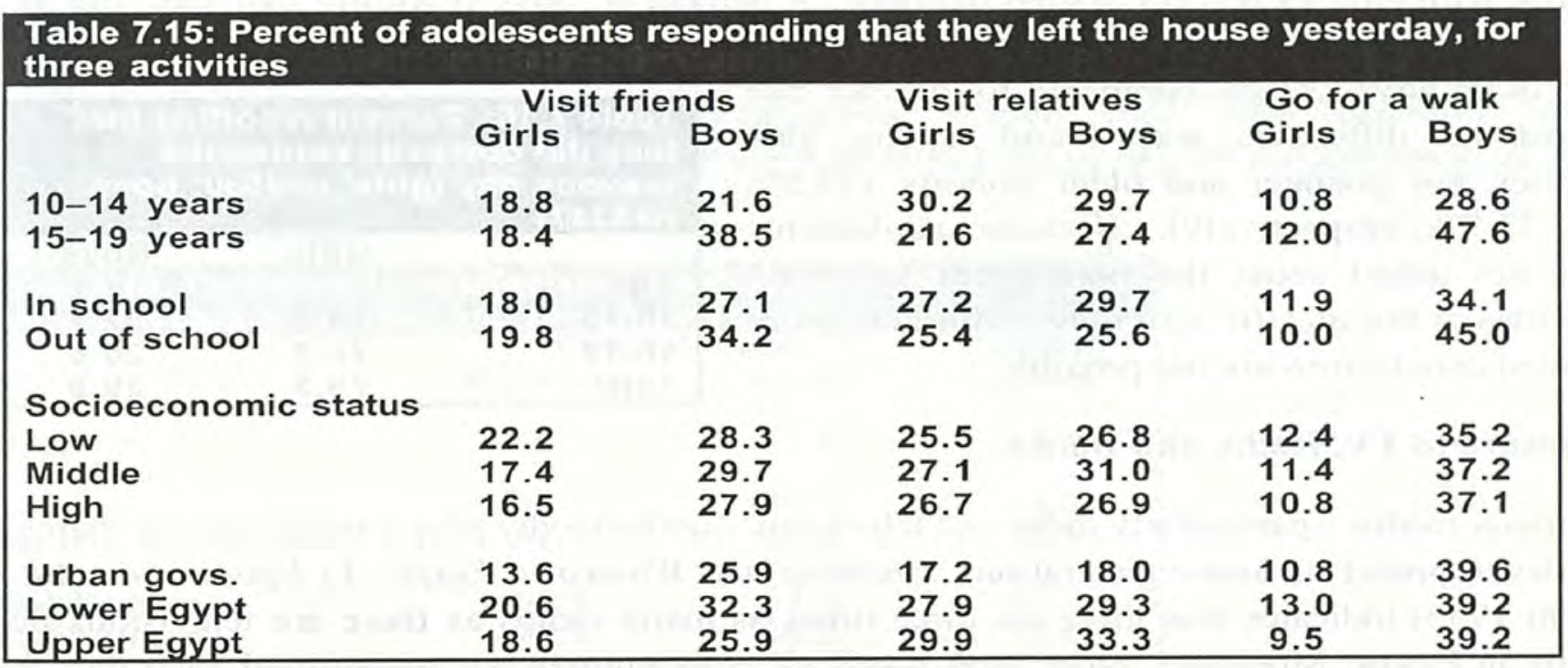

Families and relatives are essential to Egyptian social life. A question was put to adolescents regarding visiting relatives in their homes. Adolescents in Upper Egypt reported visiting relatives at home more than adolescents in any other region. There is a marked difference between the older and younger age group, with visits to relatives decreasing with age. For girls, 30 percent of the younger age group reported visiting relatives at home as opposed to 22 percent of the older age group. Younger and older boys reported 30 percent and 27 percent, respectively. For both boys and girls, being in or out of school makes little difference.

Not surprisingly, going out and walking with friends is an activity that highlights the gender differences more than any other. For example, 48 percent of adolescent boys aged 15-19 reported walking with friends compared to only 12 percent of girls in the same age group. 
This supports the commonly held notion that girls are more likely to stay at home or be allowed to go out only to visit in other homes or other controlled situations. Girls may also have less leisure time, as they report much higher levels of domestic work than boys. (data not shown).

Overall, boys report a greater level of mobility than girls. There is very little regional difference for boys while regional differences for girls can be observed, with those in Lower Egypt more likely to report walking with friends than girls in urban governorates and Upper Egypt. Among boys, there is a marked variation by school status, with 45 percent of out-ofschool boys reporting that they went out with friends yesterday as opposed to 34 percent of those in school, who presumably were more likely to be home studying.

\section{Domestic Chores}

Some adolescents have significant responsibilities in the household and the surrounding environment. These activities might include caring for younger siblings, care of elders, cooking, and general housekeeping. Table 7.16 shows adolescents' responses when asked about domestic activities undertaken during the day prior to the interview.

The table shows clear gender differences in the participation of adolescents in domestic chores, with girls 79 percent of girls but only 29 percent of boys reporting that they did any domestic chore during the previous day. More younger boys reported doing domestic chores than older boys $(32.7 \%$ compared to $20.8 \%)$, but almost no difference was found among girls between the younger and older cohorts $(79.5 \%$ and $78.7 \%$ respectively). Because adolescents were not asked about the time spent on these activities or the specific activities performed, more detailed conclusions are not possible.

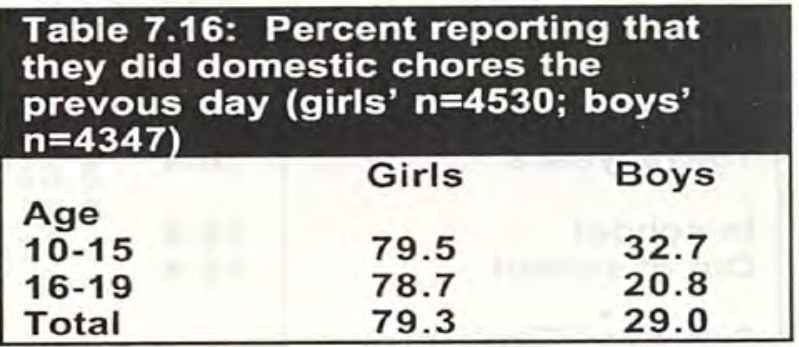

\section{Exposure to TV, Radio and Books}

The mass media - particularly radio and television - undoubtedly play a major role in shaping the development of future generations. Children and Women in Egypt: An Information Atlas (Selim 1996) indicates that there are three times as many radios as there are televisions per family in Egypt. Moreover, more total hours of programming are transmitted each day for radio than for television, at 303 and 78 hours, respectively. Within this transmission for both radio and television, only 5 percent of the time is allocated to programs that directly address adolescents. Nonetheless, radio and television are a major source for transmission of new ideas, and one of the primary conduits of global culture to young people.

Despite the significantly greater opportunities available to listen to the radio, the ASCE survey findings show that adolescents report watching television more than any other medium. Generally, watching television ranks high in all age groups except for boys 15-19 years old. Girls report watching television more than boys, perhaps because they are less mobile and less involved in physical activity outside the home. Those in the high socioeconomic level also report more television watching than those in lower strata. Both boys and girls in the younger age group watch more television than those in the older group. 
Television watching in urban governorates is significantly higher than those in Lower and Upper Egypt. More adolescents in school watched television than those out of school, perhaps because they are more likely to live in homes with television sets.

In spite of the overwhelming popularity of television, Egyptian adolescents are still listening to the radio in large numbers. Older adolescents of both genders reported listening to the radio more frequently than younger adolescents; this is particularly true among girls, with 35 percent of girls aged 16-19 reporting this activity compared to 22 percent among girls aged 10-15. Lower Egyptian adolescents (30\%) report more listening to the radio than those in either Upper Egypt (20\%) or the urban governorates (29\%) (Table 7.17).

\section{Table 7.17: Percent of adolescent girls' and boys' exposure to various media}

\begin{tabular}{|lcccc|} 
& Girls (by age group) & \multicolumn{2}{c|}{ Boys (by age group) } \\
& $10-15$ & $16-19$ & $10-15$ years & $16-19$ years \\
Listen to the radio & years & years & & \\
Watch TV & 22.2 & 34.6 & 20.6 & 30.2 \\
Read books & 81.0 & 80.8 & 80.6 & 78.4 \\
\hline
\end{tabular}

What types of programs do adolescents prefer? When questions about what was watched were posed, entertainment programs, serials, soap operas, and the like, on both radio and television, were the most popular. Other types of programs mentioned included those on social issues, educational, religious, sports-related, or news programs, and "all programs" (Table 7.18). Significantly, educational programs receive very little attention from adolescents; this was the least watched of the four broad categories of programming among both boys and girls.

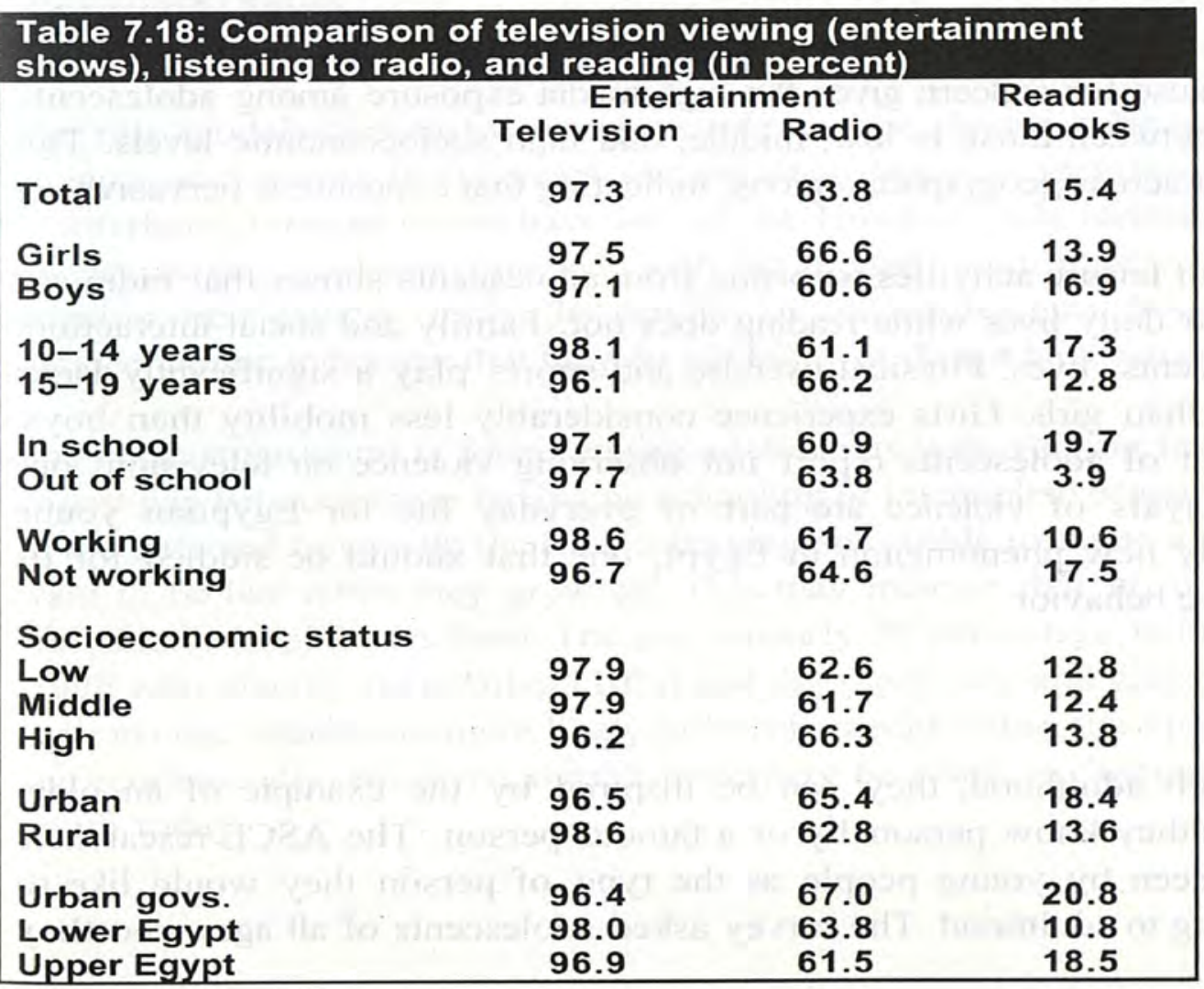


Reading (other than for school) is an activity that lags significantly behind other media activities. This varies by gender and socioeconomic status, with girls less likely to read than boys, and those in higher socioeconomic strata more likely to report reading during the previous day. For example, 13 percent of boys in the lowest socioeconomic stratum report that they read during the previous day compared to 21 percent in the highest stratum, while the levels reported for girls are 11 percent and 18 percent, respectively. Further, this activity varies with age, with older adolescents less likely to report reading than younger adolescents.

The survey asked about leisure activity that requires payment, such as going to either the cinema or a social club. This activity is the least common activity among adolescents. More boys reported cinema/club activity than girls (6\% compared to $1 \%$ in the $10-15$ age group, and $8 \%$ to $1 \%$ in the $16-19$ age group). Adolescents in the urban governorates report having gone to a cinema/club more often than those in either of the other regions, with 8 percent of boys and 2 percent of girls reporting this activity. One can speculate that the low levels reported are due to factors such as cost or the small number of these leisure facilities available in the communities where adolescents live.

\section{Violence in the Media}

Unfortunately, violence is becoming more common and more visible in every society. More than 95 percent of Egyptian adolescents across all social categories report observing violence on television. While more boys than girls reported that they see violence on television always, girls were more likely to report that they sometimes observed violence on television. The percentage of adolescents reporting that they never observe violence on television is very low (4.5\%), an indication of just how much adolescents are exposed to this phenomenon (data not shown).

This high percentage is cause for concern given the high media exposure among adolescents. There is little difference between those in low, middle, and high socioeconomic levels. This reporting is also consistent across geographic regions, indicating that exposure is pervasive.

In summary, the analysis of leisure activities reporting from adolescents shows that radio and television rank high in their daily lives while reading does not. Family and social interactions are strong links in adolescents' lives. Physical exercise and sports play a significantly larger role in the lives of boys than girls. Girls experience considerably less mobility than boys. Given that only 5 percent of adolescents report not observing violence on television; one must conclude that portrayals of violence are part of everyday life for Egyptian young people. This is a relatively new phenomenon in Egypt, one that should be studied for its potential links to aggressive behavior.

\section{ROLE MODELS}

As young people approach adulthood, they can be inspired by the example of an older individual, either someone they know personally or a famous person. The ASCE researchers wanted to know who is seen by young people as the type of person they would like to emulate as they are growing to adulthood. The survey asked adolescents of all ages who they 
consider to be their role model, the person they want to be like when they grow up. As Table 7.18 shows, for many young people, this is an alien question. Fully one-quarter of Egyptian adolescents give no answer about a role model and another 5 percent say they do not know.

The most frequently mentioned role model is father $(19.9 \%)$ followed by a variety of male relatives, such as brothers, uncles, and grandfathers (20.2\% combined). Daughters are less likely to mention mothers than sons to mention their fathers. A teacher is mentioned by 9 percent, with 6 percent naming a male teacher and 3 percent a female teacher. Community figures like the mayor, a sheikh, or an engineer were mentioned by 5 percent.

Since the item about role models was asked as an open-ended question, respondents çould and did offer a plethora of interesting answers that fell into an "Other" category. Egyptian sports figures, entertainers and religious leaders were mentioned. Famous individuals inspire some Egyptian youth, but many are historical rather than contemporary figures. Among the famous people mentioned were Avicenna, Taha Hussein, Gamal Abdel Nasser, and Amr Diab. Famous women were rarely mentioned as role models.

\begin{tabular}{|c|c|c|c|}
\hline & Girls & Boys & Total \\
\hline No role model/don't know & 32.7 & 25.5 & 29.2 \\
\hline Father & 15.9 & 24 & 19.9 \\
\hline Mother & 11.9 & 1.1 & 6.8 \\
\hline Male teacher & 3.2 & 9.4 & 6.1 \\
\hline Female teacher & 5.6 & 0.1 & 2.9 \\
\hline Male relative & 16.4 & 23.4 & 20.2 \\
\hline Female relative & 7.5 & 0.9 & 3.7 \\
\hline Community figure & 3.2 & 7.2 & 5.3 \\
\hline All other & 3.5 & 8.3 & 5.9 \\
\hline
\end{tabular}

The role models chosen by young people do not change substantially with age, although younger adolescents 10-15 years old are more likely to mention a teacher than their older counterparts, more of whom have left school. However, role models do vary substantially by socioeconomic level and residence, with urban youth and higher-status youth more likely to mention their fathers. Fully 36 percent of the adolescents from the lowest third of the socioeconomic index say that they do not know or do not have a role model.

The greatest variation is found among adolescents with varying levels of education, with the widest gap between those having no schooling or incomplete primary and all others. Over half of the girls and boys with the least schooling are unable to name a role model or person they want to be like when they grow up. This may indicate that no one in their environment is particularly inspiring to them. The gap is nearly 20 percentage points between low-education youth who identify their father $(10 \%)$ and the secondary and higher education groups $(29 \%)$. It seems that fathers are more likely to be role models when the family has succeeded socially and economically. However, overall there may be a lack of "heroes" in the lives of Egyptian youth today. 


\section{CONCLUSION}

The family context emerges as the major agent of socialization in the perception of adolescents. It provides a model for exchange of support and a range of communications models that adolescents may follow at present and in the future. The adolescents who express their opinions openly to their families and who are respected when they do so are also more likely to express their opinions to their friends when in disagreement and are more able to resist the pressure of their peer group. They are likely candidates to develop leadership qualities. They are also the most ambitious; that is, they are not very satisfied with their current situation but are the most optimistic about a better future. This group of adolescents is generally comprised of boys, older adolescents, adolescents in school, those residing in the urban governorates, or those from higher-status households.

On the other hand, girls, out-of-school adolescents, those from low-status households, residents of rural areas or from Upper Egypt are less likely to voice their opinions with their parents or peers and are more likely to receive a negative response when they do so. These groups are also confined more to the household setting and are the most restricted in their mobility and opportunities to meet with friends. It is not surprising then that these groups lack leadership qualities, given the negative experiences and the limited opportunities they have to develop these skills. Perhaps not surprisingly, these adolescents are the ones most likely to initiate acts of aggression and to be victims of aggression by others at home as well. Moreover, adolescents from low-status households and residents of Upper Egypt are the least optimistic and do not have high expectations for the future. They are the least likely to mention someone they emulate and look up to as a role model.

A less restrictive and more communicative and receptive family environment seems to be correlated with positive development of the adolescent's character, increasing his or her maturity level and coping skills and resources. Special education programs for parents that focus on the physical and psychological changes of adolescence and the development of communication skills would help adolescents to cope with the many changes during this stage of life. These programs should target both adolescents and their parents to ensure a household context that is more supportive and appreciative of this sensitive phase in the life cycle. 


\section{Chapter 8}

\section{Transitions to Marriage and Reproductive Roles}

Along with education and work, the transitions to adult reproductive and family roles form a critical part of the growing-up experience of adolescents. The years from age 10 to 19 encompass a tremendous amount of social maturation in which a young person's knowledge, awareness, and judgement increase rapidly. At the beginning of adolescence, few boys or girls show much awareness of reproductive matters. By the end of adolescence, they are physically capable of marrying and starting a family, and many have already done so. But these transitions progress at different rates for different individuals, as seen in Chapter 4 . Awareness levels are affected not only by the physical changes of maturation, but also by exposure to images on television and other media, by school curricula, and by exposure to peers and work mates. Thus the ASCE team felt it was important to understand when and how young people acquire the knowledge that will prepare them for roles as parents and partners in marriage.

This chapter explores the knowledge and range of opinions that adolescents hold on some of these topics, including gender roles, reproductive health, age of marriage, characteristics of a desirable spouse, and other issues. It also makes some comparisons between the views of parents and their children regarding communication over these topics.

\section{REPRODUCTIVE HEALTH KNOWLEDGE}

Because marriage and procreation hold central places in Egyptian life, preparation for married life is considered to be one of the most important aspects of growing to adulthood. However, adolescents in Egypt have traditionally been shielded from information about reproduction and sexuality until the time of marriage. Even information about physical maturation is often not discussed within the family, on the assumption that silence will convey the taboo nature of this topic, protect a child's innocence, and discourage inappropriate behavior. An increasing number of educators, public health experts, and parents now recognize the need for adolescents to be informed about maturation and reproductive health. However there is no general consensus about what should be taught or what the appropriate channels of transmission should be.

The survey asked all adolescents a series of questions regarding the changes of physical maturation. A subset of adolescents 16 years and older were also asked questions to assess their knowledge regarding reproductive health topics, such as knowledge of a woman's fertile period, sexually transmitted infections (STIs), and contraceptive methods. For most subjects, data on both boys and girls are presented. However, for three topics: female circumcision, menstruation, and understanding of the fertility cycle, only girls were asked the relevant questions. These questions are as far as we can probe into the sexual knowledge and experience of unmarried adolescents, as more explicit questions were not considered appropriate to ask in Egypt in a household survey. 
What and how do adolescents know about the physical changes of maturation? Nearly 70 percent of girls but only 45 percent of boys are able to describe any of the changes of puberty. As expected, this knowledge increases sharply with age. For girls, 36 percent of those 10-12 years old can name any signs of puberty compared to 94 percent of those 16-19 years old. Similar figures for boys are 12 percent of 10-12 year-olds and 80 percent of 16-19 year-olds.

From whom do adolescents report actually getting their information? The vast majority of Egyptian adolescents learn about maturity changes without speaking to family members or other adults in their community. The small role played by parents in transmitting this knowledge is revealed when comparing individual adolescent responses to those of his or her same-sex parent. Here a very interesting picture emerges. Only 7 percent of boys who know something about puberty changes report learning about puberty from their fathers, whereas 42 percent of those same fathers indicate that they talked to their sons about pubertal changes. Indeed, of 98 adolescent boys whose fathers indicated that they talked to their sons, 90 boys say they did not learn about maturity changes from their father.

A similar, though less extreme pattern emerges among mothers and daughters. Among those girls whose mothers say they spoke to them about maturity changes, more than half $(52 \%)$ report that they learned about those changes by themselves. However, 42 percent of this group report that they did indeed learn about puberty from their mothers. Overall, 31 percent of girls who know about puberty changes report learning about them from their mothers.

Parents seem to recognize that they should speak to their adolescents about these topics but do not, perhaps because they are embarrassed or lack the correct information to do so. Clearly, perceptions about father-son and mother-daughter communication on this topic are different between the generations, particularly between fathers and sons. From an adolescent's point of view, there seems to be a "culture of silence" surrounding the discussion of issues related to puberty. Combined with the high proportion who also do not think anyone should talk to adolescents (data not shown), this taboo or silence appears similar to that researchers found surrounding women's reproductive health issues in Egypt (Khattab 1993).

The most frequent answer given to the question how did you come to know about puberty changes, was "by myself/by observation" (69\% for boys and $60 \%$ for girls). This seems to further support the thesis that adolescents' knowledge is acquired in some degree of isolation. Other sources of information for boys are friends $(24 \%)$, other family members $(5 \%)$, books $(6 \%)$, and mass media (2\%). Girls report friends (14\%), older siblings (10\%), and school books $(7 \%)$ as their information sources. The insignificant role of mass media is revealing, given the high proportion of adolescents who report watching television; indeed TV viewing is the most frequently mentioned activity reported by all adolescents. But it appears not to be playing a reproductive health education role if this response is indicative ${ }^{1}$.

\footnotetext{
'This contradicts findings from a smaller survey of 15-to-24-year-old Egyptians, who reported TV as a major source of information on other aspects of reproductive health such as FGM. (Makhlouf and Amin 1995).
} 


\section{Girls' Knowledge of Fertile Period}

Understanding the female fertility cycle has been taken as a proxy for girls having basic information about their reproductive processes. Girls aged 16-19 in the health sample were asked when in the monthly cycle a woman is fertile and could conceive, with several possible response choices given. Answers were coded as correct if the girl gave the response "near the midpoint between menstrual periods," incorrect if she gave any other answer, and "don't know" if she indicated not knowing the answer. As shown in Figure 8.1.2, of the 392 girls in this group, only 15 percent gave the correct response. The majority $(58.4 \%)$ answered that they did not know. There is a high degree of misinformation among girls, with 26 percent giving incorrect answers such as "during the period," "immediately before the period," and others (Figure 8.1).

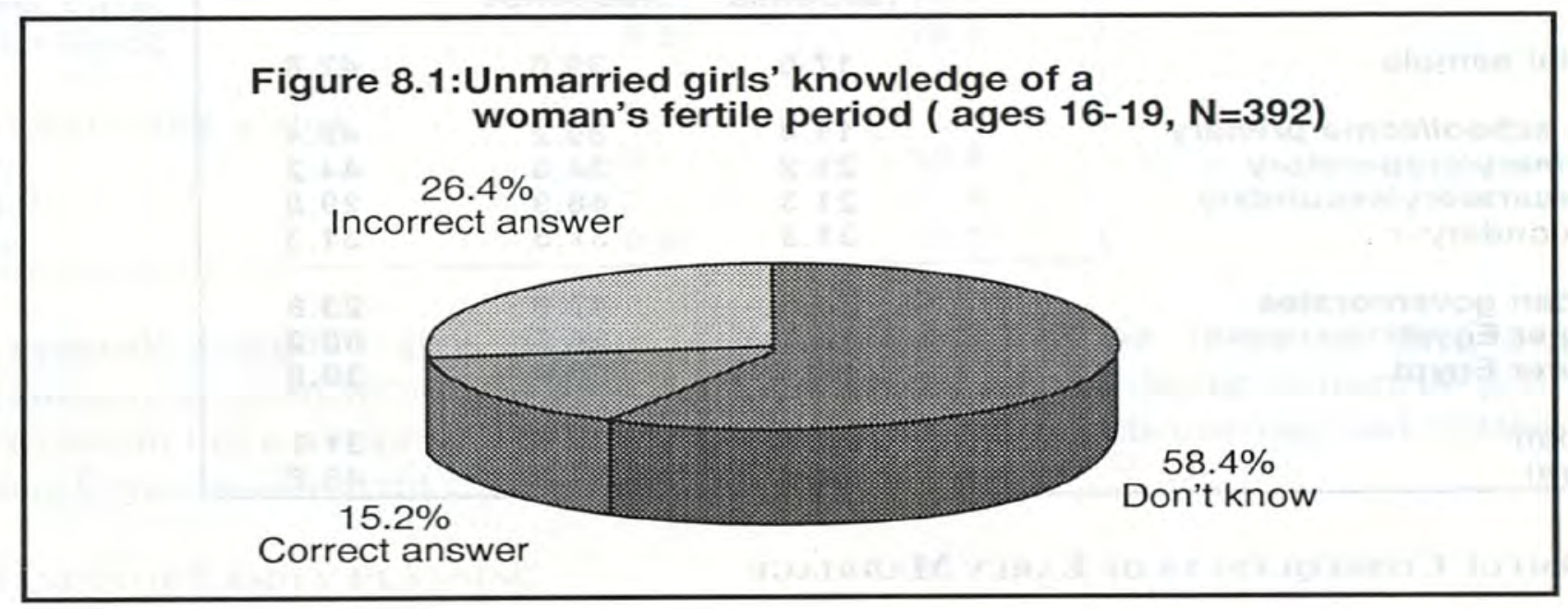

A girl's knowledge of the fertile period is greater if she is from a household where at least one parent has above an intermediate level of education. Interestingly, the reverse is true regarding her own education: a girl is somewhat more likely to know the correct answer if she herself has little or no schooling than if she has reached the end of basic education ( $15 \%$ versus $10 \%)$. Girls must reach secondary through university education before there is an appreciable increase in knowledge of the fertile period - but even for this group, less than a quarter $(22 \%)$ could give the correct response. The group of girls most likely to believe they know the answer but to respond incorrectly is graduates of basic education or vocational high schools: 30 percent of these girls give the wrong response.

Girls living in the urban governorates are more likely than either other urban or rural girls to know when a woman has her fertile period-21 percent compared to 15 percent and 13 percent, respectively. However, an even larger proportion of girls from large cities think that they know the fertile period but report incorrect answers (31\% in large cities versus $21 \%$ in other urban areas and $26 \%$ in rural areas.) 


\section{Married Adolescents' Knowledge of the Fertile Period}

Despite their marital status, the reproductive knowledge levels among married adolescents are also quite low. Only 18 percent of married adolescent women can correctly identify the fertile period (Table 8.1). Forty-three percent say they do not know the answer and the remainder $(40 \%)$ give incorrect answers. The married women's knowledge varies by education level, though in this group the variation is in the expected direction. While only 11 percent of those with no education or who have not completed primary school can give the correct response, 21 percent of those who have completed some secondary school and 31 percent of those who have completed secondary can give the correct response.

\begin{tabular}{|c|c|c|c|}
\hline & $\begin{array}{l}\text { Correct } \\
\text { response }\end{array}$ & $\begin{array}{l}\text { Incorrect } \\
\text { response }\end{array}$ & Don't know \\
\hline Total sample & 17.6 & 39.6 & 42.8 \\
\hline $\begin{array}{l}\text { No school/some primary } \\
\text { Primary/preparatory } \\
\text { Preparatory/secondary } \\
\text { Secondary + }\end{array}$ & $\begin{array}{l}11.4 \\
21.2 \\
21.3 \\
31.3\end{array}$ & $\begin{array}{l}39.2 \\
34.6 \\
48.9 \\
37.5\end{array}$ & $\begin{array}{l}49.4 \\
44.2 \\
29.8 \\
31.3\end{array}$ \\
\hline $\begin{array}{l}\text { Urban governorates } \\
\text { Upper Egypt } \\
\text { Lower Egypt }\end{array}$ & $\begin{array}{l}28.6 \\
15.0 \\
18.2\end{array}$ & $\begin{array}{l}47.6 \\
24.8 \\
50.9\end{array}$ & $\begin{array}{l}23.8 \\
60.2 \\
30.8\end{array}$ \\
\hline $\begin{array}{l}\text { Urban } \\
\text { Rural }\end{array}$ & $\begin{array}{l}28.6 \\
14.8 \\
\end{array}$ & $\begin{array}{l}39.7 \\
39.6 \\
\end{array}$ & $\begin{array}{l}31.7 \\
45.6 \\
\end{array}$ \\
\hline
\end{tabular}

\section{Harmful Consequences of Early Marriage}

Early marriage and childbearing have been prevalent in some parts of rural Egypt (see Chapter 9). The ASCE researchers wanted to gauge whether adolescent girls are aware of the potentially harmful consequences of a woman of bearing children at an early age. The sample of never-married girls aged 16-19 and all married adolescent women were asked if they think that a woman of 15 years can withstand (tethamel) a pregnancy.

Overall, most never-married girls responded that at 15 years old, a woman is not ready to withstand pregnancy $(97.6 \%)$ (Table 8.2$)$. However, there were some notable patterns among the small group of girls who believe that 15 is a safe age for pregnancy. The highest proportion answering affirmatively were girls with the least education: 8 percent of those with no education or less than primary schooling. Living in a rural area or coming from a low socioeconomic status also increases the likelihood of a positive answer. None of the girls in the highest socioeconomic category answered positively.

Perhaps not surprisingly, more of the married adolescents believe a 15 -year-old girl is ready for pregnancy $(13.9 \%)$, though this is perhaps not as high as might be expected. Patterns of variation among married adolescents were not as systematic as those among never-married girls. However, education is associated with this belief; the highest proportion of those responding affirmatively were those with no education $(18.4 \%)$. 


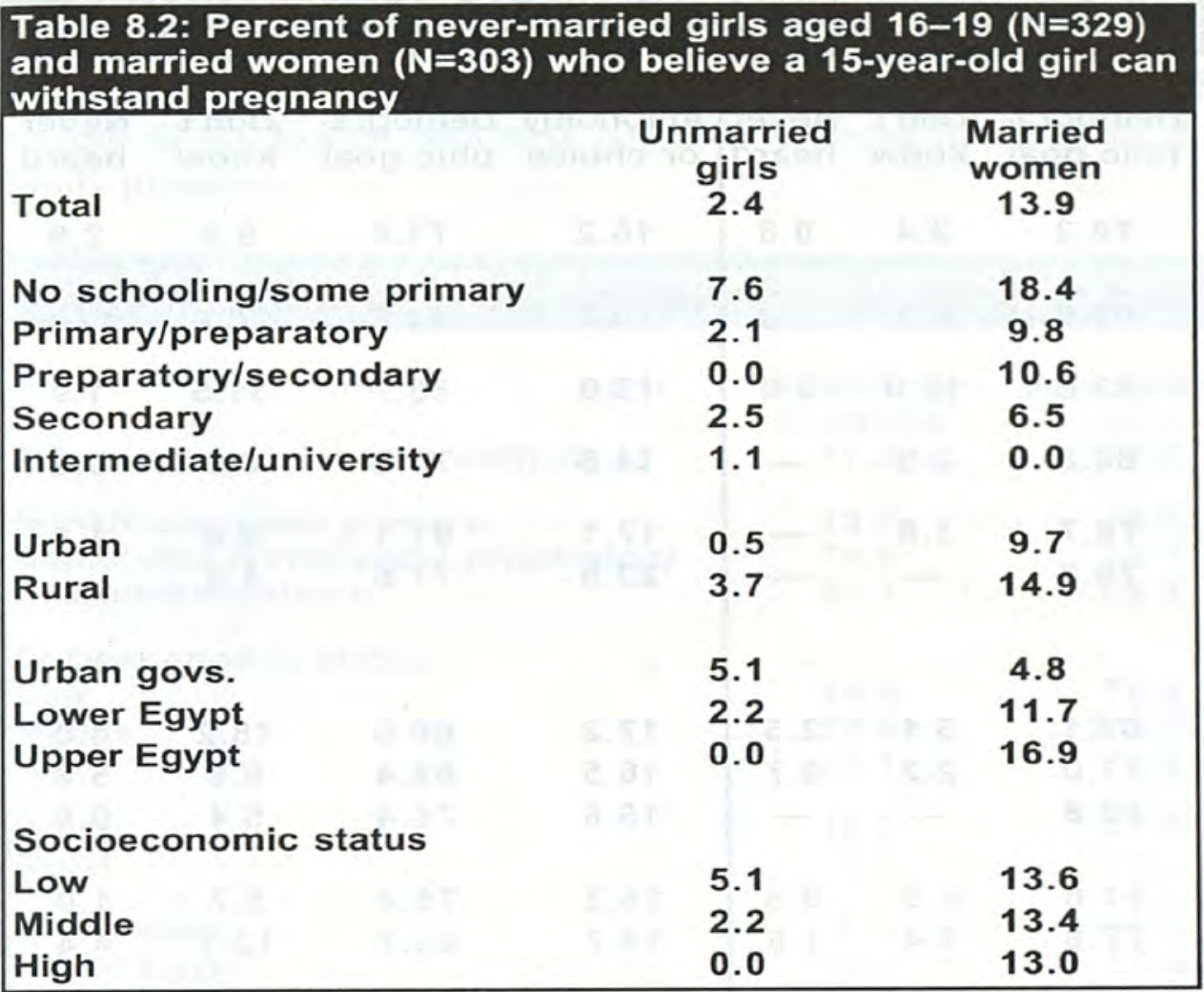

In general, Egyptian girls appear to know that 15 is an inappropriate age for pregnancy. Coupled with the high ideal age for marriage among the never-married girls (see later section) this is a hopeful sign for the future elimination of early marriage and childbearing among Egyptian adolescent girls.

\section{Meaning of Family Planning}

Egypt has had an active campaign for family planning since before this cohort of adolescents was born. Since family planning messages appear on television, in clinics, and in the basic education curriculum, most adolescents will have been exposed to some information about this subject. But how do adolescents understand or interpret this information? Do they associate family planning with gaining greater control over one's reproductive outcomes or as a means of reducing births?

In order to address this question, the survey included an open-ended question to those aged 16-19 who indicated that they had heard of family planning: "What does family planning mean to you?" We coded responses into three groupings: those who have heard of family planning but do not know what it means, those whose answers indicate a demographic meaning or government objective (for example, limit births, have fewer children, have only two children, reduce population), and those whose answers suggest that family planning gives greater autonomy or choice to a couple or a woman (for example, choosing when to have a child, being able to space one's pregnancies, having only the children I want) (Table 8.3).

Virtually all adolescents aged 16-19 report that they have heard of family planning and most have an opinion about what it means. Overall, adolescents are much more likely to give a meaning related to demographic goals or carrying out state policy. 


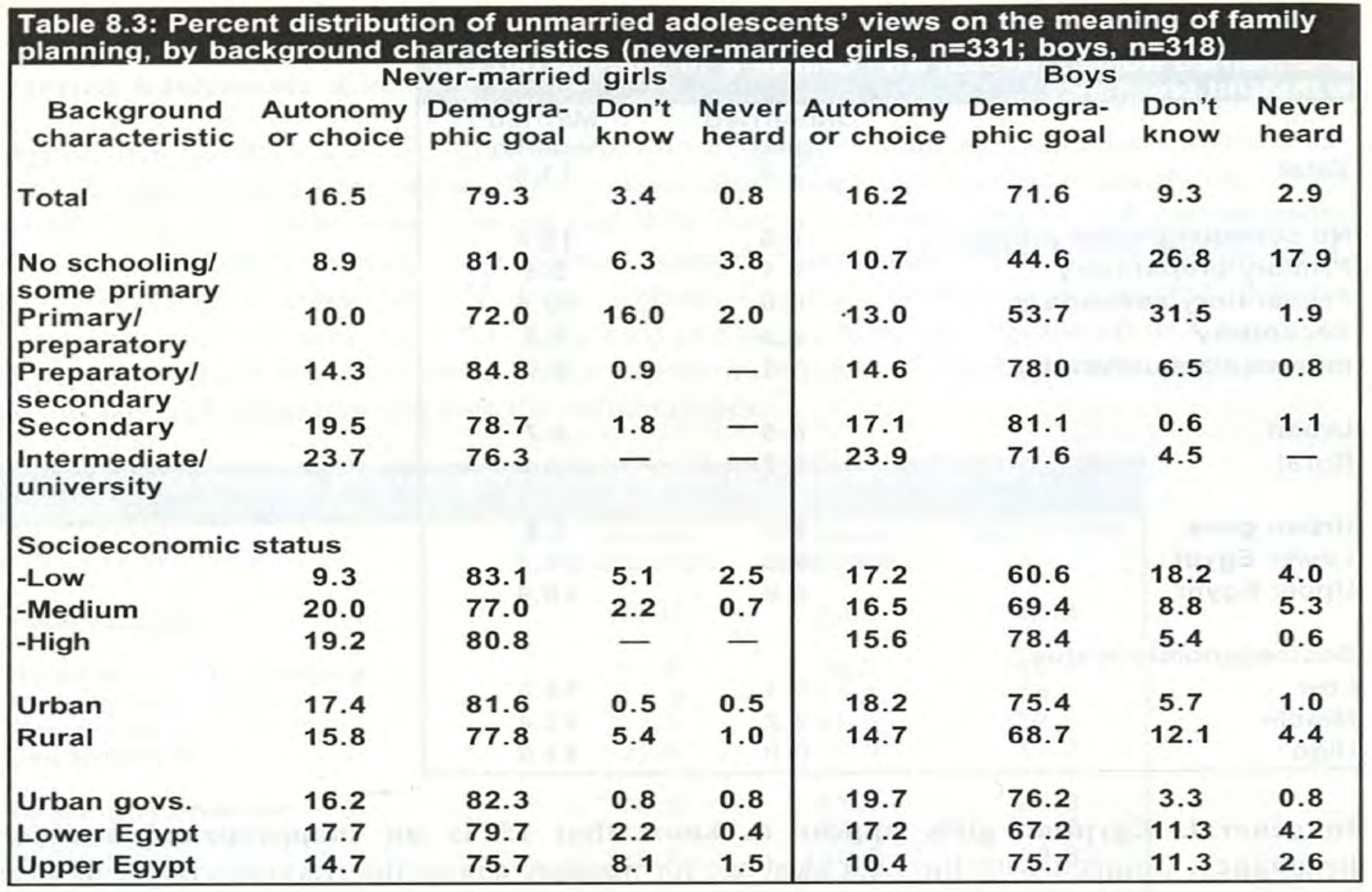

It is interesting that residence in urban governorates reinforces this interpretation of family planning for girls (82.3\% versus $75.7 \%$ in Upper Egypt and $79.7 \%$ in Lower Egypt). Conversely, as girls reach higher levels of education, they are more likely to interpret family planning as a means for increasing autonomy and choice in reproduction; 24 percent of girls with some university education versus 9 percent of girls with no education.

Slightly more boys than girls report having never heard of family planning (2.9\%), and boys are somewhat more likely to say they have heard of it but do not know what it means $(9.3 \%$ versus $3.4 \%$ for girls). Schooling is an important indicator of boys' family planning knowledge: 18 percent of boys who have never attended school report that they have not heard of family planning while few boys with any schooling report they lack this knowledge.

Overall, boys (like girls) give more weight to the demographic than to the personal choice interpretation of family planning (71.6\% and $16.2 \%$ respectively for boys). Boys from higher socioeconomic classes are more inclined to see family planning as demographic control $(78.4 \%$ versus $60.6 \%$ ). For girls there is no clear pattern, although they are somewhat more likely to interpret family planning as personal choice as their socioeconomic status increases. This finding of gender differences might point to potential conflicts in the future, when couples begin negotiating family planning decisions. Boys in Upper Egypt are the least likely group to see family planning as a means to personal autonomy (only $10 \%$ ).

Patterns of reporting the meaning of family planning among married adolescent women are similar to those of unmarried girls, that is, most see it as a demographic goal. The most 
striking difference is that more married adolescents (3.8\%) report they have never heard of family planning and even more $(7.0 \%)$ say they do not know what it means. A total of 16 percent of the lowest educated group have never heard of or do not know the meaning of family planning.

\section{Table 8.4: Meaning of family planning among married adolescents (in percent)}

\begin{tabular}{|lcccc|} 
& $\begin{array}{c}\text { Autonomy } \\
\text { or choice }\end{array}$ & $\begin{array}{c}\text { Demographic } \\
\text { goal }\end{array}$ & $\begin{array}{c}\text { Never } \\
\text { heard of } \\
\text { FP }\end{array}$ & $\begin{array}{c}\text { Don't } \\
\text { know }\end{array}$ \\
All married adolescent women & 17.4 & 71.5 & 3.8 & 7.0 \\
None/incomplete primary & 13.7 & 70.2 & 6.5 & 8.9 \\
$\begin{array}{l}\text { Completed primary/any preparatory } \\
\text { Intermediatelabove }\end{array}$ & 14.8 & 76.1 & 1.1 & 8.0 \\
Socioeconomic status & 31.7 & 68.3 & 0.0 & 0.0 \\
Low & & & & 8.2 \\
Middle & 15.5 & 70.0 & 5.5 & 6.2 \\
High & 18.0 & 72.5 & 3.4 & 0.0 \\
Urban & 26.1 & 73.9 & 0.0 & 3.0 \\
Rural & 18.2 & 77.3 & 0.0 & 8.0 \\
Urban govs. & 17.2 & 70.0 & 4.8 & \\
Lower Egypt & 9.1 & 86.4 & 0.0 & 4.5 \\
Upper Egypt & 15.2 & 77.3 & 1.5 & 6.1 \\
\hline
\end{tabular}

Knowledge of Contraceptive Methods and Sexually Transmitted Infections

\section{Knowledge of Contraceptive Methods}

The 98 percent of respondents aged 16-19 who say they know about family planning were asked to name the contraceptive methods they know (Table 8.5). Most could name at least one modern method, and both the pill and the IUD were identified by more than half the boys and girls. Gender differences are substantial, however, with girls far more likely to know of women's methods. Boys are more likely to know of natural methods like rhythm and withdrawal. Boys are also more likely to report knowledge of condoms, though overall knowledge of condoms is weak for both genders ( $14.3 \%$ of boys and only $5.1 \%$ of girls).

Boys' knowledge of contraceptives is more strongly associated with higher levels of education than is the case for girls. Condoms in particular are known by almost half of boys with secondary schooling or higher. There are regional differences concerning which methods are better known, though in general rural girls are more likely to know methods than urban girls, while the reverse is true for boys.

These findings suggest that Egypt's national family planning campaign has succeeded in reaching young people, not only through the school curriculum, but also through mass media targeting disadvantaged groups like rural, less-educated families. It also suggests that young people are exposed to family planning information before marriage, either through their families, schools, community, or the media. 


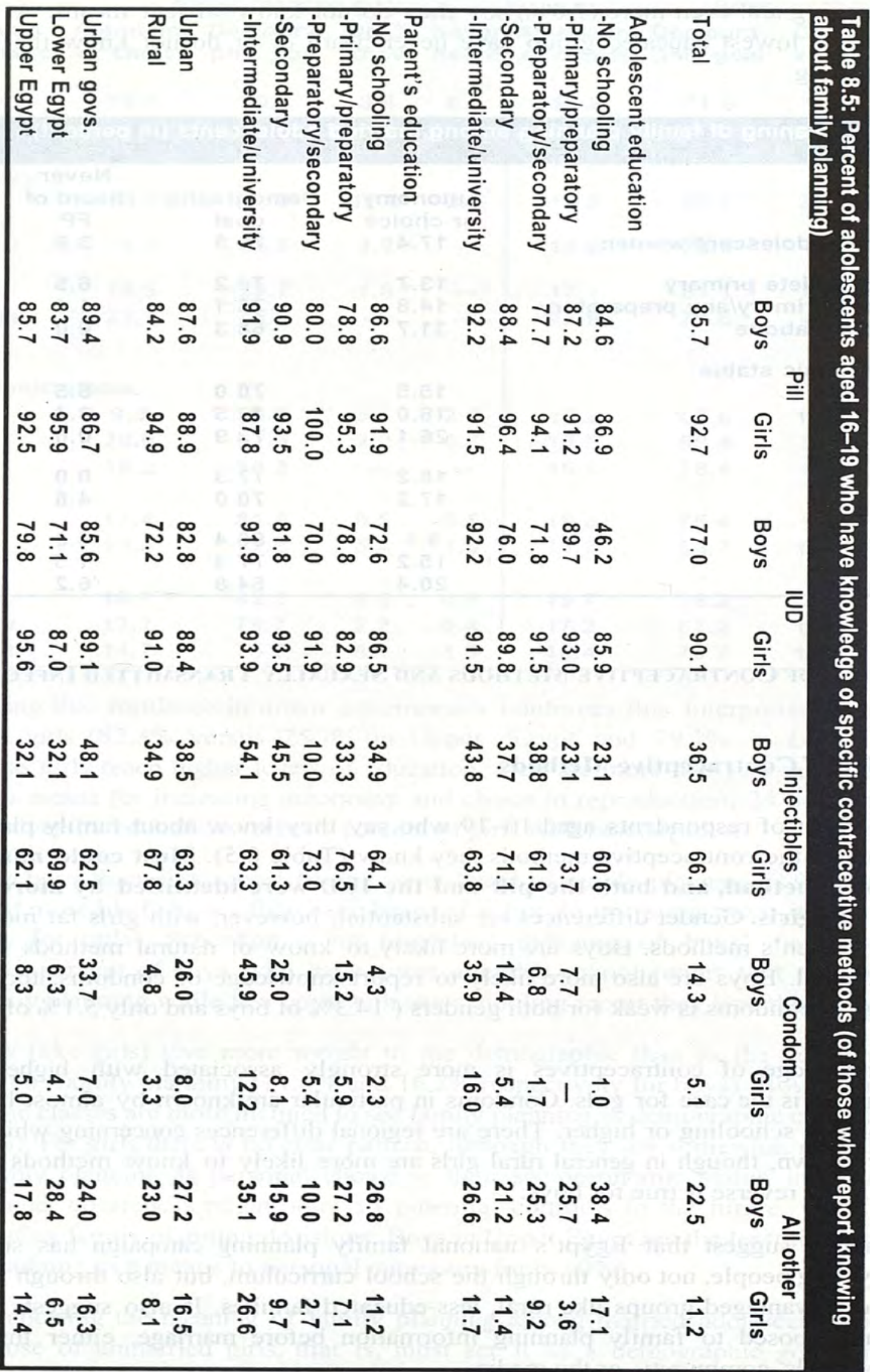




\section{Knowledge of Sexually Transmitted Infections (STIs)}

As the global AIDS epidemic has grown, Egyptians have become more exposed to mass media campaigns explaining the dangers of sexually-transmitted infections (STIs). Adolescents in school are also exposed to HIV/AIDS messages as part of the science curriculum. Yet strong taboos remain about discussing topics related to sexuality openly. The ASCE researchers wanted to know whether adolescents report any knowledge concerning these topics and to measure differences among subgroups. Table 8.6 shows the levels of knowledge about several STIs for girls and boys aged 16-19.

Overall, HIV/AIDS is the most widely-known STI, mentioned by 66 percent of girls and 76 percent of boys. The strongest predictor of an adolescent's knowledge is amount of schooling, with 92 percent of those with secondary or higher education reporting knowledge of HIV/AIDS. Only 25 percent of adolescents who never attended school or have incomplete primary report knowing about HIV/AIDS.

Girls report less knowledge of STIs in general than do boys, with the exception of reproductive tract infections. Table 8.6 shows the breakdown of reported knowledge by gender for several types of STIs.

As mentioned previously, many adolescents have heard about HIV/AIDS but far fewer report is not coupled with a widespread knowledge of condoms. Given the widespread association of condoms with illicit relationships in Egypt, we can expect some degree of underreporting of condom knowledge. This may be more likely among girls who may not think it appropriate to admit knowledge of condoms to an interviewer. However, the low level of knowledge of condoms among these older adolescents is noteworthy, given that it is the one method that can also protect against sexually transmitted infections. 


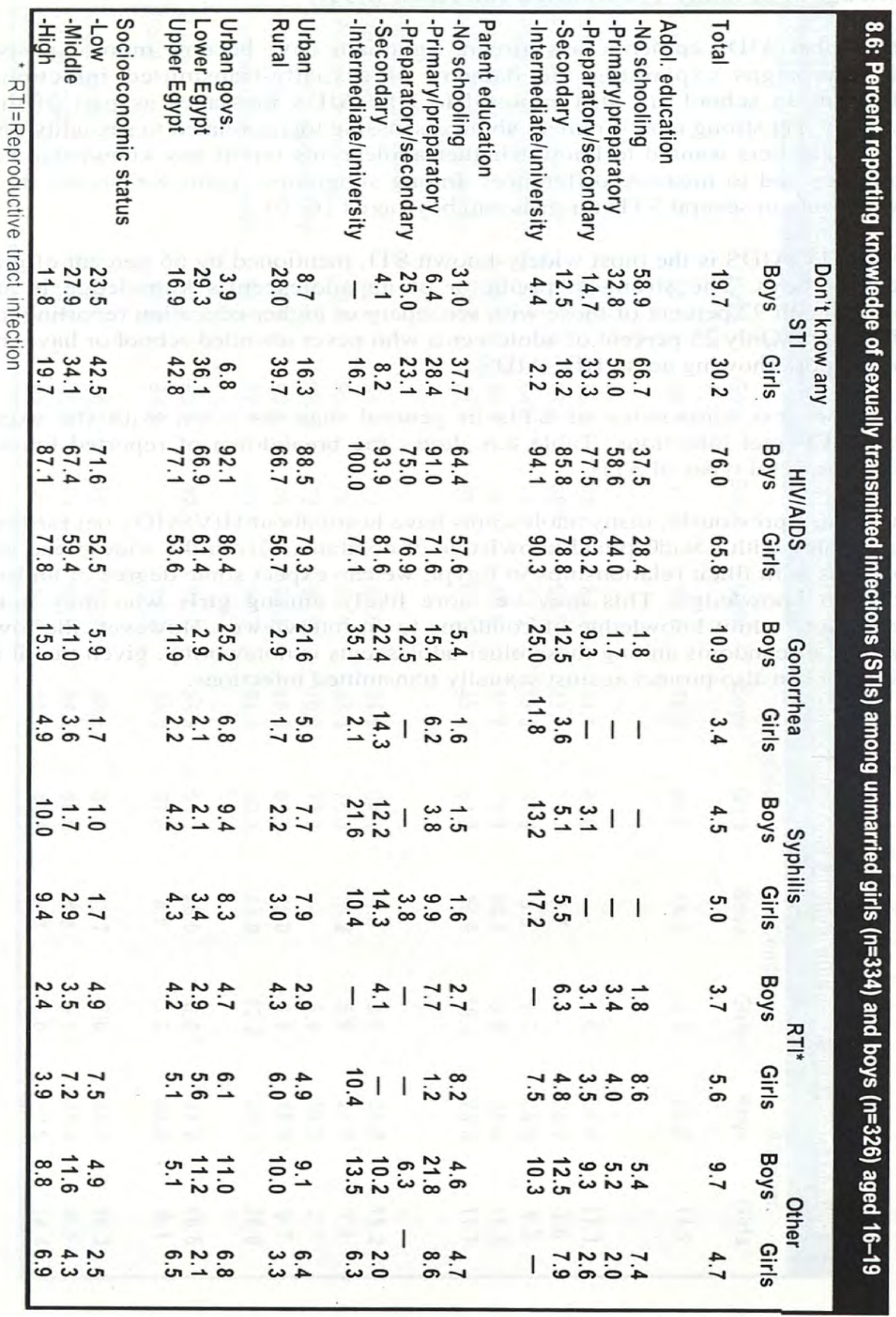


Traditionally in Egypt, adolescents were shielded from information about reproduction and sexuality until the time of their marriages. Today some of these topics are aired on public television and taught in the school curriculum. ASCE researchers wanted to know how adolescents view the importance of having information on maturation and reproduction and when and how they would want to receive the information.

Respondents aged 16-19 were asked whether or not adolescents should receive information on a variety of topics, and how and when they thought this information should be conveyed. Topics included pubertal maturation, the marriage contract and rights within marriage, healthy pregnancy and childbirth, care and breastfeeding of young children, prevention of sexually transmitted infections (STIs), and sexual relations between spouses. Given the sensitivities surrounding these issues, answers to these questions should probably be regarded as reflecting a mix of the adolescent's personal desire for information and his or her sense of what is appropriate to reveal to an interviewer.

\section{What Information Should Adolescents Receive?}

The majority of adolescent girls and boys agree that they should receive information about all issues covered in the survey (Table 8.7), with somewhat fewer saying they should have information on sexual relations. Even among issues faced only by married couples, more than 85 percent of girls and nearly 77 percent of boys believe adolescents should receive information about the care and breastfeeding of young children.

On most issues, girls tend to favor providing information to adolescents at somewhat higher rates than boys. For example, more than 89 percent of girls feel that adolescents should be informed about physical maturation compared with 73 percent of boys. The exception is regarding STI prevention; 20 percent more boys than girls believe that adolescents should be told about STIs. Nevertheless, 66 percent of girls believe this is appropriate information to be conveyed.

Approximately half of adolescents believe that they should be informed about sexual relations between married couples. This may seem contradictory given that large proportions believe it is appropriate for adolescents to learn about STI prevention. However, this probably reflects normative notions that young people should be sexually ignorant prior to marriage.

A number of background variables seem to affect adolescents' views. One of the most unexpected differences among girls is the regional variation regarding information on sexual relations. Girls in Upper Egypt are much more likely to feel this is appropriate information for adolescents $(65.2 \%)$ than those in Lower Egypt $(37.8 \%)$ or the urban governorates $(49.2 \%)$. Furthermore, girls in Lower Egypt are significantly less likely to think that adolescents should know about STI prevention than those in the other regions; only 56 percent of Lower Egyptian girls compared to 76 percent in urban governorates and 80 percent in Upper Egypt. An interesting pattern also emerges among boys regarding knowledge of childcare and breastfeeding. As their parents' level of education increases, so do boys' beliefs that adolescents should know about this topic. 


\begin{tabular}{|c|c|c|c|c|c|c|}
\hline \multirow[b]{2}{*}{$\begin{array}{l}\text { Physical changes } \\
\text { of maturation }\end{array}$} & \multicolumn{2}{|c|}{$\begin{array}{l}\text { Information } \\
\text { is } \\
\text { appropriate }\end{array}$} & \multicolumn{2}{|c|}{$\begin{array}{l}\text { If appropriate, who } \\
\text { should provide } \\
\text { information? }\end{array}$} & \multicolumn{2}{|c|}{$\begin{array}{l}\text { If appropriate, when should } \\
\text { information be provided? }\end{array}$} \\
\hline & $\begin{array}{l}\text { Boys } \\
72.5\end{array}$ & $\begin{array}{l}\text { Girls } \\
89.2\end{array}$ & $\begin{array}{l}\text { Boys } \\
\text { 1) Father } \\
\text { 2) Friend } \\
\text { 3) Sibling }\end{array}$ & $\begin{array}{l}\text { Girls } \\
\text { 1) Mother }\end{array}$ & \begin{tabular}{l}
\multicolumn{1}{c}{ Boys } \\
1) During \\
puberty \\
2) Before \\
puberty
\end{tabular} & $\begin{array}{l}\quad \text { Girls } \\
\text { 1) Before } \\
\text { menarche } \\
\text { 2) After } \\
\text { menarche }\end{array}$ \\
\hline $\begin{array}{l}\text { Marriage } \\
\text { contract/rights }\end{array}$ & 80.2 & 76.8 & 1) Father & $\begin{array}{l}\text { 1) Father } \\
\text { 2) Mother } \\
\text { 3) Both }\end{array}$ & $\begin{array}{l}\text { 1) Before } \\
\text { marriage }\end{array}$ & $\begin{array}{l}\text { 1) Before } \\
\text { marriage }\end{array}$ \\
\hline $\begin{array}{l}\text { Pregnancy and } \\
\text { childbirth }\end{array}$ & 71.3 & 87.5 & $\begin{array}{l}\text { 1) Mother } \\
\text { 2) Doctor } \\
\text { 3) Father }\end{array}$ & $\begin{array}{l}\text { 1) Mother } \\
\text { 2) Doctor }\end{array}$ & $\begin{array}{l}\text { 1) Before } \\
\text { pregnancy } \\
\text { 2) During } \\
\text { pregnancy }\end{array}$ & $\begin{array}{l}\text { 1) During } \\
\text { pregnancy } \\
\text { 2) Before } \\
\text { pregnancy }\end{array}$ \\
\hline $\begin{array}{l}\text { Breastfeeding } \\
\text { and infant care }\end{array}$ & 76.9 & 85.7 & $\begin{array}{l}\text { 1) Father } \\
\text { 2) Mother } \\
\text { 3) Doctor }\end{array}$ & $\begin{array}{l}\text { 1) Mother } \\
\text { 2) Doctor }\end{array}$ & $\begin{array}{l}\text { 1) Before } \\
\text { birth } \\
\text { 2) After birth }\end{array}$ & $\begin{array}{l}\text { 1) After birth } \\
\text { 2) Before birth }\end{array}$ \\
\hline $\begin{array}{l}\text { Prevention of } \\
\text { sexually } \\
\text { transmitted } \\
\text { infections (STIs) }\end{array}$ & 85.7 & 65.7 & $\begin{array}{l}\text { 1) Father } \\
\text { 2) Doctor } \\
\text { 3) Friend }\end{array}$ & $\begin{array}{l}\text { 1) Mother } \\
\text { 2) Doctor }\end{array}$ & $\begin{array}{l}\text { 1) Before } \\
\text { engagement }\end{array}$ & $\begin{array}{l}\text { 1) During } \\
\text { engagement }\end{array}$ \\
\hline $\begin{array}{l}\text { Sexual relations } \\
\text { among married } \\
\text { couples }\end{array}$ & 46.5 & 48.3 & $\begin{array}{l}\text { 1) Father } \\
\text { 2) Friend } \\
\text { 3) Doctor }\end{array}$ & 1) Mother & $\begin{array}{l}\text { 1) Before } \\
\text { marriage }\end{array}$ & $\begin{array}{l}\text { 1) Before } \\
\text { marriage }\end{array}$ \\
\hline
\end{tabular}

\section{When is the right time for adolescents to obtain information?}

Adolescents who agreed that they should receive information were also asked when they felt it was appropriate for adolescents to learn about these issues. Their responses varied, as expected, by the issue. In general, respondents felt information was appropriate at the time it was needed, rather than earlier as a form of preparation. For example, learning about the marriage contract was thought to be appropriate for adolescents before they signed the contract and got married, while most thought adolescents should learn about pubertal maturation while the changes were actually taking place.

Only slightly more girls thought that adolescent girls should learn about physical maturation before menstruation took place than after it occurred (36.6\% versus $30.2 \%)$. This is unexpected, considering that 60 percent of these same girls reported feeling fear or shock when they first experienced menstruation.

With regard to sexual relations and the prevention of STIs, adolescents seem to feel that information on these topics should be provided just before marriage. That is, most adolescents say that this information should be given to adolescents after they become engaged rather than as a component of general information about reproductive health given to them earlier. For example, 82 percent of the girls and 78 percent of boys who felt that someone should talk to adolescents about sexual relations felt that the right time for such discussions to take place was before marriage. 


\section{Preferred Sources of Information}

Adolescents in the survey gave quite clear messages about their preferred sources of information. When they were asked from whom adolescents should receive information or where they would go if they wanted more information, the overwhelming response in every case was: parents. This is important in light of the findings about how few parents do indeed talk with their adolescents, described earlier.

Background variables seem to differentiate among adolescents' preferences, some in not so obvious ways. Mostly, however, the ranking of their preferred information sources did not change much across any background variable, particularly not for the most frequent source, that is, parents. Rather, the variations are usually among the relative weight given to ranking the second and third most popular sources. For example, as the adolescents' socioeconomic status and level of education increase, they were relatively more likely to want information about pregnancy and childbirth from doctors than from their mothers, but mothers still ranked as the preferred source across all socioeconomic strata and education levels.

Since matters associated with sexuality and reproductive health are generally considered taboo for unmarried Egyptians, it is difficult to assess whether adolescents who say they want information from parents would actually have the courage to ask them. Given the low levels of knowledge about maturation and reproductive health found among adolescents here and elsewhere, coupled with their fairly strong beliefs that adolescents should be informed about these issues, it appears that they do not ask parents for information. Undoubtedly they would prefer that their parents initiate these discussions.

\section{REPRODUCTIVE HEALTH PRACTICES}

\section{FEMALE CIRCUMCISION}

The practice of female circumcision is widespread in Egypt, a deeply-rooted tradition shared with countries of the Nile valley and other parts of Africa. (Female circumcision is a translation of one of the Arabic terms commonly used in Egypt; the practice is also referred to in the international literature as female genital mutilation [FGM].) Female circumcision typically takes place before or just as a girl reaches puberty. Research in Egypt suggests that the practice persists because of a belief that circumcision will moderate female sexuality, assure a girl's marriageability, and that it is sanctioned by religion. Previous research among ever-married women found almost universal prevalence of circumcision with about 88 percent of mothers saying that they intend to circumcise their daughters (EDHS 1995).

Table 8.8 shows the self-reported prevalence of circumcision for girls aged 13 years and above according to various background characteristics. Thirteen was chosen as the youngest age for this table because by that age, 96 percent of circumcisions have been performed. 
Table 8.8: Percent of girls aged 13-19 circumcised by

background characteristics $(n=789)$

Overall prevalence

Prevalence

86.0

Adult schooling

-None

92.5

-Incomplete primary

97.4

-Completed primary/any prep

84.4

-Vocational secondarylabove intermediate

68.4

-Secondary +

47.9

Socioeconomic status

-Low

91.0

-Medium

90.8

-High

74.8

Urban governorates

69.4

Lower Egypt

92.8

Upper Egypt

88.2

Urban

82.4

Rural

93.5

${ }^{\star}$ Differences between categories of background variables significant at $p<.001$

The data show that 86 percent of never-married adolescent girls aged 13 to 19 in Egypt are circumcised. Figure 8.2 indicates that the peak ages for circumcision are between 9 and 13 , that is, just prior to puberty. If a girl has not been circumcised by her $16^{\text {th }}$ birthday, the data indicate that she is unlikely to be.

A prevalence of 86 percent represents at least a ten point decline from the percent prevalence for young married women aged 15-19 in the 1995 EDHS. We believe this discrepancy is due to differences between experiences of single adolescents, who represent the majority of Egyptian adolescents, and the selective group who are married (and therefore sampled in the DHS). The 1995 DHS levels of circumcision among married women are confirmed by the ASCE data on married adolescents, which show that 98 percent of that subsample have been circumcised. $^{2}$

Given the nearly universal prevalence of the practice among older women, it is important to know where change is occurring among these younger cohorts. In order to understand which population groups are less inclined to practice circumcision today, we examined a number of background characteristics to see where the declines are concentrated.

Because the ASCE data is cross-sectional rather than longitudinal, we have used life table analysis to project the experiences of the younger girls in the sample. Life table analysis is a statistical technique that assumes that the experiences of younger girls in the sample will be

\footnotetext{
${ }^{2}$ The EDHS data do not show declining prevalence rates among younger cohorts of women. However, because the EDHS sample consists only of ever-married women, and because ever-married 15-19-year-olds increasingly constitute a selective sample of adolescents in Egypt, the EDHS data are unlikely to detect any changes that may have taken place. According to the EDHS household data, under 15 percent of Egyptian women aged $15-19$ are married. Women who marry prior to 20 are an increasingly selective group, and are generally poorer and less well-educated than the majority of Egyptian adolescents. Thus, that the ASCE data show a lower rate among its never-married girls is not evidence of an inconsistency between the two data sets.
} 
similar to those of the older girls, and that also takes into consideration that the youngest girls may not have reached the age at which circumcision takes place. The figures presented in this section are based on the probability that an unmarried adolescent girl in the ASCE health subsample has been circumcised.

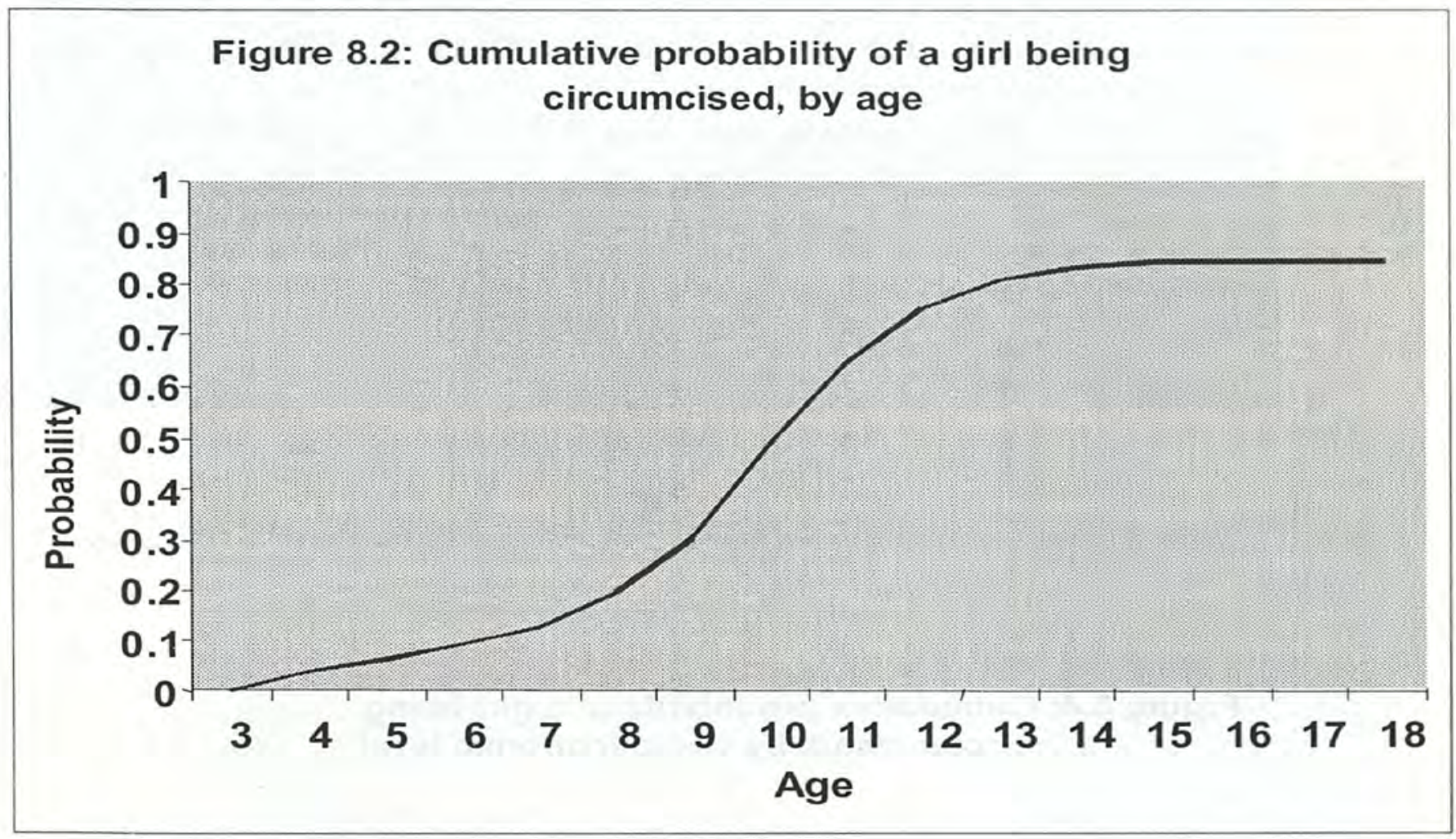

Looking at the probability of being circumcised by parental education level and by socioeconomic level (Figures 8.3 and 8.4), it is clear that circumcision among never-married girls varies greatly with socioeconomic status. However, in order to register significant declines, parents must have completed at least eleven years of schooling and/or be among the highest one-third in socioeconomic status. For example, only 48 percent of girls who have at least one parent with secondary education or higher are circumcised, a gap of more than 30 percentage points with the next lower education group. This is a significant finding, because it reinforces accumulating evidence elsewhere that education beyond basic education is necessary in order to achieve appreciable changes in behavior. With the expansion in education that has taken place in Egypt in recent years, we expect further declines in female circumcision in the future. 

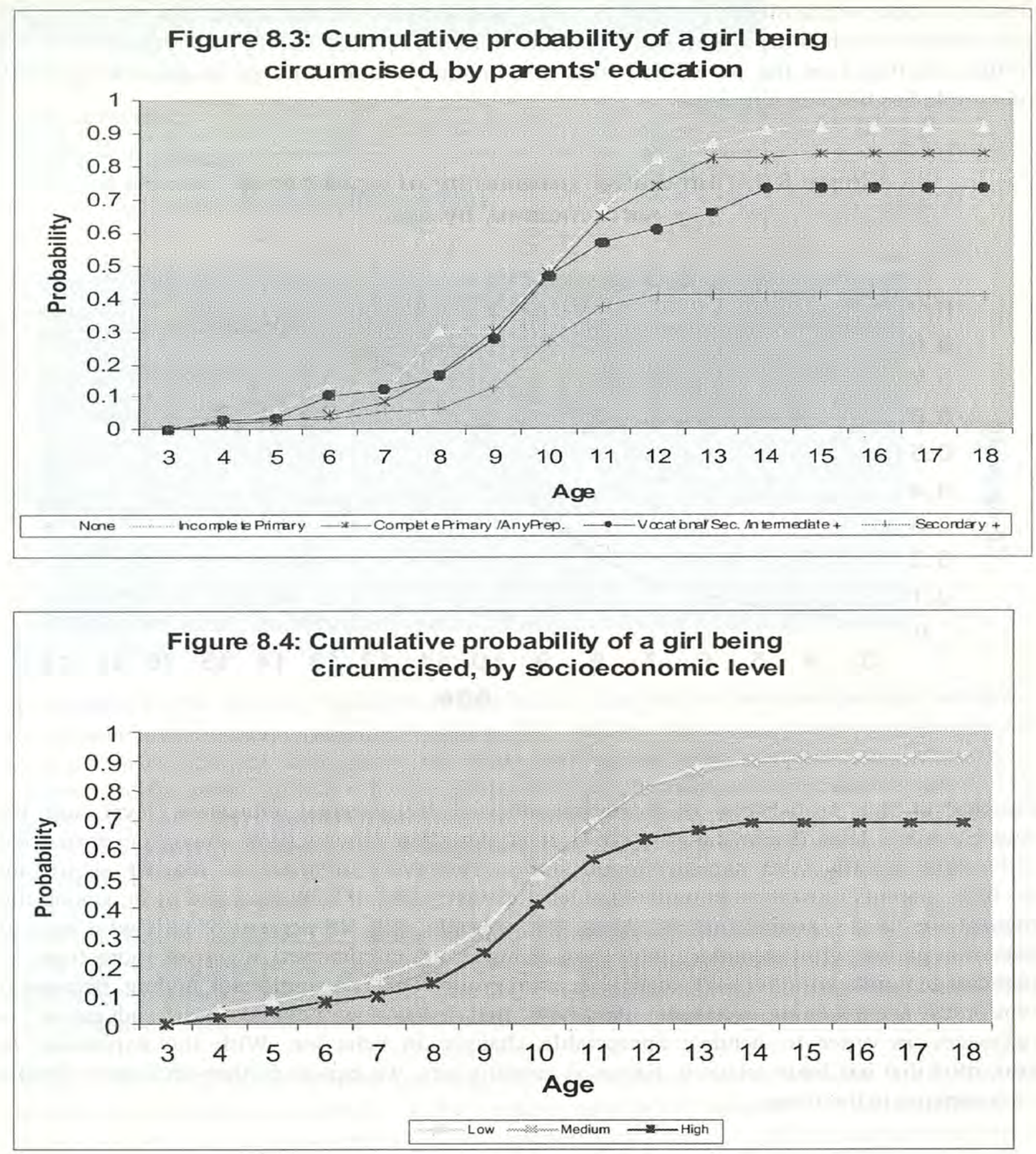

With cross-sectional data it is difficult to identify trends. However, a further indication that the prevalence of circumcision has fallen is seen when we compare younger adolescent girls to older ones using life table estimate. Figure 8.5 shows that girls aged 10-15 in 1997 are slightly less likely to be circumcised (by the time they leave adolescence) than those who are members of the next older cohort (those aged 16-19). While the differences are small, a difference in 
prevalence of 3 percent to 4 percent in this short time period does suggest that change is taking place. Since parental education has been rising for at least several decades, why should noticeable declines in circumcision appear between these two groups of girls?

One hypothesis, tested further in a forthcoming publication, is that public awareness and support for female circumcision shifted after 1994, following the International Conference on Population and Development held in Cairo. Because of media controversy, legal challenges, and accelerated NGO efforts to eliminate the practice, a previously unquestioned practice was brought into the spotlight. It is likely that more highly educated parents respond faster to new information and to shifts in social acceptability of a practice.

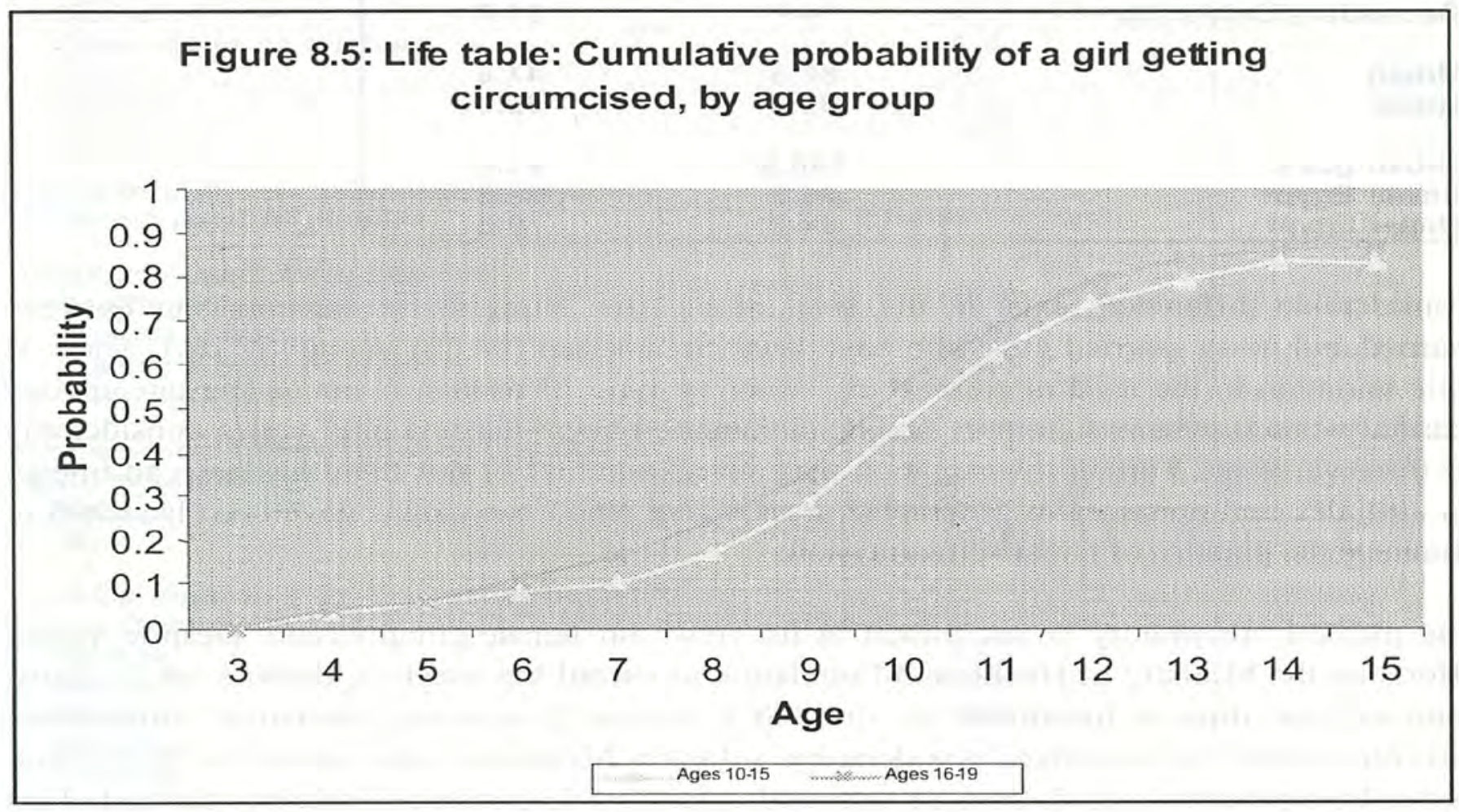

The ASCE survey provides the first estimate ever made on a nationwide basis of circumcision rates among single adolescents. The fact that our data show a recent decline in the practice among single adolescents (compared with older, married cohorts) is noteworthy and deserves further investigation. This practice appears to be closely related to a girl's social position within more traditional families and communities. Exposure to urban settings and education decreases the likelihood of parents perpetuating circumcision. Declining rates of circumcision suggest that the concerted efforts of many groups in Egypt to eliminate this practice may be having a positive impact.

\section{Support for Circumcision}

Among the group of single girls who are circumcised, there is surprisingly weak support for the practice. These girls were asked whether they believe that female circumcision is necessary for a woman to be married, and barely half agreed. Belief that circumcision is 
necessary drops to 75 percent among girls with little or no education to 32 percent among girls with education at or above the secondary level (Table 8.9).

\begin{tabular}{|lcc|}
$\begin{array}{l}\text { Table 8.9: Percent of married and never-married adolescents who } \\
\text { have been circumcised and believe circumcision is necessary } \\
\text { (married women, } n=263 ; \text { unmarried girls, } n=907 \text { ) }\end{array}$ & \\
\hline & Married & Never married \\
Total sample & 88.6 & 57.7 \\
No schooling/some primary & 95.3 & 75.0 \\
Primary/preparatory & 88.2 & 58.4 \\
Preparatory/secondary & 68.9 & 54.3 \\
Secondary/University & - & 31.7 \\
Urban & 86.5 & 47.6 \\
Rural & 89.1 & 62.8 \\
Urban govs. & 100.0 & 41.6 \\
Lower Egypt & 86.3 & 53.5 \\
Upper Egypt & 88.7 & 70.6 \\
\hline
\end{tabular}

Considerable differences exist in the level of positive support for circumcision between married and never-married girls who have been circumcised ( $88.6 \%$ versus $57.7 \%$ ). There is little variation in the level of support by region or type of residence among the circumcised married women, whereas support among circumcised never-married girls varies considerably by these variables. Further investigation may reveal whether or not there has been an impact on attitudes and practices in geographic areas where NGO campaigns have been launched to eliminate the practice of female circumcision.

The medical community is not united in its views on female circumcision. Despite recent efforts by the Ministry of Health and Population to curtail the practice, doctors are the most common practitioners mentioned by the ASCE sample. Forty-nine percent of circumcised girls report that the procedure was done by a doctor. Midwives were named by 24 percent, nurses by 8 percent, barbers by 6 percent and others by 13 percent (Table not shown). This finding supports a trend toward medicalization of circumcision also detected in the 1995 EDHS.

\section{Management of Menstruation}

The transition from childhood into adulthood occurs gradually over a number of years. However, one dramatic event for girls is the onset of menstruation. How girls react to such an important event and how they manage it thereafter may be indicative of how they will respond to the other reproductive events they will experience throughout their reproductive careers.

Many of the girls who have started menstruation describe their initial reactions to menarche quite negatively. More than 60 percent report that they felt fear, shock, or weepy with the onset of menses (Table 8.10). Thirty-six percent report that they were indifferent to its onset; that is, they had neither a positive nor a negative reaction. Only 4 percent report that they felt happy when menarche occurred. Both parents and doctors consider the timely onset 
of menses as a positive marker that a girl is growing into a healthy young woman. However, it seems that girls need more guidance and information prior to the onset of menstruation in order to alleviate the negative psychological responses reported here.

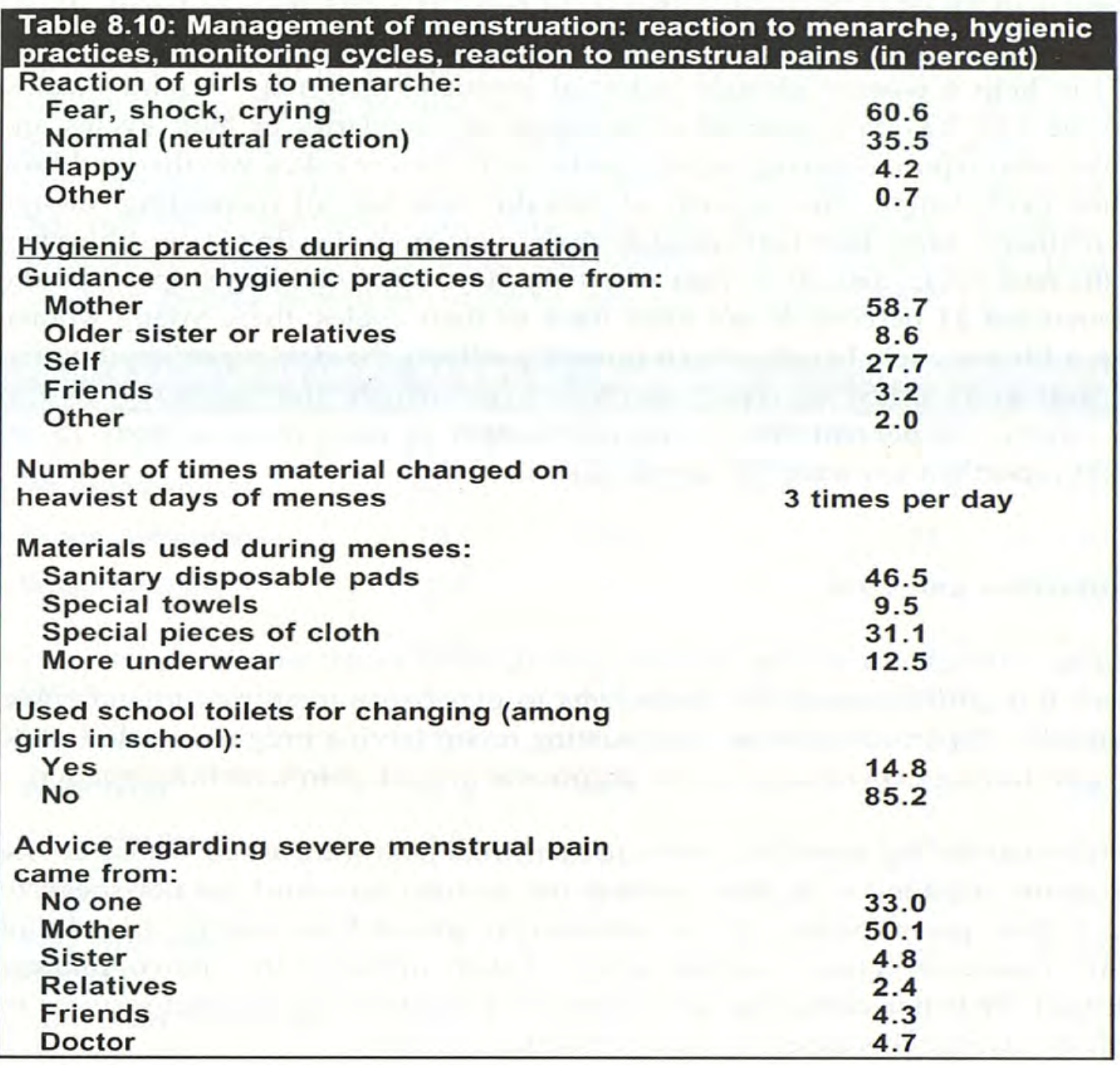

With the onset of periodic bleeding, additional hygienic practices become part of girls' regular activities. Hygienic practices during menstruation help to make the young woman feel comfortable and minimize the likelihood of infections ascending to the upper reproductive tract. More than half of girls report that they learned about hygiene from their mothers. However, a considerable percentage (27.7\%) report that they learned these practices by themselves; a small number report learning from older sisters or relatives. The majority of girls $(92.8 \%)$ do not share their underwear or non-disposable pads with any other females in the household. Nearly half $(47 \%)$ report using disposable sanitary pads and one-third use special pieces of cloth, while 13 percent put on more underwear and 10 percent have special towels purchased specifically for menses. Girls report changing 3 times per day (median) during the heaviest flow of their menses.

One of the more noteworthy findings is that only 15 percent of girls in school report using the school toilets for changing their pads during menstruation; the rest, 85 percent, say that they wait until they return home. 


\section{Length of the Menstrual Cycle}

In medical literature, the length of the menstrual cycle is counted from the first day of menses until the onset of the next bleeding. Normal cycles range from 21 to 35 days in length. Being aware of what is normal and healthy regarding her reproductive tract and monitoring her menstrual cycles can help a woman identify potential problems that may require medical attention. Girls in the ASCE survey were asked to report on regularity of their cycles and typical length. Those who reported having regular cycles were further asked whether and how they computed their cycle length. The majority of girls do some sort of monitoring, though they use different methods. More than half calculate their cycle from the first day of bleeding until the onset of the next cycle, and 20 percent count the days after bleeding stops until the new onset. The remaining 21 percent do not keep track of their cycles; these young women appear to report an arbitrary cycle length, which probably affects the data regarding duration of cycles. When girls were asked to report on their cycle length, the majority $(73.0 \%)$ responded 'every month,' 22 percent cited a specific number of days (ranging from 15-40 days), and 4 percent report not knowing the length of their cycles.

\section{Menstrual Irregularities and Pain}

Toward the beginning and end of a woman's fertile period, some cycle irregularities are to be expected. Moreover, it is quite common for adolescents to experience menstrual irregularities, pain, or both. Currently, 22 percent of those menstruating report having irregular cycles while fully 82 percent report having experienced severe abdominal or back pain with menstruation.

Adolescents who reported having experienced severe menstrual pain were asked whose advice they sought. Half report speaking with their mothers but another one-third did not speak to anyone at all about their pains. Nearly 12 percent sought advice from sisters, friends, or relatives, and only 5 percent sought medical advice. Taken together, the above findings suggest an urgent need for better counseling and education programs and targeted services to help girls successfully manage this aspect of their reproductive health.

\section{GENDER ROLE ATTITUDES AND EXPECTATIONS}

As Egypt undergoes profound social and economic changes, the roles of men and women may be changing more rapidly than attitudes and identities. For example, the need for more women to work and earn is not yet reflected widely in role attitudes. If there are wide gaps in outlook about role sharing or decisionmaking, this will affect future communication and conflict potentials within marriage. Now that counseling has become a key program objective within reproductive health and family planning, we need to understand the dynamics and gender expectations that underlie couple communication. If we uncover gender role information that runs counter to commonly held stereotypes or assumptions, it could be used to advocate more effectively for policy change. In order to understand these issues, questions were included in the ASCE survey about task and role sharing within the household, as well as decisionmaking and other issues that may arise between spouses. 
Unmarried adolescents aged 16 and older were read a series of domestic tasks, such as cleaning house, shopping, and caring for children. They were asked who currently does these tasks in their homes and who they believe should be responsible for doing them after their marriage. (Current patterns in the adolescents' homes are very close to the ideal patterns they report below and are not discussed here). While most adolescents indicated that the husband or wife should perform the activity in question, there were some who gave answers that included other household members. Therefore, answers were grouped according to whether the adolescent said men alone should be responsible, whether women alone should be responsible, or whether the task should be shared by men and women (Table 8.11).

\begin{tabular}{|c|c|c|c|c|c|c|}
\hline \multirow[b]{2}{*}{ Be breadwinner } & \multicolumn{2}{|c|}{ Men alone } & \multicolumn{2}{|c|}{ Women alone } & \multicolumn{2}{|c|}{ Shared } \\
\hline & $\begin{array}{l}\text { Boys } \\
87.2\end{array}$ & $\begin{array}{l}\text { Girls } \\
82.9\end{array}$ & $\begin{array}{l}\text { Boys } \\
1.3\end{array}$ & $\begin{array}{l}\text { Girls } \\
2.2\end{array}$ & $\begin{array}{l}\text { Boys } \\
11.6\end{array}$ & $\begin{array}{l}\text { Girls } \\
14.9\end{array}$ \\
\hline Buy provisions & 23.6 & 21.9 & 70.3 & 67.1 & 6.1 & 11.0 \\
\hline Wash clothes & 1.1 & 0.6 & 98.7 & 95.6 & 0.2 & 3.8 \\
\hline Clean house & 0.4 & 0.2 & 93.6 & 92.5 & 6.0 & 7.3 \\
\hline Cook & 1.1 & 0.6 & 97.5 & 95.2 & 1.5 & 4.2 \\
\hline Fetch water & 27.0 & 9.9 & 60.4 & 72.8 & 12.6 & 17.3 \\
\hline Work land & 69.4 & 85.7 & 2.4 & 7.1 & 28.2 & 7.1 \\
\hline Feed children & 3.9 & 0.9 & 88.0 & 95.1 & 8.1 & 4.1 \\
\hline Wash children & 0.0 & 0.9 & 97.8 & 94.2 & 2.2 & 4.9 \\
\hline $\begin{array}{l}\text { Play with/watch } \\
\text { children }\end{array}$ & 7.5 & 1.5 & 54.3 & 63.7 & 38.2 & 34.8 \\
\hline $\begin{array}{l}\text { Take children to/from } \\
\text { school }\end{array}$ & 52.8 & 41.0 & 21.0 & 31.3 & 26.2 & 27.5 \\
\hline $\begin{array}{l}\text { Help children with } \\
\text { homework }\end{array}$ & 33.8 & 16.1 & 22.8 & 32.3 & 43.3 & 51.4 \\
\hline $\begin{array}{l}\text { Take children to } \\
\text { doctor when sick }\end{array}$ & 58.4 & 31.0 & 14.5 & 17.9 & 27.1 & 51.1 \\
\hline $\begin{array}{l}\text { Take care of wife } \\
\text { when ill }\end{array}$ & 57.6 & 57.6 & 7.5 & 17.8 & 34.8 & 24.5 \\
\hline $\begin{array}{l}\text { Take care of husband } \\
\text { when ill }\end{array}$ & 6.9 & 2.4 & 58.7 & 83.7 & 34.3 & 13.9 \\
\hline
\end{tabular}

For the most part, adolescents do not say that household and childrearing tasks should be shared. For example, more than 80 percent stated that men should be the sole breadwinners while more than 90 percent say that women should wash the clothing, clean the house, and cook. The tasks that elicited a greater proportion of "sharing" responses were: taking children to school, helping children with homework, taking children to the doctor, and caring for spouses who are sick. 
Girls and boys differ in the amount of sharing they agree to, but those differences are not consistently in one direction. Girls approve of greater sharing for doctor's visits, for example, while boys are more likely than girls to approve of sharing in working the land.

For selected activities and roles, we investigated whether attitudes toward sharing varied by schooling level of the adolescent or the parent, as well as socioeconomic status and the region and type of residence. Specifically we wanted to test a hypothesis that respondents who are better educated, or who come from urban governorates or better educated and wealthier families are more likely to think that both men and women should be responsible for doing domestic tasks. In general, there were no systematic patterns. Table 8.12 displays the results for adolescent education levels only.

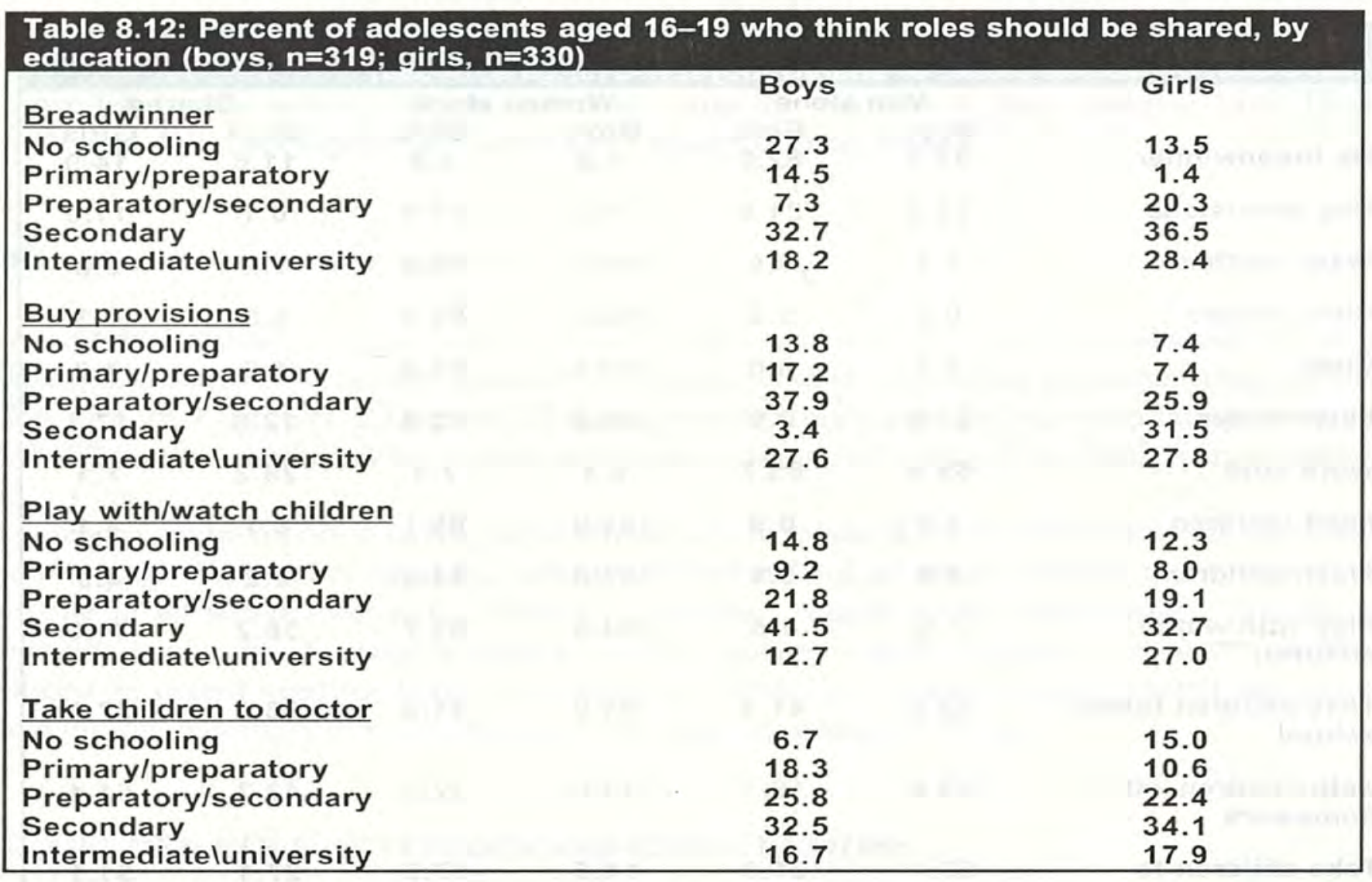

\section{DECISIONMAKING}

In addition to asking about task sharing, adolescents were asked about whether husbands and wives should share in making decisions about domestic and familial issues. Table 8.13 shows the percentage of girls and boys aged 16-19 who favor husbands making decisions alone, wives making decisions alone, or sharing decisionmaking. In comparison to task sharing, positive attitudes toward shared decisionmaking are much more prevalent among both boys and girls, with girls having somewhat more favorable views toward decision sharing. 
Table 8.13: Percent of adolescents aged 16-19 who think household-related

decisions should be made by the husband alone, the wife alone, or be shared

(boys' $n=319$; girls' $n=380$ )

\begin{tabular}{|c|c|c|c|c|c|c|}
\hline \multirow{3}{*}{ Household budget } & \multicolumn{2}{|c|}{ Husband alone } & \multicolumn{2}{|c|}{ Wife alone } & \multicolumn{2}{|c|}{ Shared } \\
\hline & Boys & Girls & Boys & Girls & Boys & Girls \\
\hline & 41.9 & 22.9 & 4.8 & 5.4 & 53.3 & 71.8 \\
\hline $\begin{array}{l}\text { Wife working } \\
\text { outside the home }\end{array}$ & 62.7 & 32.0 & 2.9 & 10.2 & 34.3 & 57.8 \\
\hline Another baby & 24.2 & 9.9 & 1.5 & 4.5 & 74.3 & 85.6 \\
\hline Girl's education & 23.5 & 7.8 & 1.7 & 3.8 & 74.8 & 85.6 \\
\hline Boy's education & 25.8 & 8.0 & 0.8 & 2.3 & 73.3 & 89.7 \\
\hline $\begin{array}{l}\text { Contraceptive } \\
\text { use }\end{array}$ & 12.7 & 9.0 & 12.3 & 8.6 & 75.1 & 82.4 \\
\hline $\begin{array}{l}\text { Children's } \\
\text { healthcare }\end{array}$ & 8.3 & 2.4 & 7.6 & 9.0 & 84.1 & 88.7 \\
\hline
\end{tabular}

However, in two important areas, namely household budget and whether the wife works outside the home, both boys and girls, but particularly boys, feel that the husband should make the decision on his own. For these two domains, support for shared decisionmaking increases with education, although not systematically. For example, fewer than half $(44.2 \%)$ of girls with the lowest level of education think that husbands and wives should share in the decision about the wife working outside the home, while about two-thirds of those who have been to secondary school think the decision should be shared (Table 8.14).

However, education appears to operate differently for boys and girls with regard to effects on some gender role attitudes. As Table 8.14 shows, the effect of increased schooling is not straightforward for boys. In general, girl's attitudes seem to shift more and in an egalitarian direction as a result of exposure to schooling. This points the possibility of future conflicts among couples with similar education levels over these issues.

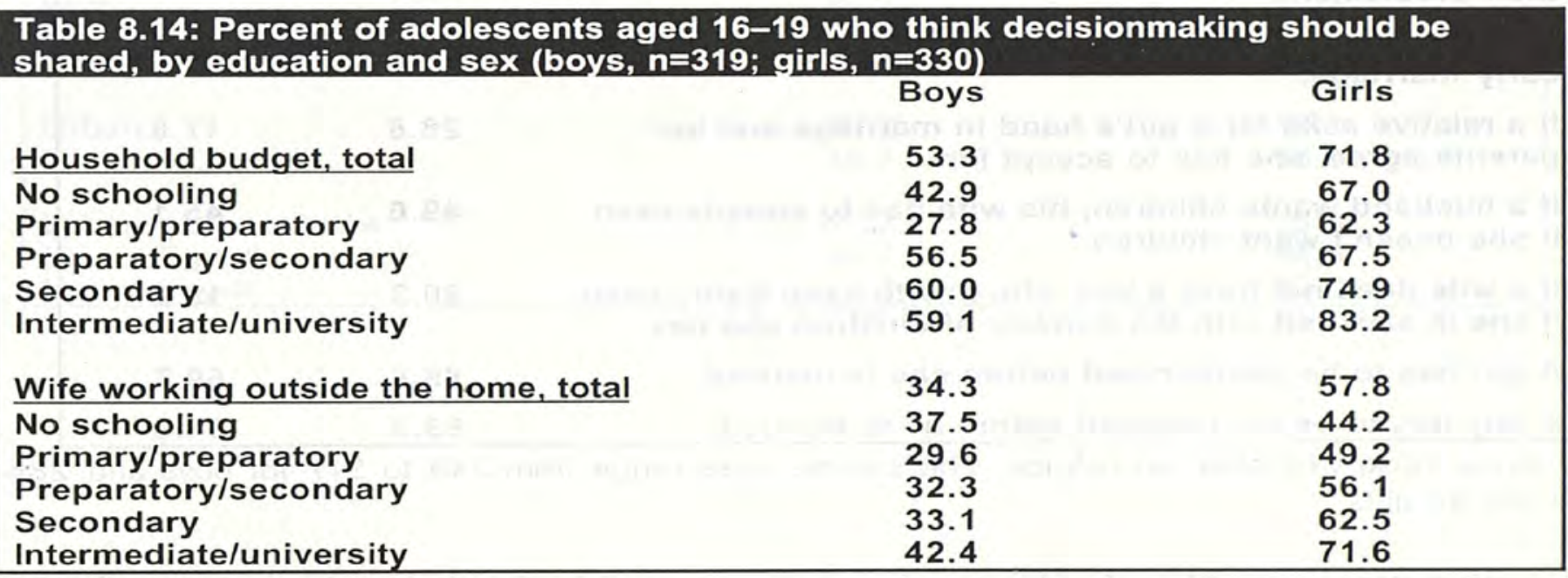


It is interesting to speculate about why young people would be more prepared to share decisionmaking than to share tasks in marriage. Several explanations are possible: One is that this pattern is a reflection of the reality they observe in their own families, of considerable joint decisionmaking but relatively little sharing of roles. Another compelling explanation is that stating or enacting stereotypical gender role behavior is part of establishing a clear masculine or feminine identity for adolescents.

\section{Other Gender Dynamics}

In addition to the specific set of questions about sharing of tasks and household decisions, adolescents were asked their opinions on each of a series of 12 statements about gender roles and contemporary social issues, including questions about divorce, family planning, desire for male children, and circumcision (Table 8.15). For a few statements, namely, "A wife has to take her husband's permission for everything," "A husband has to know about pregnancy, childbirth, and their problems," and "A boy has to be circumcised before he is married," support is nearly universal, between 89 and 99 percent agree among both boys and girls.

\begin{tabular}{|c|c|c|}
\hline $\begin{array}{l}\text { A wife has to take her husband's permission for } \\
\text { everything. }\end{array}$ & $\begin{array}{r}\text { Boys } \\
91.1\end{array}$ & $\begin{array}{l}\text { Girls } \\
88.5\end{array}$ \\
\hline $\begin{array}{l}\text { If a wife differs with her husband's opinion, she must } \\
\text { accept his opinion. }\end{array}$ & 74.5 & 59.7 \\
\hline $\begin{array}{l}\text { The current marriage contract gives more rights to men } \\
\text { than women. }\end{array}$ & 50.9 & 39.5 \\
\hline $\begin{array}{l}\text { It is the husband who decides what to do with money left } \\
\text { over after the household's needs are met. }\end{array}$ & 75.7 & 49.5 \\
\hline $\begin{array}{l}\text { Family planning is not important if the family has the } \\
\text { resources. }\end{array}$ & 21.9 & 17.3 \\
\hline $\begin{array}{l}\text { The husband has to know about pregnancy, childbirth and } \\
\text { their problems. }\end{array}$ & 92.9 & 89.0 \\
\hline $\begin{array}{l}\text { If a girl has not gone to school, the best thing for her is an } \\
\text { early marriage. }\end{array}$ & 45.5 & 32.7 \\
\hline $\begin{array}{l}\text { If a relative asks for a girl's hand in marriage and her } \\
\text { parents agree, she has to accept him. }\end{array}$ & 28.8 & 17.8 \\
\hline $\begin{array}{l}\text { If a husband wants children, his wife has to comply even } \\
\text { if she doesn't want children. }\end{array}$ & 49.6 & 45.1 \\
\hline $\begin{array}{l}\text { If a wife does not have a boy, she has to keep trying even } \\
\text { if she is satisfied with the number of children she has. }\end{array}$ & 20.3 & 19.2 \\
\hline A girl has to be circumcised before she is married. & 89.6 & 69.7 \\
\hline A boy has to be circumcised before he is married. & 99.3 & 94.6 \\
\hline
\end{tabular}

Among those who state an opinion. The sample sizes range from 249 to 317 for boys and 286 to 400 for girls.

For other statements, "Family planning is not important if the family has the resources," "If a relative asks for a girl's hand in marriage and her parents agree, she should accept," and "If a woman does not have a boy she has to keep trying even if she is satisfied with the number of 
children she has," there is minimal support: Between 72 percent and 84 percent disagree. As with the other attitudes examined in this chapter, girls are considerably more likely to express egalitarian views than boys. For example, girls are less likely than boys $(59.7 \%$ versus $74.5 \%)$ to agree that a woman should accept her husband's opinion even if they differ.

For the two statements with the largest differences between girls and boys, we investigated whether the degree of support varied more by gender or by other background characteristics. Tables 8.16 and 8.17 suggest that gender differences in opinion dominate socioeconomic differences, although multivariate analysis is required to confirm this. Moreover, for girls there is greater variability by socioeconomic status, residence, and parents' education than there is for boys, suggesting that boys present a more monolithic front with regard to gender role attitudes. For example, the difference in the level of support for female circumcision between the lowest and highest educational groups for boys is 31 percent $(100.0 \%-68.6 \%)$; for girls it is 56 percent $(92.0 \%-35.6 \%)$. In other words, education appears to have a greater impact on girls' attitudes than boys. That schooling has less of an effect on boys may suggest that male gender role attitudes are more deeply entrenched.

\begin{tabular}{|c|c|c|}
\hline & Boys & Girls \\
\hline $\begin{array}{l}\text { Adolescent education } \\
\text { No schooling/some primary }\end{array}$ & 85.7 & 707 \\
\hline Primary/preparatory & 86.5 & 58.7 \\
\hline Preparatory/secondary & 72.4 & 53.5 \\
\hline Secondary & 75.1 & 40.5 \\
\hline Intermediate/university & 66.7 & 27.2 \\
\hline Parent education & & \\
\hline No schooling & 79.8 & 52.3 \\
\hline Primary/preparatory & 75.0 & 57.0 \\
\hline Preparatory/secondary & 75.0 & 34.1 \\
\hline Secondary & 61.7 & 38.3 \\
\hline Intermediate/university & 59.5 & 34.0 \\
\hline Socioeconomic status & & \\
\hline Low & 69.1 & 60.2 \\
\hline Medium & 77.4 & 50.4 \\
\hline High & 76.5 & 36.4 \\
\hline Urban & 69.2 & 37.3 \\
\hline Rural & 80.7 & 56.5 \\
\hline Urban governorates & 67.2 & 35.8 \\
\hline Lower Egypt & 80.9 & 54.5 \\
\hline Upper Egypt & 74.3 & 52.0 \\
\hline
\end{tabular}




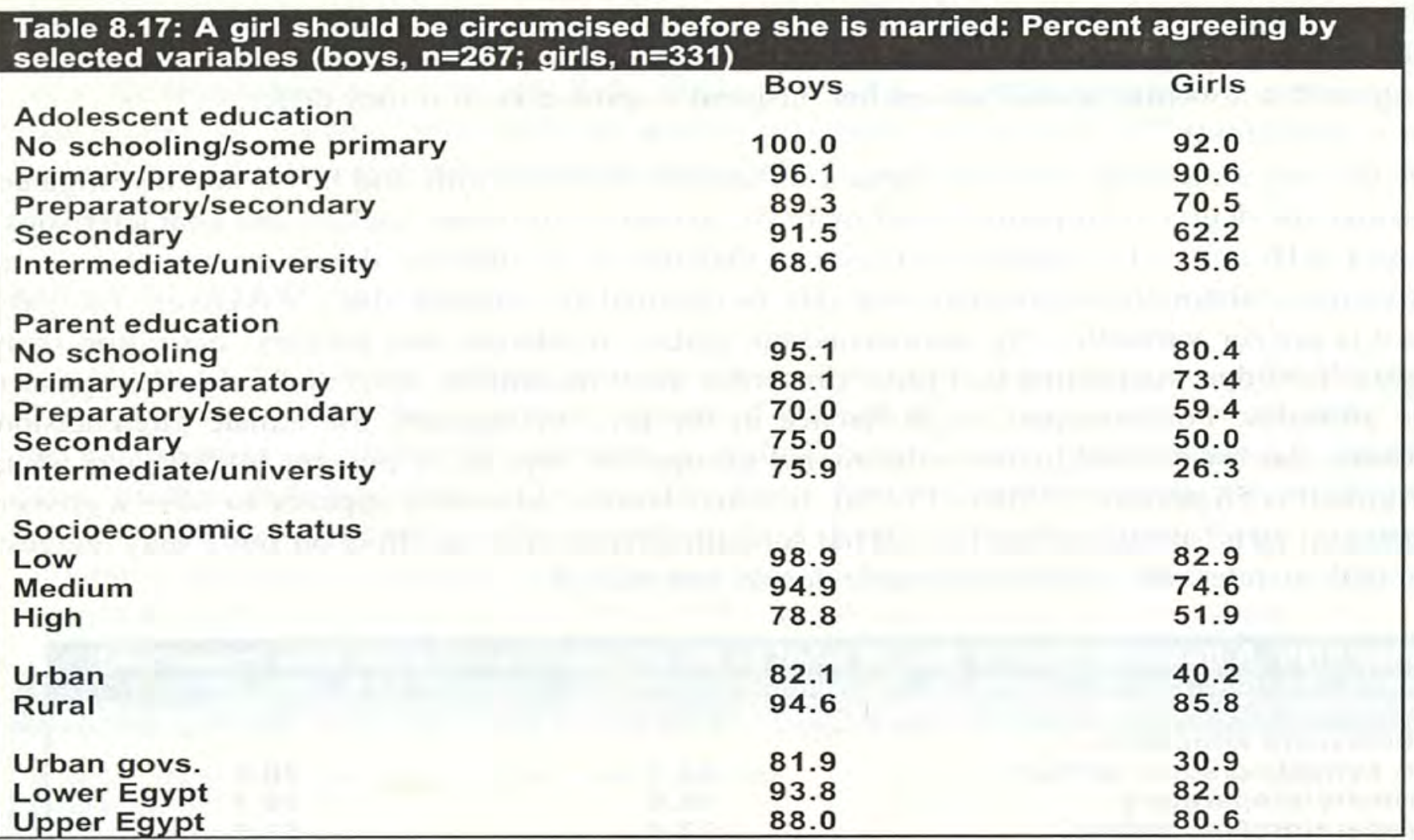

\section{CHARACTERISTICS OF THE IDEAL SPOUSE}

\section{Ideal Age for Marriage}

Delaying marriage for girls after adolescence is now widely believed to be important for improving a woman's status in marriage, as well as improving health outcomes for her and her offspring. However, traditional practices have favored early marriage in Egypt. The study team was interested in adolescent attitudes toward the appropriate age for girls and boys to marry. Table 8.18 indicates the mean ideal age given by girls, boys, and their parents for both female and male marriage. Interestingly, girls think that marriage should be later for both males and females than do boys. Girls suggest that women should be age 20.8 on average when they marry while boys give answers that are on average one-half year earlier (20.2). The gender gap is even greater for the ideal age for males to marry; girls think boys should marry on average at 25.0 years, while boys think they should be a full year younger (24.0).

Parents, on average, think it best for girls to marry at younger ages than both their male and female children indicate is desirable; the ideal age given by mothers and fathers for girls to marry is less than 20-or while girls are still in adolescence. On the other hand, parents think boys should marry later than boys themselves think. Preferring a later marriage age for boys is understandable, since parents may have a greater appreciation for both the financial burdens and greater responsibility entailed in becoming a husband. But why do parents prefer an earlier age for girls to marry than do either boys or girls themselves? This could reflect the earlier ages at which girls married in their generation, or it could represent a customary interest 
in protecting female chastity. Finding such a "generation gap" means that more policy attention should be given to parental attitudes regarding early marriage.

\begin{tabular}{|lcccc|}
\hline \multicolumn{4}{|l}{ Table 8.18: Mean age suitable for marriage, as reported by adolescents and parents } \\
\hline \multirow{2}{*}{ Mean age for girls } & Boys & Girls & Fathers & Mothers \\
N & 20.2 & 20.8 & 19.5 & 19.0 \\
& 828 & 1,024 & 3,228 & 2,880 \\
Mean age for boys & 24.0 & 25.0 & 24.7 & 24.4 \\
N & 880 & 925 & 3,186 & 2,828 \\
\hline
\end{tabular}

As expected, girls and boys who are educated, who come from educated families, who are wealthier, and who live in the urban governorates favor delayed marriage for both males and females (Table 8.19). Yet within virtually every subgroup, girls give older ages than do their male counterparts. Moreover, the gender difference widens with increasing levels of education. For example, both boys and girls who have never been to school or who have not completed primary think girls should marry at 19.3 years. Girls who have attended secondary school give 21.2 as a suitable age for girls to marry whereas boys who have attended secondary school think girls should be on average only 20.4 when they marry.

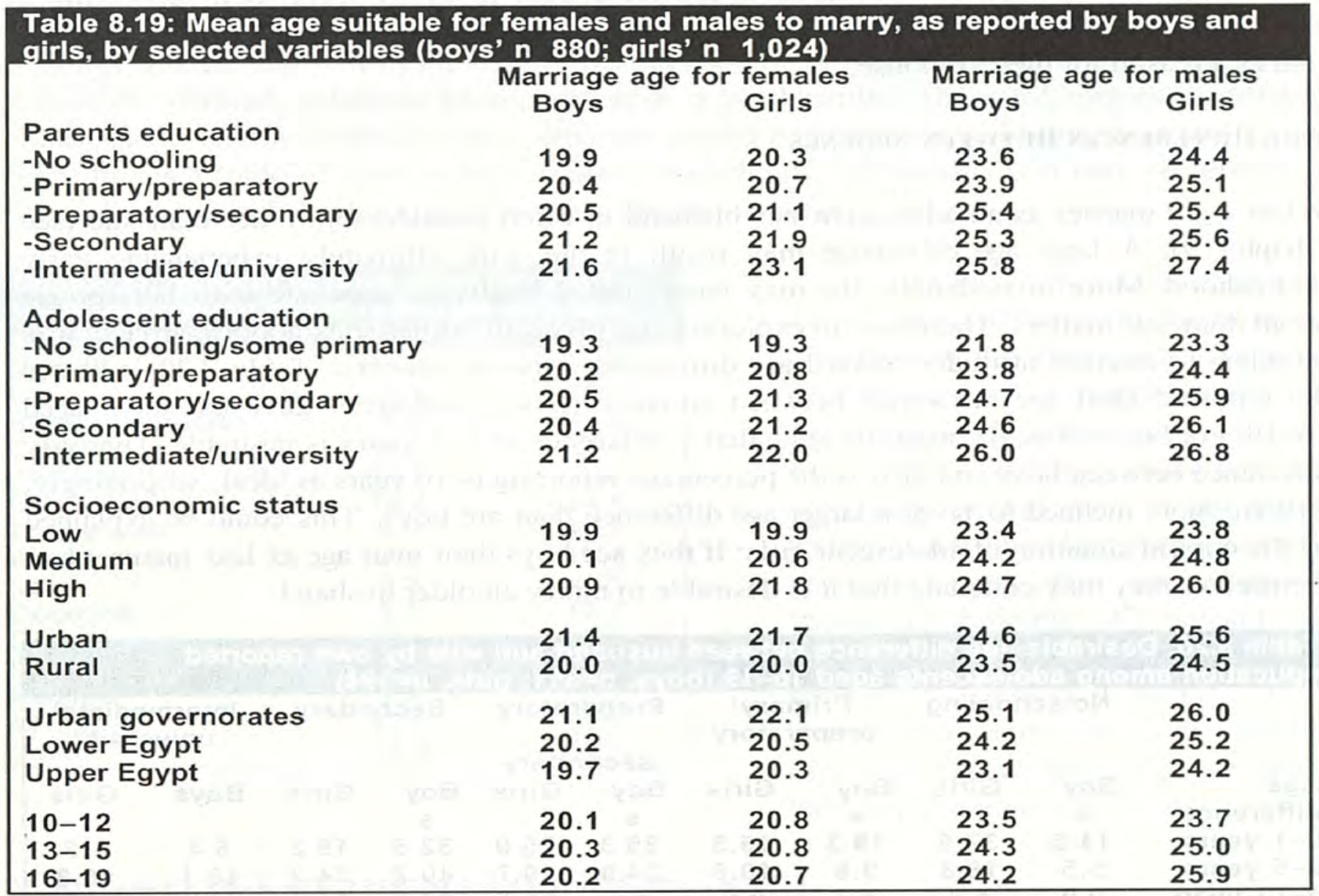


In sum, girls have somewhat more progressive attitudes toward delaying marriage than do boys and parents. While boys have more modern ideas about delayed marriage for girls than their parents, they are eager for marriage themselves.

In addition to asking about appropriate age at marriage, adolescents were also asked why the age they indicated was suitable. By and large the responses given did not vary according to the age considered desirable. For female age at marriage, only the factor of completing education as a reason for the age specified revealed some variability. A greater percentage of both boys and girls indicating that late marriage for women is desirable (defined as greater than or equal to age 22) gave schooling as a reason. More than one-third of boys and more than half of girls who thought age 22 or greater was most suitable mentioned schooling, compared to approximately 10 percent of those who thought age 19 or younger was ideal for girls (data not shown).

As for male age at marriage, education also featured much more prominently in the justification for late marriage (defined as age 26 or greater). A difference also emerged around the issue of supporting a household. Respondents who thought boys should marry late were more inclined to give "financing a household" as a reason. For example 63 percent of boys who thought 26 or higher was a desirable age for a male to marry mentioned supporting a household, whereas less than half of those who thought age 20 or younger was desirable gave that as a reason for their response.

\section{Age Differences Between Spouses}

When a girl marries as an adolescent her husband is often considerably older than she (see Chapter 9). A large age difference may result in the wife ultimately experiencing early widowhood. More immediately, she may have limited ability to negotiate with her spouse about domestic matters. Therefore, in exploring the views of adolescents about marriage, it is revealing to examine attitudes toward age differences between spouses. Table 8.20 indicates the reported ideal age difference between spouses among adolescent girls and boys aged 16-19. For both sexes, the majority state that a difference of 2-5 years is desirable. The only difference between boys and girls is the percentage reporting 6-10 years as ideal; surprisingly, girls are more inclined to favor a larger age difference than are boys. This could be explained by the current situation of adolescent girls: If they see boys their own age as less mature than themselves they may conclude that it is desirable to marry an older husband.

\begin{tabular}{|c|c|c|c|c|c|c|c|c|c|c|}
\hline \multirow{6}{*}{$\begin{array}{l}\text { Age } \\
\text { difference } \\
0-1 \text { years } \\
2-5 \text { years } \\
6-10 \text { years } \\
\text { Doesn't } \\
\text { matter }\end{array}$} & \multicolumn{2}{|c|}{ No schooling } & \multicolumn{2}{|c|}{$\begin{array}{l}\text { Primaryl } \\
\text { preparatory }\end{array}$} & \multicolumn{2}{|c|}{$\begin{array}{c}\text { Preparatory } \\
\text { / } \\
\text { secondary }\end{array}$} & \multicolumn{2}{|c|}{ Secondary } & \multicolumn{2}{|c|}{$\begin{array}{c}\text { Intermediate/ } \\
\text { university }\end{array}$} \\
\hline & $\begin{array}{c}\text { Boy } \\
s\end{array}$ & Girls & $\begin{array}{c}\text { Boy } \\
\text { s }\end{array}$ & Girls & Boy & Girls & $\begin{array}{c}\text { Boy } \\
\text { s }\end{array}$ & Girls & Boys & Girls \\
\hline & 14.5 & 37.5 & 19.3 & 16.3 & 25.3 & 25.0 & 32.5 & 19.2 & 8.4 & 1.9 \\
\hline & 9.5 & 18.8 & 9.8 & 10.5 & 24.9 & 19.7 & 40.7 & 34.2 & 15.1 & 16.8 \\
\hline & 0.0 & 4.9 & 4.3 & 9.6 & 4.5 & 25.5 & 26.1 & 31.4 & 26.1 & 31.4 \\
\hline & 36.8 & 31.6 & 0.0 & 0.0 & 21.1 & 31.2 & 26.3 & 26.3 & 15.8 & 10.5 \\
\hline
\end{tabular}


When preferred age difference reported by adolescents is examined separately by education level, a positive association is revealed, particularly among girls. Girls who have been to secondary school are considerably more likely to favor a large age difference than are those who have less schooling. Boys with more schooling are also inclined to think that husbands should be older than wives. Perhaps the reasoning behind this attitude is financial; among the better-educated, the older the husband, the more likely he is to have established himself and become economically secure. However, the wife need only wait until she is socially and biologically mature, which comes at an earlier age. Thus, better-educated adolescents may see an economic rationale for a large gap, whereas those who are not educated, whose prospects for advancement are limited, do not.

\section{Characteristics of Ideal Spouse}

Since marriage is embarked upon as a lifelong relationship, compatibility of the two individuals is an important aspect determining whether the marriage will be happy or conflictual. Adolescents aged 16-19 were asked what they thought were the most important qualities in a spouse. While the majority of both sexes think a spouse should be polite, and an equal proportion want a spouse who loves them, there were significant differences between boys and girls in the other desired characteristics. A greater proportion of girls think that strong character, a good nature, treating people well, wealth, and good job are important qualities in a husband (Table 8.21). A greater proportion of boys think it important that their spouse be virtuous, religious, polite, and from a good family. These differences in desired spouse characteristics reflect the very different gender expectations within marriage in Egypt. Since this is a topic of conversation in many households, adolescents also may be reflecting the preferences and choices voiced by adult family members.

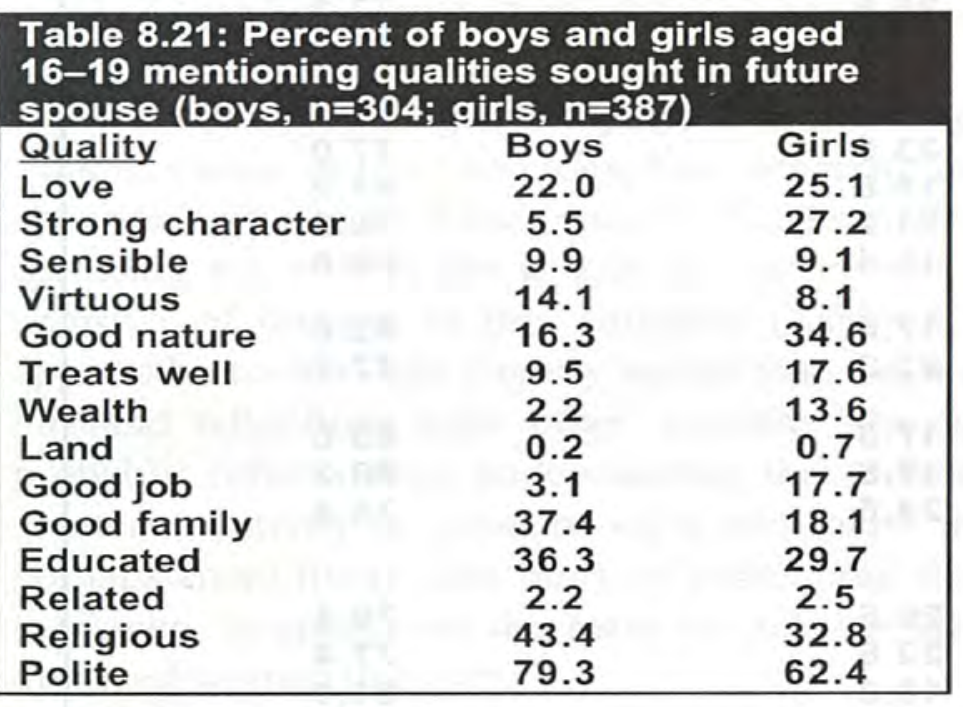

By and large, desired characteristics do not vary consistently by level of schooling of the adolescent. The one exception, not surprisingly, is education itself (data not shown). Both boys and girls who have been to secondary school are much more inclined than their less well-educated peers to think that an educated spouse is desirable: 47 percent of both boys and girls who have been to secondary school think this characteristic important, compared to less than 10 percent of those who have not completed primary).

\section{KNOWLEDGE OF THE MARRIAGE CONTRACT}

As adolescents look ahead to marriage, do they have accurate information about the rights and responsibilities available in the Egyptian marriage contract? The marriage contract includes 
provisions for an initial payment to the bride's family (mahr) and sets out conditions to be fulfilled in case of divorce or death of the husband. Islamic personal status law also allows each party to the contract to include additional conditions; for example, it gives a woman the right to initiate divorce, similar to that which is automatic for men, if she specifies her right, called the 'esma, at the time of signing the marriage contract. While adding these clauses would establish more equality in the terms of marriage, in practice very few couples in Egypt today add any of the optional clauses to the marriage contract.

The ASCE survey asked 696 adolescents aged 16-19 to tell the interviewer what they understood to be the meaning of esma in the marriage contract. Answers were coded as correct if the respondent knew the esma gives both women and men the right to divorce. Other answers, such as only the wife having the right, were coded as incorrect.

As Table 8.22 shows, the rights of divorce in the marriage contract are not well understood by adolescents. Only 20 percent of the sample give an accurate answer and 80 percent answer incorrectly or do not know. Most incorrect answers were from respondents who believe that giving a woman the right to divorce takes the same right away from her husband. This misinformation may explain in part the low percentage of couples who choose this option. A striking gender difference emerges, with girls nearly twice as likely as boys to correctly understand the meaning of 'esma.

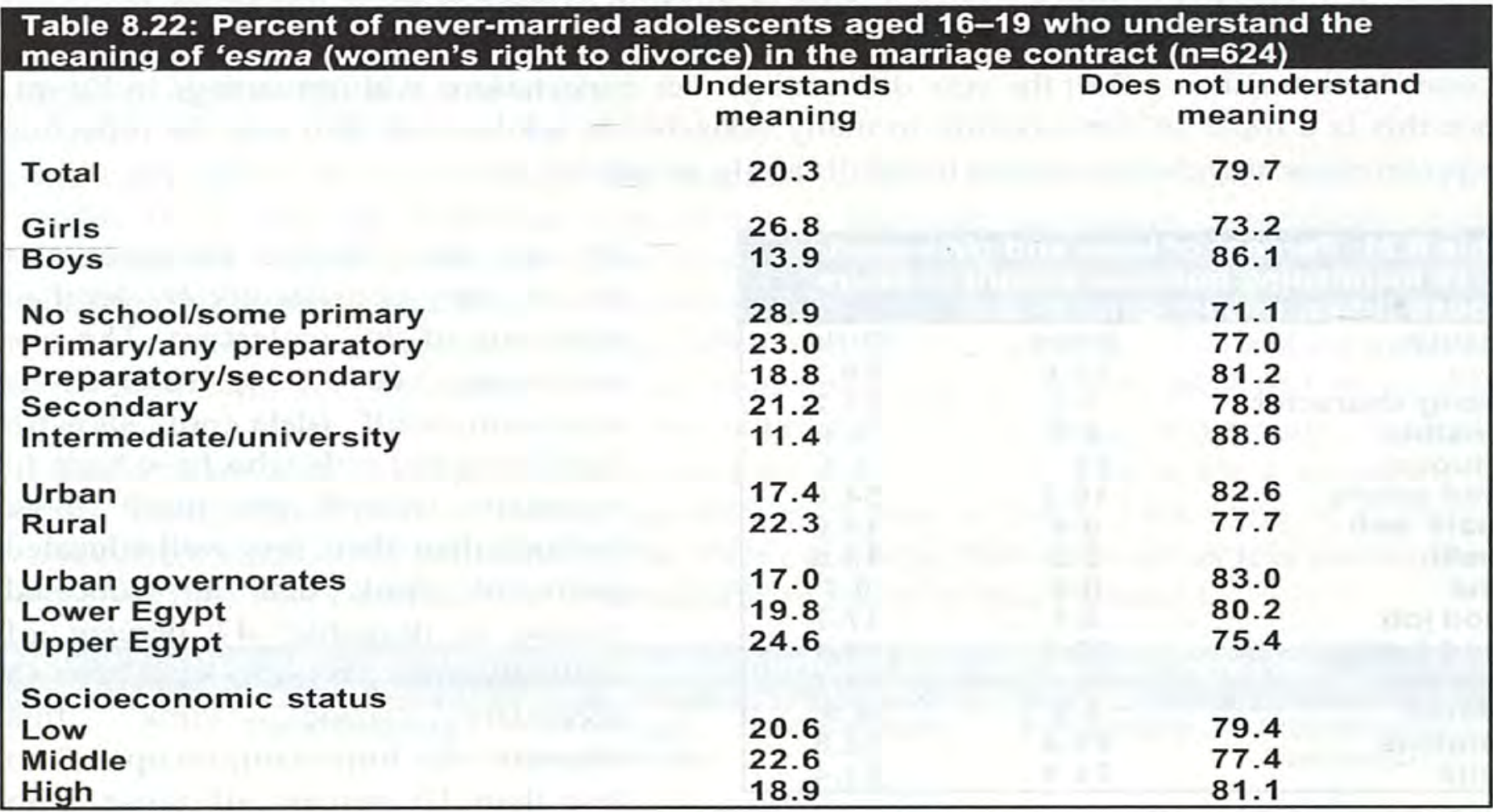

Residence, region, and socioeconomic status do not seem to differentiate greatly among adolescents' knowledge on this topic. However there is a strong and unexpected relationship to education. Higher levels of education - both of the parents and the adolescent-have a strong negative relationship with knowledge of the 'esma. Unlike other questions related to information, where higher levels of education are associated with greater knowledge, in this 
case the relationship is reversed. No education at all, or lower levels of education increase the likelihood that both boys and girls will accurately know the meaning of women's divorce rights in the marriage contract.

This finding could have two possible explanations. One is that longer experience in the education system exposes students to incorrect information or attitudes concerning this topic. Another explanation, equally plausible, is that among more educated groups, women's

right t. divorce is less accepted or less openly discussed, so that adolescents from those househ, lds are more poorly informed about the issue.

\section{Marred Adolescents}

We wanted to know whether passing through the experience of marriage would have an effect on levels of accurate information about the marriage contract. The results show that married adolescent women are slightly less well informed than their unmarried counterparts; only 20 percent know the correct meaning. This suggests that other sources of information about rights of divorce are more important than having actually undergone marriage negotiations and signing of the contract. This finding is perhaps not surprising, given the high proportion of married women in Egypt who have not seen or read their marriage contract.

\section{DIVORCE}

At an age when young people are preparing for marriage, what do they think about divorce? Boys and girls aged 16-19 were asked whether they approve of a husband or wife initiating divorce in a number of situations, ranging from everyday household management issues to more serious issues such as domestic violence.

Adolescent boys are generally more approving of divorce overall than adolescent girls. That is, except in just two cases, boys are more likely than girls to approve of divorce in any situation initiated by either spouse. For example, 86 percent of boys approve of a husband divorcing his wife if she is rude to her in-laws while only 62 percent of adolescent girls approve of divorce in this situation (Table 8.23). Even in the exceptional cases, girls' approval rates are only slightly higher than the boys': for example, only 4 percent higher if a husband talks/flirts with other women. The greater acceptance of divorce among boys probably reflects their understanding that divorce is a male prerogative in Islam and their greater sensitivity to missteps on wives' parts than husbands'. Girls, on the other hand, are perhaps more likely than boys to understand that women stand to lose more from divorce than men, to appreciate the harm to children, and to understand the stigma often placed on divorced women in Egypt.

The lower rate of approval among girls for nearly every reason for divorce is significant: This contradicts the rationale often given for denying women the right to initiate divorce, that because women are ostensibly more emotional by nature than men, the right to divorce would encourage women to initiate divorce every time they had a disagreement with their husbands. While it is impossible to know if adolescents' responses to these hypothetical situations would hold true if they were faced with these situations in reality, the data imply that 
adolescent girls would actually be less inclined than boys to initiate divorce.

Both adolescent girls and boys are more likely to approve of a husband initiating divorce than a wife in the identical situation. For example, 91 percent of boys approve of a husband divorcing his wife if she flirts with other men while only 61 percent approve of a wife divorcing her husband if he flirts with other women. Similarly, 88 percent of girls approve of a husband initiating divorce in this situation compared to only 65 percent who approve of wives divorcing their husbands for the same behavior.

However, in some cases boys are significantly more likely to approve of divorce initiated by a woman than adolescent girls. For example, 35 percent more boys than girls approve of a wife initiating a divorce if her husband is sterile (58.9\% versus $24.0 \%$ ). Similarly, nearly 16 percent more boys than girls approve of a wife initiating divorce if her husband does not provide her with enough money for household expenses (57.9\% versus $42.4 \%)$. These high levels of approval may be closely related to boys' concepts of masculinity. That is, providing for a household or fathering children may be integral to their understanding of masculinity. Rather than reflecting sympathy for women in these situations, boys' approval of divorce may reflect a negative reaction to problems that challenge their notions of masculinity.

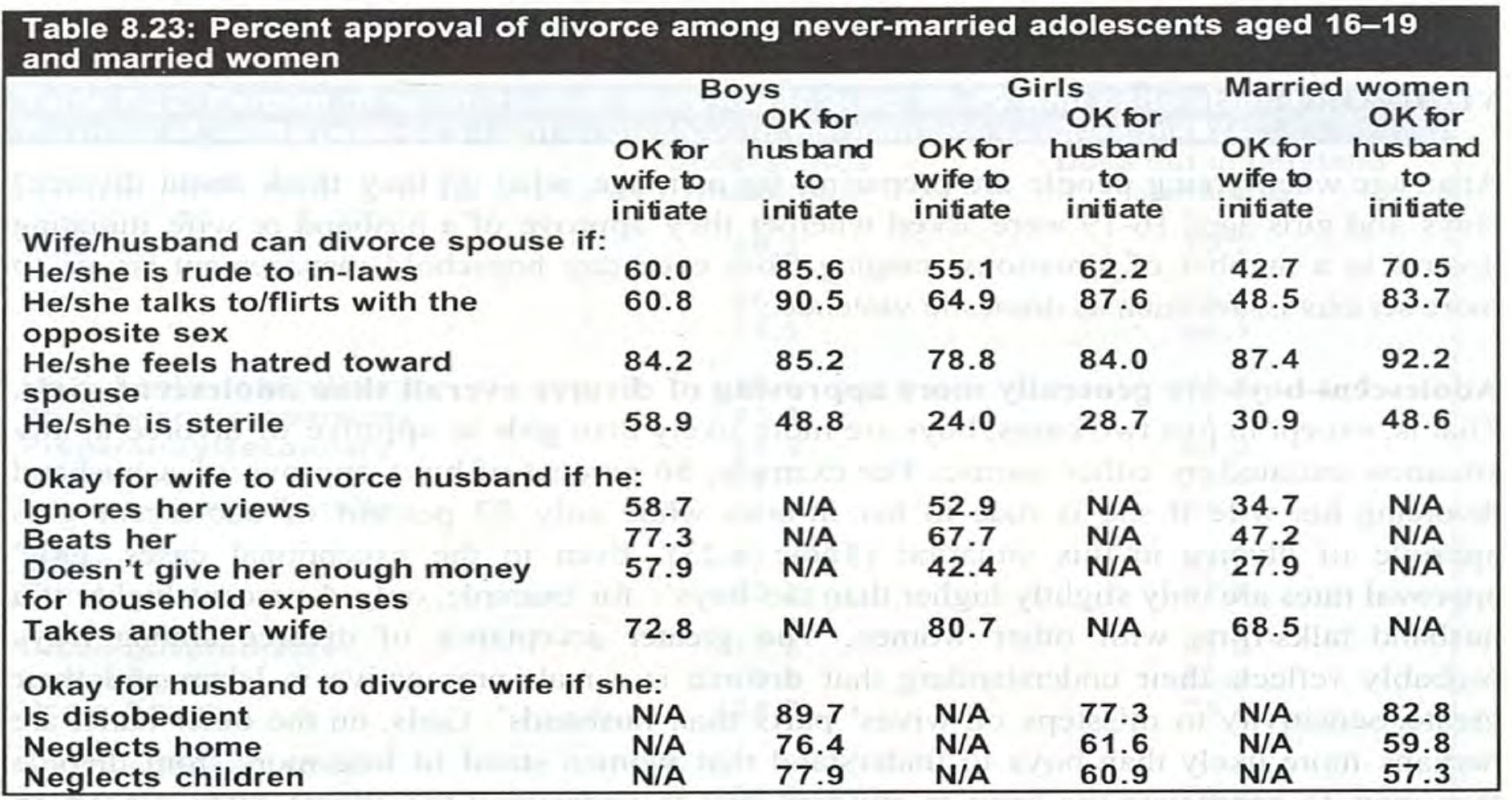

Interestingly, adolescent boys are more willing to approve of a husband initiating divorce because his wife is disobedient than because she neglects the home or the children $(89.7 \%$ versus $76.4 \%$ and $77.9 \%$, respectively). Disobedience also ranks quite high among adolescent girls as a legitimate reason for a husband to initiate divorce, with 77 percent of girls approving. This may reflect the conventional understanding of the marriage "exchange" between husbands and wives; that is, husbands support their wives and in return wives provide their husbands with more immaterial needs, such as respect, comfort, and obedience. 
Like their unmarried counterparts, married adolescent women are more accepting of divorce if it is initiated by the husband than by the wife. Forty-three percent of married adolescents believe that a wife is justified in requesting a divorce if her husband is rude to her parents, whereas 71 percent believe a husband is justified if his wife is rude to his parents. Even in the case of actual hatred of one's spouse, 87 percent believe that the wife is justified in divorcing while 92 percent believe that the husband is justified.

These gender-based differences in opinion remain even for situations in which one spouse neglects his or her traditional roles in the household. For example, if a wife neglects the home or the children, 60 percent and 57 percent of married adolescents, respectively, feel the husband is justified in requesting a divorce, whereas only 28 percent believe a wife is justified if her husband does not provide her with money for the household or for the children.

One noteworthy finding is the relative unwillingness of married women to approve of a woman initiating divorce if her husband beats her, compared to never-married adolescents of both sexes. While 77 percent of boys and 68 percent of single girls would approve of a woman divorcing her husband in this situation, only 47 percent of the married sample approves.

Married adolescents are less willing to approve of divorce than never-married girls or boys, for almost every other situation. This holds true regardless of which spouse initiated the divorce. While 58 percent of boys and 42 percent of never-married girls approve of a woman divorcing her husband if he does not provide her with enough money to meet household * expenses, only 28 percent of married adolescents feel that divorce is appropriate in that situation. Similarly, only 35 percent of married adolescents feel that a wife is justified in initiating divorce if her husband ignores her views, compared to 53 percent of never-married girls and 59 percent of boys. These differences may be due to the biased nature of the married sample, or to the real experiences of married women. Being a part of a marriage helps a woman to understand more what divorce entails and to have a more realistic picture of the type of relationship she can negotiate with her husband.

\section{CONCLUSION}

The transitions to marriage and reproductive roles carry adolescents through physical changes of maturation and social changes regarding their attitudes and expectations for future family life. The ASCE survey shows that many adolescents do not have the necessary basic information about these matters. They refrain from speaking to parents and other adults, but at the same time they would like to have more information and guidance.

Girls in particular are in need of more supportive hygiene facilities at school. Unnecessary suffering is caused because girls do not seek medical attention for severe menstrual pain. On the positive side, prevalence rates of female circumcision appear to be dropping among this generation of girls. 
With regard to gender role attitudes, most adolescents prefer role segregation. However, differences are found between boys and girls. In general, girls have more egalitarian views about role sharing and are less supportive of divorce. Few girls or boys are knowledgeable about the potential use of clauses to modify the nature of the marriage contract. 


\section{Chapter 9}

\section{Ever-Married Adolescent Women}

In recent years, a number of social, cultural, and economic factors have dramatically changed the patterns of marriage and parenthood in Egypt. The high costs associated with marriage and supporting a family and increased opportunities for women's education and employment have raised the average marriage age for women and reduced fertility preferences. However, Egypt still has one of the lowest average marriage ages for girls among Arab countries. The many negative consequences of early marriage and childbearing for adolescents, their children, and society make it essential to understand the dynamics and consequences of these relationships. Understanding adolescent marriage will help to better target program and policy interventions to reduce the prevalence of early marriage and ameliorate the life conditions of those who do marry during adolescence. Thus the ASCE researchers felt it was important to investigate the many dimensions of married adolescents' lives.

As discussed in Chapter 2, the survey attempted to interview every married adolescent woman identified through the household screening process. The screening process identified 353 ever-married adolescent females, of whom 317 were successfully interviewed, a dropout rate of 10 percent $^{1,2}$. Because marriage is a multi-stage process in Egypt, the definition of marriage used was the point at which a married couple began living together in one household (Dukhla).

Married adolescents are a special group in Egypt, sharing few characteristics with the overall population of adolescent girls. In some of the following analysis, the sample of never-married girls aged 16-19 was used as a comparison group to illustrate the uniqueness of the married sample ${ }^{3}$.

\section{PREVALENCE AND CLUSTERING OF ADOLESCENT MARRIAGE}

The ASCE survey found a national prevalence of adolescent marriage of 11.7 percent. Based on data from the 1996 Egyptian census, this prevalence level results in 725,385 married adolescent women in Egypt between the ages of 10 and 19.

The region-specific prevalence rates shown in Table 9.1 provide evidence of the marked regional differences in marriage patterns. It is clear that rural Upper Egypt and rural Lower Egypt are the main pockets of early marriage among adolescent girls.

\footnotetext{
'Since only 7 of the ever-married women were divorced or separated, we will refer to the sample as "married."

2 Those who were interviewed and those who dropped out resembled each other enough to ensure that any bias introduced by this drop-out was minimal (data not shown).

${ }^{3}$ This group was selected because most of the questions on reproductive health and gender roles were asked only of never-married girls above age 16 , though they were asked of all ever-married women.
} 
Table 9.1: Region-specific prevalence rates of all identified ever-married adolescents aged 16-19

Region
Urban govs.
Lower Urban
Lower Rural
Upper Urban
Upper Rural
Total

\begin{tabular}{cc}
$\begin{array}{c}\text { Married adolescents } \\
\text { aged 16-19 }\end{array}$ & $\begin{array}{c}\text { Total adolescent } \\
\text { females aged 16-19 }\end{array}$ \\
29 & 556 \\
24 & 227 \\
112 & 1,015 \\
31 & 321 \\
139 & 693 \\
335 & 2,812 \\
\hline
\end{tabular}

\begin{tabular}{c|} 
Prevalence \\
$\%$ \\
5.2 \\
10.6 \\
11.0 \\
9.7 \\
20.1 \\
11.9 \\
\hline
\end{tabular}

\begin{tabular}{|cccc|}
\hline \multicolumn{3}{|c|}{ Table 9.2: Age-specific prevalence of all ever-married adolescent women identified } \\
\hline Age & $\begin{array}{c}\text { Frequency of } \\
\text { married } \\
\text { adolescents }\end{array}$ & $\begin{array}{c}\text { Frequency of } \\
\text { females }\end{array}$ & $\begin{array}{c}\text { Prevalence } \\
\%\end{array}$ \\
13 & 1 & 849 & 0.1 \\
14 & 3 & 878 & 0.3 \\
15 & 14 & 856 & 1.6 \\
16 & 49 & 852 & 5.8 \\
17 & 75 & 790 & 9.5 \\
18 & 103 & 708 & 14.5 \\
19 & 108 & 522 & 20.7 \\
$20^{*}$ & 396 & 929 & 42.6 \\
Total & 749 & 6,385 & 11.7 \\
\hline
\end{tabular}

${ }^{*}$ Adolescents aged 20 were included because of suspected age rounding from age 19 to age 20.

Table 9.2 shows the age-specific prevalence rates for adolescent marriage in Egypt, using all of the ever-married women identified by the survey. The highest prevalence rate is observed in the 19 year-old group at 21 percent. Because of a trough in the number of 19 year-old never-married women identified by the survey, we suspected age-rounding might have taken place. Thus we also calculated the age-specific marriage rate for 20 year-olds, and found it to be more than 42 percent. Because the extent of this age-rounding cannot be measured, the figure for the 19 year-olds should be considered an underestimate. Thus the difference between the rates for 19 and 20 year-olds is probably not as great as it appears in Table 9.2.

\section{Underage Marriage}

Only 2 percent of married adolescent women report that they are currently below age 16, the legal age of marriage for females. However, 28 percent of the total married sample interviewed report having been married before the age of 16 . One would expect these numbers to be roughly equal, as it is unlikely that the rate of early marriage is decreasing quickly enough to produce all of this difference. This discrepancy suggests that young women are less willing to admit their real age if they are still below the legal age of marriage because of potential legal ramifications. Once they have passed the legal age of marriage, however, young women seem more willing to admit that they were married before the legal age. Thus it is difficult to determine precisely how many underage girls were identified by the survey.

As the age-specific prevalence of marriage indicates, marriage between ages 13 and 15 is not widespread, though because of the potential skewing discussed above, these rates are probably underestimated. However, the momentum increases markedly for ages 16 and above, 
nearly 6 percent at age 16 jumping to nearly 21 percent by age 19 . By age 20 , the prevalence is 43 percent (again bearing in mind the effects of age-rounding), suggesting a considerable clustering of marriage events as girls pass out of the adolescent decade.

\section{DESCRIPTION OF THE MARRIED SAMPLE}

\section{Socioeconomic Status}

A socioeconomic index was created based on the presence of particular assets in the home thought to distinguish among household economic situations. The socioeconomic data obtained in the survey relate to the current living situations of the married adolescents. Since most are living in the extended households of their husbands or in nuclear households, this data does not generally reflect the socioeconomic status of their families of origin. The data may be further skewed by the large intergenerational transfer of assets that takes place when a couple gets married in Egypt. Nevertheless, the data provide information on the present living conditions of ever-married adolescents.

The married adolescents are almost evenly distributed among the three socioeconomic strata; 33 percent are presently in the lowest category, 31 are in the middle category, and 36 percent are in the highest.

\section{Educational Attainment}

Not surprisingly, the educational attainment of married adolescents is lower than their nevermarried counterparts. This can be explained both by the fact that married adolescents are a selective group, over-representing less well-educated households, and because girls are required to drop out of school upon marrying, thus pre-empting the continuation of their education. That 52 percent of the married sample aged 16-19 has either never attended school or only attended some primary school is striking compared to just 19 percent of nevermarried females aged 16-19. The disparity remains between the two groups at all levels of educational attainment. Table 9.4 shows the comparison between the two groups. Forty-four percent of unmarried girls aged 16-19 have attained a secondary or higher level of education, compared to only 17 percent of the married sample in the same age group. Furthermore, 37 percent of the married sample reports that they are unable to read the newspaper, compared to just 3 percent of the never-married group.

Approximately 15 percent of married adolescents who never attended school have attended literacy classes. At the time of the survey, not a single married adolescent reported currently attending literacy classes. Unfortunately, 40 percent of those attending attended literacy classes for less than one month, implying that the classes were not convenient or well-suited to their needs. 
Table 9.3: Percent comparison of highest education level attained by married ( $N=335)$ and never-married $(\mathrm{N}=\mathbf{2 8 7 2})$ adolescent females aged $16-19$

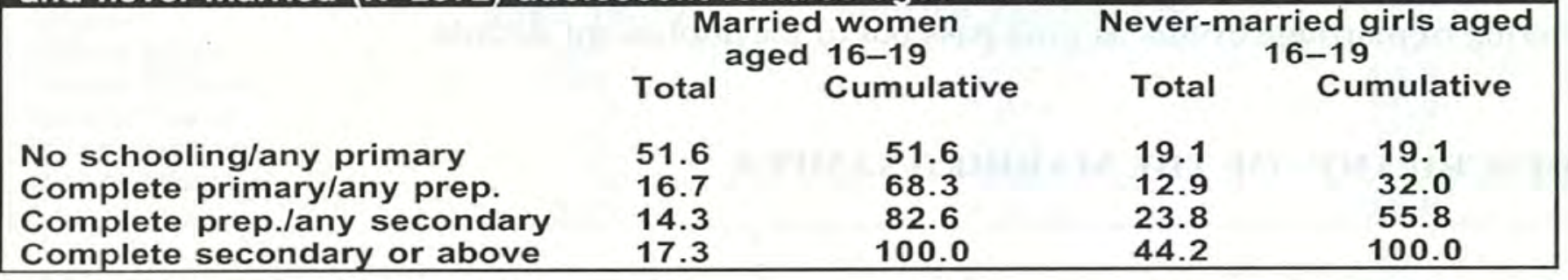

\section{Reasons Married Adolescents Drop Out and Never Attend}

Among married adolescent women, marriage was the most frequent reason reported for dropping out of school, but less than one-quarter $(23.2 \%)$ name this as the primary reason. Table 9.4 shows that a number of other reasons for dropping out are reported almost as frequently as marriage. Nearly 18 percent of the young women cite their own poor performance in school as their reason for dropping out, while another 15 percent report that they do not feel that education is important for them, and 13 percent report that their families could not afford the expenses for their education.

\begin{tabular}{|c|c|c|c|c|c|c|}
\hline \multirow{3}{*}{$\begin{array}{l}\text { Family cannot afford } \\
\text { education expenses } \\
\text { She was needed to help } \\
\text { with housework }\end{array}$} & \multirow{2}{*}{$\begin{array}{l}\text { Total } \\
13.2\end{array}$} & \multicolumn{2}{|c|}{$\begin{array}{l}\text { Type of } \\
\text { residence }\end{array}$} & \multicolumn{3}{|c|}{ Region of residence } \\
\hline & & $\begin{array}{r}\text { Urban } \\
15.9\end{array}$ & $\begin{array}{c}\text { Rural } \\
12.1\end{array}$ & $\begin{array}{l}\text { Urban } \\
\text { govs. } \\
11.8\end{array}$ & $\begin{array}{l}\text { Lower } \\
\text { Egypt } \\
5.6\end{array}$ & $\begin{array}{l}\text { Upper } \\
\text { Egypt } \\
22.2\end{array}$ \\
\hline & 7.3 & 2.3 & 9.3 & 0.0 & 8.5 & 7.9 \\
\hline $\begin{array}{l}\text { Education isn't important } \\
\text { to her }\end{array}$ & 15.2 & 18.2 & 14.0 & 35.3 & 18.3 & 6.3 \\
\hline $\begin{array}{l}\text { Girls' education isn't } \\
\text { important to her family }\end{array}$ & 7.3 & 6.8 & 7.5 & 11.8 & 5.6 & 7.9 \\
\hline $\begin{array}{l}\text { Marriage } \\
\text { Didn't do well in school } \\
\text { Other }\end{array}$ & $\begin{array}{l}23.2 \\
17.9 \\
15.9\end{array}$ & $\begin{array}{l}22.7 \\
13.6 \\
20.5\end{array}$ & $\begin{array}{c}23.4 \\
19.6 \\
14\end{array}$ & $\begin{array}{c}17.6 \\
5.9 \\
17.6\end{array}$ & $\begin{array}{l}15.5 \\
28.2 \\
18.3\end{array}$ & $\begin{array}{c}33.3 \\
9.5 \\
12.7\end{array}$ \\
\hline
\end{tabular}

Most notably, Table 9.5 demonstrates that the young women who report dropping out because of marriage were actually significantly older on average at dropout than those reporting other reasons for dropout. On one level this is not surprising, as a girl who drops out at age 9 is not likely to be doing so in order to get married. On another level however, this provides strong evidence that young women who marry early are not necessarily dropping out in order to get married. Rather, three-quarters are dropping out for other reasons and then getting married, perhaps because they have less to fill their time or because of family pressures. Those who drop out to get married are actually getting more education than the other dropouts. This has important implications for any interventions aimed at reducing levels of early marriage. 


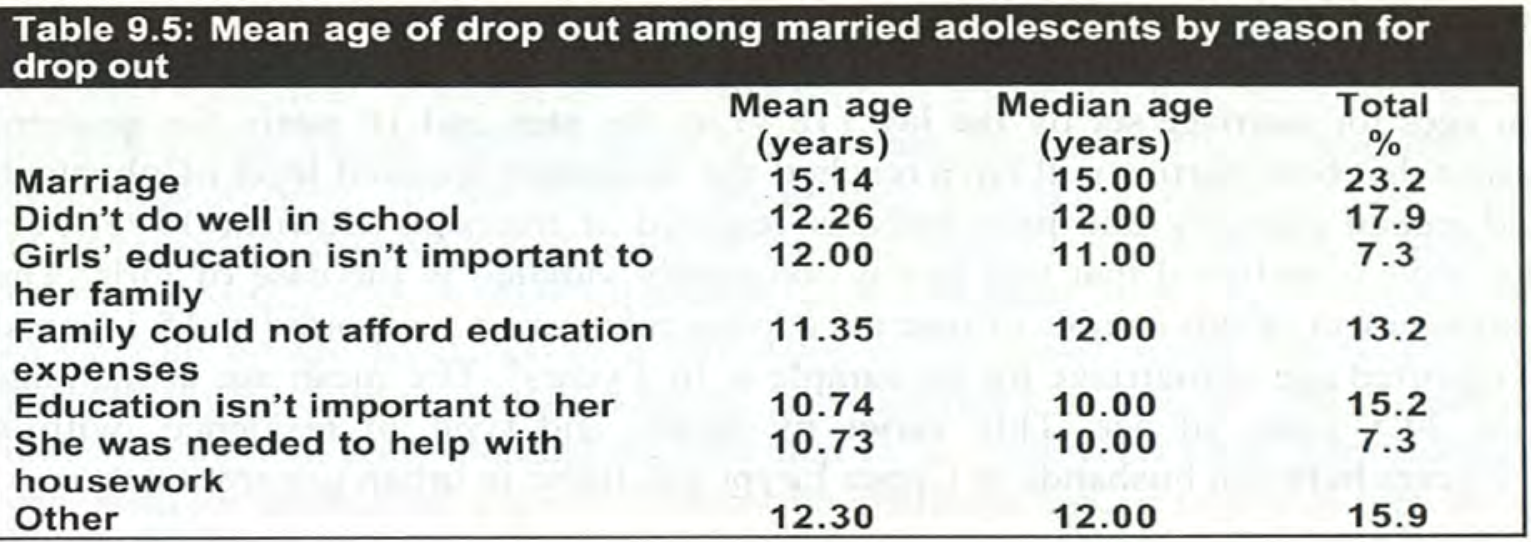

Table 9.6 shows the primary reasons that uneducated married adolescents give for why they believe their parents never sent them to school. The families of these married adolescents appear to place a low value on girls' education, with more than half of the married women $(51.3 \%)$ reporting that as the reason they never attended school. Financial difficulty was the second most common reason $(30.8 \%)$ followed by household help needed $(17.1 \%)$.

\begin{tabular}{|c|c|c|c|c|c|c|}
\hline \multirow{3}{*}{$\begin{array}{l}\text { Girls' education is not } \\
\text { important to her family }\end{array}$} & \multirow{2}{*}{$\begin{array}{l}\text { Total } \\
51.3\end{array}$} & \multicolumn{2}{|c|}{$\begin{array}{l}\text { Type of } \\
\text { residence }\end{array}$} & \multicolumn{3}{|c|}{ Region of residence } \\
\hline & & $\begin{array}{l}\text { Urban } \\
38.5\end{array}$ & $\begin{array}{l}\text { Rural } \\
52.9\end{array}$ & $\begin{array}{c}\text { Urban } \\
\text { govs. } \\
0.0\end{array}$ & $\begin{array}{c}\text { Lower } \\
\text { Egypt } \\
22.6\end{array}$ & $\begin{array}{c}\text { Upper } \\
\text { Egypt } \\
63.1\end{array}$ \\
\hline & & & & 1000 & 419 & 2500 \\
\hline $\begin{array}{l}\text { Family cannot afford education } \\
\text { expenses }\end{array}$ & 30.8 & 46.2 & 28.8 & & 47.9 & \\
\hline $\begin{array}{l}\text { She was needed to help with } \\
\text { housework }\end{array}$ & 17.1 & 7.7 & 18.3 & 0.0 & 9.7 & 20.2 \\
\hline
\end{tabular}

The three main reasons for never attending school are aspects of the same economic-related phenomenon: Families make rational allocations of resources based on the perceived value and costs of those investments. The need for a girl's household labor, coupled with her lower likelihood of being financially responsible for a household (that is, the lower likelihood of a financial benefit from her education), make the cost of her education very high for a family with few resources at its disposal. These findings support those in Chapter 5 to demonstrate the greater sensitivity of girls' school enrollment and retention levels to contextual factors and macro-level events. The addition of cost-recovery measures, such as school fees, in the absence of other changes, can put girls' education out of reach for some families.

\section{CHARACTERISTICS OF ADOLESCENT MARRIAGE}

What characterizes the households of married adolescents? What sorts of relationships do they establish with their husbands? In addition to the widely known risks of early childbearing, early marriage has other consequences for adolescent women. In order to understand further the environment in which married adolescents live, the ASCE survey investigated the nature of the marriage negotiation process and the gender roles and power dynamics within relationships after marriage. (Ongoing case studies for a qualitative component of the ASCE survey on preparations for marriage and reproductive roles will help shed more light on these issues in the near future.) 
The minimum ages for marriage set by the law (18 years for men and 16 years for women) attempt to ensure that both parties will have reached the minimum required level of physical, emotional, and mental maturity and preparedness required at marriage (Zulficar 1995). Yet smaller studies have established that this law is commonly violated in the case of girls. The mean age at engagement of this sample of married adolescent women is reported at 15.1 years, and the mean reported age of marriage for the sample is 16.2 years ${ }^{4}$. The mean age at marriage of husbands is 24.5 years of age. This varies by region and type of residence, with a difference of 2 years between husbands in Upper Egypt and those in urban governorates.

Table 9.7 compares the actual reported ages of marriage for both married adolescent women and their husbands, with married adolescent women's reported ideal ages for both. Perhaps not surprisingly, married adolescents' mean ideal age of marriage for women varies by their own age at marriage; that is, the older their age at marriage, the higher their ideal age for women. However, what they consider the ideal age of marriage for men is not associated with their own age at marriage. Significantly, the young women's mean reported age at marriage is between 2 and 3 years lower than their ideal age of marriage for women, and this holds true across all background variables. Conversely, their husbands married at or later than the young women's ideal age of marriage for men.

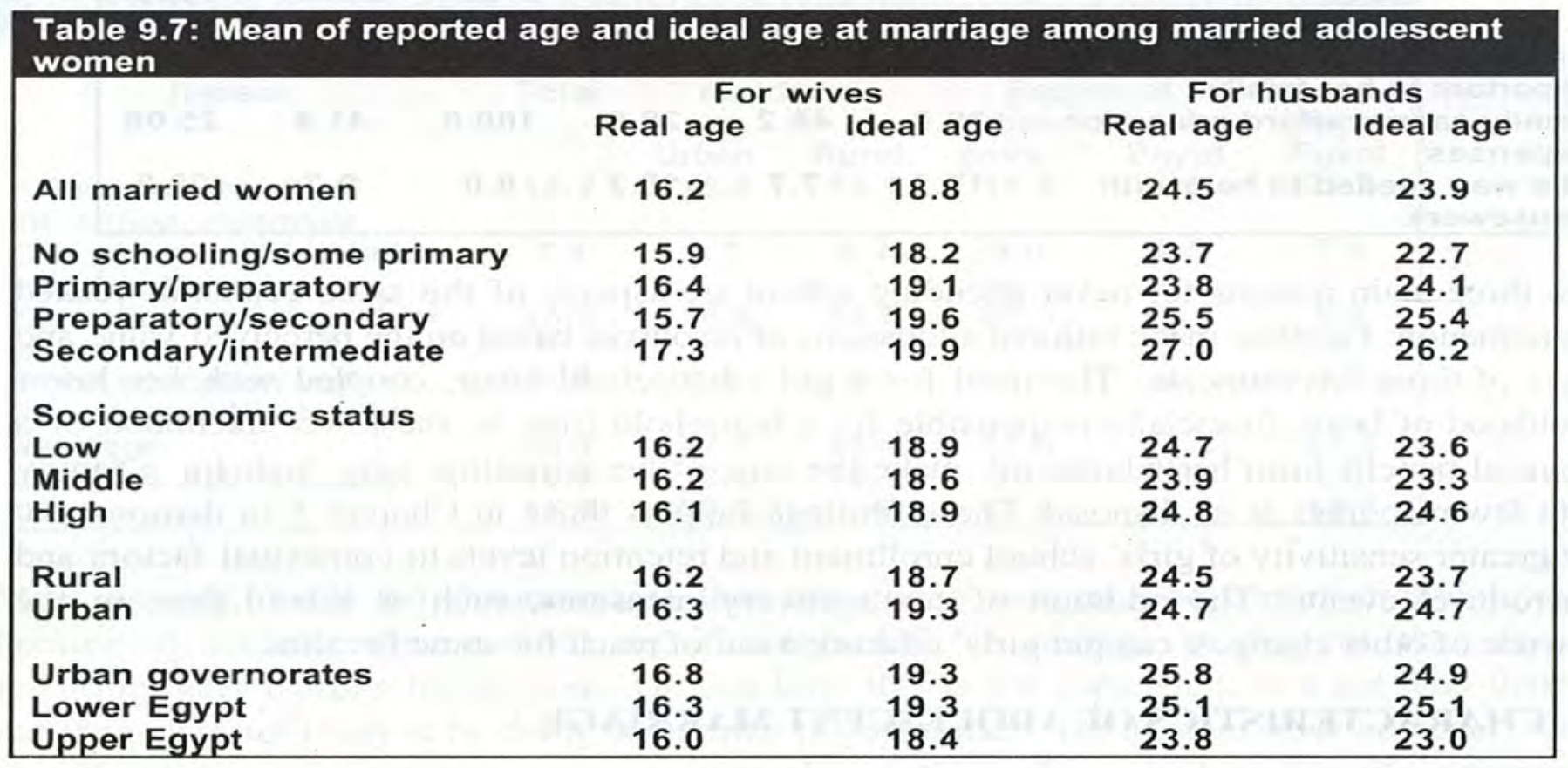

\section{Age Difference Between Wives and Husbands}

The difference in age between wives and husbands has an impact on the nature of the relationship a woman forms with her husband. Researchers have found that large differences

\footnotetext{
${ }^{4}$ These figures are valid only for describing the married adolescents sampled by the survey. That is, it would be statistically invalid to generalize to the population of married Egyptian adolescents because less than 50 percent of the original sample of adolescents has experienced marriage.
} 
in age may reduce a young woman's ability to negotiate with her spouse about domestic matters. Moreover, it increases the likelihood of a woman being widowed while her children are still young. Given that Egyptian widows are discouraged from remarrying because it is thought to be better for the children, the women and their children are thus more likely to be in economically disadvantaged households. The women in our married sample are on average 8.3 years younger than their husbands, with a median of 8 years. Spousal age differences range from no age difference to a difference of 34 years. While our findings reveal that 70 percent of women married men who are 10 years older or less, 30 percent married men 11 or more years older, and 7 percent married men 15 or more years older. Surprisingly, this did not vary with the adolescent's level of education, marriage age, or region or type of residence.

The 1995 Egyptian Demographic and Health Survey (EDHS) findings allow us to compare our findings on adolescent marriages with those of older women. The EDHS results for married women younger than 18 years are quite similar to the ASCE results: The EDHS respondents were on average 8.8 years younger than their husbands. However, among married women between ages 18 and 24, the age difference was only 6.8 years on average, and for those aged 25-29 it was only 4.7 years. Thus the lower autonomy that a large age difference is thought to indicate is more likely for married adolescents than for their slightly older counterparts.

The real age difference found between these young married women and their husbands is quite different from their ideal situation. Married adolescents in the ASCE survey on average say that a difference of less than 4 years between husbands and wives is ideal. Coupled with their reported preference for later ages at marriage, it is clear that these women have accommodated to marriages that fall short of their preferences.

\section{Final Decision Regarding Marriage}

More than 62 percent of married adolescents report that their fathers had the final decision on who they would marry, while 22 percent report that they themselves had the final decision. This varies significantly by current socioeconomic status, with 31 percent of those in the high strata reporting they made the final decision, while only 16 percent of those in the lowest strata report making the decision. While it is not certain that their current socioeconomic status reflects that of their family of origin, this relationship is still an important, though not surprising, finding. Decision-making did not vary significantly by region or type of residence. Moreover it did not vary by whether or not the young woman married a relative.

These young women probably did play a role in the decision-making process regarding their marriages. However, marriage in Egypt usually involves negotiations between the bride's father and the groom or his father and possibly other relatives. These negotiations have as much to do with economics as the compatibility of the couple. Given these dynamics, it is probable that the fathers of these young women made the final decisions regarding the marriages, though probably not without input from the young woman and/or her mother. 
There is a long-standing tradition of marriage between family members in Egypt, with cousin marriages historically considered ideal. More than 59 percent of the married women in the sample married a man related to them. Of those young women who report that they married a relative, 35 percent married a paternal relative. Another 10 percent report that they married a relative of both parents. These results are higher than those for older married women in the EDHS, which found that among women aged 20-24, 44 percent married a relative and 37 percent of those aged 25-29 did so.

\section{Living Arrangements of Married Adolescents}

More than 73 percent of the sample report that they lived with the husband's family after marriage, with less than one-quarter $(22.2 \%)$ reporting that they lived alone as a couple after marriage (Table 9.8). Not surprisingly, those who marry a man in the high socioeconomic stratum are much more likely to live on their own after marriage than those who marry from the lower stratum. The likelihood of a couple living on their own after marriage is highly associated with the adolescent's level of education, though the positive relationship between education and socioeconomic status may distort the strength of this relationship.

\begin{tabular}{|lccc}
\hline $\begin{array}{l}\text { Table 9.8: Living arrangements of married adolescents following } \\
\text { marriage }\end{array}$ & $\begin{array}{c}\text { Private } \\
\text { residence }\end{array}$ & Her family & His family \\
\hline All married women & 22.2 & 4.7 & 73.1 \\
No schooling/some & 13.6 & 3.6 & 82.8 \\
primary & & & \\
Primary/preparatory & 26.4 & 9.4 & 64.2 \\
Preparatory/secondary & 29.8 & 2.1 & 68.1 \\
Secondary/intermediate & 40.4 & 6.4 & 53.2 \\
Socioeconomic status & & & \\
Low & 19.8 & 6.1 & 73.6 \\
Middle & 24.7 & 2.2 & 73.2 \\
High & 22.1 & 5.6 & 72.6 \\
Urban & 47.0 & 0.0 & 53.0 \\
Rural & 15.6 & 6.0 & 78.4 \\
Urban governorates & 68.2 & 0.0 & 31.8 \\
Lower Egypt & 25.0 & 4.5 & 70.5 \\
Upper Egypt & 13.6 & 5.6 & 80.9 \\
\hline
\end{tabular}

Notably, 68 percent of young women in the urban governorates (mainly in Cairo and Alexandria) report living in their own private homes after marriage. Compared to married adolescents in other regions, this is a high rate of nuclear household formation. However, it is lower than the overall prevalence of nuclear households in the urban governorates among the general population. 
The EDHS collected information on location of residence at the start of marriage and the age at marriage among married women between ages 15 and 49 . A clear pattern emerges from these data: The older a woman is at marriage, the more likely she is to have lived in a private residence at the start of her marriage. For example, 68 percent of those women who were less than 18 years old when they married lived with their husband's family, compared to 50 percent of those who married between the ages of 18 and 24, and 28 percent of those married between ages 25 and 29. This EDHS data represent the experiences of all married women surveyed regardless of their present age; however, given the increasing prevalence of nuclear households in Egypt, this discrepancy by age would probably be even greater if the data were limited to women married during the previous decade. Thus it is clear that a woman married during adolescence is quite likely to begin her married life negotiating her new roles with both her husband and his extended family.

\section{GENDER ROLES IN THE HOUSEHOLD}

What type of relationships do these married adolescents have with their husbands? How are household tasks divided among members of the household and to what extent is decisionmaking shared between them? Married adolescents were asked who is responsible for a variety of tasks within the household, such as cleaning and earning the primary income, and who makes decisions on a variety of household issues, including contraceptive use and the household budget.

\section{Task Sharing Between Spouses}

There is a pattern of traditional division of labor in the households of these married adolescents. Almost no one reports that roles are shared between husband and wife for tasks such as earning the primary income ("breadwinner"), cleaning the house, or buying provisions. Only slightly more than 1 percent of the married women report that they share the role of breadwinner with their husband, and no married women report sharing the housekeeping duties with their husbands. The only significant variations in responsibility were explained by household size; not surprisingly, these roles are different if the couple lives within an extended household. As the number of individuals residing in a household increases, the likelihood that either the husband or wife has sole responsibility for a given task decreases.

\section{DECISION-MAKING IN THE HOUSEHOLD}

Household decision-making appears to be less gender-segregated than tasks, with large proportions of married women reporting shared decision-making in important household issues.

As Table 9.9 shows, the proportions of respondents reporting shared decision-making in a variety of household issues vary considerably by region of residence. For example, in the urban governorates, 90 percent of respondents report that the use of contraception is a shared decision between wife and husband, whereas only 57 percent in Upper Egypt report sharing in that decision. Similarly, decisions regarding the household budget are more likely to be 
shared in the urban governorates $(76.2 \%)$ than in either Lower or Upper Egypt $(47.6 \%$ and $48 \%$ respectively). The decision that husbands are least likely to share is whether a wife is permitted to take up paid employment outside the home. This could be explained by the strongly held view that the husband is the sole breadwinner in a family (see above) or a perception that work would prevent the woman from tending to her responsibilities in the household.

\begin{tabular}{|c|c|c|c|c|}
\hline & $\begin{array}{c}\text { Having } \\
\text { another baby }\end{array}$ & $\begin{array}{l}\text { Household } \\
\text { budget }\end{array}$ & $\begin{array}{c}\text { Use of } \\
\text { contraception }\end{array}$ & $\begin{array}{c}\text { Wife's } \\
\text { employment }\end{array}$ \\
\hline All married adolescents & 71.3 & 50.2 & 66.8 & 30.3 \\
\hline $\begin{array}{l}\text { No schooling/some primary } \\
\text { Primary/preparatory } \\
\text { Preparatory/secondary } \\
\text { Secondary/intermediate }\end{array}$ & $\begin{array}{l}72.3 \\
75.0 \\
51.4 \\
83.3\end{array}$ & $\begin{array}{l}47.5 \\
54.2 \\
46.5 \\
57.9\end{array}$ & $\begin{array}{l}66.2 \\
66.7 \\
62.5 \\
74.3\end{array}$ & $\begin{array}{l}27.3 \\
28.8 \\
26.1 \\
45.7\end{array}$ \\
\hline $\begin{array}{l}\text { Urban govs. } \\
\text { Lower Egypt } \\
\text { Upper Egypt }\end{array}$ & $\begin{array}{l}73.7 \\
83.2 \\
60.3\end{array}$ & $\begin{array}{l}76.2 \\
47.6 \\
48.0\end{array}$ & $\begin{array}{l}89.5 \\
76.6 \\
57.1\end{array}$ & $\begin{array}{l}27.3 \\
40.7 \\
22.1 \\
\end{array}$ \\
\hline
\end{tabular}

The EDHS data allow us to compare these marriage dynamics with older married women. While there is little variation by age in sharing the decision to have another baby, there is significant variation in decisions regarding the household budget and the use of contraception. Among the EDHS sample, 43 percent of women aged 20-29 report sharing in household budget decisions and 83 percent of women aged 20-29 report that the decision to use contraception was a joint one. [Twenty-eight percent of adolescent women (ages 15-19) in the EDHS reported sharing in household budget decisions and 66 percent shared in decisions regarding contraception.]

\section{Other Gender Dynamics}

Married adolescents were asked several additional questions that assess the gender dynamics in their marital relationships, including: "A woman must take her husband's permission for everything," "If a husband's and wife's opinions differ, the husband's decision is final," and "The husband decides how to spend any remaining money after household expenses are met." Table 9.10 makes it clear how significant a young woman's education is in changing the reported dynamics between her and her husband. For example, 87 percent of women with little or no education say that if their views differ from their husbands' views, their husbands' decisions are final, compared with only 63 percent among those with a secondary or intermediate level of education. A similar pattern is found among the responses to the other two questions.

\section{Permission to go out}

Respondents were also asked their understanding of the statement: "A wife must take her husband's permission to go out." Nearly 76 percent of married adolescents say this statement means that a husband can refuse to give his permission for his wife to go out, whereas 24 percent indicate that it means that a wife should tell her husband where she is going when she 
leaves the house. This varies across region of residence, with 77 percent of married adolescents in urban governorates saying that this means the husband can refuse permission to go out, while 66 percent and 83 percent of married adolescents in Lower and Upper Egypt, respectively, define permission to go out in the same manner. Interestingly this dynamic did not vary significantly by the level of adolescent education.

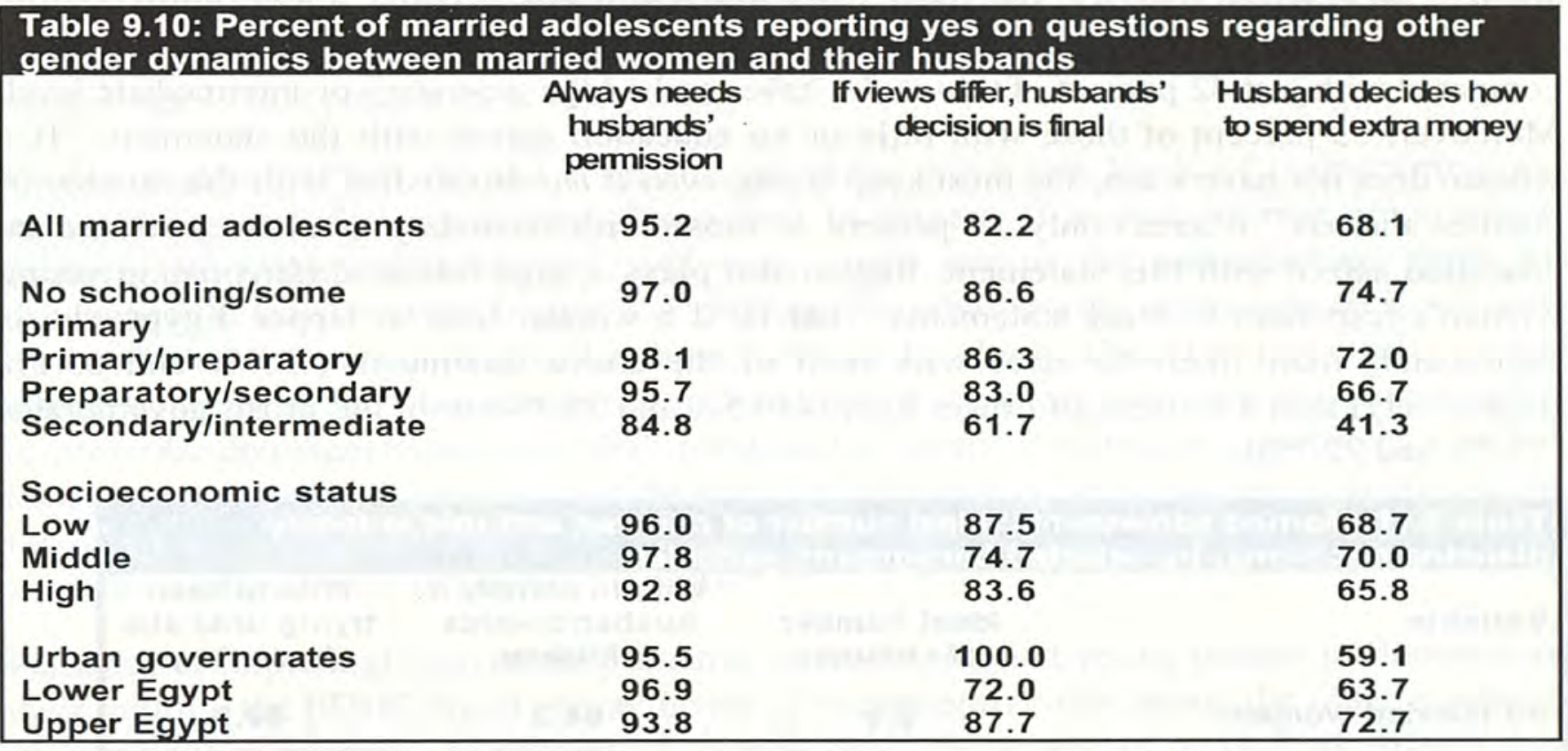

\section{REPRODUCTIVE HEALTH}

\section{FAMily Size Goals}

Approximately 57 percent of married adolescents report having discussed the ideal family size with their husbands. However, this behavior varies significantly by type of residence, that is, 82 percent of the respondents in urban governorates reported discussing their family size goals with their husbands, compared to 64 percent and 48 percent of Lower and Upper Egyptian respondents, respectively. More importantly, the married adolescent's level of education had a large impact on whether or not she discussed family size goals with her husband. Only 47 percent of those with little or no education had discussed it with their husbands, compared to 72 percent of those with a secondary or above intermediate education. Most of the couples $(78.2 \%)$ are in agreement regarding the number of children they would like to have, though this also varies by region of residence and the level of adolescent education. Residents of urban governorates report that their husbands are more likely to agree with them (94.4\%) compared to 82 percent of Lower Egypt and 70 percent of Upper Egypt residents.

Table 9.11 shows the variations in the ideal number of children among married adolescents. Overall, married adolescents believe that the ideal number of children for a family is 2.9 - or 3 - children. Similar ideal numbers were found among all married women in the EDHS sample. The ideal number of children appears to be somewhat associated with region of residence. Married adolescents in the urban governorates and in Lower Egypt desire 2.6 children on 
average, while the mean for those living in Upper Egypt is 3.1. The desired number of children decreases slightly as the adolescent's education level increases; however, this was not a statistically significant difference.

One of the most striking findings of this data is the strong impact of the young woman's education on her views of her proper decision-making role in planning her family. When asked whether they agreed with the statement: "If a husband wants children, a wife must comply even if she does not want children," 76 percent of those with little or no education agreed compared with just 42 percent of those who have reached the secondary or intermediate level. Moreover, 53 percent of those with little or no education agreed with the statement: "If a woman does not have a son, she must keep trying even if she is satisfied with the number of children she has," whereas only 16 percent of those with secondary or above intermediate education agreed with this statement. Region also plays a large role in differentiating young women's responses to these statements. That is, if a woman lives in Upper Egypt, she is significantly more likely to agree with both of the above statements (73.9\% and $53.1 \%$ respectively) than a resident of Lower Egypt (59.5\% and $28.3 \%$ ) or of the urban governorates ( $72.7 \%$ and $22.7 \%)$.

\begin{tabular}{|c|c|c|c|}
\hline Variable & $\begin{array}{l}\text { Ideal number } \\
\text { of children }\end{array}$ & $\begin{array}{l}\text { Wife to comply if } \\
\text { husband wants } \\
\text { children }\end{array}$ & $\begin{array}{l}\text { Wife to keep } \\
\text { trying until she } \\
\text { has a boy }\end{array}$ \\
\hline All married women & 2.9 & 68.2 & 40.8 \\
\hline $\begin{array}{l}\text { No schooling/some primary } \\
\text { Primary/preparatory } \\
\text { Preparatory/secondary } \\
\text { Secondary/intermediate }\end{array}$ & $\begin{array}{l}3.0 \\
2.8 \\
2.8 \\
2.5\end{array}$ & $\begin{array}{l}76.1 \\
71.7 \\
61.4 \\
41.9\end{array}$ & $\begin{array}{l}53.3 \\
34.0 \\
27.7 \\
15.9\end{array}$ \\
\hline $\begin{array}{l}\text { Socioeconomic status } \\
\text { Low } \\
\text { Middle } \\
\text { High }\end{array}$ & $\begin{array}{l}2.9 \\
2.8 \\
2.9\end{array}$ & $\begin{array}{l}70.2 \\
66.3 \\
67.9\end{array}$ & $\begin{array}{l}46.7 \\
40.4 \\
35.7\end{array}$ \\
\hline $\begin{array}{l}\text { Urban } \\
\text { Rural }\end{array}$ & $\begin{array}{l}2.7 \\
2.9\end{array}$ & $\begin{array}{l}57.1 \\
71.2\end{array}$ & $\begin{array}{l}27.7 \\
44.3\end{array}$ \\
\hline $\begin{array}{l}\text { Urban governorates } \\
\text { Lower Egypt } \\
\text { Upper Egypt }\end{array}$ & $\begin{array}{r}2.6 \\
2.6 \\
3.1 \\
\end{array}$ & $\begin{array}{l}72.7 \\
59.5 \\
73.9\end{array}$ & $\begin{array}{l}22.7 \\
28.3 \\
53.1\end{array}$ \\
\hline
\end{tabular}

Early childbearing carries with it significant health risks to both the mother and child; the younger the woman, the greater the risk..$^{5}$ Therefore, it is important to understand the dynamics of pregnancy and birth among adolescent marriages in Egypt. Three strategies can be employed for a society to ensure that its children are born in healthy circumstances: (1) delay the age at first marriage, (2) delay the first birth, and (3) increase the length of time between the first birth and subsequent pregnancies.

\footnotetext{
${ }^{5}$ While a review of this research is beyond the scope of this report, the 1995 Egyptian Demographic and Health Survey (EDHS) thoroughly documented these risks among Egyptian women and their children.
} 


\section{Control Over Reproductive Activities}

If marriage has already taken place, as it has for this sample of young women, only two of these strategies remain. However, Egyptian culture places significant pressure on newly married couples to have a first birth as soon as possible in order to establish their fertility. The dynamics of childbearing among this sample demonstrates that this pressure remains strong. Among those married adolescents who have ever been pregnant, the average duration of time between marriage and first pregnancy is 4.2 months, and the median is 2 months. The median age of first pregnancy is 17.6 years.

Further evidence of this cultural norm at work exists in the low levels of contraceptive use among this group of young women. Fewer than 16 percent of women who are not currently pregnant are using contraceptives ${ }^{6}$, and every single one of the contraceptive users has experienced at least one birth (range: 1-3 children). In other words, contraception is not used by married adolescents until after they have had their first birth. These low levels of use could also be evidence of the phenomenon documented by some researchers that physicians refuse to prescribe contraceptives (other than condoms) to married adolescents until they establish their fertility. Finally, it may indicate the need for information about the use of contraception for spacing births as well as for limiting them, and more information about the dangers of short birth intervals to both mother and child.

Perhaps not surprisingly, given the pressures on newly married young people to demonstrate their fertility, the EDHS found greater levels of contraceptive use among the older women in its sample. For example, 33 percent of women aged 20-24 and 48 percent of women aged 25-29 reported using a contraceptive method.

\section{Current Physiological Condition}

The distribution of the married adolescents by their current physiologic condition is as follows: 31 percent are currently pregnant, 31 percent are currently breastfeeding and are not pregnant, 37 percent are neither pregnant nor breastfeeding currently, and 1 percent are both pregnant and breastfeeding (Table 9.12).

\begin{tabular}{|c|c|c|}
\hline Current condition & Frequency & Percent \\
\hline $\begin{array}{l}\text { Pregnant } \\
\text { Breastfeeding } \\
\text { Pregnant and } \\
\text { breastfeeding } \\
\text { Neither pregnant nor } \\
\text { breastfeeding }{ }^{\star}\end{array}$ & $\begin{array}{c}93 \\
94 \\
4\end{array}$ & $\begin{array}{c}30.5 \\
30.8 \\
1.3\end{array}$ \\
\hline
\end{tabular}

The median number of pregnancies among adolescent women currently pregnant or with a past pregnancy experience is $1($ mean=1.36) and the median number of children among this group is also 1 (mean=0.7).

\footnotetext{
${ }^{6}$ This is consistent with the findings of the 1995 EDHS, which found an almost identical level of contraceptive practice among married adolescents aged 15-19.
} 
Although early pregnancy carries serious health risks to mother and child, proper antenatal care can reduce them. The early detection and subsequent management of health risks can improve outcomes significantly. A positive finding is that nearly 70 percent of currently pregnant adolescents have sought antenatal care, the majority of whom $(85.7 \%)$ made these visits during the first trimester of pregnancy (Table 9.13). Forty-four percent sought this care because they wanted a safe pregnancy, and 43 percent sought care because they had some health complaints. The mean number of antenatal care visits was 2.6 and the median was 2 (Table 9.14).

\begin{tabular}{lc|}
$\begin{array}{l}\text { Table 9.13: Timing of first antenatal } \\
\text { visit among currently pregnant women } \\
(\mathrm{N}=70)\end{array}$ \\
\hline & Percent \\
1st trimester & 85.7 \\
2nd trimester & 12.9 \\
3rd trimester & 1.4 \\
\hline
\end{tabular}

\begin{tabular}{|c|c|}
\hline 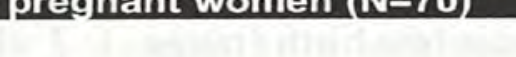 & Percent \\
\hline Safe pregnancy & 44.3 \\
\hline $\begin{array}{l}\text { Health complaints (fever, } \\
\text { fatigue, vomiting) } \\
\text { Others }\end{array}$ & $\begin{array}{l}42.8 \\
12.9\end{array}$ \\
\hline
\end{tabular}

\section{Pregnancy Outcomes of Married Adolescents}

More than 50 percent of the ever-married adolescents (158/316) report having had a previous pregnancy experience. The following analysis is restricted to this subsample who report a previous pregnancy.

A pregnancy can have three possible outcomes: live birth, miscarriage/abortion, or stillbirth. The levels of these pregnancy outcomes in a population are important indicators of the health of the mother and of the health facilities available to her. The level of miscarriage/abortion among the sample was calculated by subtracting the number of live births and stillbirths from the total number of previous pregnancies (total pregnancies - [live + stillbirths]). This calculation indicates that 14 percent of the sample (22/158) experienced a miscarriage or spontaneous abortion. A portion of this subgroup, 12 of 22 women (and slightly more than 7 percent of the entire subsample of 158) has never experienced delivery; that is, their only pregnancies ended in miscarriage (Table 9.15).

\begin{tabular}{|c|c|c|c|c|c|}
\hline Outcome & $\begin{array}{l}\text { Frequency } \\
\text { of outcome }\end{array}$ & $\begin{array}{c}\text { No. who have } \\
\text { had this } \\
\text { experience }\end{array}$ & $\begin{array}{c}\text { No. of } \\
\text { women } \\
\text { exposed }\end{array}$ & $\begin{array}{c}\% \text { who have } \\
\text { had this } \\
\text { experience }\end{array}$ & $\begin{array}{c}\text { Rate per } \\
1,000^{*}\end{array}$ \\
\hline Miscarriage & 29 & 22 & 158 & 13.9 & $137.4^{\mathrm{a}}$ \\
\hline Stillbi & 8 & 8 & 146 & 5.5 & $45.7^{b}$ \\
\hline Infant death & 13 & 11 & 143 & 7.7 & $74.3^{b}$ \\
\hline
\end{tabular}

*: Rate per $1,000=$ (frequency of outcome / total of relevant events) $\times 1000$

a: The denominator comprises total previous pregnancies (211) experienced by the 158 married women

b: The denominator comprises total live births (175) by 143 married women

Thus, 92 percent of this sub-sample (146/158) has experienced the delivery of a pregnancy. For these adolescents, two possible outcomes remain, either a live birth or a stillbirth. For the 
purposes of this survey, a stillbirth was defined as "a baby delivered showing no signs of life". More than 5 percent of the sample (8/146) report having had a stillbirth; that is, slightly less than 95 percent of those adolescents who have experienced delivery have had a successful delivery. Furthermore, 8 percent of the group of women who had a live birth (11/143) report that they have had at least one infant death. These figures translate into rates of 46 stillbirths per 1,000 live births and 74 infant deaths per 1,000 live births among the married adolescents. The time reference for these rates extends over the period 1993-1997 (approximately over the four years preceding the survey).

While the ASCE sample is small, these rates are extremely high, compared to the outcomes usually experienced by women in their $20 \mathrm{~s}$, who are thought to be in the best condition for childbearing. For example, the 1995 EDHS found a rate of infant death among married women aged $20-29$ to be 66 deaths per 1,000 live births during the period 1985-1995. Since the estimate of infant mortality among married adolescents refers to a more recent period than the EDHS estimate and also since infant mortality in Egypt has been declining sharply since the mid-eighties, a more recent estimate of infant deaths among women in the age group 20-29 should be even less than 66 per 1,000 live births, widening the gap between them and married adolescents even further. Thus childbearing during adolescence in Egypt is a risky undertaking. This underscores the importance of delaying marriage and childbearing, particularly in the presence of other socioeconomic or health problems.

\section{Delivery Experiences of Married Adolescents}

Adolescents were asked to report on where they delivered their most recent pregnancy and who assisted them at delivery. Tables 9.16 and 9.17 present the findings. The ASCE survey found that 66 percent of married adolescents give birth at home. Dayas (traditional birth attendants) and physicians were most frequently reported as the birth attendants assisting

\begin{tabular}{|c|c|}
\hline $\begin{array}{l}\text { Place of delivery } \\
\text { Home } \\
\text { Hospital/clinic }\end{array}$ & $\begin{array}{l}\text { Percent } \\
66.4 \\
33.6\end{array}$ \\
\hline
\end{tabular}
with delivery regardless of location of delivery ( $48.6 \%$ and $44.3 \%$, respectively). Given that the Child Law of 1996 made it illegal for non-physicians, except those who are registered as midwives or assistant midwives, to attend deliveries by adolescents, it is perhaps not surprising that these figures are somewhat lower than those found by the 1995 EDHS ( $54.6 \%$ by a daya and $33.9 \%$ by a physician). However, nearly half of all adolescent pregnancies reported by the ASCE sample are still being delivered by traditional birth attendants. Interestingly, though, doctors are also found to be assisting with home deliveries; Table 9.17 shows that 17.2 percent of home deliveries were assisted by a doctor. 


Table 9.17: Who assisted at delivery of most recent pregnancy
\begin{tabular}{|lcccccc|}
\hline $\begin{array}{l}\text { Place of } \\
\text { delivery }\end{array}$ & Daya & $\begin{array}{c}\text { Mother-in- } \\
\text { law }\end{array}$ & $\begin{array}{c}\text { Midwife } \\
\text { unit }\end{array}$ & Doctor & No one & Total \\
$\begin{array}{l}\text { Home } \\
\text { Row \% }\end{array}$ & 68 & 4 & 4 & 16 & 1 & 93 \\
$\begin{array}{l}\text { Hospital } \\
\text { or clinic }\end{array}$ & 73.1 & 4.3 & 4.3 & 17.2 & 1.1 & 100.0 \\
$\begin{array}{l}\text { Row \% } \\
\text { Total }\end{array}$ & 68 & & 1 & 46 & & 47 \\
$\%$ & 48.6 & 4 & 2.1 & 97.9 & & 100.0 \\
\end{tabular}

\section{Breastfeeding Practices Among Adolescent Mothers}

Early initiation of breastfeeding after delivery has many benefits for both the mother and the infant, which include widely known immunological benefits to the infant. Equally important is the duration of breastfeeding; medical literature recommends that the optimal duration of breastfeeding is 2 years. We examined the breastfeeding practices among ever-married adolescents who reported having given birth and who were able to recall the birthdate of the child. Among this group, 97 percent (116/119) reported birthdates within a period of 2 years. To minimize recall bias, the following analysis is restricted to this group.

The pattern of breastfeeding initiation for all women who report breastfeeding (currently or in the past) was as follows: 46 percent started breastfeeding less than one hour after delivery, 15 percent after a period of longer than one hour after delivery but less than one day, and onethird, or 35 percent, started at least one day after delivery. The slow initiation of breastfeeding should be a focus of concern for those involved in mother-child health programs (Tables 9.18 and 9.19).

\begin{tabular}{|c|c|c|}
\hline Current status & No. & Percent \\
\hline Currently breastfeeding & 97 & 83.6 \\
\hline $\begin{array}{l}\text { Not currently } \\
\text { breastfeeding } \\
\text { Total }\end{array}$ & $\begin{array}{c}19 \\
116\end{array}$ & $\begin{array}{c}16.4 \\
100.00\end{array}$ \\
\hline
\end{tabular}

\begin{tabular}{|c|c|}
\hline Breastfeeding initiation & Percent \\
\hline Within one hour of delivery & 45.7 \\
\hline $\begin{array}{l}\text { More than an hour but less than } \\
\text { one day postdelivery } \\
\text { More than one day postdelivery }\end{array}$ & $\begin{array}{l}14.8 \\
34.5\end{array}$ \\
\hline
\end{tabular}

Because only 19 women in this group were not currently breastfeeding at the time of the survey $(16.4 \%)$, the data on the duration of breastfeeding is based on this small number of women who have initiated and stopped breastfeeding. However, among those who were not currently breastfeeding, the average duration of breastfeeding was 8.4 months (median, 5 months) and the range was 1-21 months. 


\section{CONCLUSION}

Although adolescent marriage is becoming less frequent in Egypt, it is still common enough to be of serious concern. Moreover, as education and employment opportunities expand for women and the age of marriage continues to increase, married adolescents are becoming an increasingly selective and disadvantaged group. The preceding analysis makes it clear that married adolescent women are seriously disadvantaged vis à vis their never-married peers. This is true for nearly all dimensions that will shape the opportunities and resources available to them and, by extension, to their children.

Although married adolescents comprise only a small proportion of adolescents in Egypt, their real numbers are large. Given the serious consequences of early marriage and childbearing for these young women and their children, public officials and communities must not simply wait for the problem to disappear on its own. 


\section{Some Implications for Advocacy and Action}

This report offers a comprehensive overview of adolescent life in Egypt today. The outlook for adolescents contains both positive and negative elements. On one hand, the survey found that enrollment in schools has been increasing and that some persistent gend er disparities in health and education are narrowing. On the other hand, the ASCE survey identified widespread anemia and parasitic infection among adolescents from a wide range of backgrounds, as well as significant growth stunting. The study found fewer married adolescent women than expected, but determined that they are a very disadvantaged group with extremely poor pregnancy outcomes.

We must treat the problems we have identified with the same holistic perspective we used to investigate adolescence. Interventions to improve school performance, for example, will be less effective if factors outside of the school environment, such as an adolescent's health status or need to work, are not also addressed. In some cases, further research is needed to evaluate effective pilot interventions. In other areas, needed actions are clear. Based on the study findings, the study team has outlined some recommendations for policy and program action below. Though they are mostly separated here by sector for purposes of clarity, they should be regarded as a complete package of recommendations for implementation across all sectors if they are to successfully address the problems outlined.

\section{HEALTH PRIORITIES}

\section{Anemia And Parasites}

The interrelated problems of anemia and parasitic infections are the most prevalent health conditions among adolescents. While the greatest impact can be seen among poorer adolescents and those in rural areas with poor infrastructure, these conditions cut across all geographic regions and are surprisingly common even among well-off adolescents.

Thus nutrition and hygiene education campaigns would be important first steps in eradicating these problems. Obvious target audiences include adolescents and parents, as well as health providers and pharmacists, given the frequent utilization of their services by adolescents. Messages should be tailored to each of these target audiences and careful attention should be paid to making the messages comprehensible and meaningful to people without a health background.

The campaign should address the importance of and the components of a healthy diet (emphasizing in particular those foods rich in iron), the way that fruits and vegetables can facilitate the absorption of iron, and how drinking tea after meals can interfere with iron 
absorption. Other messages to prevent parasitic infection should address the importance of hygienic practices, even in the absence of running water or sewerage connections. Parents should be informed of these widespread health problems and encouraged to help their children develop healthy behaviors.

Given the high exposure to the mass media reported by all adolescents (including those out of school, in rural areas, and from lower-income households), the media could be an effective tool to reach very large numbers of adolescents. Parents and health care providers might also be reached through the media, but focus group research should be done to determine the most effective ways to reach these target audiences.

Health messages should be carefully developed to inform and motivate adolescents. Campaigns in other countries have used sports figures and other celebrities to promote healthy behaviors. Given the popularity of football (soccer) in Egypt and the notoriety of the national team after winning the 1998 Africa Cup, perhaps one of the stars of the national team could be contracted to participate in such a campaign. Egypt also has world class athletes (in water ballet for example) who could be utilized to encourage girls' sports participation, as well as good nutrition and hygiene.

Schools are another systematic way to reach young people, given the increasing enrollment rates in Egypt. Increased attention to health and hygiene messages in the curriculum throughout the schooling process would be one way to reach young people with important health messages. The School Health Insurance System (SHIS) is another avenue for reaching adolescents with preventive care messages. Deworming and iron supplements should both be provided routinely through the SHIS. In addition, nutrition and hygiene education that draws attention to the prevalence of these conditions can help lower their incidence among in-school adolescents.

An education campaign could be supported by a national effort to provide subsidized iron tablets. Another role of the education campaign, then, would be to direct people to outlets from which they could get iron tablets and cures for parasitic infection. At the same time, policymakers should be planning for the longer-term goal of providing water and sanitation infrastructure to underserved communities. Studies are needed to evaluate the impact and cost effectiveness of these programs.

Treating chronic yet common health conditions will make not only for improved wellbeing among adolescents but also increased productivity, scholastic performance, and retention in school.

\section{Health Care System and Services}

The private sector was found in this survey to be the main provider of health services to adolescents, in spite of the availability of the SHIS and other government services. As health section reforms progress, these findings need to be considered carefully. Developing an effective delivery point for adolescent health services would not only improve the wellbeing of this age group but would allow the government to allocate and utilize its limited resources 
more efficiently. The following points should be considered in order to establish an effective, integrated health care package for this age group, within a family health context.

The first issue that must be considered is the appropriate entry point for this age group into the health service system. As noted above, this survey found the private sector to be the most commonly utilized service provider among adolescents. However, the parallel SHIS could serve about two-thirds of this population, those who are enrolled in school. Although our survey has shown a low level of SHIS utilization, it is still a wide-reaching system that could be made more effective. The SHIS should begin by focusing on widespread heath conditions such as anemia and parasites among in-school adolescents.

The Ministry of Health might consider establishing and adolescent health service package in within the primary health care sector. This could be done economically by specifying one day per week when specially trained staff would be available to see adolescents. The entry point to the SHIS might also become the Primary Health Care sector, as it is for Infant Health Insurance. In the interest of equity among members of this age group (vis à vis school enrollment status), this would be an effective way to reach adolescents who are out of school and who may be in greater need of health care services.

Any restructuring of the health sector to better reach adolescents will require some reallocation of personnel and a close examination of job descriptions and necessary skills at the primary health care level. For example, one common reason cited for not using the SHIS was the unavailability of the school doctor, often due to the fact that doctors are in charge of more than one school. Ensuring that a trained provider is available in each school during the entire school day may be one way to increase the currently low utilization of the SHIS. Moreover, providers serving adolescents should be specially trained to work with this age group. Adolescents have greater information and counseling needs and problems unique to this life stage; providers must be able to respond to those needs and make adolescents feel comfortable.

\section{The School Health Environment}

Much more could be done to make schools into healthy learning environments for young people. In addition to improving school health services, attention should also be paid to other school-based services and facilities to create such an environment and to ensure that the school provides the space and a model for healthy living.

For example, given the high levels of smoking found among boys in this survey, a campaign to promote "smoke-free schools" could be organized, encouraging all adults and students to refrain from smoking on school grounds. Such a campaign would emphasize the value of a smoke-free environment but also encourage healthy behavior among young people.

Attention to other services and facilities is also required to create a healthy environment. For example, very few girls report using the school toilet facilities during menstruation, clearly indicating the need for improved privacy, hygiene, and availability of these facilities. 
Improvements in opportunities for physical activity are also needed in schools (and elsewhere), particularly for girls. Physical activity (other than through domestic chores) is an important component of a healthy lifestyle. However, this survey found that very few adolescent girls in Egypt get any physical activity and rarely frequent sports facilities. In fact, only 5 percent reported any physical activity during the week prior to interview. In other developing countries, increasing opportunities for physical activity among girls has demonstrated clear positive effects on self-esteem, confidence levels, stress reduction, and overall health and well-being (Jaffe and Manzar 1992).

Schools should be active in promoting physical activity among all adolescents, but especially among girls. Because of mobility restrictions, girls have fewer venues for physical activity available to them. Of those girls who report any physical activity, most play at schools. Thus schools are already considered by parents as appropriate locations for girls; schools should go further to encourage physical activities for girls under conditions that would be acceptable to both girls and their parents. Moreover, official agencies and NGOs should invest more in appropriate sports facilities for girls.

\section{EDUCATION}

Although school enrollment is increasing in Egypt, more effort should be made to increase community and parental awareness of the importance of education for both sexes, but especially for girls in rural areas and Upper Egypt. Focus should be placed on getting both girls and boys enrolled early in the system before they miss the cut-off age for primary enrollment. Because of the sensitivity of girls' (and boys') enrollment and retention to economic factors, scholarships should be made available to low-income families to help them with school fees and focus on primary and middle school ages.

With economic conditions changing rapidly in Egypt, the school curriculum should be more directly linked to the job market and future economic roles. A number of survey findings make this need very clear. Both parents and children cite increased social status as the main value of education rather than future economic benefits. Furthermore, boys in urban areas have higher dropout rates than other boys, presumably because there are more opportunities for them to engage in economic activity. If vocational training were better integrated into the schooling system, the schooling process would be more relevant to adolescents' future economic roles.

With enrollment and retention levels increasing steadily, more attention can now be paid to improving the quality of education, both in terms of achievement levels and the schooling process. Performance (the outcome measure of education) is still low overall, indicating that students are emerging from school ill-equipped for the challenges of employment or participation in democratic society. Furthermore, the most common reason reported for school drop-out among adolescents is poor performance. Once adolescents drop out of school, they risk losing the skills they did acquire and have few opportunities to acquire the ones they did not. Much could also be done to improve the schooling process to make it more 
engaging, interactive, and student-centered than it is presently. Just as health conditions are most effectively targeted at an early age, so too achievement and quality of education would be most effectively addressed by policy beginning at the primary stage.

\section{Literacy Classes}

Literacy classes have been largely unsuccessful in reaching those adolescents who have dropped out of school. More research is needed to determine the reasons behind this failure, perhaps due to program content, inappropriate scheduling, or the social perceptions young people have about attending literacy classes. Literacy training could be integrated into activities with wider appeal to youth, including income generation, sports, and skills training.

\section{EMPLOYMENT}

Because many adolescents are earning well through their work, better incentives are needed to influence decisions in favor of education. A stronger link between the school curriculum and the job market would help to weight these decisions in favor of increased education. As previously mentioned, vocational training and/or other job training should also be closely integrated into the education system. Even though working adolescents are earning well, they are working long hours in work environments that are hazardous to their health and safety. The minimum legal age for work and length of the working day should be enforced, and the safety of the workplace should be regularly inspected. Since these are difficult tasks for official agencies, a greater role could be played by community groups in monitoring the health and safety of working youth.

The large numbers of unmarried young women who are not in school and not working suggests a serious underutilization of their time. Work opportunities should thus be expanded for this group of older girls to give them more productive opportunities and access to resources. This will enhance their standing in the family and help them to resist being pressured into early marriage. Effective vocational training programs can target unmarried adolescent girls who have already left school. Other livelihoods programs should aid lesseducated girls in finding appropriate work or setting up their own small businesses.

\section{REPRODUCTIVE HEALTH}

Adolescents do not have enough necessary information about their bodies, maturation, or other aspects of reproductive health to help them through adolescence successfully and prepare them for future reproductive roles. They would like this information to come from parents, but there is little dialogue between parents and their children on these issues, probably due to lack of parental knowledge and cultural taboos.

Moreover, because there is little information on these topics available from reliable media sources or the school curriculum, most adolescents report that what knowledge they do have has been learned on their own or through observation. Experiences elsewhere have shown that much of the information acquired in this way is inaccurate and thus potentially harmful. 
NGO and public programs should target both girls and boys with information about this lifestage, while also equipping parents with knowledge and communication skills. Schools could also play a role in helping adolescents through this tumultuous period of their lives, by providing information at appropriate ages and counseling services utilizing specially trained providers, as well as teaching good communication skills. Schools can also assist girls in the management of their menstruation by upgrading toilet facilities.

\section{MARRIED ADOLESCENTS}

Although adolescent marriage is becoming less frequent in Egypt, it is still common enough to be of serious concern, especially because pregnancy usually occurs almost immediately after marriage. Given the extremely poor pregnancy and birth outcomes among this group of young women, public officials and communities must not simply wait for the problem to disappear on its own.

Many of the women who marry during adolescence have never attended school or have dropped out at an early age. Consequently, emphasis should continue on enrolling girls in school and retaining them for as long as possible. Expanding work opportunities for unmarried out-of-school girls could help to delay marriage, as well as provide them with more resources and productive opportunities. Communities and public officials also should place more emphasis on the enforcement of the legal minimum marriage age restriction already in place. Egypt may consider raising the legal marriage age for girls, as have a number of other developing countries.

For young women who do get married during adolescence, the high likelihood of an immediate pregnancy puts them and their children at increased risk of illness and death. More effort should be placed on campaigns for increasing awareness of the negative health implications of early childbearing, particularly among parents, future husbands, and community opinion leaders. Moreover, the widespread practice of discouraging young married couples from using contraceptives should be addressed through education on the health benefits of delaying a first birth and of birth spacing. Egyptian families might be less likely to encourage early marriage and immediate childbearing if they are more aware of the attendant risks.

Failing that, program emphasis should be placed on the importance of monitoring pregnancy at the local Maternal and Child Health $(\mathrm{MCH})$ unit. Close supervision could at least help to reduce some of the risks of childbearing during adolescence.

One promising means to target this group is through the ma'zoun, the civil and religious official who draws up and registers the marriage contract. Special training should be organized for ma'zouns on the medical risks of early childbearing, which typically follows marriage almost immediately. An initiative could also be undertaken with the ma'zoun to link the couple up with the health care system. He could register them at the local health and/or $\mathrm{MCH}$ unit, or advise them of its presence so that they visit it on their own initiative. Programs of 
pre-marital counseling, successfully implemented elsewhere in the region, could be adapted for the Egyptian context.

Because the phenomenon of adolescent marriage exists in specific pockets around the country, particularly rural Upper and Lower Egypt, effective outreach to married adolescents could be done effectively through localized campaigns with carefully targeted messages.

\section{CONCLUSION}

To face the major challenge of improving adolescent wellbeing, integrated investments in health, education, and job preparation are needed. Fortunately, Egypt has an emerging alliance between key government agencies, NGOs, and researchers committed to implementing a national strategy in the field of adolescent health. Several promising initiatives are addressing the needs of adolescents for reproductive health information and services, as well as campaigning to eliminate the practice of female circumcision. These partnerships can be extended to other fields by including a broader group of government agencies and the private sector. An investment in adolescent wellbeing now will confer substantial benefits on Egypt in future decades. 


\section{Data Gathering, Processing, and Management}

\section{Field Operations Managers}

Ms. Zeinab Gamal

Mr. Esmat Kheir

\section{FieLd SUPERVISORS}

Etimad Abdel Rahim El Sherif, Assistant Lecturer

Manal Mohamed Mostapha Darwish, Demonstrator

Magdi Benyamin Mina Boulos

Sabra Mohamed Ahmed

Mohamed Adam

\section{Field Work TEAM}

Abeer Ahmed Makawi

Abeer Imam

Ahmed Abdel-Fattah

Ahmed Fathy El-Shallah

Ahmed Galal

Ahmed Hamed Fahmy

Ahmed Salah

Ahmed Shoura

Amal Abdel-Rahman

Amal Refaat

Amira Yaseen

Ashraf Sayed

Azza Mostafa Mahmoud

Dalal Ibrahim

Ghada Abdallah

Hamida el-Shahat

Hamida Mahfouz

Hanaa Abbas

Hassan Abdel-Sattar

Heba Fathy

Howayda Abou el-Wafa

Ihab Zakarya

Ikbal Abdel-Naby

Ilham Hassan

Iman El-Kashef
Iman Salah

Khadiga Mahmoud

Khaled Said

Lamyaa Soliman

Mahmoud Shehata

Maisa Abdouh

Manal Abdel-Aziz

Manal Abdel-Hafiz

Marcel Botros

Moaz Ibrahim

Mohamed Abdel-Fattah

Mohamed Atteyat-Allah

Mohamed Mortada

Mohamed Rizk

Mona Abdel-Aziz

Mona Hefzy

Mona Mohamed Mohmoud

Mona Samy

Nadia Gaber Bishr

Nagwa Mohamed Abdel-Fattah

Nesiba Khalil

Samah Abdel-Rehim

Sameh Zein

Sherine Ismail

Sherine Yousef 
Tahseen Ibrahim

Tamer Mohamed Nabil

Wael Mohamed Hussein

OfFice Operations AND Coding

Mohamed Amin

Zeinab Aly

Iman Farouk

Abeer Fikry

Programmers

Amal Sakr

Sahar el-Sheneity

DAta EnTRy

Hanaa Mohamed Sanad

Iman Hamed Fahmy

Amr Shoukry

Motaz Fateh-El-Rahman
Walid Saber

Yaser Eid

Zeinab el-Demerdas

Data Processing

Dr. Hanan Ali Hassan

Dr. Zakarya Abdel Samei

Dina Magdy

Alyaa Zahran

Mayada Aref

Rania Sakr

Tahra Abdel-Latif

\section{Additional Data Processing}

El-Daw Abdallah, Social Research Center, The American University in Cairo (AUC)

Wesley Clark, The Population Council, New York

\section{Clinical Examiners, Ministry of Health and Population}

Adel Ali Ali Ismail

Ali El-Sayed

Angele Wadie Sourial

Azza Hamdi Hassan El-Ghandour

Gamal Aboul Maati Salih

Hani Rashid Geid

Hassan Ali Saad Salem

Hossam el Din Ibrahim el Khaligi

Hossam el Din Ibrahim el Naggar

Ibtisam Ibrahim el Desouky

Inas Helmi Farghali

Inas Mahmoud Samy

Itimad Adel-Rahim El-Sharif

Leila Soliman

Magdi Benyamin Mina

Manal Mohamed Mostapha Darwish

Marcele Michel Georgy

Mohamed Adam

Mohamed Ihsan Abdella el-Aowmary
Mossad Melihi Mohamed Deeb

Mostapha El-Eoussy El-Teras

Nader Shawgi Demian Abdel-Shahid

Nagwa Abdel-Latif El-Ishari

Nahla Abdle-Khalek Hassan

Nahla Khamis Ibrahim

Nasra Sayed Mohamed El-Haggan

Nevine Khattab Hossam El-Din

Noha Ahmed Mohamed Darwish

Sabra Mohamed Ahmed

Salah El-Din Ali El-Sayed

Salwa Fayez Fedeil

Sanaa Ali Mohamed Sharaf

Samiha Abdel-Dayem Mohamed Abdel-

Dayem

Taha Mohamed Abdel-Tawab

Tharwat Wanis Nakhla

Wagdi Farouk Abdel-Razik 


\section{Consultants and Reviewers}

Development and grading of tests in Arabic and Mathematics

Dr. Mostafa Abdel-Samei, Cairo University

Dr. Ibrahim el-Shafei, Cairo University

Supervisor of urine and stool sample analysis

Dr. Amel Abdel Fatah el Sahn, High Institute of Public Health, Alexandria University

Consultant Psychologist during instrument development:

Dr. Jawad Fatayer, The American University in Cairo

\section{Senior Advisors, Research Design}

Dr. Cynthia Lloyd, The Population Council, New York

Dr. Barbara Mensch, The Population Council, New York

Dr. Ali Zarzour, Assiut Univerisy

\section{Reviewers}

Dr. Josette Abdallah, The American University in Cairo

Dr. Leila el-Zeini, Cairo University

Dr. Mahmoud Fathalla, Assiut University

Dr. Ron Hess, Center for Communication Programs, Johns Hopkins University

Dr. Cynthia Lloyd, The Population Council, New York

Dr. Zeba Sathar, The Population Council, Pakistan 


\section{APPENDIX II}

\section{National Senior Advisory Committee}

Dr. Moushira el Shafei

H. E. Prof. Dr. Maher Mahran

Eng. Mohamed Ragab Sharaby

Dr. Abdel Latif Heneidy

Dr. Esmat Mansour

Dr. Wagida Anwar

Mr. Ahmed Lotfy

Dr. Ali Zarzour

Dr. Amina el Guindi

Ms. Arlette Osseiran

Mr. A/Muneim Abu Nuwar

Mr. Earl Wall

Ms. Eman Omran

Ms. Hala Shenouda

Dr. Hoda Rashad

Mrs. Ines El Ibrachi

Dr. Jocelyn De Jong

Ms. Julie Hanson-Swanson

Dr. Kamal Lolah

Dr. Leila Bisharat

Ms. Magy Mahrous

Dr. Mahmoud Fathalla

Dr. Mahmoud Gamal el Din

Ms. Marie Assaad

Ms. Marike Boot

Mr. Martin Soutter

Ms. Mellon Tanamly

Mr. Nabil Samuel

Dr. Nadia Gamal

Ms. Naella Refaat

Ms. Sahir Abul Hadi

Ms. Sally Patton

Ms. Vanesa Tobin

Ms. Wafaa William
Ministry of Health and Population

National Population Council

Ministry of Education

Center for Public Mobilization and Statistics (CAPMAS)

Ministry of Health and Population

Ministry of Health and Population

Youth Association for Population and Development

Faculty of Medicine, Assiut University

National Council for Childhood and Motherhood (NCCM)

The Netherlands Embassy

United Nations Population Fund (UNFPA)

CARE International

Canadian International Development Agency (CIDA)

Canadian International Development Agency CIDA

Social Research Center / The American University in Cairo

United Nations Education, Social, and Cultural Organization

The Ford Foundation

Centre for Development and Population Activities (CEDPA)

National NGO Commission for Population and Development (NCPD)

United Nations Fund for Children (UNICEF)

CARE International

Rockefeller Foundation / Assiut University

The World Bank

NCPD / FGM Task Force

The Netherlands Embassy

Canadian International Development Agency (CIDA)

United States Agency for International Development (USAID)

Coptic Evangelical Organization for Social Services (CEOSS)

Program Planning and Monitoring Unit (PPMU)

Canadian International Development Agency (CIDA)

UNFPA

United States Agency for International Development (USAID)

United Nations Fund for Children (UNICEF)

Coptic Evangelical Organization for Social Services (CEOSS) 


\section{List of Primary Sampling Units (shiakhas and villages) by Governorate}

Governorate

Cairo

Alexandria

Port Said

Suez

Damietta

Dakahlia

Sharkia

Kalyubia Madinet Kalyub

Kafr el Sheikh Madinet Kafr el Sheikh

Madinet Abu Hamad

Madinet Abu Kebir

Bigam

Bahteem

Villages

Ain Shams el Sharkia

Arab Abu Tawila

Minyat el Sirg

Masaken el Zawya el Hamra

Hadaek el Kobba

Masaken el Amireya el Shamaleya

El Mabyada

El Sakakini

Taht el Rabe

El Atris

El Basateen el Sharkia

Tora el Balad

Kafr el Elo

El Mandara Kebly

Sidi Bishr Kebly

Tolombat el Tabia

Sidi Gaber

El Ibrahimia Bahari

El Bab el Gedid And Menasha

El Galaa

Kism Thaleth

Madinet Dekernes

Kafr Mit Abu Ghaleb

El Maasara

Manshiet Gamal

Mit el Koramaa

Shubrahur

El Mandara

Diarb el Khodr

El Soufia

Senita el Refaeyeen

Abu Yaseen

Bani Amer

Kamrouna

Arab el Rawashda

Balaks

Shablanga

Manshiet Abas

El Halafi

Ezab el Khalig el Bahari 


\begin{tabular}{|c|c|c|}
\hline \multirow[t]{4}{*}{ Gharbia } & Kism Tani (Tanta) & Saft Torab \\
\hline & Kism Tani (el Mahalla el Kobra) & El Gaafaria \\
\hline & & Benofar \\
\hline & & Senebara \\
\hline \multirow[t]{4}{*}{ Menoufia } & Madinet Ashmoun & Tanoub and Manshiet el Salam \\
\hline & & Manshiet Asem \\
\hline & & Telwana \\
\hline & & Tanbesha \\
\hline \multirow[t]{6}{*}{ Behera } & Madinet Damanhour (Tamous) & El Khadra \\
\hline & Madinet Damanhour (Nakraha) & El Gorn and Kafr Hosam \\
\hline & & Manshiet Ghorbal and el \\
\hline & & Basateen \\
\hline & & Zohour el Omaraa \\
\hline & & Bastara \\
\hline Ismailia & & Sarabioum \\
\hline \multirow[t]{4}{*}{ Giza } & El Dokki & El Kebabat \\
\hline & Gezirat Imbaba & El Torfaya \\
\hline & Gezirat el Dahab & Abu Ghaleb \\
\hline & Madinet Oseem & \\
\hline \multirow[t]{3}{*}{ Beni Suif } & Madinet Beni Suif & Kom Abu Radi and Sidi Salem \\
\hline & & Kafr Gomaa and el Fakaei \\
\hline & & Nazlet Hana Hana \\
\hline \multirow[t]{2}{*}{ Fayoum } & Madinet el Fayoum (Kism Awal) & El Tawfikia \\
\hline & & El Khaledia \\
\hline \multirow[t]{4}{*}{ Minia } & Madinet el Minia (Kism Rabei) & Gezirat Sharouna \\
\hline & & Sila el Sharkia \\
\hline & & Manshiet el Dahab el Baharia \\
\hline & & Rida \\
\hline \multirow[t]{3}{*}{ Assiut } & Madinet Dayrout & El Atamna \\
\hline & 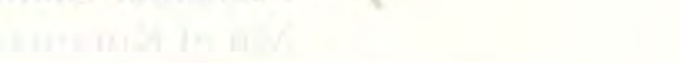 & Gahdam \\
\hline & & Bani Mohamed el Shahabia \\
\hline \multirow[t]{4}{*}{ Sohag } & Madinet el Menshat & Fazara \\
\hline & & El Sheikh Makram \\
\hline & & El Bawareek \\
\hline & & El Sheikh Marzouk \\
\hline \multirow[t]{3}{*}{ Qena } & Madinet Armant & Awlad Negm el Keblia \\
\hline & & El Towayrat \\
\hline & & Danfeek \\
\hline Aswan & Madinet Aswan (Shiakha Oula) & $\begin{array}{l}\text { El Mahameed } \\
\text { El Hegz Bahari }\end{array}$ \\
\hline
\end{tabular}




\section{APPENDIX IV}

\section{Quality of the Data}

Due to the innovative nature of the study and the complexity of the sampling design, it was important to assess the quality of the data collected. Three main concerns are: The accuracy of reporting the age of the adolescent, the level and pattern of response rates, and the impact of non-response on the overall quality and representativeness of the sample (discussed in Chapter 3). The results of this investigation should be taken into consideration in the presentations and discussions in this document.

\section{THE ACCURACY OF AGE REPORTING}

Figure 1 displays the age distribution of individuals 9-20 years in all sampled households screened for the purposes of the survey. The results indicate that some of the eligible adolescents, aged 10 or $18-19$, were probably shifted to the ages of 9 and 20 respectively, making them ineligible for selection and interview. The process of smoothing the age-curve results in an increase in the number of eligible adolescents in screened households by about 700. Assuming the same response rate, the size of the core sample of adolescents successfully interviewed should have been higher by $400-500$ cases, comprising less than 5 percent of those actually interviewed. The sub-sample subjected to the second interview using the health instrument followed by the clinical examination and collection of specimen of urine and stool lost about 100-125 cases due to inaccurate reporting of age. The loss is divided almost equally between the ages 10 and 18-19. As a result, the number of adolescents in the age range 16-19 in the health sub-sample is reduced by 8 percent. For all reported ages above 20, age-heaping at figures ending with zero or five is evident. All results involving the age of responsible adults are grouped into five-year age groups.

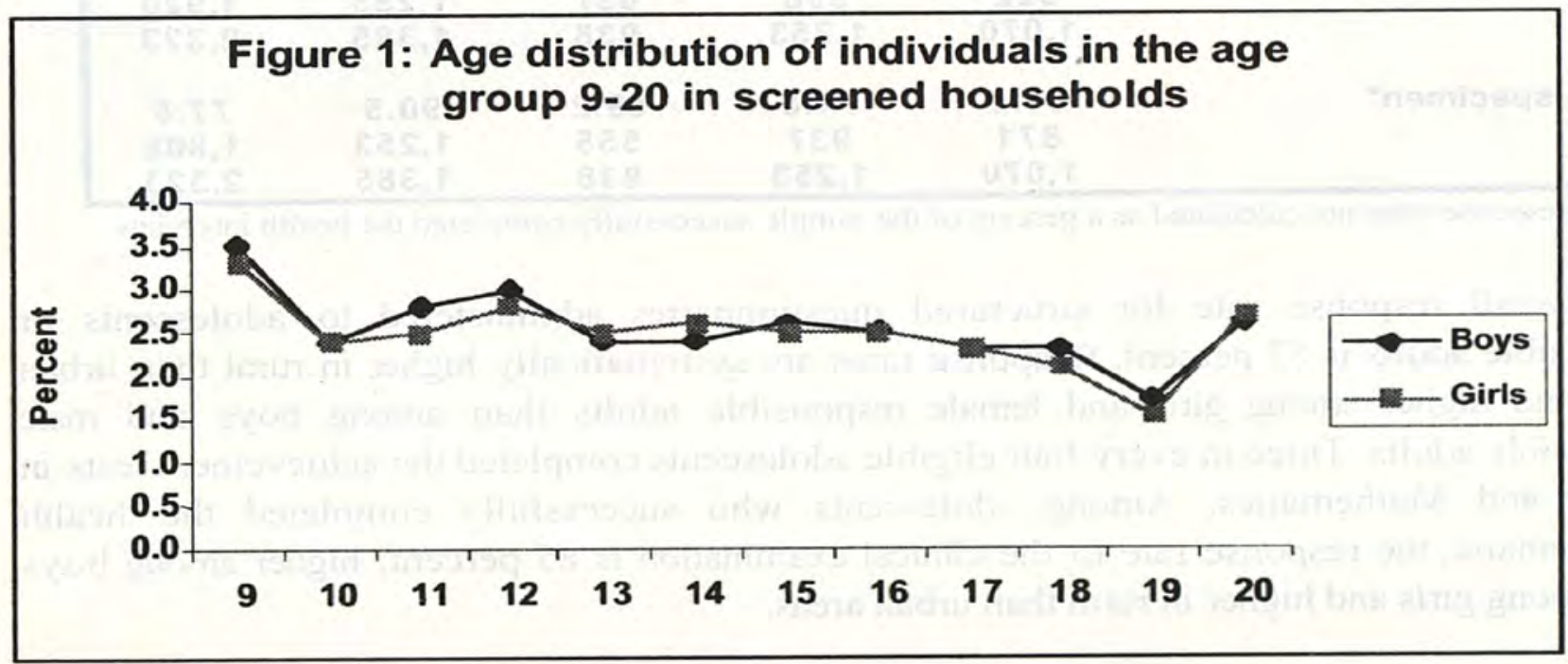




\section{LEVEL AND PATTERN OF RESPONSE RATES}

Table 1 provides the response rate, the number of adolescents successfully interviewed and the number originally selected by type of instrument, sex of respondent, and urban/rural type of residence.

\begin{tabular}{|c|c|c|c|c|c|}
\hline & Males & Females & Urban & Rural & Total \\
\hline $\begin{array}{l}\text { Core adolescent } \\
\text { questionnaire }\end{array}$ & $\begin{array}{l}82.1 \\
4,354 \\
5,303\end{array}$ & $\begin{array}{c}89.7 \\
4,774 \\
5,323\end{array}$ & $\begin{array}{l}82.7 \\
3,659 \\
4,423\end{array}$ & $\begin{array}{l}88.2 \\
5,469 \\
6,203\end{array}$ & $\begin{array}{c}86.0 \\
9,128 \\
10,626\end{array}$ \\
\hline $\begin{array}{l}\text { Health sub-sample } \\
\text { questionnaire }\end{array}$ & $\begin{array}{l}80.7 \\
1,070 \\
1,326\end{array}$ & $\begin{array}{l}94.2 \\
1,253 \\
1,330\end{array}$ & $\begin{array}{c}84.8 \\
938 \\
1,105\end{array}$ & $\begin{array}{l}89.3 \\
1,385 \\
1,550\end{array}$ & $\begin{array}{l}87.5 \\
2,323 \\
2,656\end{array}$ \\
\hline Achievement test in Arabic & $\begin{array}{l}73.3 \\
1,858 \\
2,536\end{array}$ & $\begin{array}{l}80.3 \\
1,855 \\
2,310\end{array}$ & $\begin{array}{l}71.4 \\
1,534 \\
2,149\end{array}$ & $\begin{array}{l}80.8 \\
2,179 \\
2,697\end{array}$ & $\begin{array}{l}76.6 \\
3,713 \\
4,846\end{array}$ \\
\hline $\begin{array}{l}\text { Achievement test in } \\
\text { Mathematics }\end{array}$ & $\begin{array}{l}75.2 \\
1,908 \\
2,536\end{array}$ & $\begin{array}{c}81.6 \\
1,884 \\
2,310\end{array}$ & $\begin{array}{c}72.0 \\
1,548 \\
2,149\end{array}$ & $\begin{array}{l}83.2 \\
2,244 \\
2,697\end{array}$ & $\begin{array}{l}78.3 \\
3,792 \\
4,846\end{array}$ \\
\hline $\begin{array}{l}\text { Responsible adults } \\
\text { questionnaire }\end{array}$ & $\begin{array}{l}82.6 \\
3,274 \\
3,965\end{array}$ & $\begin{array}{l}93.1 \\
2,939 \\
3,157\end{array}$ & $\begin{array}{l}83.5 \\
2,552 \\
3,056\end{array}$ & $\begin{array}{l}90.0 \\
3,661 \\
4,066\end{array}$ & $\begin{array}{l}87.2 \\
6,213 \\
7,122\end{array}$ \\
\hline Clinical examination* & $\begin{array}{c}88.7 \\
949 \\
1,070\end{array}$ & $\begin{array}{l}82.7 \\
1,036 \\
1,253\end{array}$ & $\begin{array}{l}71.0 \\
666 \\
938\end{array}$ & $\begin{array}{c}95.2 \\
1,319 \\
1,385\end{array}$ & $\begin{array}{l}85.4 \\
1,985 \\
2,323\end{array}$ \\
\hline Test for anemia* & $\begin{array}{c}88.2 \\
947 \\
1,070\end{array}$ & $\begin{array}{c}82.3 \\
1,033 \\
1,253\end{array}$ & $\begin{array}{l}71.0 \\
668 \\
938\end{array}$ & $\begin{array}{c}94.5 \\
1,312 \\
1,385\end{array}$ & $\begin{array}{l}85.0 \\
1,980 \\
2,323\end{array}$ \\
\hline Urine specimen ${ }^{\star}$ & $\begin{array}{c}86.2 \\
922 \\
1,070\end{array}$ & $\begin{array}{c}79.6 \\
998 \\
1,253\end{array}$ & $\begin{array}{l}67.9 \\
637 \\
938\end{array}$ & $\begin{array}{c}92.6 \\
1,283 \\
1,385\end{array}$ & $\begin{array}{l}82.7 \\
1,920 \\
2,323\end{array}$ \\
\hline Stool specimen* & $\begin{array}{c}81.4 \\
871 \\
1,070 \\
\end{array}$ & $\begin{array}{c}74.8 \\
937 \\
1,253 \\
\end{array}$ & $\begin{array}{r}59.2 \\
555 \\
938 \\
\end{array}$ & $\begin{array}{l}90.5 \\
1,253 \\
1,385 \\
\end{array}$ & $\begin{array}{l}77.8 \\
1,808 \\
2,323 \\
\end{array}$ \\
\hline
\end{tabular}

*: The response rates are calculated as a percent of the sample successfully completed the health interview.

The overall response rate for structured questionnaires administered to adolescents or responsible adults is 87 percent. Response rates are systematically higher in rural than urban areas and higher among girls and female responsible adults than among boys and male responsible adults. Three in every four eligible adolescents completed the achievement tests in Arabic and Mathematics. Among adolescents who successfully completed the health questionnaire, the response rate to the clinical examination is 85 percent, higher among boys than among girls and higher in rural than urban areas. 
Table 2 shows the differentials in response rates among adolescents randomly selected for the core individual interview by sex, age, school-enrollment and work status.

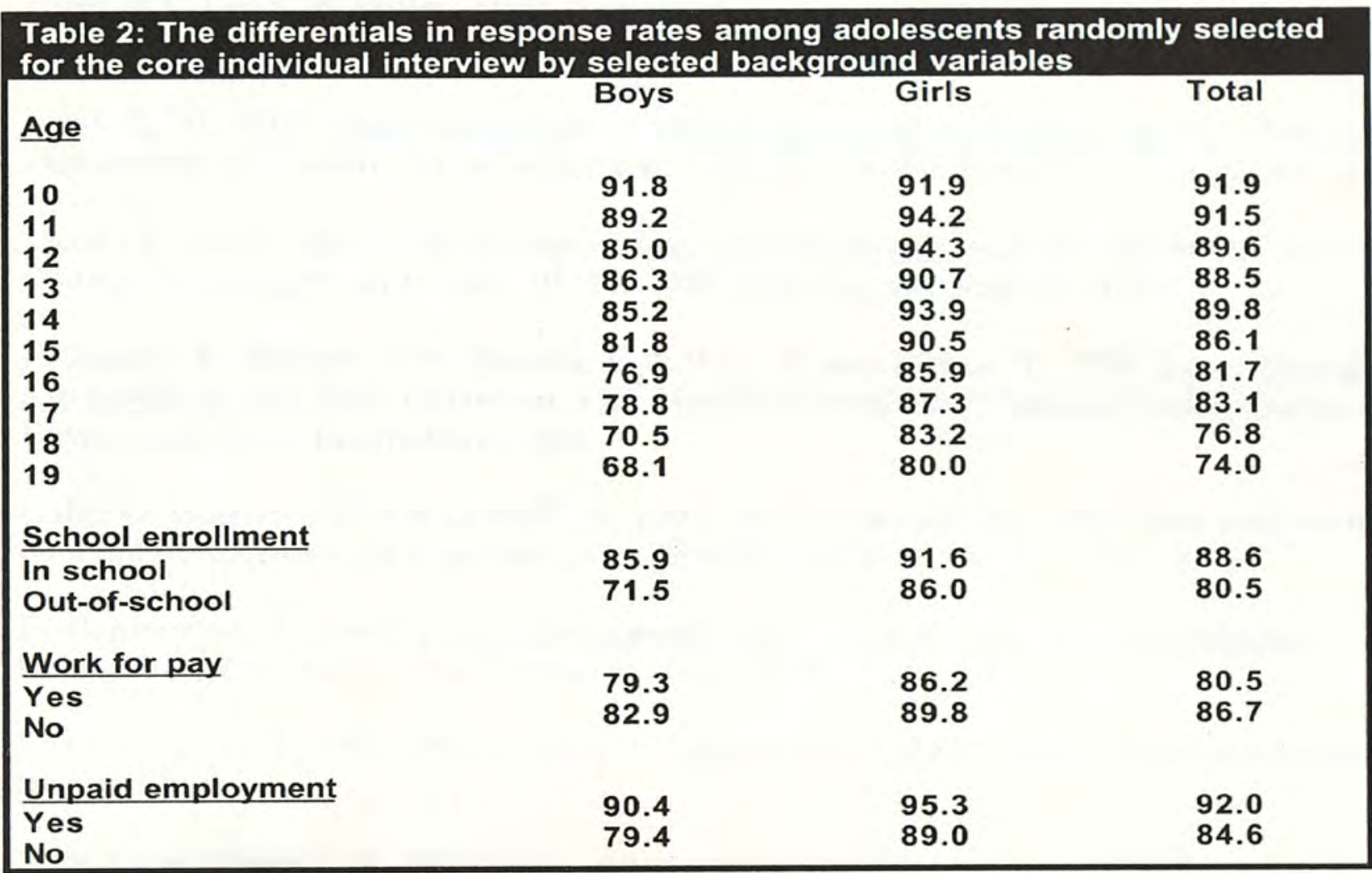

Response rates start at a high level of 92 percent among boys and girls 10 years old. The rates are higher among girls than boys for every age. They decline with increasing age to reach a level of 68 percent among boys aged 19 and 80 percent among girls in the same age. Enrollment status had a more significant impact on response rates of boys than work status. The lowest response rate is reported among boys out-of-school. Among working adolescents, the response rate of those in unpaid employment is higher than in paid jobs. Adolescents in unpaid employment usually do not have strict working hours. Unlike adolescents working for pay, it is not very difficult to interview them at home or in the nearby family business or on the farm. 


\section{Bibliography}

Allen, AVH and DS Ridley. 1970. Further observations on the formol-ether concentration technique for fecal parasites. Journal of Clinical Pathology, 23:545-546.

Attallah, NL. 1977. Age at menarche of schoolgirls in Egypt. A short report. London, UK: Department of Growth and Development, Institute of Child Health, University of London.

Dunn FL. 1968. The TIF direct smear as an epidemiological tool. World Health Organization (WHO) Monograph Series, No. 39: 439-449. Geneva, Switzerland: WHO.

El-Zanaty, F; Hussein, EM; Shawky, GA; Way, A; and Kishor, S. 1996. Egypt demographic and health survey 1995. Calverton, MD: National Population Council (Arab Republic of Egypt) and Macro International, Inc.

Galal, O; Harrison, G; and Qureshi, A. 1991. Socioeconomic and nutritional status effects on pubertal development in Egyptian girls. Clinical Research, January 1991, 43-51.

El-Hammamsy, L. 1994. Early marriage and reproduction in two Egyptian villages.

Occasional Monograph. The Population Council/UNFPA, Cairo, Egypt.

El-Hammamsy, L. 1995. Bibliography on adolescents. Cairo, Egypt: The Population Council. (unpublished).

Jaffe, L and Manzer, R. 1992. Girls' perspectives: Physical activity and self-esteem. Melpomene, 11, 3:14-28.

Jelliffe, DB. 1966. The assessment of the nutritional status of the community (with special reference to field surveys in developing regions of the world). WHO Monograph Series, No. 53: 64-69.

Khattab, HAS. 1992. The silent endurance: Social conditions of women's reproductive health in rural Egypt. Cairo, Egypt: UNICEF and The Population Council.

Makhlouf, H and Amin, SZ. 1995. Enquiring the knowledge of Egyptian youth on reproductive health: Summary of final results. Cairo, Egypt: Cairo Demographic Center and The Egyptian Family Planning Association.

Must, A; Dallal, GE; and Dietz, WH. 1991. Reference data for obesity: $85^{\text {th }}$ and $95^{\text {th }}$ percentiles of body mass index $\left(\mathrm{wt} / \mathrm{ht}^{2}\right)$ - a correction. American Journal of Clinical Nutrition, vol. 54: 773.

Papanek H and Ibrahim B. 1981. Economic participation of Egyptian women: Implications for labor force creation and industrial policy. Report to U.S. Agency for International Development (Cairo, Egypt), December 1981.

Richardo, FO; Hassan, F; Cline, BL; El-Alamy, MA. 1984. An evaluation of quantitative techniques for $S$. haematobium eggs in urine preserved with carbol fuchsin. American 
Journal of Tropical Medicine and Hygiene, 33: 857-861.

Selim, S. 1996. Children and women in Egypt. An information atlas. Cairo, Egypt: National Council for Childhood and Motherhood.

Shafey, H. 1998. Adolescence and state policy in Egypt. Cairo, Egypt: The Population Council.

Tanner JM. 1975. Growth and endocrinology of the adolescent. In LI Gardner (Ed.), Endocrine and Genetic Diseases of Children and Adolescents. $2^{\text {nd }}$ ed. Philadelphia, PA: WB Saunders.

World Health Organization (WHO). 1996. The health of youth: A cross-national survey. WHO Regional Publications, European Series, No. 69.

---- 1995. Physical status. The use and interpretation of anthropometry. Report of a WHO Expert Committee. WHO Technical Report Series, No. 854: 263-311.

----. 1983. Measuring change in nutritional status. Geneva, Switzerland: WHO.

---. 1968. Nutritional anemias: report of a WHO Scientific Group. WHO Technical Report Series, No. 405. Geneva, Switzerland: WHO.

Zulficar, M. 1995. Women in development: A legal study. Cairo, Egypt: UNICEF. 


\section{About the Authors}

\section{Primary InVestigators}

Sahar EI-Tawila, Ph.D., is a Research Associate with the Social Research Center at the American University in Cairo. She holds a Ph.D. and an M.Sc. in statistics from the School of Economics and Political Science at Cairo University and has obtained professional certificates in survey sampling from the University of Michigan and in demography from Princeton University. Formerly she was a research associate professor in the Department of Statistics at Cairo University. Her research interests include development, poverty and life opportunities of young people with a particular focus on education.

Omaima El-Gibaly, M.D., Ph.D., is a Lecturer in the Department of Public Health and Community Medicine, Assiut University. She is also Manager of the Primary Health and Social Care Center at Assiut University. She holds an M.Sc. and Ph.D. in public health and a medical degree from Assiut Medical School. Areas of research interest include reproductive health, interventions in the primary health care setting, gender, and health services research. Previous experience includes work with Family Health International through the Egyptian Fertility Care Society, UNICEF, and The Ford Foundation in addition to current work with The Population Council Regional Office of West Asia and North Africa.

Barbara Ibrahim, Ph.D., is Regional Director for the Population Council's Regional Office for West Asia and North Africa, Cairo. She holds a Ph.D. in sociology from Indiana University and an M.A. in sociology from The American University in Beirut. Formerly she was a program officer for urban poverty with the Ford Foundation and taught sociology at The American University in Cairo. Her publications and research interests have focused on women's labor force participation, indigenous philanthropy, and youth and social change.

Fikrat el-Sahn, M.B., Ch.B., M.Sc., D.P.H., Dr.P.H., is Professor of Nutrition at the High Institute for Public Health, Alexandria University. She holds a doctorate in public health from the Faculty of Medicine at Alexandria University and an M.Sc. in medical biochemistry from Faculty of Medicine at Calgary University in Canada. She has worked previously with WHO, UNICEF, IDRC, and ACCD in research focused on the health and nutrition of women and children. Her main research and publications have focused on these topics as well as on the health and nutrition of the elderly.

Sunny Sallam, M.B., Ch.B., Dr.P.H., is Professor of Epidemiology and Vice Dean at the High Institute for Public Health, Alexandria University. She holds a medical degree and doctorate in public health from the Faculty of Medicine at Alexandria University and an M.P.H. from the University of North Carolina. She has worked previously with the Ford Foundation, IDRC, the US Agency for International Development, International Planned Parenthood Federation and other international and Egyptian national organizations, primarily on infectious diseases and family planning. Her present interests include adolescent health, reproductive health, and development. 


\section{Other Contributors}

Susan M. Lee, M.H.S., is a Research Fellow with the Population Council, Regional Office for West Asia and North Africa, Cairo. She holds an M.H.S. in population dynamics from the School of Hygiene and Public Health at Johns Hopkins University with a focus on reproductive health and family planning. Formerly she worked with the UNDP-World Bank Water and Sanitation Program and the Planned Parenthood Federation of America. Her research interests and publications focus on include adolescent reproductive health, health behavior and communication, and gender issues in water and sanitation service provision.

Barbara Mensch, Ph.D., is a Senior Associate in the Policy Research Division at The Population Council's headquarters in New York. For the past four years, she has also served as a project director for the division's research on adolescence and the transition to adulthood in developing countries. Previous work at The Population Council has focused on assessing the quality of care provided by reproductive health and family planning programs. Previously she worked at the School of Public Health at Columbia University conducting research on adolescent pregnancy and drug use. She holds an M.A. and Ph.D. in sociology and demography from Princeton University, a B.A. and M.A. in social and political sciences from Cambridge University, and a B.A. in history from Wellesley College.

Hind Wassef, M.A., is a Research Assistant at The Population Council Regional Office for West Asia and North Africa in Cairo. She holds an M.A. in comparative literature and a B.A. in political science from The American University in Cairo. Her research focuses on issues in contemporary education, discourse analysis, and gender issues, especially violence against women.

Sarah Bukhari, M.A., is a Program Administrator with the Population Council Regional Office for West Asia and North Africa, Cairo. She holds an M.A. in political science from The American University in Cairo with a focus on development studies. Her research interests include female genital mutilation and community development.

Osman Galal, M.D., Ph.D., is a Professor of Community Health Sciences at the University of California, Los Angeles School of Public Health. He obtained his Ph.D. from the University of Birmingham in the United Kingdom. Previously he was the director of the Nutrition Institute in Cairo, Egypt. His main research interests and publications have focused on child health and development. 
Cover photographs courtesy of:

United Nations Population Fund (UNFPA)

American University in Cairo - Public Relations Office

Kamal Khalifa

Moushira Elgeziri

Al-Shams Club - Sports Archives 

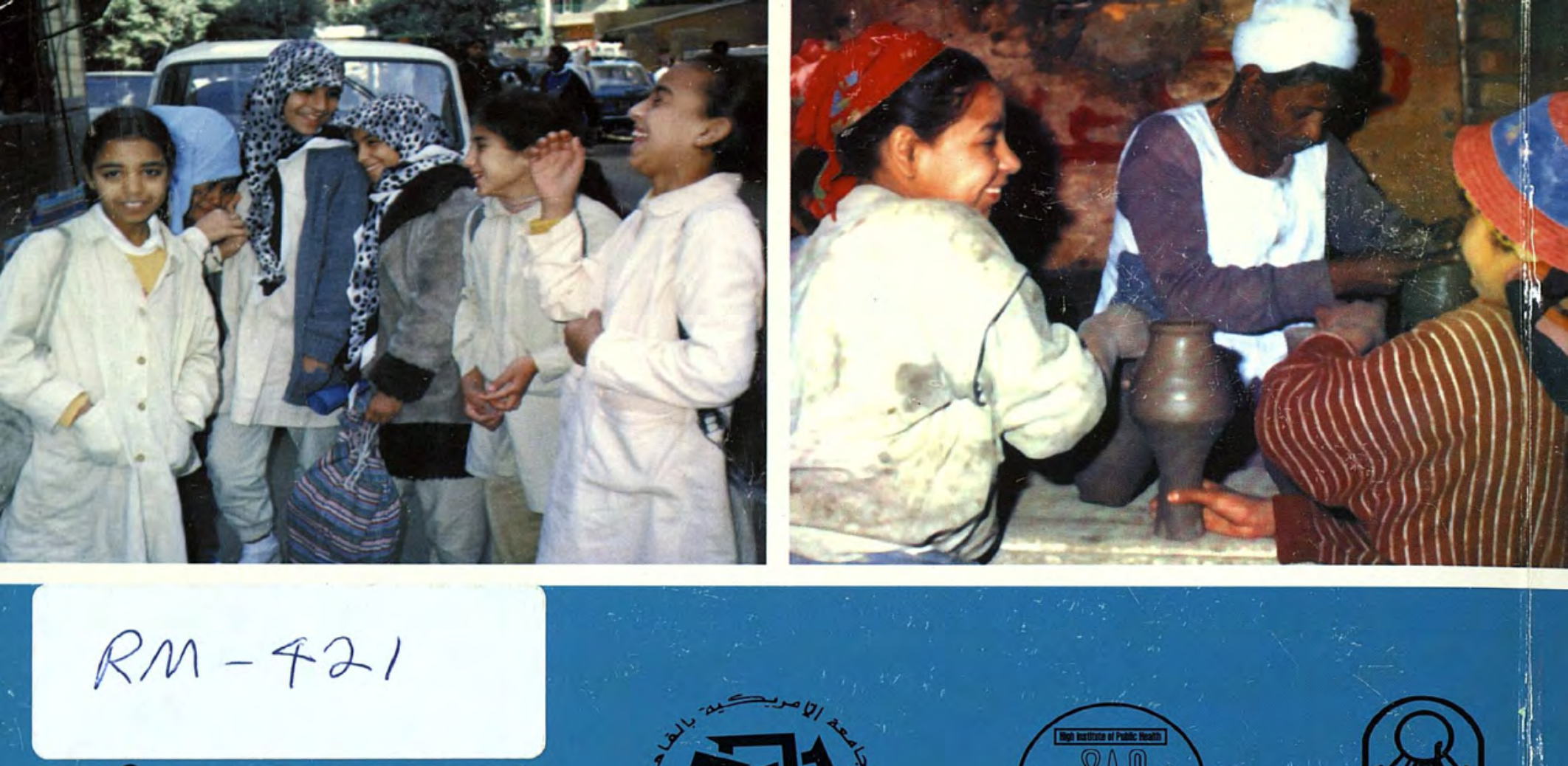

1 Population Council
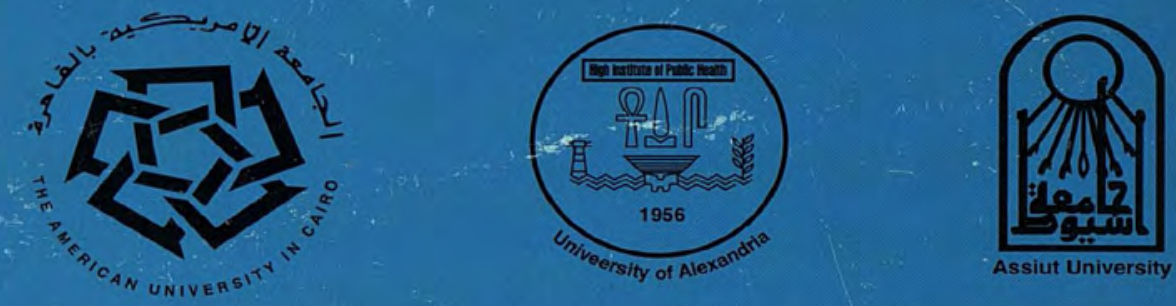

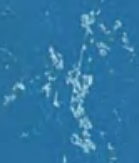

This report highlights the findings from a nationally. representative survey of adolescents and their parents, conducted in Egypt in 1997. The survey attempted to gain a fuller understanding of the major developmental 'tasks' each adolescent undertakes as he or she moves toward adulthood, as well as the services and institutions available in Egypt to support those transitions. Major topics include education, work roles, health, socialization and psychological adjustment, as well as gender roles and preparation for marriage. 